\title{
Dynamics of oxygen saturation, fluid and blood pressure during hemodialysis and their associations with clinical outcomes
}

Citation for published version (APA):

Zhang, H. (2018). Dynamics of oxygen saturation, fluid and blood pressure during hemodialysis and their associations with clinical outcomes. [Doctoral Thesis, Maastricht University]. Datawyse / Universitaire Pers Maastricht. https://doi.org/10.26481/dis.20181218hz

Document status and date:

Published: 01/01/2018

DOI:

10.26481/dis.20181218hz

Document Version:

Publisher's PDF, also known as Version of record

Please check the document version of this publication:

- A submitted manuscript is the version of the article upon submission and before peer-review. There can be important differences between the submitted version and the official published version of record.

People interested in the research are advised to contact the author for the final version of the publication, or visit the DOI to the publisher's website.

- The final author version and the galley proof are versions of the publication after peer review.

- The final published version features the final layout of the paper including the volume, issue and page numbers.

Link to publication

\footnotetext{
General rights rights.

- You may freely distribute the URL identifying the publication in the public portal. please follow below link for the End User Agreement:

www.umlib.nl/taverne-license

Take down policy

If you believe that this document breaches copyright please contact us at:

repository@maastrichtuniversity.nl

providing details and we will investigate your claim.
}

Copyright and moral rights for the publications made accessible in the public portal are retained by the authors and/or other copyright owners and it is a condition of accessing publications that users recognise and abide by the legal requirements associated with these

- Users may download and print one copy of any publication from the public portal for the purpose of private study or research.

- You may not further distribute the material or use it for any profit-making activity or commercial gain

If the publication is distributed under the terms of Article $25 \mathrm{fa}$ of the Dutch Copyright Act, indicated by the "Taverne" license above, 


\section{Dynamics of oxygen saturation, fluid and blood pressure during hemodialysis and their associations with clinical outcomes}

Hanjie Zhang

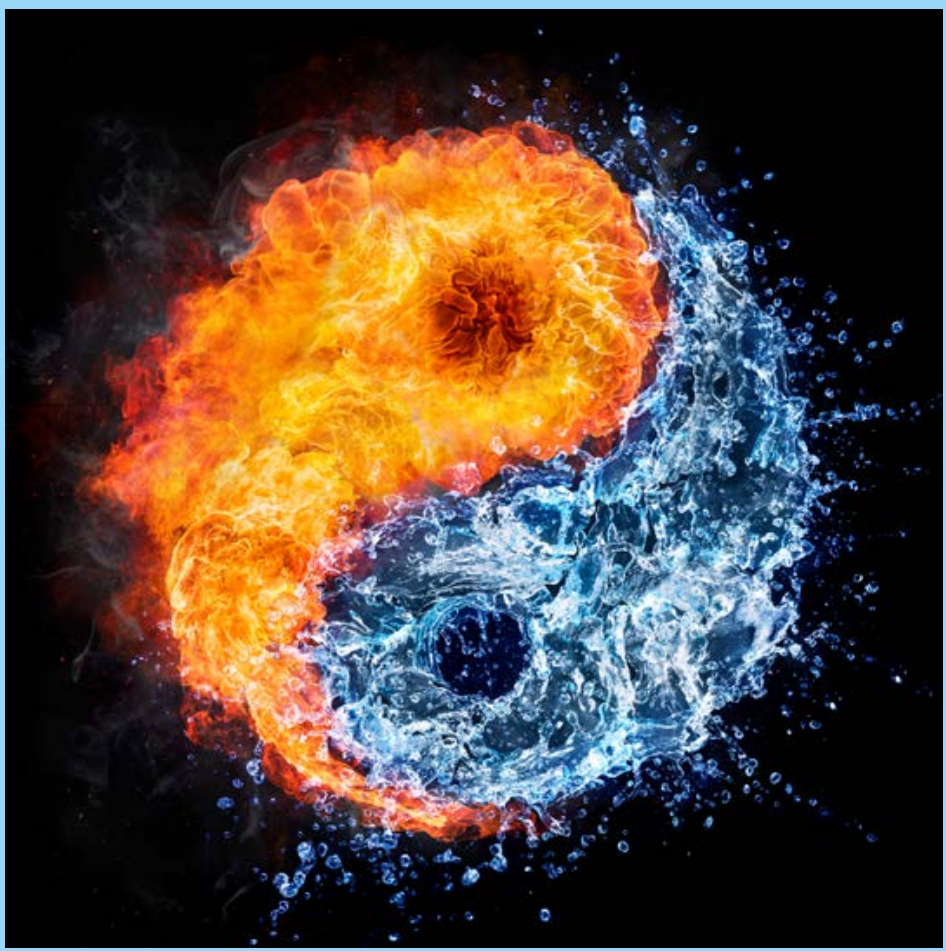


All rights are reserved. No part of this book may be reproduced or transmitted in any form or by any means, without the written permission from the author or, where appropriate, the publisher of the article.

(c) Hanjie Zhang, Maastricht 2018

Layout: $\quad$ Tiny Wouters

Cover design: Datawyse Universitaire Pers Maastricht

Production: Datawyse Universitaire Pers Maastricht

ISBN: $\quad 978-94-6380-130-0$

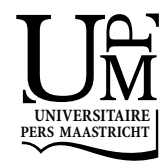




\title{
Dynamics of oxygen saturation, fluid, and blood pressure during hemodialysis and their associations with clinical outcomes
}

\author{
Dissertation \\ to obtain the degree of Doctor at Maastricht University, \\ on the authority of the Rector Magnificus, \\ Prof.dr. Rianne M. Letschert \\ in accordance with the decision of the Board of Deans, \\ to be defended in public \\ on Tuesday 18 December 2018, at 12.00 hours
}

by

Hanjie Zhang 


\section{Promotores:}

Prof. dr. J.P. Kooman

Prof. dr. P. Kotanko, Renal Research Institute and Icahn School of Medicine at Mount Sinai, New York, USA

\section{Copromotores :}

Dr. F.M. van der Sande

Dr. J.G. Raimann, Renal Research Institute, New York, USA

\section{Beoordelingscommissie:}

Prof. dr M.E.A. Spaanderman (voorzitter)

Dr. C.F.M. Franssen, Universitair Medisch Centrum Groningen

Prof. dr. B. Meijers, University Hospital Leuven, Belgium

Prof. dr. F.W. Prinzen

Dr. L. Schouten 


\section{Contents}

$\begin{array}{lll}\text { Chapter } 1 & \text { Introduction } & 7\end{array}$

Chapter 2 Intradialytic hypoxemia and clinical outcomes in patients on hemodialysis

Chapter 3 Intradialytic hypertension is associated with low intradialytic arterial 45 oxygen saturation

Chapter 4 Intradialytic central venous oxygen saturation is associated with clinical outcomes in hemodialysis patients

Chapter 5 Association between intradialytic central venous oxygen saturation and ultrafiltration volume in chronic hemodialysis patients

Chapter 6 All-cause mortality in relation to changes in relative blood volume during hemodialysis

Chapter 7 Association of peridialytic systolic blood pressure change and pre-dialysis systolic blood pressures on mortality among hemodialysis patient

Chapter 8 General discussion

Summary

Valorization

Acknowledgments

Curriculum Vitae 



\section{Chapter 1}

Introduction 



\section{Background of hemodialysis}

Hemodialysis (HD) is a lifesaving treatment which benefits nearly 2 million people worldwide $^{1}$. HD operates by a combination of diffusion and convection. Diffusion is based on a concentration gradient, and serves for the removal of uremic toxins, as well as for electrolytes such as potassium and phosphate whose serum levels are often elevated in patients with end stage renal disease (ESRD). On the other hand, diffusion also serves for the influx of beneficial substances such as bicarbonate from the dialysate to the blood of the patients. Next to the concentration gradient between blood and dialysate, there are several factors which determine the rate of diffusion, such as the dialysis membrane, the size, charge and protein binding of the solute, the blood flow rate and the dialysate rate. Convection is the movement of fluid based on a pressure gradient between the two sides of membrane in the dialyzer. Through convection, the excess fluid which accumulates in the period between 2 dialysis sessions (the inter-dialytic period) is removed from the patient. The amount thus removed is also called ultrafiltration volume. HD is a particularly efficient, intermittent treatment, which is able to remove uremic toxins and correct abnormalities in fluid status, electrolyte and acid-base balance over a short time period in order to restore physiological conditions until the next treatment is provided. However, due to the efficiency of the HD treatment it also induces extreme, rapid changes in the internal environment of the patient, which may have both immediate clinical consequences such as intra-dialytic hypotension due to sudden uncompensated decreases in the circulating intravascular volume, which may also lead to subclinical organ damage with cumulative extent of consequence with increases in dialysis vintage $\mathrm{e}^{2,3}$. Additionally, the treatment also poses a combination of circulatory, respiratory and thermal stressors.

While the incidence of catastrophic complications such as acute myocardial infarction and anaphylactic reactions leading to the need of resuscitation during HD is relatively low $^{4}$, that of moderate to severe intra-dialytic complications such as intra-dialytic hypotension, muscle cramps, nausea, vomiting, headache, itching, chest pain, back pain, fever and chills, is considerably higher. These latter complications, while not immediately life-threatening, can nonetheless be painful and debilitating, and, in some cases, even compromise a patient's long-term health. The incidence of intra-dialytic hypotension is assumed to be around 20\% but may vary between 5 to $30 \%$ varying according to the definition. Commonly used definitions include the minimal intradialytic systolic blood pressure (SBP) (definitions range from 90 to $100 \mathrm{mmHg}$ ), decreases of a certain magnitude (ranging from 20 to $30 \mathrm{mmHg}$ ) in SBP from one measurement to another or from the HD start to a respective intradialytic measurement, and documented counteractive measures for intradialytic hypotension (IDH) such as saline administration ${ }^{5}$. In the HD (HEMO) study, the prevalence of sessions with IDH when applying different definitions of IDH was compared. While the 
overall HEMO study defined IDH as a session requiring a documented intervention (such as UF reduction or saline) the prevalence of sessions with document IDH was $19.1 \%$, but only $11.3 \%$ with defining it based on the occurrence of a nadir SBP less $90 \mathrm{mmHg}^{6}$. A more recent study assessing 44,801 treatments in 1137 patients, in which intra-dialytic hypotension defined IDH as a decrease in SBP by more than $30 \mathrm{mmHg}$ to a level of less than $90 \mathrm{mmHg}$, reported an prevalence was $17.2 \%^{7}$. However, even in the absence of symptoms, HD may lead to reduction in tissue perfusion, which was shown to cause persistent damage in vital organs such as the heart and brain ${ }^{2,3,8,9}$. These damages are eve further aggravated by reduced oxygen delivery to the tissues in the presence of intra-dialytic hypoxemia, shown to be present in a substantial fraction of HD patients causing an increased risk of all-cause mortality.

The healthy individual's response to hypovolemia is determined by a constriction of the resistance and capacitance vessels, as well by an increase in myocardial contractility and heart rate. The capability for this physiologic response to hypovolemia is often found impaired in HD patients due to patient-related factors, such as cardiac dysfunction and autonomous neuropathy ${ }^{5,10}$. In addition, thermal stress, induced by HD leads to a redistribution of blood volume to the vasodilated skin vessels counteracting the normal response to hypovolemia. For this reason, cooling or individualization of various aspect of the dialysis treatment (including electrolytes, acid-base correction, fluid volume removal and others) has been proposed. Some of these interventions have shown to increase vascular reactivity, centralize the intravascular blood volume, as well as to reduce hypoperfusion-related complications such as cardiac stunning and white matter lesions in long-term observations ${ }^{3,11,12}$. As such, these interventions provide simple tools to alleviate at least partly the hemodynamic challenge of HD to the body.

Given the fact that the relatively short duration of conventional dialysis treatments increases circulatory stress ${ }^{11}$, the combination of more frequent or extended dialysis sessions was suggested to lead to a reduction in the hemodynamic burden to the patient and to associate with a reduction in myocardial stunning ${ }^{13}$, additionally reducing interdialytic cardiac strain and left ventricular mass. However, the benefits of extension and frequency increase need to be balanced against the potential side effects of these intervention, such as vascular access complications and a decline in residual renal function in those with high residual urine volumes ${ }^{14}$, and should be an decision individualized on a patient level.

\section{Intradialytic hypoxemia in chronic HD patients}

Patients with chronic kidney disease (CKD) show a vast spectrum of signs and symptoms as a resultant of damages in different organs also including heart and brain. 
Recently, pulmonary manifestations associated with CKD have gained increased attention in clinical practice and research. Links between abnormalities in cardiac and pulmonary function and renal damage have been established, and it has been proposed to classify the associated clinical manifestations as "cardio-pulmonary-renal" syndrome ${ }^{15}$.

In the general population, arterial oxygen saturation is a useful indicator of arterial oxygenation and a routine measurement for many diagnostic applications. Consistently, for the study of respiratory pathologies in HD patients, the measurement of the hemoglobin oxygen saturation is also remarkably valuable. More than 20 years ago, it has been demonstrated that arterial oxygen saturation decreases during extracorporeal renal replacement therapy ${ }^{16}$, and more recently a comparable observation has been made also for central venous oxygen saturation ${ }^{17}$.

\section{Current technologies for the measurement of blood oxygenation}

A number of devices allow clinicians to assess the blood oxygen saturation. Blood gas analyzers measure partial pressure of oxygen in blood samples using an electrode to measure the electric currents generated from a set of oxidation-reduction reactions. Once partial pressure of oxygen is obtained the analyzer calculates the oxygen saturation using empiric models which may differ between manufacturers ${ }^{18}$. Oxygen saturation can be measured non-invasively by optical methods utilizing the fact that oxygenated and deoxygenated hemoglobin have different light absorption characteristics. Pulse-oximetry probes are usually attached to a finger to measure arterial oxygen saturation either in a static and continuous fashion ${ }^{19,20}$. Near-infrared spectroscopy is used for measurement of regional tissue oxygen saturation ${ }^{21,22}$. Of particular relevance to the dialysis field is the measurement of oxygen saturation in the extracorporeal circuit during dialysis (CritLine Monitor ${ }^{\mathrm{TM}}$; CLM, see Figure 1.1). This device obtains oxygen saturation using different wavelengths and absorption-based algorithms. Depending on the vascular access type arterial or central venous oxygen saturation can be measured. 


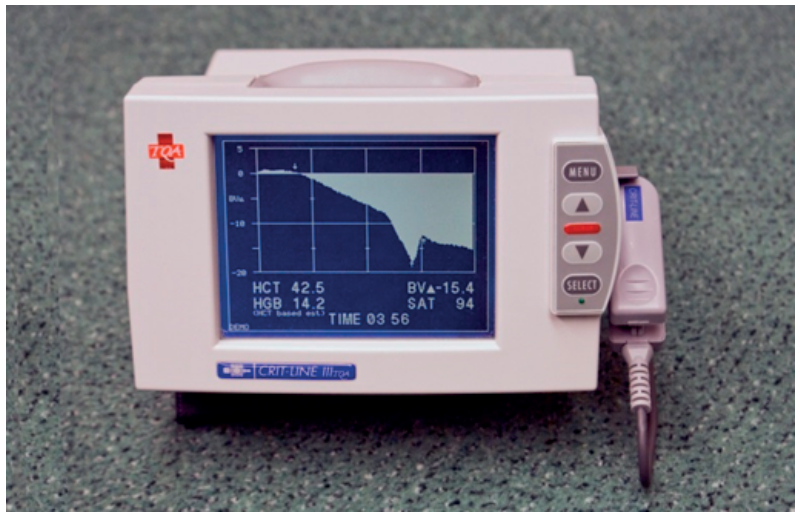

Figure 1.1 CritLine Monitor ${ }^{\mathrm{TM}}$; CLM. Oxygen saturation, hematocrits, hemoglobin and relative blood volume displayed on the screen during the HD treatment.

\section{Arterial oxygenation during HD}

Arterial oxygenation during HD will be discussed in Chapter 2. In HD patients with arteriovenous vascular access partial pressure of oxygen can be determined from measurements in the arterial blood line of the extracorporeal circuit, based on work by Nielsen and Jensen who reported a high correlation between blood gases in the radial artery and the arterial line of HD patients with a well-functioning fistula ${ }^{23}$.

While intradialytic hypoxemia is well recognized since the early days of $\mathrm{HD}^{24-26}$, epidemiological data from large populations are missing. Consequently, clinical correlates of intradialytic hypoxemia are not well understood and associations with hard clinical outcomes have not yet been assessed. A low arterial oxygen saturation status is the common terminal pathway of multiple functional and structural pathologies; sleep apnea, chronic obstructive pulmonary disease, pulmonary edema, and pulmonary calcification which are particularly prevalent in HD patients ${ }^{27-31}$.

In individuals dwelling below 1000 m altitude, an arterial oxygen saturation between $96 \%$ and $99 \%$ is considered normal ${ }^{32}$. While there is no universally agreed upon definition of hypoxemia, most references consider arterial oxygen saturation less or equal to $90 \%$ as indicative of hypoxemia ${ }^{33-35}$. Of note in this context, oxygen supply to tissues depends not only on arterial oxygen saturation, but also on the hemoglobin content of the blood, tissue perfusion and on oxygen release from hemoglobin in the tissues.

While hypoxemia is the common terminal pathway of multiple pathologies, congestive heart failure (CHF) and sleep apnea, two conditions that very often result in 
hypoxemia, are particularly prevalent in $\mathrm{HD}$ patients ${ }^{27-29}$. Additionally, there is a growing body of evidence suggesting a considerably high prevalence of chronic obstructive pulmonary disease in CKD patients ${ }^{30,36}$. Notwithstanding etiology, hypoxemia and hypoxia are associated with a host of acute and chronic sequelae affecting multiple organ systems ${ }^{37-39}$, including the cardiovascular system ${ }^{40,41}$, wound healing ${ }^{42}$, pro-inflammatory pathways ${ }^{43}$, and the central nervous system ${ }^{44}$. Particularly sequelae such as inflammation and changes in vascular smooth muscles and endothelium are known to accelerate arteriosclerosis, which is a commonly found condition with deleterious consequences in HD patients ${ }^{45,46}$. Furthermore, hypoxemia also impairs resilience against reactive oxygen species and may increase erythrocyte apoptosis (eryptosis) ${ }^{47}$. Noteworthy, in patients with $\mathrm{CHF}$ and sleep apnea it was observed that not only the frequency, but also the time spent with arterial oxygen saturation below 90\%, the so-called "hypoxic burden", is a predictor for a lack of capability to compensate hemodynamic stress ${ }^{48}$.

As mentioned above, technological advances made routine continuous measurements of blood oxygen saturation during HD treatments feasible ${ }^{49}$. Recent deployment of the CLM in a large population of U.S. HD patients allowed us to conduct research into associations between intradialytic arterial oxygen saturation and clinical outcomes. In Chapter 2, the epidemiology of intradialytic arterial oxygen saturation, and the associations between arterial oxygen saturation and clinical outcomes were studied. The association between peridialytic SBP change and arterial oxygen saturation will be discussed in Chapter 3. In most HD patients' blood pressure at the end of HD (postHD) is below starting levels (preHD). While the peridialytic blood pressure decline is mainly attributed to salt and fluid volume removal ${ }^{50}$, in some patients, postHD blood pressure is regularly increasing above the preHD level ${ }^{51,52}$. This phenomenon termed intradialytic hypertension is recurrent and persistent in a subset of maintenance HD patients. While there is currently no universally accepted definition of intradialytic hypertension, many authors use a peridialytic rise of SBP of $\geq 10 \mathrm{mmHg}$ as a threshold ${ }^{53,54}$. Cohort studies have shown an intradialytic hypertension prevalence of 8 to $13 \%{ }^{51,53}$. Patients suffering from intradialytic blood pressure increase have an increased risk for hospitalizations and mortality compared to those whose blood pressure decreases during $\mathrm{HD}^{53,54}$. Park et al. reported in a large cohort study that both a $30 \mathrm{mmHg}$ peridialytic SBP decrease or any peridialytic SBP rise were associated with increased mortality rates ${ }^{55}$. This emphasizes the risks associated with intradialytic hypertension and the clinical need to identify the underlying mechanisms and study preventive measures.

Of particular interest in the context of our work are the pathways that result in a SBP rise in the face of low arterial oxygen saturation. Poor arterial oxygen saturation may result in tissue hypoxia. Evidence from both humans and rodents indicates that hypoxia 
triggers sympathetic activation and elevation of blood pressure ${ }^{56-59}$, a peripheral chemoreflex that has also been reported in healthy subjects and patients with hypertension, obstructive sleep apnoea and heart failure ${ }^{60}$. The sensitivity of this peripheral chemoreflex is particularly enhanced in patients with sleep apnea, which is highly prevalent in ESRD patients and frequently associated with hypertension ${ }^{61,62}$. Additionally, sympathetic overactivity has been observed in HD patients with intradialytic hypertension ${ }^{63}$, rendering fluid overload, impaired respiratory function and ventilation-perfusion-mismatch as potential causes or contributing factors at the least of intradialytic hypoxemia ${ }^{64}$. It further was hypothesized that intradialytic hypoxemia may stimulate sympathetic activation directly ${ }^{65,66}$. Testing this hypothesis of a direct link would however require simultaneous measurements of arterial oxygen saturation, sympathetic activity, and blood pressure, during HD, a study that has, to the best of our knowledge, not yet been done. To evaluate the association between low intradialytic arterial oxygen saturation and intradialytic hypertension with the data available to us, we performed extensive analyses reported in Chapter 3.

\section{Central venous oxygenation during HD}

Next to arterial oxygenation, central venous oxygenation during HD is also of great interest and we conducted analyses to evaluate the association between central venous oxygenation and clinical outcomes. These analyses will be discussed in Chapter 4 and Chapter 5. Central venous oxygen saturation can easily be estimated in HD patients with central venous catheters where the catheter tip is usually located at the cavoatrial junction. Central venous oxygen saturation is clinically valuable as it is a surrogate of pulmonary artery mixed venous oxygen saturation, which reflects cardiac output, tissue oxygen delivery, and tissue oxygen extraction ${ }^{67}$. There has been debate regarding the use of central venous oxygen saturation as a surrogate for mixed venous oxygen saturation. Animal studies in dogs and pigs have demonstrated a good correlation between central venous oxygen saturation and mixed venous oxygen saturation $^{68,69}$. Human studies have also shown a linear association, however mixed venous oxygen saturation measurements are consistently lower than central venous oxygenation $^{70}$. This is likely due to the fact that the central venous oxygen saturation is mostly a measure of upper body oxygen consumption while the mixed venous oxygen saturation includes deoxygenated blood from the lower body and coronary sinus ${ }^{71}$.

Central venous oxygen saturation measurements are currently used in critical care and post-surgery monitoring. Rivers et al. have advocated for early goal directed care in sepsis, with measurement of central venous oxygen saturation as one of these measures ${ }^{72}$. Obtaining central venous oxygen saturation $>70 \%$ was associated with improved outcomes ${ }^{73,74}$. Studies showed benefits of monitoring central venous oxygen saturation during high risk surgery, where central venous oxygen saturation guided fluid and volume resuscitation was associated with improvements in length of intensive 
care unit stay, morbidity and mortality ${ }^{73,74}$. Low central venous oxygen saturation or mixed venous oxygen saturation indicate inadequate tissue oxygenation, either from decreased cardiac output and oxygen delivery or high extraction of oxygen at the tissue level. Despite a body of literature showing the utility of central venous oxygen saturation monitoring, data in the dialysis population is scarce.

Central venous oxygen saturation is determined by oxygen delivery to and oxygen consumption of the arms, head, and upper portion of the torso; the former depends on the arterial oxygen saturation content and the cardiac output. At rest with stable arterial oxygen saturation, hemoglobin, and tissue oxygen consumption, central venous oxygen saturation can serve as a surrogate of cardiac output. Poor oxygen delivery can be caused by decreased cardiac output, e.g. from CHF or reduced cardiac preload, or decreased arterial oxygen saturation content, e.g. due to anemia or hypoxemic states. Oxygen consumption is determined by metabolic status and is altered in sepsis, fever, exercise and sedation ${ }^{75}$. Central venous oxygen saturation in the general population is poorly defined, as obtaining this measurement requires a central venous catheter, and patients who require central venous catheters placement are generally significantly ill. One study in healthy subjects found a central venous oxygen saturation of $76.8 \pm 5.2 \%$ during cardiac catheterization ${ }^{76}$.

Studies in non-uremic populations, have found that abnormal central venous oxygen saturation levels are associated with worse morbidity and mortality ${ }^{72,74,77-80}$. In a recent study in 4,477 ICU patients, it was found that patients with central venous oxygen saturation levels lower than $60 \%$ or higher than $80 \%$ had worse outcomes compared with the patients with central venous oxygen saturation levels between $60 \%$ to $80 \%{ }^{77}$. Central venous oxygen saturation levels in HD patients have not been well described. In patients who have ESRD with central venous catheters as the vascular access, central venous oxygen saturation can be easily and continuously obtained during HD treatments by using the CLM. The CLM is used routinely in Renal Research Institute dialysis clinics, which allowed us to investigate the central venous oxygen saturation in maintenance HD patients. In Chapter 4, we evaluated the baseline characteristics of patients with different levels of intradialytic central venous oxygen saturation and to examine the associations between central venous oxygen saturation and mortality.

Chapter 5 investigates the associations between intradialytic fluid volume removal and central venous oxygen saturation. In the majority of HD (HD) patients, residual urinary output decreases in the early months after dialysis initiation ${ }^{81,82}$, favoring a positive fluid balance between two consecutive dialysis sessions. This interdialytic weight gain results primarily in an expansion of the extracellular volume ${ }^{83}$. Excessive and chronic extracellular volume expansion is associated with cardiovascular morbidity, such as hypertension, left ventricular hypertrophy, pulmonary congestion, inflammation, and increased mortality ${ }^{84-87}$. In most HD sessions, the ultrafiltration rate exceeds the refill 
rate of fluid from the interstitium into the vascular space, resulting in a decline in blood volume, potentially leading to IDH and decreased perfusion of vital organs ${ }^{88-91}$.

Fluid overload is a commonly found problem and volume management a major challenge in the treatment of this population. In the Medicare ESRD population, the sudden death/cardiac arrhythmias would account for 37\% of all deaths in the 2015 United States Renal Data System report. While the prevalence of cardiac disease is higher in older HD patients, the prevalence of cardiac disease in patients aged 20-44 years is greatly elevated compared to an age-matched general population ${ }^{92}$. While risk factors operative in the general population such as hypertension, diabetes mellitus and hyperlipidemia are reported as contributors to the high cardiovascular mortality, dialysis specific factors such as anemia, hypoalbuminemia, and chronic inflammation are putting dialysis patients at a substantially higher risk ${ }^{93}$. $\mathrm{CHF}$ is highly prevalent among ESRD patients, and HD treatment factors such as recurrent hemodynamic stress due to high ultrafiltration rates, intradialytic cardiac stunning due to decreased myocardial perfusion, and episodes of IDH may worsen the condition $2,90,94$

The concurrence of CHF and ESRD makes fluid management particularly challenging. Not only are these patients more volume sensitive and prone to volume overload, but $\mathrm{CHF}$ patients are particularly prone to hypotension, and fluid removal is limited by IDH episodes. A common therapeutic response to IDH is to administer saline boluses and often by the end of treatment patients are unable to attain their prescribed fluid status target because of saline given or decreases of the ultrafiltration rates. Additionally, episodes of IDH are not only uncomfortable for patients, but associated with worse outcomes $^{6}$.

Central venous oxygen saturation is determined by cardiac output, hemoglobin levels, arterial oxygen saturation, and oxygen extraction by the organs that drain into the superior vena cava. Therefore, central venous oxygen saturation may serve as a proxy of cardiac output, more specifically of upper body blood flow ${ }^{95,96}$. This relationship has been recognized for decades and intensivists use central venous oxygen saturation for directed fluid management in sepsis, trauma, and post-surgery. A study in 18 maintenance HD patients revealed a significant inverse association between central venous oxygen saturation at the end of dialysis and ultrafiltration volume corrected for body weight ${ }^{17}$, which the authors hypothesized to be due to a reduction of cardiac output by ultrafiltration ${ }^{11}$. However, the dynamical changes of central venous oxygen saturation relative to ultrafiltration volume corrected for body weight are currently unclear and we aimed to contribute to the currently published knowledge with the analyses shown in Chapter 5. In this chapter we aimed to explore the relationship between intradialytic central venous oxygen saturation changes and ultrafiltration 
volume corrected for body weight in a large and diverse population of chronic HD patients, employing automated intradialytic minute-to-minute measurements of central venous oxygen saturation during multiple treatments per patient.

\section{Relative blood volume during HD}

Chapter 6 will focus on relative blood volume (RBV) during HD. Hematocrit was measured quasi-continuously using CLM. The CLM reports the RBV once per minute throughout the dialysis treatment. The relative blood volume (expressed in $\%$ of the blood volume at the start of dialysis) at time t was calculated as follows:

$$
\operatorname{RBV}(\%) \text { at time } t=\left(\frac{\mathrm{HCT}_{0}}{\mathrm{HCT}_{\mathrm{t}}}-1\right) \times 100+100
$$

$\mathrm{HCT}_{0}$ and $\mathrm{HCT}_{\mathrm{t}}$ are the hematocrits at the start of $\mathrm{HD}$ and at a given time $t$ during $\mathrm{HD}$, respectively.

Intradialytic monitoring of RBV has been introduced to clinical routine with the expectation that it may prevent IDH by allowing the staff or the dialysis machine to maintain the RBV above a patient-specific critical level ${ }^{97-100}$, below which the chance of IDH was likely to occur. Since some of the technologies derive RBV changes from measured hematocrit changes, the term "crash-crit" has been coined. Unfortunately, no firm evidence for the existence of a specific crash-crit (or, conversely, a RBV threshold) has been provided. Andrulli et al. was not able to identify critical RBV levels for the development of symptomatic hypotension, neither in hypotensive, normotensive, nor hypertensive patients, showing the variability of RBV across patients and also across treatments ${ }^{101}$.

RBV monitoring is in frequent use both in the United States and abroad. However, there is a glaring paucity of data that associate intradialytic RBV levels with outcomes, resulting in primarily empirical use of RBV monitoring.

Fluid management in standard in-center HD has been likened to sailing between Scylla and Charybdis: on one hand, ultrafiltration is the only means to remove fluid accumulated between HD treatments and to avoid acute and chronic fluid overload; on the other hand, excessive fluid removal may impact intradialytic hemodynamic stability. Indeed, HD-induced blood volume reduction is considered an important causal factor of intradialytic cardiovascular instability and depends on rates of ultrafiltration and vascular refilling ${ }^{102,103}$. Given these competing factors, it is conceivable that on a population level and over the course of an HD session certain RBV ranges are associated with lower (or higher) mortality. While the genesis of the 
RBV curve is easy to understand qualitatively as the relative difference between ultrafiltration rate and vascular refilling rate, attempts to quantitatively model and predict RBV dynamics are notoriously complicated and currently not applicable to routine care ${ }^{104}$. The matter is further complicated by the absence of randomized controlled trials looking at the relationship between the attainment of RBV targets and patient outcomes. In this situation, clinical practitioners who use RBV monitoring resort to a qualitative and empirical assessment of RBV curves, where flat curves are considered to indicate fluid overload and steep curves intravascular volume depletion that may precipitate IDH ${ }^{105,106}$. In Chapter 6, we will fill this knowledge gap by exploring the association between achieved intradialytic RBV levels and all-cause mortality in a large, diverse, and for the United States representative HD population.

\section{Peridialytic SBP change and pre-dialysis SBPs among HD patients}

In Chapter 7, peridialytic SBP change and pre-dialysis SBP on mortality among HD patients will be discussed. Absence of an accepted, normal BP range for dialysis patients is a major barrier for developing definitions for BP-related clinical phenomena. A major concern is which BP parameter to use among HD population: peridialytic, intradialytic or/and interdialytic BP's; mainly due to lack of definitive evidence on which one of these is more strongly associated with outcomes ${ }^{107,108}$. To date, BP's pre- and post-HD BP levels form the basis of the National Kidney Foundation's Kidney Outcomes Quality Initiative (KDOQI) guidelines ${ }^{109}$. Nonetheless, conflicting data exists; although consistently more studies based on large cohorts of patients showing elevated mortality in patients with low pre-dialysis BP, particularly low systolic blood pressure (SBP); but not with high BP levels $\left.{ }^{110-113}\right)$. Contrastingly, some large epidemiologic studies using peridialytic BP changes have shown an inverse J-shaped or U-shaped association with adverse outcomes ${ }^{53,55,111,114}$.

Although HD is associated with a decline in BP in most of cases, and intradialytic hypotension remains a major focus of attention; intradialytic increases in BP can occur in up to $15 \%$ prevalent HD patients and are also associated with adverse outcomes ${ }^{53,54,115}$. Park et al. ${ }^{55}$ reported that both SBP decreases or any peridialytic SBP rise during HD were associated with higher mortality rates.

The pathophysiology of both increases and decreases of BP during HD is not fully understood and is mostly multifactorial. Factors associated with the development of intradialytic hypotension include, next to the removal of vast volumes of fluid during dialysis, an impaired vasoreactivity, a reduced sympathetic response, older age, atherosclerosis, poor cardiac reserve and removal of vast volume of fluid ${ }^{116,117}$; while intradialytic hypertension has been associated with chronic fluid overload, increased peripheral vascular resistance, among others ${ }^{118,119}$. 
Despite the vast literature and the evidence regarding pre-dialysis SBP and peridialytic SBP changes; not previous data are there exploring the nature of interaction between pre-dialysis SBP and peridialytic SBP change with outcomes. The goal of Chapter 7 was exploring the association between pre-dialysis SBP and peridialytic SBP changes by studying both together as continuous variables with all-cause mortality in a large and diverse United States representative HD population.

The following aims will be discussed in this thesis:

- To assess the epidemiology of intradialytic arterial oxygen saturation, and to explore associations between arterial oxygen saturation and clinical outcomes. (Chapter 2)

- $\quad$ To study the association between peridialytic SBP change and intradialytic arterial oxygen saturation in the HD cohort. (Chapter 3 )

- To evaluate the baseline characteristics of patients with different levels of intradialytic Central venous oxygen saturation and to examine the associations between Central venous oxygen saturation and mortality. (Chapter 4)

- To explore the relationship between intradialytic Central venous oxygen saturation changes and ultrafiltration volume corrected for body weight in a large and diverse population of chronic HD patients. (Chapter 5)

- To study the association between achieved intradialytic RBV levels and all-cause mortality in a large, diverse, and for the United States representative HD population. (Chapter 6)

- $\quad$ To explore the association between peridialytic SBP change and pre-dialysis SBP with all-cause mortality in HD patients. (Chapter 7) 


\section{References}

1. Anand S, Bitton A, Gaziano T. The gap between estimated incidence of end-stage renal disease and use of therapy. PLoS One. 2013;8:e72860.

2. Assa $\mathrm{S}$, et al. Hemodialysis-induced regional left ventricular systolic dysfunction: prevalence, patient and dialysis treatment-related factors, and prognostic significance. Clin J Am Soc Nephrol. 2012;7: 1615-1623.

3. Eldehni MT, Odudu A, McIntyre CW. Randomized clinical trial of dialysate cooling and effects on brain white matter. J Am Soc Nephrol. 2015;26:957-965.

4. Karnik JA, et al. Cardiac arrest and sudden death in dialysis units. Kidney Int. 2001;60:350-357.

5. Chou JA, Kalantar-Zadeh K, Mathew AT. A brief review of intradialytic hypotension with a focus on survival. Semin Dial. 2017;30(6):473-480.

6. Flythe JE, Xue H, Lynch KE, Curhan GC, Brunelli SM. Association of mortality risk with various definitions of intradialytic hypotension. J Am Soc Nephrol. 2015;26:724-734.

7. Sands JJ, et al. Intradialytic hypotension: frequency, sources of variation and correlation with clinical outcome. Hemodial Int. 2014;18:415-422.

8. Dasselaar JJ, et al. Haemodialysis is associated with a pronounced fall in myocardial perfusion. Nephrol Dial Transpl. 2009;24:604-610.

9. Mclntyre CW, Odudu A. Hemodialysis-associated cardiomyopathy: a newly defined disease entity. Semin Dial. 2014;27:87-97.

10. Kooman J, et al. EBPG guideline on haemodynamic instability. Nephrol Dial Transpl. 2007;22 Suppl 2: ii22-44.

11. Cornelis $\mathrm{T}$, et al. Acute hemodynamic response and uremic toxin removal in conventional and extended hemodialysis and hemodiafiltration: a randomized crossover study. Am J Kidney Dis. 2014; 64:247-256.

12. Kooman JP, Katzarski K, van der Sande FM, Leunissen KM, Kotanko P. Hemodialysis: a model for extreme physiology in a vulnerable patient population. Semin Dial. 2018.

13. Jefferies HJ, Virk B, Schiller B, Moran J, McIntyre CW. Frequent hemodialysis schedules are associated with reduced levels of dialysis-induced cardiac injury (myocardial stunning). Clin J Am Soc Nephrol. 2011;6:1326-1332.

14. Cornelis $T$, et al. Vascular access vulnerability in intensive hemodialysis: a significant Achilles' heel? Blood Purif. 2014;37:222-228.

15. Husain-Syed F, et al. Cardio-Pulmonary-Renal Interactions: A Multidisciplinary Approach. J Am Coll Cardiol. 2015;65:2433-2448.

16. Jones JG, Bembridge JL, Sapsford DJ, Turney JH. Continuous measurements of oxygen saturation during haemodialysis. Nephrol Dial Transpl. 1992;7:110-116.

17. Harrison LE, Selby NM, Mclntyre CW. Central venous oxygen saturation: a potential new marker for circulatory stress in haemodialysis patients? Nephron Clin Pr. 2014;128:57-60.

18. Severinghaus JW. Blood gas calculator. J Appl Physiol. 1966;21:1108-1116.

19. Nitzan M, Romem A, Koppel R. Pulse oximetry: fundamentals and technology update. Med Devices 2014; 7:231-239.

20. Jubran A. Pulse oximetry. Crit Care. 2015;19:272.

21. Foo JY, Chua KP, Tan XJ. Clinical applications and issues of oxygen saturation level measurements obtained from peripheral sites. J Med Eng Technol. 2013;37:388-395.

22. Scheeren TW, Schober P, Schwarte LA. Monitoring tissue oxygenation by near infrared spectroscopy (NIRS): background and current applications. J Clin Monit Comput. 2012;26:279-287.

23. Nielsen AL, Jensen H/E. Oxygen status: a standard evaluation in uremic patients? Dial Transplant. 1994;23:288-297.

24. Johnson NR, Bischel MD, Boylen CT, Mohler JG, Barbour BH. Hypoxia and hyperventilation in chronic hemodialysis. Clin Res 1970;19:145.

25. Sherlock JE, Yoon Y, Ledwith JW, Letteri JM. Respiratory gas exchange during hemodialysis. Proc Clin Dial Transpl. Forum 1972;2:171-174.. 
26. Carlon GC, Campfield PB, Goldiner PL, Turnbull AD. Hypoxemia during hemodialysis. Crit Care Med 1979;7:497-499.

27. Harnett JD, et al. Congestive heart failure in dialysis patients: prevalence, incidence, prognosis and risk factors. Kidney Int. 1995;47:884-890.

28. Roumelioti ME, et al. Sleep-disordered breathing and excessive daytime sleepiness in chronic kidney disease and hemodialysis. Clin J Am Soc Nephrol. 2011;6:986-994.

29. Unruh ML, et al. Sleep apnea in patients on conventional thrice-weekly hemodialysis: comparison with matched controls from the Sleep Heart Health Study. J Am Soc Nephrol. 2006;17:3503-3509.

30. Plesner LL, et al. Chronic obstructive pulmonary disease in patients with end-stage kidney disease on hemodialysis. Hemodial Int. 2016;20(1):68-77.

31. Jarava C, et al. Pulmonary calcification in chronic dialysis patients. Nephrol Dial Transpl. 1993;8: 673-674.

32. McFarland RA. XI - Psychophysiological Implications of Life at Altitude and Including the Role of Oxygen in the Process of Aging. in Physiological Adaptations (ed. Bullard, M. K. Y. M. H. W.) 157-181 (Academic Press, 1972). doi:http://dx.doi.org/10.1016/B978-0-12-774650-0.50017-3

33. O'Driscoll BR, Howard LS, Davison AG. BTS guideline for emergency oxygen use in adult patients. Thorax 2008;63:vi1-vi68.

34. Morris RW, Buschman A, Warren DL, Philip JH, Raemer DB. The prevalence of hypoxemia detected by pulse oximetry during recovery from anesthesia. J Clin Monit. 1988;4:16-20.

35. Tyler IL, Tantisira B, Winter PM, Motoyama EK. Continuous monitoring of arterial oxygen saturation with pulse oximetry during transfer to the recovery room. Anesth Analg. 1985;64:1108-1112.

36. Kent $\mathrm{BD}$, et al. The impact of chronic obstructive pulmonary disease and smoking on mortality and kidney transplantation in end-stage kidney disease. Am J Nephrol. 2012;36:287-295.

37. Dempsey JA, Veasey SC, Morgan BJ, O'Donnell CP. Pathophysiology of sleep apnea. Physiol Rev 2010;90:47-112.

38. Pierson DJ. Pathophysiology and clinical effects of chronic hypoxia. Respir Care. 2000;45:33-39.

39. Prabhakar NR, Semenza GL. Adaptive and maladaptive cardiorespiratory responses to continuous and intermittent hypoxia mediated by hypoxia-inducible factors 1 and 2. Physiol Rev. 2012;92:967-1003.

40. Dumitrascu R, Heitmann J, Seeger W, Weissmann N, Schulz R. Obstructive sleep apnea, oxidative stress and cardiovascular disease: lessons from animal studies. Oxid Med Cell Longev 2013;2013: 234631.

41. Lucking EF, O'Halloran KD, Jones JF. Increased cardiac output contributes to the development of chronic intermittent hypoxia-induced hypertension. Exp Physiol. 2014;99:1312-1324.

42. Lee $\mathrm{A}$, et al. Hypoxia-induced changes in $\mathrm{Ca}(2+)$ mobilization and protein phosphorylation implicated in impaired wound healing. Am J Physiol Cell Physiol. 2014;306:C972-C985.

43. Taylor CT. Interdependent roles for hypoxia inducible factor and nuclear factor-kappaB in hypoxic inflammation. J Physiol. 2008;586:4055-4059.

44. Lavie L. Oxidative stress in obstructive sleep apnea and intermittent hypoxia--revisited--the bad ugly and good: implications to the heart and brain. Sleep Med Rev. 2015;20:27-45.

45. Shroff RC, et al. Dialysis accelerates medial vascular calcification in part by triggering smooth muscle cell apoptosis. Circulation. 2008;118:1748-1757.

46. Stam F, et al. Impaired renal function is associated with markers of endothelial dysfunction and increased inflammatory activity. Nephrol Dial Transpl. 2003;18:892-898.

47. Lang F, Lang E, Foller M. Physiology and pathophysiology of eryptosis. Transfus Med Hemother 2012;39:308-314.

48. Gottlieb JD, et al. Hypoxia, not the frequency of sleep apnea, induces acute hemodynamic stress in patients with chronic heart failure. J Am Coll Cardiol. 2009;54:1706-1712.

49. Balter $\mathrm{P}$, Artemyev $\mathrm{M}$, Zabetakis $\mathrm{P}$. Methods and challenges for the practical application of crit-line monitor utilization in patients on hemodialysis. Blood Purif. 2015;39:21-24.

50. Dinesh K, et al. A model of systolic blood pressure during the course of dialysis and clinical factors associated with various blood pressure behaviors. Am J Kidney Dis. 2011;58:794-803.

51. Van Buren PN, Kim C, Toto RD, Inrig JK. The prevalence of persistent intradialytic hypertension in a hemodialysis population with extended follow-up. Int J Artif Organs. 2012;35:1031-1038. 
52. Cirit $\mathrm{M}$, et al. 'Paradoxical' rise in blood pressure during ultrafiltration in dialysis patients. Nephrol Dial Transpl. 1995;10:1417-1420.

53. Inrig JK, et al. Association of intradialytic blood pressure changes with hospitalization and mortality rates in prevalent ESRD patients. Kidney Int. 2007;71:454-461.

54. Inrig JK, Patel UD, Toto RD, Szczech LA. Association of blood pressure increases during hemodialysis with 2-year mortality in incident hemodialysis patients: a secondary analysis of the Dialysis Morbidity and Mortality Wave 2 Study. Am J Kidney Dis. 2009;54:881-890.

55. Park J, et al. A comparative effectiveness research study of the change in blood pressure during hemodialysis treatment and survival. Kidney Int. 2013;84:795-802.

56. Lusina SJ, et al. Long-term intermittent hypoxia increases sympathetic activity and chemosensitivity during acute hypoxia in humans. J Physiol. 2006;575:961-970.

57. Shell B, Faulk K, Cunningham JT. Neural Control of Blood Pressure in Chronic Intermittent Hypoxia. Curr Hypertens Rep. 2016;18:19.

58. Ferreira CB, et al. Brainstem areas activated by intermittent apnea in awake unrestrained rats. Neuroscience. 2015;297:262-271.

59. Prabhakar NR, Kumar GK. Mechanisms of sympathetic activation and blood pressure elevation by intermittent hypoxia. Respir Physiol Neurobiol. 2010;174:156-161.

60. Kara T, Narkiewicz K, Somers VK. Chemoreflexes - Physiology and clinical implications. Acta Physiol Scand. 2003;177:377-384.

61. Roumelioti ME, Brown LK, Unruh ML. The relationship between volume overload in end-stage renal disease and obstructive sleep apnea. Semin Dial. 2015;28(5):508-13

62. Zoccali C, Mallamaci F, Tripepi G. Sleep apnea in renal patients. J Am Soc Nephrol. 2001;12: 2854-2859.

63. Rubinger D, Backenroth R, Sapoznikov D. Sympathetic activation and baroreflex function during intradialytic hypertensive episodes. PLoS One 2012;7:e36943.

64. Campos I, et al. Intradialytic Hypoxemia in Chronic Hemodialysis Patients. Blood Purif. 2016;41: 177-187.

65. Hering D, et al. Tonic chemoreflex activation contributes to the elevated muscle sympathetic nerve activity in patients with chronic renal failure. J Hypertens. 2007;25:157-161.

66. Xie A, Skatrud JB, Puleo DS, Morgan BJ. Exposure to hypoxia produces long-lasting sympathetic activation in humans. J Appl Physiol. 2001;91:1555-1562.

67. Walley KR. Use of central venous oxygen saturation to guide therapy. Am J Respir Crit Care Med 2011; 184:514-520.

68. Reinhart K, Rudolph T, Bredle DL, Hannemann L, Cain SM. Comparison of central-venous to mixedvenous oxygen saturation during changes in oxygen supply/demand. Chest. 1989;95:1216-1221.

69. Schou H, Perez de Sa V, Larsson A. Central and mixed venous blood oxygen correlate well during acute normovolemic hemodilution in anesthetized pigs. Acta Anaesthesiol Scand. 1998;42:172-177.

70. Chawla LS, et al. Lack of equivalence between central and mixed venous oxygen saturation. Chest. 2004;126:1891-1896.

71. Scheinman MM, Brown MA, Rapaport E. Critical assessment of use of central venous oxygen saturation as a mirror of mixed venous oxygen in severely ill cardiac patients. Circulation. 1969;40: 165-172.

72. Rivers $\mathrm{E}$, et al. Early goal-directed therapy in the treatment of severe sepsis and septic shock. N Engl J Med. 2001;345:1368-1377.

73. Collaborative Study Group on Perioperative Scv, O. M. Multicentre study on peri- and postoperative central venous oxygen saturation in high-risk surgical patients. Crit Care. 2006;10:R158.

74. Pearse $\mathrm{R}$, et al. Changes in central venous saturation after major surgery, and association with outcome. Crit Care. 2005;9:R694-R699.

75. Vincent JL, ebrary Inc. Yearbook of intensive care and emergency medicine 2005. (2005).

76. Barratt-Boyes BG, Wood EH. The oxygen saturation of blood in the venae cavae, right-heart chambers, and pulmonary vessels of healthy subjects. J Lab Clin Med. 1957;50:93-106.

77. Balzer F, et al. High central venous saturation after cardiac surgery is associated with increased organ failure and long-term mortality: an observational cross-sectional study. Crit Care. 2015;19:168.

78. Textoris J, et al. High central venous oxygen saturation in the latter stages of septic shock is associated with increased mortality. Crit Care. 2011;15:R176. 
79. Scalea TM, et al. Central venous oxygen saturation: a useful clinical tool in trauma patients. J Trauma. 1990;30:1539-1543.

80. Futier $\mathrm{E}$, et al. Central venous $\mathrm{O}(2)$ saturation and venous-to-arterial $\mathrm{CO}(2)$ difference as complementary tools for goal-directed therapy during high-risk surgery. Crit Care. 2010;14:R193.

81. Rottembourg J, et al. Evolution of residual renal function in patients undergoing maintenance haemodialysis or continuous ambulatory peritoneal dialysis. Proc. Eur. Dial. Transplant Assoc. 1983;19:397-403.

82. Misra M, et al. Effect of cause and time of dropout on the residual GFR: A comparative analysis of the decline of GFR on dialysis. Kidney Int. 2001;59:754-763.

83. Dou Y, Zhu F, Kotanko P. Assessment of Extracellular Fluid Volume and Fluid Status in Hemodialysis Patients: Current Status and Technical Advances. Semin. Dial. 2012;25:377-387.

84. Kalantar-Zadeh $\mathrm{K}$, et al. Fluid retention is associated with cardiovascular mortality in patients undergoing long-term hemodialysis. Circulation. 2009;119:671-679.

85. Wizemann $\mathrm{V}$, et al. The mortality risk of overhydration in haemodialysis patients. Nephrol Dial Transpl. 2009;24:1574-1579.

687. Xu Y, et al. Hypertension, fluid overload and micro inflammation are associated with left ventricular hypertrophy in maintenance hemodialysis patients. Ren. Fail. 2013;35:1204-1209.

87. Dekker MJ, et al. Impact of fluid status and inflammation and their interaction on survival: a study in an international hemodialysis patient cohort. Kidney Int. 2017;91:1214-1223.

88. Daugirdas JT. Dialysis hypotension: a hemodynamic analysis. Kidney Int. 1991;39:233-246.

89. van der Sande F, Kooman JP, Leunissen K. Intradialytic hypotension-new concepts on an old problem. Nephrol Dial Transpl. 2000;15(11):1746-1748.

90. Mclntyre CW, et al. Hemodialysis-induced cardiac dysfunction is associated with an acute reduction in global and segmental myocardial blood flow. Clin J Am Soc Nephrol. 2008;3:19-26.

91. Buchanan C, et al. Intradialytic cardiac magnetic resonance imaging to assess cardiovascular responses in a short-term trial of hemodiafiltration and hemodialysis. J. Am. Soc. Nephrol. 2017;28: 1269-1277.

92. United States Renal Data System. 2015 USRDS annual data report: Epidemiology of kidney disease in the United States. (National Institutes of Health, National Institute of Diabetes and Digestive and Kidney Diseases, 2015).

93. Foley RN, Parfrey PS. Risk factors for cardiac morbidity and mortality in dialysis patients. Curr Opin Nephrol Hypertens. 1994;3:608-614.

94. Burton JO, Jefferies HJ, Selby NM, Mclntyre CW. Hemodialysis-induced cardiac injury: determinants and associated outcomes. Clin J Am Soc Nephrol. 2009;4:914-920.

95. Yazigi $A$, et al. Correlation between central venous oxygen saturation and oxygen delivery changes following fluid therapy. Acta Anaesthesiol Scand. 2008;52:1213-1217.

96. Perner A, Haase N, Wiis J, White JO, Delaney A. Central venous oxygen saturation for the diagnosis of low cardiac output in septic shock patients. Acta Anaesthesiol Scand. 2010;54:98-102.

97. Barth $C$, et al. Characteristics of hypotension-prone haemodialysis patients: is there a critical relative blood volume? Nephrol Dial Transpl. 2003;18:1353-1360.

98. Steuer RR, Leypoldt JK, Cheung AK, Harris DH, Conis JM. Hematocrit as an indicator of blood volume and a predictor of intradialytic morbid events. Asaio J 1994;40:M691-M696.

99. Steuer RR, Leypoldt JK, Cheung AK, Senekjian HO, Conis JM. Reducing symptoms during hemodialysis by continuously monitoring the hematocrit. Am. J. Kidney Dis. 1996;27:525-532.

100. Santoro A, et al. Blood volume controlled hemodialysis in hypotension-prone patients: A randomized, multicenter controlled trial. Kidney Int. 2002;62:1034-1045

101. Andrulli S, et al. The role of blood volume reduction in the genesis of intradialytic hypotension. Am. J. Kidney Dis. 2002;40:1244-1254.

102. Daugirdas JT. Dialysis hypotension: A hemodynamic analysis. Kidney Int. 1991;39:233-246.

103. Daugirdas JT. Pathophysiology of dialysis hypotension: An update. Am. J. Kidney Dis. 2001;38:S11-S17.

104. De Los Reyes VAA, et al. A physiologically based model of vascular refilling during ultrafiltration in hemodialysis. J. Theor. Biol. 2016;390:146-155.

105. Lopot F, Kotyk P, Bláha J, Forejt J. Use of continuous blood volume monitoring to detect inadequately high dry weight. Int. J. Artif. Organs. 1996;19:411-414. 
106. Beige J, et al. Computational analysis of blood volume curves and risk of intradialytic morbid events in hemodialysis. Kidney Int. 2000;58:1805-1809.

107. Charra B, et al. Survival as an index of adequacy of dialysis. Kidney Int. 1992;41(5):1286-1291

108. Mazzuchi N, Carbonell E, Fernandez-Cean J. Importance of blood pressure control in hemodialysis patient survival. Kidney Int. 2000;58(5):2147-54

109. K/DOQI clinical practice guidelines for cardiovascular disease in dialysis patients. Am J Kidney Dis. 2005;45:S1-153

110. Salem MM. Hypertension in the haemodialysis population: Any relationship to 2-years survival? Nephrol. Dial. Transplant. 1999;14(1):125-128.

111. Kalantar-Zadeh K, Kilpatrick RD, McAllister CJ, Greenland S, Kopple J. D. Reverse epidemiology of hypertension and cardiovascular death in the hemodialysis population: The 58th annual fall conference and scientific sessions. Hypertension. 2005;45(4):811-817.

112. Port FK, et al. Predialysis blood pressure on survival in hemodialysis patients. Kidney Int. 2017;91: 755756.

113. Robinson BM, et al. Blood pressure levels and mortality risk among hemodialysis patients in the dialysis outcomes and practice patterns study. Kidney Int. 2012;82(5):570-580.

114. Zager PG, et al. ' $U$ ' curve association of blood pressure and mortality in hemodialysis patients. Medical Directors of Dialysis Clinic, Inc. Kidney Int. 1998;54(2):561-569.

115. Chen J, Gul A, Sarnak MJ. Management of intradialytic hypertension: the ongoing challenge. Semin Dial. 2006;19:141-145.

116. Daugirdas JT. Pathophysiology of dialysis hypotension: An update. Am J Kidney Dis. 2001;38(4 Suppl 4):S11-S17

117. van der Sande FM, et al. Novel Insights into the Pathogenesis and Prevention of Intradialytic Hypotension. Blood Purif. 2018;45:230-235.

118. Van Buren PN, et al. Extracellular Volume Overload and Increased Vasoconstriction in Patients With Recurrent Intradialytic Hypertension. Kidney Blood Press Res. 2016;41:802-814.

119. Agarwal R, Light RP. Intradialytic hypertension is a marker of volume excess. Nephrol Dial Transpl. 2010;25:3355-3361. 


\section{Chapter}

Intradialytic hypoxemia and clinical outcomes in

patients on hemodialysis

Meyring-Wösten $A^{*}$, Zhang $H^{*}$, Ye X, Fuertinger DH, Chan L, Kappel F, Artemyev M, Ginsberg N, Wang Y, Thijssen S, Kotanko P *contributed equally

Clin J Am Soc Nephrol. 2016;11(4):616-625 


\section{Abstract}

\section{Background and objectives}

Intradialytic hypoxemia has been recognized for decades, but its associations with outcomes have not yet been assessed in a large patient cohort.

\section{Design, setting, participants, \& measurements}

This retrospective cohort study was conducted between January 2012 and January 2015. Blood oxygen saturation was recorded every minute during hemodialysis in patients with arterio-venous access. A 6-month baseline period with at least ten treatments with oxygen saturation measurements preceded a 12-month follow-up. Patients were stratified by the presence or absence of prolonged intradialytic hypoxemia, defined as oxygen saturation below $90 \%$ for at least one third of the treatment time. Demographic, laboratory, treatment data, and hospitalization and mortality rates were compared between the groups. Multivariate Cox regression analysis was employed to assess baseline predictors of all-cause mortality during follow-up.

\section{Results}

One hundred (10\%) out of 983 patients had prolonged intradialytic hypoxemia. These patients were older (+3.6 years, $95 \%$ confidence interval $[95 \% \mathrm{Cl}] 0.8$ to 6.3 ), had longer dialysis vintage $(+1.2$ years, $95 \% \mathrm{Cl} 0.3$ to 2.1$)$, and higher prevalences of congestive heart failure $(+10.8 \%, 95 \% \mathrm{Cl} 1.6$ to 20.7$)$ and chronic obstructive pulmonary disease $(+13 \%, 95 \% \mathrm{Cl} 5$ to 21.2$)$. They also resembled an inflammatory phenotype, with lower serum albumin levels $(-0.1 \mathrm{~g} / \mathrm{dl}, 95 \% \mathrm{Cl}-0.2$ to 0$)$ and higher neutrophil-to-lymphocyte ratios $(+1,95 \% \mathrm{Cl} 0.5$ to 1.6$)$. They had lower hemoglobin levels $(-0.2 \mathrm{~g} / \mathrm{dl}, 95 \% \mathrm{Cl}-0.4$ to 0$)$ and required more erythropoietin (+1374 units per hemodialysis treatment, $95 \% \mathrm{Cl} 343$ to 2405). During follow-up all-cause hospitalization (1113 hospitalizations, univariate hazard ratio 1.46 [95\% $\mathrm{Cl} 1.22$ to 1.73$]$ ) and mortality (89 deaths, adjusted hazard ratio 1.98 [95\% Cl 1.14 to 3.43$]$ ) were higher in patients with prolonged intradialytic hypoxemia.

\section{Conclusion}

Prolonged intradialytic hypoxemia was associated with laboratory indicators of inflammation, higher erythropoietin requirements, and higher all-cause hospitalization and mortality. 


\section{Introduction}

While intradialytic hypoxemia is well recognized since the early days of hemodialysis ${ }^{1-3}$, epidemiological data from large populations are missing. Consequently, clinical correlates of intradialytic hypoxemia are ill-defined and associations with hard clinical outcomes have not yet been assessed.

In individuals dwelling below $1000 \mathrm{~m}$ altitude, an arterial oxygen saturation $\left(\mathrm{SaO}_{2}\right)$ between $96 \%$ and $99 \%$ is considered normal ${ }^{4}$. While there is no universally agreed upon definition of hypoxemia, most references consider $\mathrm{SaO}_{2} \leq 90 \%$ as indicative of hypoxemia ${ }^{5-7}$. Of note, oxygen supply to tissues depends not only on $\mathrm{SaO}_{2}$, but also on the hemoglobin content of the blood, tissue perfusion and oxygen release from hemoglobin in the tissues.

While hypoxemia is the common terminal pathway of multiple pathologies, congestive heart failure (CHF) and sleep apnea are particularly prevalent in hemodialysis patients $^{8-10}$. Additionally, there is growing literature about the prevalence of chronic obstructive pulmonary disease (COPD) in chronic kidney disease patients ${ }^{11,12}$. Notwithstanding etiology, hypoxemia and hypoxia are associated with a host of acute and chronic sequelae affecting multiple organ systems (13-15), including the cardiovascular system $(16,17)$, wound healing $(18)$, pro-inflammatory pathways (19), and the central nervous system (20). Some of these pathologies are highly prevalent in hemodialysis patients, for example inflammation and changes in vascular smooth muscles and endothelium, processes that accelerate arteriosclerosis $(21,22)$. Hypoxemia also impairs resilience against reactive oxygen species (ROS) and may increase erythrocyte apoptosis (eryptosis) (23). Noteworthy, in patients with CHF and sleep apnea it was observed that not only the frequency, but also the time spent with $\mathrm{SaO}_{2}$ below $90 \%$, the hypoxic "burden", is a predictor for hemodynamic stress (24).

Technological advances made routine continuous measurement of blood oxygen saturation during hemodialysis feasible (25). Depending on the type of vascular access, the Crit-Line monitor ${ }^{\mathrm{TM}}$ (CLM) can determine central-venous or arterial oxygen saturation.

Recent deployment of the CLM in a large population of U.S. hemodialysis patients allowed us to conduct research into associations between intradialytic $\mathrm{SaO}_{2}$ and clinical outcomes. The goals of this study were (1) to assess the epidemiology of intradialytic $\mathrm{SaO}_{2}$, and (2) to explore associations between $\mathrm{SaO}_{2}$ and clinical outcomes. 


\section{Materials and methods}

\section{Population and study design}

This observational retrospective multi-center data base study was conducted in a cohort of chronic hemodialysis patients from 17 facilities of the Renal Research Institute (RRI) between January 2012 and January 2015. These clinics were located in North Carolina ( 6 clinics; 108 to 205 meters above sea level), 3 clinics each in California (8 to 31 meters), Connecticut (20 to 70 meters), and New York City (28 meters), and 1 clinic each in Michigan (220 meters), and Illinois (180 meters). In these clinics, CLM use is standard care, albeit with some utilization variability related to the phased device roll-out. Patients were treated with bicarbonate dialysate and polysulfone membranes. A 6-months baseline period and a 12-months follow-up period were defined on a patient level. The baseline period started on the date of a patient's first $\mathrm{SaO}_{2}$ measurement between January 2012 and September 2014. Patients were censored in the event of transplantation, treatment modality change, transfer, recovery of kidney function, or end of study period (January $31^{\text {st }}, 2015$ ). Only patients with at least 10 eligible $\mathrm{SaO}_{2}$ measurements during baseline and 6 month of data were included in the analysis. The study was approved by the New England Institutional Review Board (\#14-446) which waived the need for informed consent.

\section{Measurement of oxygen saturation}

Intradialytic $\mathrm{SaO}_{2}$ was measured by the CLM (Fresenius Medical Care North America, Waltham, MA, USA), a device approved by the U.S. Food and Drug Administration for the measurement of hematocrit and oxygen saturation in the extracorporeal circuit. It reports oxygen saturation $1 \mathrm{x} /$ minute. The manufacturer reported accuracy of $\mathrm{SaO}_{2}$ measurement is $2 \%$. CLM data were transferred to the RRI data warehouse and subsequently to the study database.

\section{Clinical and laboratory data}

Laboratory measurements (Spectra Laboratories, New Jersey, NJ, USA) were downloaded to the RRI data warehouse and extracted to the study database.

\section{Data eligibility}

CLM values with the following characteristics were deemed implausible or unreliable and hence excluded: relative blood volume $>102 \%$; $\mathrm{SaO}_{2}>100 \%$; hematocrit levels $\leq 15 \%$ or $>55 \%$; and data points collected after the end of the prescribed treatment time. In the absence of acceptable data during more than $50 \%$ of the treatment time, the entire treatment was excluded. Likewise, treatments were excluded if the rate of 
change of relative blood volume was greater than 5 percent points compared to values 10 minutes and 5 minutes earlier on $\geq 1$ occasion, if $\mathrm{SaO}_{2}$ of $50 \%$ was recorded more than 40 times, or the mean intradialytic $\mathrm{SaO}_{2}$ was $\leq 80 \%$, a level indicative of venous rather than arterial blood.

\section{Comorbidities}

Congestive heart failure (CHF), diabetes, and chronic obstructive pulmonary disease (COPD) were defined using ICD-9 codes.

\section{Statistical analysis}

Descriptive statistics comprised mean ( \pm standard deviation; SD) for continuous variables and percentages for categorical variables. Non-normally distributed variables were expressed as median (25th, 75th percentile). Statistics of $\mathrm{SaO}_{2}$ variables were calculated first per hemodialysis treatment, then per patient and finally per group. Start $\mathrm{SaO}_{2}$ was defined as the mean $\mathrm{SaO}_{2}$ between treatment minutes 5 and 20, and End $\mathrm{SaO}_{2}$ as the mean $\mathrm{SaO}_{2}$ between the final 20 and 5 minutes; these time intervals were selected to avoid potential interference with priming and rinsing procedures.

Patients were stratified into 2 groups, based on an a priori definition of prolonged intradialytic hypoxemia (PIH). Diagnosis of PIH required the presence of hypoxemia, defined as $\mathrm{SaO}_{2} \leq 90 \%$, during on average more than $1 / 3$ of the recorded treatment time. Patients not fulfilling this definition served as controls. We also conducted investigations using mean $\mathrm{SaO}_{2}$ and the \% of treatment time spent with $\mathrm{SaO}_{2} \leq 90 \%$ as continuous variables. Group comparisons employed Chi-square, Fisher's exact and two sample t-tests, respectively; mean group differences with $95 \%$ confidence intervals $(95 \% \mathrm{Cl})$ are presented.

Hospitalization rates during follow-up were calculated as hospitalizations per patient year, 95\% Cls were computed by bootstrapping. Kaplan-Meier plots and Cox proportional hazards models were constructed to explore survival characteristics.

To adjust for potential confounders, minimally and fully adjusted Cox models complemented the crude hazard ratio (HR) analysis. Confounders were selected based on their documented or hypothesized association with exposure and outcome. We employed an incremental modeling strategy to assess the stability and spectrum of HR point estimates. Confounders in the minimally adjusted model were age, gender, and presence of COPD and CHF. In addition, the fully adjusted model included levels of serum albumin and hemoglobin, epoetin alfa (EPO) dose, neutrophil-to-lymphocyte ratio (NLR), interdialytic weight gain (IDWG; in $\mathrm{kg}$ ), post-HD systolic blood pressure 
(PostSBP), ultrafiltration rate normalized to treatment time and post-HD weight (UFR), presence of diabetes, race, and vintage. In a variant of the fully adjusted model we added body mass index (BMI) or obesity (defined as BMI $>30 \mathrm{~kg} / \mathrm{m}^{2}$ ).

Statistical analyses were performed using SAS version 9.3 (SAS Institute, Cary, NC) and R i386 3.0.2 (libraries: ggplot2, splines, survival, pspline, mgcv, assist) (R Foundation for Statistical Computing, Vienna, Austria).

\section{Results}

\section{Patient characteristics}

Out of 1,532 patients with $\mathrm{SaO}_{2}$ measurements, 547 patients (36\%) were excluded because they had less than 10 treatments with eligible CLM recordings during baseline or less than 6 month of data (Figure 2.1).

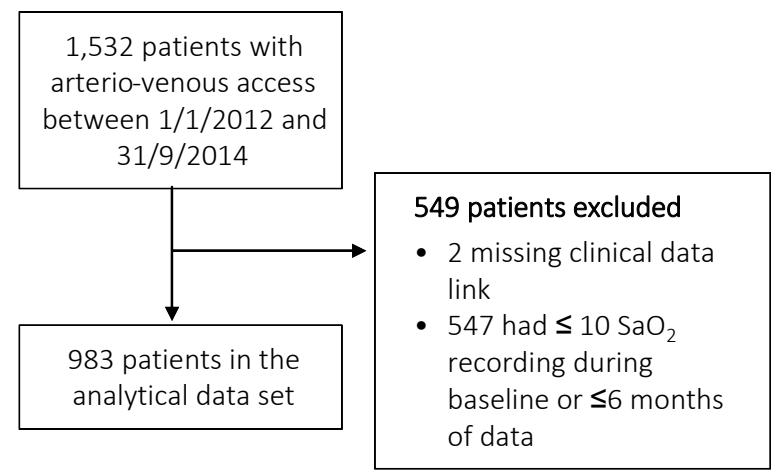

Figure 2.1 Study flow chart

The final cohort comprised 983 hemodialysis patients with a total of 29,986 treatments with eligible $\mathrm{SaO}_{2}$ recordings ( $30.5 \pm 12.5$ per patient). Age was $62.1 \pm 15.2$ years, $59 \%$ were male, and $52.6 \%$ were white. Dialysis vintage was $3.9 \pm 4.1$ years, $52.3 \%$ were diabetic, $23.3 \%$ had CHF and $8.4 \%$ had COPD. Chart review indicated that 16 patients received supplemental oxygen during in total 96 treatments. Supplemental oxygen flow rates were documented in 11 patients (range 1.5 to $3 \mathrm{l} / \mathrm{min}$ ).

Compared to the excluded patients, those in the analytical dataset were more likely to be white, and to suffer from diabetes, CHF, and COPD. In addition, they had 
significantly lower IDWG, serum bicarbonate, inflammatory markers, received less EPO, and spent less time below $90 \% \mathrm{SaO}_{2}$ (Supplemental Tables S2.2, S2.3).

\section{Baseline $\mathrm{SaO}_{2}$}

Across all patients mean intradialytic $\mathrm{SaO}_{2}$ was $92.8 \pm 1.8 \%$. On average, patients spent $10 \%$ and $3 \%$ of their treatment time at $\mathrm{SaO}_{2} \leq 90 \%$ and $\leq 87 \%$, respectively (Table 2.1 ). $\mathrm{SaO}_{2}$ increased from $92.6 \pm 1.9 \%$ at treatment start to $93.2 \pm 1.8 \%$ at the end.

Table 2.1 Baseline characteristics of the entire study population and after stratification into groups with and without prolonged intradialytic hypoxemia

\begin{tabular}{|c|c|c|c|c|c|}
\hline \multirow[t]{2}{*}{ Variables } & \multirow{2}{*}{$\begin{array}{l}\text { All patients } \\
\text { Mean } \pm \text { SD }\end{array}$} & \multicolumn{3}{|c|}{ Prolonged intradialytic hypoxemia } & \multirow[t]{2}{*}{ P-value } \\
\hline & & $\begin{array}{l}\text { Present } \\
\text { Mean } \pm S D\end{array}$ & $\begin{array}{c}\text { Absent } \\
\text { Mean } \pm S D\end{array}$ & $\begin{array}{c}\text { Difference between } \\
\text { groups } \\
\text { Mean }(95 \% \mathrm{Cl})\end{array}$ & \\
\hline Patients (N) & 983 & 100 & 883 & & \\
\hline $\begin{array}{l}\text { Treatments with } \mathrm{SaO}_{2} \\
\text { measurements (Number } \\
\text { per patient) }\end{array}$ & $30.5 \pm 12.5$ & $29.6 \pm 11.4$ & $30.6 \pm 12.7$ & $-1(-3.6$ to 1.6$)$ & $0.44^{2}$ \\
\hline \multicolumn{6}{|l|}{ Demographics } \\
\hline Gender (\% male) & 59.0 & 53.0 & 59.6 & $-6.6(-17.0$ to 3.7$)$ & $0.20^{1}$ \\
\hline Race (\% white) & 52.6 & 51.0 & 52.7 & $-1.7(-12.4$ to 8.4$)$ & $0.74^{1}$ \\
\hline Age (years) & $62.1 \pm 15.2$ & $65.3 \pm 13.0$ & $61.7 \pm 15.4$ & $3.6(0.8$ to 6.3$)$ & $0.01^{2}$ \\
\hline $\mathrm{BMI}\left(\mathrm{kg} / \mathrm{m}^{2}\right)$ & $28.7 \pm 7.7$ & $29.5 \pm 7.6$ & $28.6 \pm 7.8$ & $0.9(-0.8$ to 2.5$)$ & $0.30^{2}$ \\
\hline Obese $^{5}(\%)$ & 35.1 & 41.3 & 34.3 & $6.9(-3.5$ to 17.8$)$ & $0.21^{1}$ \\
\hline \multicolumn{6}{|l|}{ Oxygen saturation } \\
\hline Mean $\mathrm{SaO}_{2}(\%)$ & $92.8 \pm 1.8$ & $89.1 \pm 1.6$ & $93.2 \pm 1.3$ & $-4.1(-4.4$ to -3.8$)$ & $<0.001^{2}$ \\
\hline Median $\mathrm{SaO}_{2}(\%)$ & $92.9 \pm 1.8$ & $89.3 \pm 1.6$ & $93.3 \pm 1.3$ & $-4.0(-4.4$ to -3.7$)$ & $<0.001^{2}$ \\
\hline Minimum $\mathrm{SaO}_{2}(\%)$ & $90.4 \pm 2.8$ & $85.2 \pm 2.8$ & $91.0 \pm 2.2$ & $-5.8(-6.4$ to -5.2$)$ & $<0.001^{2}$ \\
\hline Maximum $\mathrm{SaO}_{2}(\%)$ & $94.5 \pm 1.4$ & $92.1 \pm 1.2$ & $94.8 \pm 1.1$ & $-2.7(-2.9$ to -2.5$)$ & $<0.001^{2}$ \\
\hline $\mathrm{SD} \mathrm{SaO}_{2}(\%)$ & $0.8 \pm 0.4$ & $1.4 \pm 0.5$ & $0.7 \pm 0.3$ & 0.7 (0.6 to 0.8$)$ & $<0.001^{2}$ \\
\hline $\begin{array}{l}\% \text { of time spent below } \\
90 \% \mathrm{SaO}_{2}(\%)\end{array}$ & $10.3 \pm 18.5$ & $57.6 \pm 18.2$ & $4.9 \pm 7.8$ & 52.7 (49.1 to 56.3 ) & $<0.001^{2}$ \\
\hline $\begin{array}{l}\% \text { of time spent below } \\
87 \% \mathrm{SaO}_{2}(\%)\end{array}$ & $2.6 \pm 8.7$ & $19.2 \pm 20.0$ & $0.7 \pm 2.1$ & 18.5 (14.6 to 22.5$)$ & $<0.001^{2}$ \\
\hline Start $\mathrm{SaO}_{2}(\%)$ & $92.6 \pm 1.9$ & $88.8 \pm 1.9$ & $93.1 \pm 1.4$ & $-4.3(-4.7$ to -3.9$)$ & $<0.001^{2}$ \\
\hline End $\mathrm{SaO}_{2}(\%)$ & $93.2 \pm 1.8$ & $89.7 \pm 1.6$ & $93.6 \pm 1.3$ & $-3.9(-4.2$ to -3.5$)$ & $<0.001^{2}$ \\
\hline \multicolumn{6}{|l|}{ Comorbidities } \\
\hline Diabetes (\%) & 52.3 & 56.0 & 51.9 & $4.1(-6.1$ to 14.1$)$ & $0.43^{1}$ \\
\hline $\mathrm{CHF}(\%)$ & 23.3 & 33.0 & 22.2 & 10.8 (1.6 to 20.7$)$ & $0.02^{1}$ \\
\hline COPD (\%) & 8.4 & 20.0 & 7.1 & 12.9 (5.0 to 21.2$)$ & $<0.001^{1}$ \\
\hline \multicolumn{6}{|l|}{$\begin{array}{l}\text { Treatment related } \\
\text { parameters }\end{array}$} \\
\hline Vintage (years) & $3.9 \pm 4.1$ & $5.0 \pm 4.3$ & $3.8 \pm 4.1$ & $1.2(0.3$ to 2.1$)$ & $0.008^{2}$ \\
\hline Pre-dialysis SBP (mmHg) & $146.9 \pm 19.4$ & $147.2 \pm 19.5$ & $146.9 \pm 19.4$ & $0.3(-3.7$ to 4.4$)$ & $0.87^{2}$ \\
\hline Post-dialysis SBP (mmHg) & $137.2 \pm 18.2$ & $139.2 \pm 19.7$ & $136.9 \pm 18.0$ & $2.3(-1.5$ to 6.0$)$ & $0.24^{2}$ \\
\hline IDWG (kg) & $2.3 \pm 0.8$ & $2.5 \pm 0.8$ & $2.3 \pm 0.8$ & $0.2(0.0$ to 0.4$)$ & $0.03^{2}$ \\
\hline $\begin{array}{l}\text { IDWG (\% of post-HD } \\
\text { weight) }\end{array}$ & $2.9 \pm 1.0$ & $3.0 \pm 1.0$ & $2.8 \pm 1.0$ & 0.2 (0.0 to 0.4$)$ & $0.06^{2}$ \\
\hline Treatment time ( $\mathrm{min})$ & $215.9 \pm 25.0$ & $215.6 \pm 24.3$ & $216.0 \pm 25.1$ & $-0.4(-5.6$ to 4.8$)$ & $0.89^{2}$ \\
\hline $\begin{array}{l}\text { Ultrafiltration rate } \\
(\mathrm{ml} / \mathrm{h} / \mathrm{kg})\end{array}$ & $8.1 \pm 3.0$ & $8.6 \pm 2.9$ & $8.0 \pm 3.0$ & $0.6(-0.1$ to 1.2$)$ & $0.07^{2}$ \\
\hline Ultrafiltration volume (I) & $2.3 \pm 0.8$ & $2.4 \pm 0.8$ & $2.2 \pm 0.9$ & 0.2 (0.0 to 0.3$)$ & $0.05^{2}$ \\
\hline Equilibrated Kt/V & $1.5 \pm 0.3$ & $1.5 \pm 0.2$ & $1.5 \pm 0.3$ & 0.0 (0.0 to 0.0$)$ & $0.28^{2}$ \\
\hline Dialysate sodium (mmol/l) & $137.2 \pm 0.5$ & $137.2 \pm 0.4$ & $137.2 \pm 0.5$ & $0.0(-0.1$ to 0.1$)$ & $0.41^{2}$ \\
\hline
\end{tabular}


Table 2.1 (continued)

\begin{tabular}{|c|c|c|c|c|c|}
\hline \multirow[t]{2}{*}{ Variables } & \multirow{2}{*}{$\begin{array}{l}\text { All patients } \\
\text { Mean } \pm S D\end{array}$} & \multicolumn{3}{|c|}{ Prolonged intradialytic hypoxemia } & \multirow[t]{2}{*}{ P-value } \\
\hline & & $\begin{array}{c}\text { Present } \\
\text { Mean } \pm \text { SD }\end{array}$ & $\begin{array}{c}\text { Absent } \\
\text { Mean } \pm \text { SD }\end{array}$ & $\begin{array}{c}\text { Difference between } \\
\text { groups } \\
\text { Mean }(95 \% \mathrm{Cl}) \\
\end{array}$ & \\
\hline Patients (N) & 983 & 100 & 883 & & \\
\hline \multicolumn{6}{|l|}{ Laboratory parameters } \\
\hline Serum albumin (g/dl) & $4.0 \pm 0.3$ & $3.9 \pm 0.3$ & $4.0 \pm 0.3$ & $-0.1(-0.2$ to 0.0$)$ & $0.006^{2}$ \\
\hline $\mathrm{Hgb}(\mathrm{g} / \mathrm{dl})$ & $10.9 \pm 0.9$ & $10.7 \pm 0.9$ & $10.9 \pm 0.9$ & $-0.2(-0.4$ to 0.0$)$ & $0.02^{2}$ \\
\hline Serum sodium (mmol/l) & $138.8 \pm 2.6$ & $138.4 \pm 3.0$ & $138.9 \pm 2.5$ & $-0.5(-1.1$ to 0.1$)$ & $0.13^{2}$ \\
\hline $\begin{array}{l}\text { Serum potassium } \\
(\mathrm{mmol} / \mathrm{l})\end{array}$ & $4.8 \pm 0.5$ & $4.9 \pm 0.5$ & $4.8 \pm 0.5$ & 0.1 (0.0 to 0.2 ) & $0.06^{2}$ \\
\hline PTH $(\mathrm{pg} / \mathrm{ml})$ & $549 \pm 500$ & $543 \pm 665$ & $550 \pm 478$ & $-6(-142$ to 129$)$ & $0.93^{2}$ \\
\hline Serum calcium (mg/dl) & $8.9 \pm 0.6$ & $8.8 \pm 0.7$ & $9.0 \pm 0.6$ & $-0.2(-0.3$ to 0.0$)$ & $0.01^{2}$ \\
\hline $\begin{array}{l}\text { Serum phosphorous } \\
(\mathrm{mg} / \mathrm{dl})\end{array}$ & $5.3 \pm 1.2$ & $5.2 \pm 1.2$ & $5.3 \pm 1.2$ & $-0.1(-0.3$ to 0.2$)$ & $0.68^{2}$ \\
\hline $\begin{array}{l}\text { Serum bicarbonate } \\
(\mathrm{mmol} / \mathrm{l})\end{array}$ & $23.2 \pm 2.0$ & $23.5 \pm 2.1$ & $23.2 \pm 2.0$ & $0.3(-0.1$ to 0.7$)$ & $0.15^{2}$ \\
\hline WBC $(1000 / \mu \mathrm{l})$ & $6.6 \pm 3.1$ & $6.7 \pm 2.0$ & $6.6 \pm 3.2$ & $0.1(-0.3$ to 0.6$)$ & $0.49^{2}$ \\
\hline Platelets $(1000 / \mu \mathrm{l})$ & $205.0 \pm 62.9$ & $197.2 \pm 64.8$ & $205.9 \pm 62.7$ & $-8.7(-22.1$ to 4.7$)$ & $0.20^{2}$ \\
\hline NLR & $3.7 \pm 2.1$ & $4.6 \pm 2.6$ & $3.6 \pm 2.0$ & $1.0(0.5$ to 1.6$)$ & $<0.001^{2}$ \\
\hline Ferritin (ng/ml) & $923 \pm 460$ & $884 \pm 389$ & $927 \pm 467$ & $-43(-126$ to 40$)$ & $0.31^{2}$ \\
\hline Transferrin saturation (\%) & $33.7 \pm 8.7$ & $29.5 \pm 8.0$ & $34.2 \pm 8.7$ & $-4.7(-6.5$ to -2.9$)$ & $<0.001^{2}$ \\
\hline Serum iron $(\mu \mathrm{g} / \mathrm{dl})$ & $77.7 \pm 22.4$ & $67.5 \pm 21.3$ & $78.9 \pm 22.2$ & $-11.4(-16.0$ to -6.8$)$ & $<0.001^{2}$ \\
\hline Medication & $\begin{array}{l}\text { Median }\left(25^{\text {th }}\right. \\
75^{\text {th }} \text { percentile) }\end{array}$ & $\begin{array}{l}\text { Median }\left(25^{\text {th }}, 75^{\text {th }}\right. \\
\text { percentile })\end{array}$ & $\begin{array}{l}\text { Median }\left(25^{\text {th }}, 75^{\text {th }}\right. \\
\text { percentile) }\end{array}$ & & \\
\hline $\begin{array}{l}\text { Epo Dose (units per } \\
\text { treatment) }\end{array}$ & $1584(610,3240)$ & $2173(900,4471)$ & $1531(603,3156)$ & 642 (213 to 976$)$ & $0.006^{4}$ \\
\hline $\begin{array}{l}\text { Iron Dose (mg per } \\
\text { treatment) }\end{array}$ & $15.1(7.1,23.3)$ & $16.8(7.5,24.3)$ & $14.7(7.1,23.3)$ & $2.1(-0.9$ to 4.2$)$ & $0.41^{4}$ \\
\hline Patients receiving & 1.6 & 1 & 1.7 & $-0.7(-2.3$ to 1.9$)$ & $1.0^{3}$ \\
\hline supplemental oxygen (\%) & $\mathrm{N}=16$ & $N=1$ & $N=15$ & & \\
\hline Treatments with & 0.3 & 0.3 & 0.3 & $0(-0.2$ to 0.2$)$ & $0.61^{3}$ \\
\hline supplemental oxygen (\%) & $N=96$ & $N=8$ & $N=88$ & & \\
\hline
\end{tabular}

${ }^{1}$ Chi-square test; ${ }^{2}$-test; ${ }^{3}$ Fisher's exact test; ${ }^{4}$ Wilcoxon test; ${ }^{5} \mathrm{BMI} \geq 30 \mathrm{~kg} / \mathrm{m}^{2}$; SD: standard deviation; $\mathrm{Cl}$ : confidence interval; $\mathrm{BMI}$ : body mass index; $\mathrm{SaO}_{2}$ : arterial oxygen saturation; $\mathrm{CHF}$ : congestive heart failure; COPD: chronic obstructive pulmonary disease; SBP: systolic blood pressure; IDWG: interdialytic weight gain; Hgb: hemoglobin; WBC: white blood cells; NLR: neutrophil-to-lymphocyte ratio; Epo: epoetin alfa

One hundred patients (10.2\%) experienced PIH. PIH patients had a significantly lower mean, median, minimum, maximum, starting, and ending $\mathrm{SaO}_{2}$ and spent on average $58 \%$ and $20 \%$ of their treatment time at $\mathrm{SaO}_{2} \leq 90 \%$ and $\leq 87 \%$, respectively. The variability of $\mathrm{SaO}_{2}$ levels was significantly higher in PIH patients (SD 1.4 vs. 0.7\%).

$\mathrm{SaO}_{2}$ declined after dialysis start both in patients with and without $\mathrm{PIH}$, with nadir $\mathrm{SaO}_{2}$ after around 40 minutes (Figure 2.2). $\mathrm{SaO}_{2}$ declined by 0.3 percent points in controls, and by 0.5 percent points in $\mathrm{PIH}$ patients. 


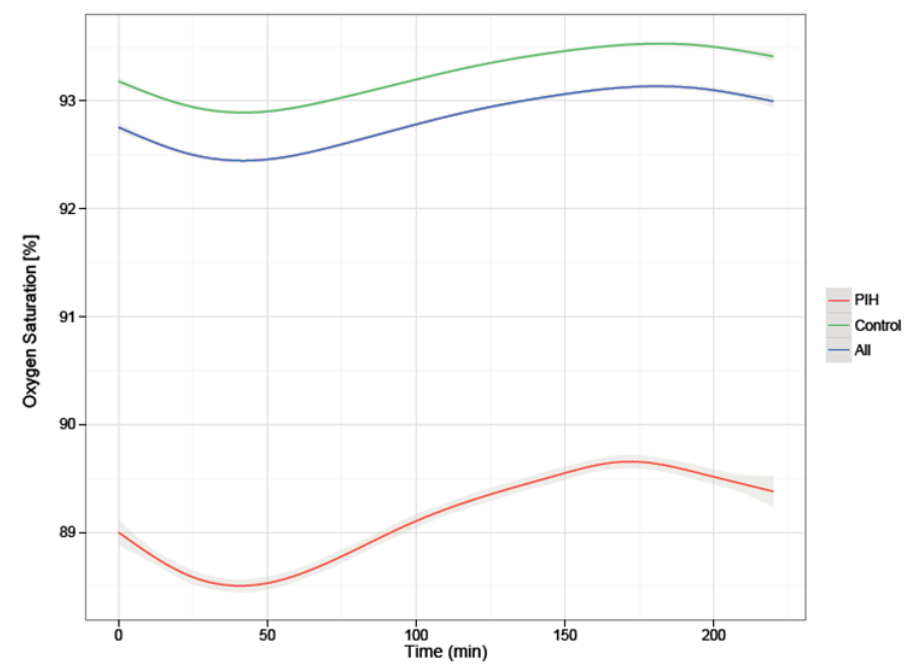

Figure 2.2 Time course of mean arterial oxygen saturation and 95\% confidence interval in chronic HD patients

\section{Associations between PIH and baseline clinical characteristics}

$\mathrm{PIH}$ was associated with older age, longer dialysis vintage, slightly higher IDWG, and higher prevalence of CHF and COPD. PIH patients had higher NLR, lower levels of albumin, hemoglobin, serum iron, and transferrin saturation. They received on average 1,374 units of EPO more per treatment (PIH: mean 3,823 units; non-PIH: mean 2,449 units; $P=0.01$ ). Groups did not differ with respect to gender, race, BMI, pre- and postdialytic systolic blood pressure, ultrafiltration volume, UFR, treatment time, serum bicarbonate, white blood cells, platelet counts, ferritin, and iron dose.

\section{$\mathrm{PIH}$ and outcomes during follow-up}

\section{All-cause hospitalization}

We recorded 1,113 hospitalizations, 150 in $\mathrm{PIH}$ patients and 963 in the controls, resulting in 2.21 (95\% $\mathrm{Cl} 0$ to 3.4$)$ and 1.55 (95\% Cl 0 to 2.04$)$ hospitalizations per patient year, respectively. Thus, PIH was associated with 0.66 additional hospitalizations per patient year $(P=0.009)$. The univariate $\mathrm{HR}$ of hospitalization of $\mathrm{PIH}$ was $1.46(95 \% \mathrm{Cl} 1.22$ to $1.73 ; P=0.007)$. 


\section{All-cause mortality}

Eighty-nine patients died during follow-up, 18 in the PIH group and 71 controls. The mortality rate per 100 patient-years was 24.1 in the PIH group and 10.2 in the controls. Univariate Kaplan-Meier analysis indicated a significantly higher mortality in $\mathrm{PIH}$ patients $(P<0.001$, log-rank test; Figure 2.3). Sixty-nine PIH patients and 668 controls were censored, due to end of study ( $\mathrm{PIH} \mathrm{N}=62$; controls $\mathrm{N}=610$ ) or transfer to another facility ( $\mathrm{PIH} \mathrm{N}=7$; controls $\mathrm{N}=58$ ).

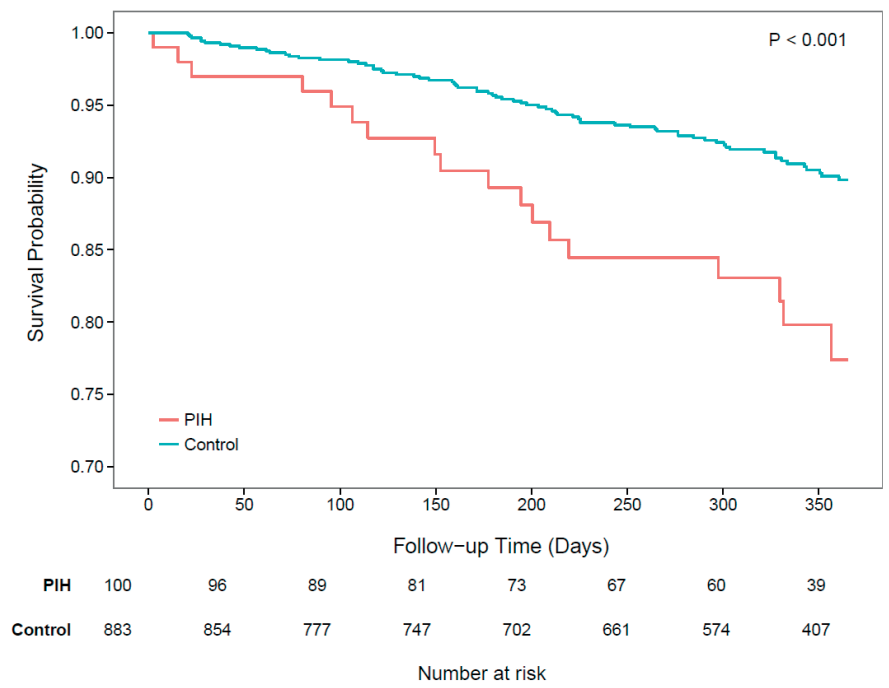

Figure 2.3 Kaplan-Meier estimates of survival probabilities. Patients were stratified by the presence (PIH) or absence (control) of prolonged intradialytic hypoxemia. The number of patients at risk is indicated in the table below the graph. The time to death differs significantly between the two groups $(P<0.001$ by log-rank test)

Analysis treating $\mathrm{SaO}_{2}$ and \% of treatment time spent below $90 \% \mathrm{SaO}_{2}$ as continuous variables indicated an almost linear association with all-cause mortality for both (Figure 2.4, Supplemental Table S2.1). Multivariate analysis corroborated the higher allcause mortality in $\mathrm{PIH}$ patients in unadjusted, minimally and fully adjusted Cox proportional hazards models (Table 2.2, Supplemental Figure S2.2). Including BMI or obesity to the fully adjusted model results were materially identical (data not shown). 

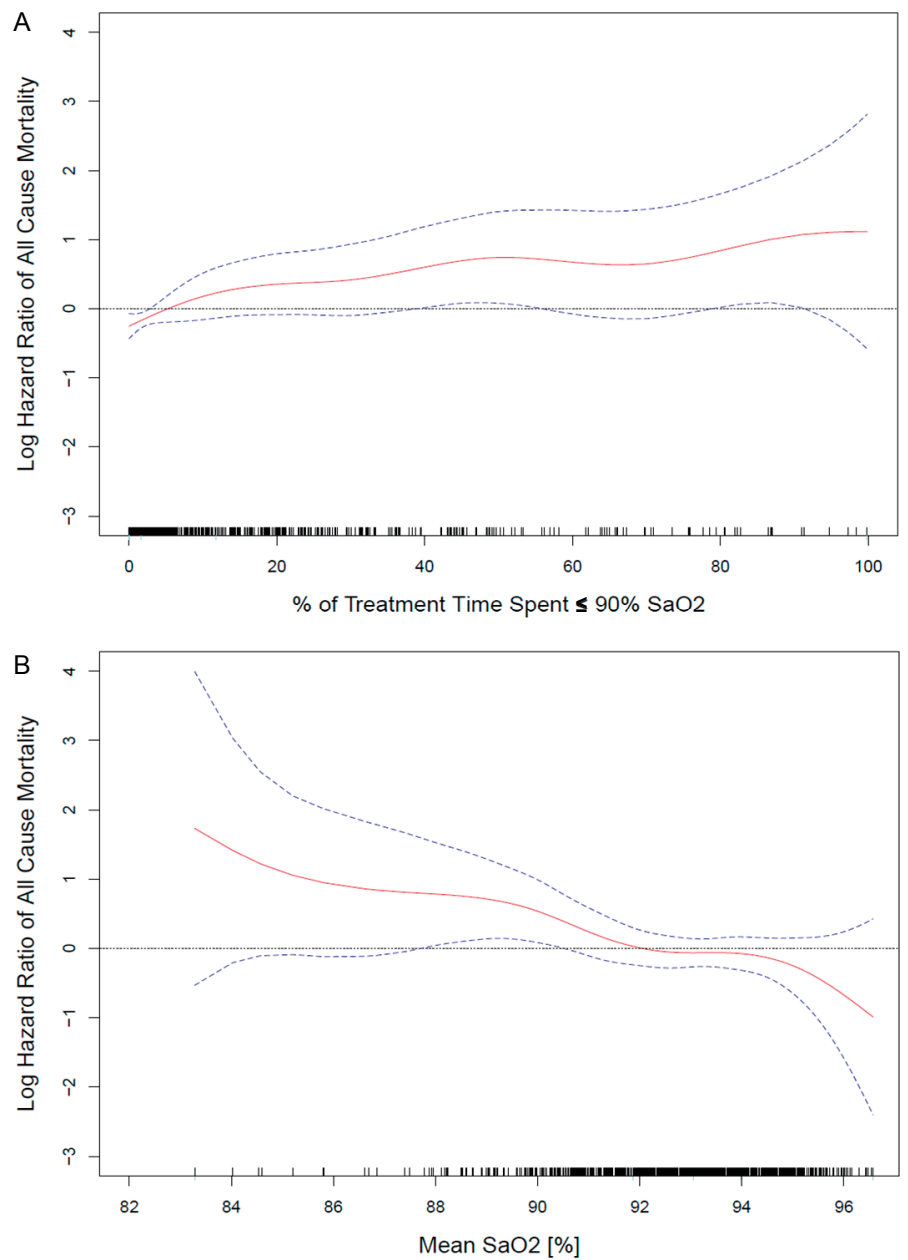

Figure 2.4 Association between intradialytic arterial oxygen saturation and all-cause mortality. Hazard ratio for $(A)$ average $\%$ of time spent below $90 \%$ oxygen saturation during treatments and (B) mean arterial oxygen saturation. SaO2: arterial oxygen saturation

Table 2.2 Crude and adjusted hazard ratios (HR) for all-cause mortality. Because of partially incomplete data six censored patients were not considered in the fully adjusted Cox model.

\begin{tabular}{lcccccc}
\hline Outcome Events & \multicolumn{2}{c}{ Crude $^{\mathrm{a}}$} & \multicolumn{2}{c}{ Minimally adjusted $^{\mathrm{b}}$} & \multicolumn{2}{c}{ Fully adjusted $^{\mathrm{c}}$} \\
\cline { 2 - 7 } & $\mathrm{HR}(95 \% \mathrm{Cl})$ & P-value & $\mathrm{HR}(95 \% \mathrm{Cl})$ & P-value & $\mathrm{HR}(95 \% \mathrm{Cl})$ & P-value \\
\hline $\begin{array}{l}\text { All-cause } \\
\text { mortality }\end{array}$ & $2.37(1.41$ to 3.97) & 0.001 & $2.07(1.22$ to 3.51) & 0.007 & $1.98(1.14$ to 3.43) & 0.02 \\
\hline
\end{tabular}

${ }^{a}$ Unadjusted model. ${ }^{b}$ Adjusted for age, gender, COPD and CHF. ${ }^{c}$ Adjusted for age gender, race, vintage, COPD, CHF, diabetes, albumin, hemoglobin, Epoetin alfa Dose, NLR, IDWG, post-dialysis SBP and UFR 
$\mathrm{Cl}$ : confidence interval; COPD: chronic obstructive pulmonary disease; CHF: congestive heart failure; NLR: neutrophil-to-lymphocyte ratio; IDWG: interdialytic weight gain; SBP: systolic blood pressure; UFR; ultrafiltration rate

\section{Sensitivity analysis}

To explore the influence of CHF and COPD on outcomes we performed a sensitivity analysis. First, the hospitalization rates were computed in both groups with and without patients with COPD or CHF, respectively. While the hospitalization rate in controls was unaffected by excluding COPD or CHF patients, it decreased in the PIH group (Supplemental Table S2.4). Second, we calculated the HR of death without COPD or CHF patients; interestingly, the HR increased from 1.98 to 2.21 (Supplemental Table S2.5).

\section{Discussion}

Our research in a large cohort of chronic hemodialysis patients indicates a high rate of intradialytic hypoxemia, with $10 \%$ experiencing prolonged intradialytic hypoxemia (PIH), a condition characterized by hypoxemia lasting more than $1 / 3$ of the dialysis treatment time. Our main finding is a significant association between $\mathrm{PIH}$ and clinical outcomes, most notably all-cause hospitalization and mortality. Moreover, PIH patients showed a laboratory profile compatible with an inflammatory phenotype, and significantly higher EPO use. CHF and COPD were more prevalent in PIH patients.

Hypoxemia during hemodialysis has been recognized since the early days of dialysis ${ }^{26-}$ 32. Over the years several mechanistic explanations have been put forward. Sleep apnea is highly prevalent in dialysis patients and hypoxemia has been observed in patients while sleeping on dialysis ${ }^{33,34}$. Reduced respiratory drive has been incriminated, since $\mathrm{CO}_{2}$ may diffuse from the blood into the dialysate, resulting in decreased partial pressure of $\mathrm{CO}_{2}$. As breathing is tightly controlled by chemoreceptors which respond to the partial pressure of $\mathrm{CO}_{2}$ as well as $\mathrm{pH}$ in the blood and cerebrospinal fluid, a reduction in $\mathrm{CO}_{2}$ tension may result in hypoventilation and hypoxemia $^{35}$. Fluid overload, pulmonary congestion, and pulmonary calcification may affect oxygen diffusion, resulting in reduced blood oxygenation; therefore, approaching dry weight should improve $\mathrm{SaO}_{2}$. Indeed, Anand ${ }^{36}$ found a positive relationship between the slope of the relative blood volume curve, an indirect marker of volume status, and change in $\mathrm{SaO}_{2}$ indicating a contribution of volume overload to hypoxemia. In our study, $\mathrm{SaO}_{2}$ at the end of dialysis was above starting levels and $\mathrm{PIH}$ patients had a slightly higher IDWG, pointing towards fluid status as a factor impacting $\mathrm{SaO}_{2}$. Agerelated changes of the respiratory system, such as a reduced neuro-mechanical link 
between chemosensors, brain stem and respiratory muscles, may impact blood gases $^{37}$. In that context it is noteworthy that PIH patients were older, had a longer HD vintage, and a higher $\mathrm{SaO}_{2}$ variability, possibly reflecting respiratory control instability. Previous studies related a high variability and decrease of $\mathrm{SaO}_{2}$ during dialysis to intradialytic hypotension ${ }^{38,39}$. Unfortunately we can neither corroborate nor refute this observation, because hypotensive episodes were not uniformly documented. Of note, we did not observe a difference in blood pressure between the two groups. Although a contribution of intradialytic hypoxemia to the morbidity and mortality of hemodialysis patients has been hypothesized ${ }^{26,40,41}$, this study shows - to the best of our knowledge - for the first time an association between adverse clinical outcomes and intradialytic hypoxemia. The decision to perform a dichotomous analysis and take $1 / 3$ of treatment time below $90 \%$ as threshold was based on the "hypoxic burden" concept described in patients with CHF. The notion of "prolonged intradialytic hypoxemia" was developed in appreciation of this concept ${ }^{24}$. Since CLM use is standard care in the participating clinics bias by indication is highly unlikely.

Intermittent hypoxemia has been subject of considerable research. While modest and acute intermittent hypoxemia may have beneficial effects, severe and chronic intermittent hypoxemia appears to be pathogenic ${ }^{42}$. Chronic intermittent hypoxia results in impaired baroreceptor function, vasodilation, high blood pressure, and increased production of $\operatorname{ROS}^{43}$. While ROS activate protective transcription factors like hypoxia inducible factor-1 $\alpha$ (HIF-1 $\alpha$ ) and nuclear factor (erythroid derived 2)-like 2 (Nrf2), they also stimulate pro-inflammatory transcription factors, like nuclear factor $\mathrm{KB}$ (NFKB) and activator protein 1 (AP1). At low or moderate ROS concentrations pathways essential for repair and survival predominate, high ROS levels promote inflammation and injury ${ }^{20}$. While we have no data on ROS in our population, it is tempting to speculate that the inflammatory laboratory phenotype observed in $\mathrm{PIH}$ patients may be related to oxidative stress. Of note, oxidative stress also impairs erythrocyte function; in particular it may result in reduced cell deformability and thus contribute to an increased erythrocyte removal from the circulation and thus reduced life $\operatorname{span}^{44,45}$.

Given the fact that hypoxia is the primary stimulus for EPO production, showing higher EPO utilization in PIH patients seems counterintuitive. PIH patients not only had a higher EPO use but also lower hemoglobin levels, indicating some degree of EPO resistance. An obvious link may exist between the EPO hyporesponsiveness and the aforementioned inflammatory phenotype of $\mathrm{PIH}$ patients, which may result in limited iron availability, a reduced number of EPO receptors, and impaired EPO receptor signaling ${ }^{46}$. Recent evidence suggests that hypoxemia may impact erythrocyte resilience against oxidative stress. The erythrocyte ROS resilience depends on the availability of reduced glutathione (GSH), which is recycled from glutathione disulfide (GSSG) through the action of glutathione reductase and nicotinamide adenine 
dinucleotide phosphate (NADPH) as a substrate. Glucose entering the erythrocytes is subject to metabolism in two pathways, the Embden-Meyerhof pathway (EMP), the source of adenosine triphosphate (ATP), and the hexose monophosphate pathway (HMP), the sole source of NADPH in erythrocytes. Deoxygenized hemoglobin favors EMP substrate fluxes over HMP, resulting in reduced NADPH synthesis and eventually less resilience to oxidative stress ${ }^{47}$. Against this physiological background we hypothesize that hypoxemia-induced impaired erythrocyte ROS resilience may result in shortened erythrocyte life span, a recognized cause of EPO resistance ${ }^{48}$. Testing this hypothesis will require carefully designed in vitro and clinical studies.

Our study has limitations, first and foremost its observational nature, which prevents conclusions concerning causality. Second, longer follow-up periods are desirable. Third, we have no data which would allow us to address the hypotheses formulated above in greater detail. Lastly, we have no information on baseline $\mathrm{SaO}_{2}$ and scarce records of supplemental oxygen use during dialysis, an intervention which clearly affects $\mathrm{SaO}_{2}$. Carefully conducted prospective trials are necessary to address these limitations.

From a clinical standpoint it will be essential to develop care pathways for PIH patients. Given the plethora of pathologies resulting in hypoxemia a multidisciplinary approach including pulmonologists will be critical to translate these findings into improved patient care.

One potential intervention could be the administration of oxygen during dialysis. While large and comprehensive trials are missing, a few small studies showed a positive effect of intradialytic oxygen administration. Diroll ${ }^{38}$ reported that intranasal oxygen (2 $\mathrm{l} /$ minute) normalized $\mathrm{SaO}_{2}$ and blood pressure in a hypoxemic hemodialysis patient. In a study of 8 hemodialysis patients, intranasal oxygen $\left(2 \mathrm{l} /\right.$ minute) improved $\mathrm{SaO}_{2}$ and vascular refill ${ }^{49}$. Yap ${ }^{50}$ showed in 7 chronic hemodialysis patients that intranasal oxygen (4 I/minute) protected against an intradialytic $\mathrm{SaO}_{2}$ decline. Taken together, limited data indicate some desirable effects of supplemental oxygen, but firm conclusions are currently elusive.

\section{Conclusion}

Prolonged intradialytic hypoxemia (PIH) is associated with an inflammatory phenotype, hyporesponsiveness to EPO, higher hospitalization and mortality. A better understanding of its pathophysiology, clinical consequences and medical management requires future carefully designed in vitro and clinical studies. 


\section{References}

1. Johnson N, Bischel M, Boylen C, Mohler J, Barbour B. Hypoxia and hyperventilation in chronic hemodialysis. Clin Res. 1970;19:145.

2. Sherlock JE, Yoon Y, Ledwith JW, Letteri JM: Respiratory gas exchange during hemodialysis. Proc Clin Dial Transplant Forum. 1972;2:171-4.

3. Carlon GC, Campfield PB, Goldiner PL, Turnbull AD. Hypoxemia during hemodialysis. Crit Care Med. 1979;7:497-499.

4. McFarland RA. XI - Psychophysiological Implications of Life at Altitude and Including the Role of Oxygen in the Process of Aging. In: Physiological Adaptations. edited by BULLARD, M. K. Y. M. H. W.,cademic Press, 1972:157-181.

5. O'Driscoll BR, Howard LS, Davison AG.: BTS guideline for emergency oxygen use in adult patients. Thorax. 2008;63:vi1-vi68.

6. Morris RW, Buschman A, Warren DL, Philip JH, Raemer DB. The prevalence of hypoxemia detected by pulse oximetry during recovery from anesthesia. J Clin Monit. 1988;4:16-20.

7. Tyler IL, Tantisira B, Winter PM, Motoyama EK: Continuous monitoring of arterial oxygen saturation with pulse oximetry during transfer to the recovery room. Anesth Analg. 1985;64:1108-1112.

8. Harnett JD, Foley RN, Kent GM, Barre PE, Murray D, Parfrey PS. Congestive heart failure in dialysis patients: prevalence, incidence, prognosis and risk factors. Kidney Int. 1995;47:884-890.

9. Roumelioti ME, Buysse DJ, Sanders MH, Strollo P, Newman AB, Unruh ML. Sleep-disordered breathing and excessive daytime sleepiness in chronic kidney disease and hemodialysis. Clin J Am Soc Nephrol. 2011;6:986-994.

10. Unruh ML, Sanders MH, Redline S, Piraino BM, Umans JG, Hammond TC, Sharief I, Punjabi NM, Newman AB. Sleep apnea in patients on conventional thrice-weekly hemodialysis: comparison with matched controls from the Sleep Heart Health Study. J Am Soc Nephrol. 2006;17:3503-3509.

11. Plesner LL, Warming PE, Nielsen TL, Dalsgaard M, Schou M, Host U, Rydahl C, Brandi L, Kober L, Vestbo J, Iversen K. Chronic obstructive pulmonary disease in patients with end-stage kidney disease on hemodialysis. Hemodialysis international International Symposium on Home Hemodialysis, 2015

12. Kent BD, Eltayeb EE, Woodman A, Mutwali A, Nguyen HT, Stack AG. The impact of chronic obstructive pulmonary disease and smoking on mortality and kidney transplantation in end-stage kidney disease. Am J Nephrol. 2012;36:287-295.

13. Dempsey JA, Veasey SC, Morgan BJ, O'Donnell CP. Pathophysiology of sleep apnea. Physiol Rev. 2010;90:47-112.

14. Pierson DJ. Pathophysiology and clinical effects of chronic hypoxia. Respir Care. 2000;45:39-51; discussion:51-33.

15. Prabhakar NR, Semenza GL. Adaptive and maladaptive cardiorespiratory responses to continuous and intermittent hypoxia mediated by hypoxia-inducible factors 1 and 2. Physiol Rev. 2012;92:967-1003.

16. Dumitrascu R, Heitmann J, Seeger W, Weissmann N, Schulz R. Obstructive sleep apnea, oxidative stress and cardiovascular disease: lessons from animal studies. Oxid Med Cell Longev. 2013;2013:234631.

17. Lucking EF, O'Halloran KD, Jones JF. Increased cardiac output contributes to the development of chronic intermittent hypoxia-induced hypertension. Exp Physiol. 2014;99:1312-1324.

18. Lee A, Derricks K, Minns M, Ji S, Chi C, Nugent MA, Trinkaus-Randall V. Hypoxia-induced changes in $\mathrm{Ca}(2+)$ mobilization and protein phosphorylation implicated in impaired wound healing. Am J Physiol Cell Physiol. 2014;306:C972-985.

19. Taylor CT. Interdependent roles for hypoxia inducible factor and nuclear factor-kappaB in hypoxic inflammation. J Physiol. 2008;586:4055-4059.

20. Lavie L. Oxidative stress in obstructive sleep apnea and intermittent hypoxia--revisited--the bad ugly and good: implications to the heart and brain. Sleep Med Rev. 2015;20:27-45.

21. Shroff RC, McNair R, Figg N, Skepper JN, Schurgers L, Gupta A, Hiorns M, Donald AE, Deanfield J, Rees L, Shanahan CM. Dialysis accelerates medial vascular calcification in part by triggering smooth muscle cell apoptosis. Circulation. 2008;118:1748-1757. 
22. Stam F, van Guldener C, Schalkwijk CG, ter Wee PM, Donker AJ, Stehouwer CD. Impaired renal function is associated with markers of endothelial dysfunction and increased inflammatory activity. Nephrol Dial Transplant. 2003;18:892-898.

23. Lang F, Lang E, Foller M. Physiology and pathophysiology of eryptosis. Transfus Med Hemother. 2012;39:308-314.

24. Gottlieb JD, Schwartz AR, Marshall J, Ouyang P, Kern L, Shetty V, Trois M, Punjabi NM, Brown C, Najjar SS, Gottlieb SS. Hypoxia, not the frequency of sleep apnea, induces acute hemodynamic stress in patients with chronic heart failure. J Am Coll Cardiol. 2009;54:1706-1712.

25. Balter $P$, Artemyev $M$, Zabetakis $P$. Methods and challenges for the practical application of crit-line monitor utilization in patients on hemodialysis. Blood Purif. 2015;39:21-24.

26. Jones JG, Bembridge JL, Sapsford DJ, Turney JH. Continuous measurements of oxygen saturation during haemodialysis. Nephrol Dial Transplant. 1992;7:110-116.

27. Fawcett S, Hoenich NA, Laker MF, Schorr W, Jr., Ward MK, Kerr DN. Haemodialysis-induced respiratory changes. Nephrol Dial Transplant. 1987;2:161-168.

28. Cardoso M, Vinay P, Vinet B, Leveillee M, Prud'homme M, Tejedor A, Courteau M, Gougoux A, St-Louis G, Lapierre L, et al. Hypoxemia during hemodialysis: a critical review of the facts. Am J Kidney Dis. 1988;11:281-297.

29. De Broe ME, De Backer WA. Pathophysiology of hemodialysis-associated hypoxemia. Adv Nephrol Necker Hosp. 1989;18:297-315.

30. Igarashi H, Kioi S, Gejyo F, Arakawa M. Physiologic approach to dialysis-induced hypoxemia. Effects of dialyzer material and dialysate composition. Nephron. 1985;41:62-69.

31. De Backer WA, Verpooten GA, Borgonjon DJ, Vermeire PA, Lins RR, De Broe ME. Hypoxemia during hemodialysis: effects of different membranes and dialysate compositions. Kidney Int. 1983;23: 738-743.

32. Jacob Al, Gavellas G, Zarco R, Perez G, Bourgoignie JJ. Leukopenia, hypoxia, and complement function with different hemodialysis membranes. Kidney Int. 1980;18:505-509.

33. Nicholl DD, Ahmed SB, Loewen AH, Hemmelgarn BR, Sola DY, Beecroft JM, Turin TC, Hanly PJ. Clinical presentation of obstructive sleep apnea in patients with chronic kidney disease. Journal of clinical sleep medicine : J Clin Sleep Med. 2012;8:381-387.

34. Chan CT, Hanly P, Gabor J, Picton P, Pierratos A, Floras JS. Impact of nocturnal hemodialysis on the variability of heart rate and duration of hypoxemia during sleep. Kidney Int. 2004;65:661-665.

35. Pierson DJ. Respiratory considerations in the patient with renal failure. Respir Care. 2006;51:413-422.

36. Anand S, Sinha AD, Agarwal R. Determinants and short-term reproducibility of relative plasma volume slopes during hemodialysis. Clin J Am Soc Nephrol. 2012;7:1996-2001.

37. Janssens JP, Pache JC, Nicod LP. Physiological changes in respiratory function associated with ageing. Eur Respir J. 1999;13:197-205.

38. Diroll D. Oxygen as an adjunct to treat intradialytic hypotension during hemodialysis. Nephrol Nurs J. 2014;41:420-423.

39. Mancini E, Corazza L, Cannarile D, Soverini M, Cavalcanti S, Cavani S, Fiorenzi A, Santoro A. Short term variability of oxygen saturation during hemodialysis is a warning parameter for hypotension appearance. Computers in Cardiology. 2008. IEEE, 2008:881-884

40. Alfakir M, Moammar MQ, Ali MI, Alhatem E, Curran RD, Saoud RM, Chandran C, Khan MA, Debari VA Pulmonary gas exchange during hemodialysis: a comparison of subjects with and without COPD on bicarbonate hemodialysis. Ann Clin Labor Sci. 2011;41:315-320.

41. Nielsen AL, Jensen HAE. Oxygen status: a standard evaluation in uremic patients? Dial Transplant. 1994;23:288.

42. Navarrete-Opazo A, Mitchell GS. Therapeutic potential of intermittent hypoxia: a matter of dose. Am J Physiol Regul Integr Comp Physiol. 2014;307(10):R1181-1197.

43. Foster GE, Poulin MJ, Hanly PJ. Intermittent hypoxia and vascular function: implications for obstructive sleep apnoea. Exp Physiol. 2007;92:51-65.

44. Mohanty JG, Nagababu E, Rifkind JM. Red blood cell oxidative stress impairs oxygen delivery and induces red blood cell aging. Front Physiol. 2014;5:84. 
45. Mao TY, Fu LL, Wang JS. Hypoxic exercise training causes erythrocyte senescence and rheological dysfunction by depressed Gardos channel activity. J Appl Physiol. 2011;111:382-391.

46. van der Putten K, Braam B, Jie KE, Gaillard CA. Mechanisms of Disease: erythropoietin resistance in patients with both heart and kidney failure. Nat Clin Pract Nephrol. 2008;4:47-57.

47. Rogers SC, Said A, Corcuera D, McLaughlin D, Kell P, Doctor A. Hypoxia limits antioxidant capacity in red blood cells by altering glycolytic pathway dominance. FASEB J. 2009;23:3159-3170.

48. Dou Y, Kruse A, Kotanko P, Rosen H, Levin NW, Thijssen S. Red blood cell life span and 'erythropoietin resistance'. Kidney Int. 2012;81:1275-1276.

49. Steuer RR ZD, Bell DA, Leypoldt JK, Glennie A, Black M. Nasal oxygen imediately and significantly enhances plasma refilling rate in hemodialysis patients, Q4: Dialysis: oxidative stress. Nephrol Dial Transplant. 2001;16:A138-A142.

50. Yap JC, Wang YT, Poh SC. Effect of oxygen on breathing irregularities during haemodialysis in patients with chronic uraemia. Eur Respir J. 1998;12:420-425. 


\section{Supplementary material}

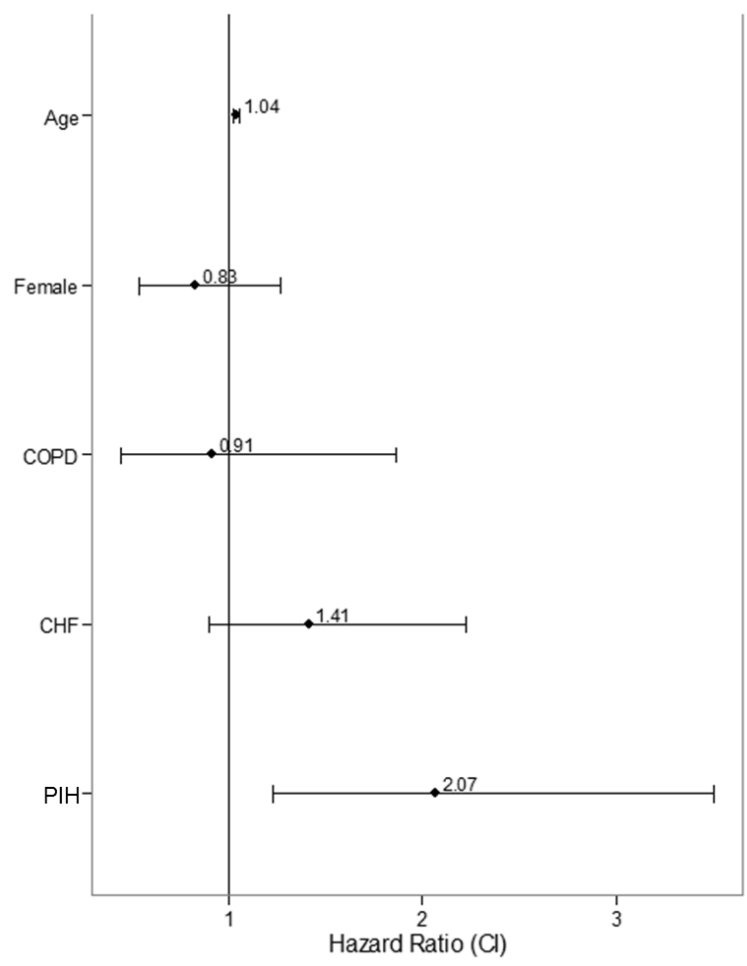

Figure S2.1 All-cause mortality hazard ratios and 95\% confidence intervals for age, gender, COPD, CHF and prolonged intradialytic hypoxemia $(\mathrm{PIH})$

Table S2.1 Hazard ratios of all-cause mortality in categories of \% of hemodialysis treatment time spent below or equal to $90 \% \mathrm{SaO}_{2}$

\begin{tabular}{lccc}
\hline \% of time spent $\leq \mathrm{SaO}_{2} 90 \%$ & Number of patients in category & $\begin{array}{c}\text { Hazard ratio } \\
\text { (95\% Confidence interval) }\end{array}$ & P-value \\
\hline$>5$ & 354 & $1.78(1.18$ to 2.70$)$ & 0.006 \\
$>10$ & 267 & $1.83(1.21$ to 2.81$)$ & 0.005 \\
$>15$ & 215 & $2.04(1.32$ to 3.16) & 0.001 \\
$>20$ & 170 & $1.71(1.06$ to 2.75$)$ & 0.03 \\
$>25$ & 139 & $1.83(1.11$ to 3.00) & 0.02 \\
$>30$ & 115 & $2.17(1.31$ to 3.60) & 0.003 \\
$>35$ & 97 & $2.27(1.34$ to 3.86) & 0.002 \\
$>40$ & 81 & $2.40(1.38$ to 4.18) & 0.002 \\
$>45$ & 67 & $2.30(1.25$ to 4.22) & 0.007 \\
$>50$ & 54 & $2.07(1.04$ to 4.12) & 0.04 \\
\hline
\end{tabular}

Note, the categories are not mutually exclusive, e.g. patients in the last category (>50\%) are also included all previous categories. $\mathrm{N}=983$ 
Table 2.2 Comparison of patients excluded from analysis and the final study cohort. Patients with $\leq 10$ treatments with $\mathrm{SaO} 2$ measurements during baseline and $\leq 6$ month of baseline data were excluded from final study cohort

\begin{tabular}{|c|c|c|c|c|}
\hline Characteristics & $\begin{array}{l}\text { Excluded } \\
\text { Mean } \pm \text { SD }\end{array}$ & $\begin{array}{l}\text { Included } \\
\text { Mean } \pm \text { SD }\end{array}$ & $\begin{array}{c}\text { Difference } \\
\text { Mean }(95 \% \mathrm{Cl})\end{array}$ & P-value \\
\hline Patients (N) & 547 & 983 & & \\
\hline $\begin{array}{l}\text { Treatments with } \mathrm{SaO}_{2} \text { measurements } \\
\text { (number per patient) }\end{array}$ & $4.8 \pm 6.0$ & $30.5 \pm 12.5$ & $-25.7(-26.6$ to -24.8$)$ & $<0.001^{2}$ \\
\hline $\begin{array}{l}\text { Patients with prolonged intradialytic } \\
\text { hypoxemia }(\%)\end{array}$ & 15.2 & 10.2 & $5.0(1.4$ to 8.6$)$ & $0.006^{1}$ \\
\hline \multicolumn{5}{|l|}{ Demographics } \\
\hline Gender (\% male) & 59.0 & 59.0 & 0.0 & $0.96^{1}$ \\
\hline Race (\% white) & 44.6 & 52.6 & -8.0 & $0.003^{1}$ \\
\hline Age (years) & $63.0 \pm 14.9$ & $62.1 \pm 15.2$ & 1 (-0.6 to 2.5$)$ & $0.23^{2}$ \\
\hline $\mathrm{BMI}\left(\mathrm{kg} / \mathrm{m}^{2}\right)$ & $29.1 \pm 8.0$ & $28.7 \pm 7.7$ & $0.4(-0.4$ to 1.3$)$ & $0.33^{2}$ \\
\hline \multicolumn{5}{|l|}{ Oxygen saturation } \\
\hline Mean $\mathrm{SaO}_{2}(\%)$ & $92.7 \pm 2.7$ & $92.8 \pm 1.8$ & $-0.2(-0.4$ to 0.1$)$ & $0.16^{2}$ \\
\hline Median $\mathrm{SaO}_{2}(\%)$ & $92.7 \pm 2.3$ & $92.9 \pm 1.8$ & $-0.1(-0.4$ to 0.1$)$ & $0.20^{2}$ \\
\hline Minimum $\mathrm{SaO}_{2}(\%)$ & $90.0 \pm 3.7$ & $90.4 \pm 2.8$ & $-0.4(-0.8$ to 0.0$)$ & $0.03^{2}$ \\
\hline Maximum $\mathrm{SaO}_{2}(\%)$ & $94.5 \pm 1.8$ & $94.5 \pm 1.4$ & $0.0(-0.2$ to 0.1$)$ & $0.79^{2}$ \\
\hline $\mathrm{SD} \mathrm{SaO}_{2}(\%)$ & $0.9 \pm 0.7$ & $0.8 \pm 0.4$ & 0.1 (0.0 to 0.1$)$ & $0.009^{2}$ \\
\hline$\%$ of time spent below $90 \% \mathrm{SaO}_{2}(\%)$ & $12.8 \pm 24.7$ & $10.3 \pm 18.5$ & $2.7(0.2$ to 4.9$)$ & $0.03^{2}$ \\
\hline$\%$ of time spent below $87 \% \mathrm{SaO}_{2}(\%)$ & $3.8 \pm 13.2$ & $2.6 \pm 8.7$ & $1.3(0.0$ to 2.5$)$ & $0.05^{2}$ \\
\hline Start $\mathrm{SaO}_{2}(\%)$ & $92.5 \pm 2.4$ & $92.6 \pm 1.9$ & $-0.1(-0.3$ to 0.1$)$ & $0.35^{2}$ \\
\hline End $\mathrm{SaO}_{2}(\%)$ & $93.0 \pm 2.5$ & $93.2 \pm 1.8$ & $-0.2(-0.4$ to 0.1$)$ & $0.17^{2}$ \\
\hline \multicolumn{5}{|l|}{ Comorbidities } \\
\hline Diabetes (\%) & 43.7 & 52.3 & -8.6 & $0.001^{1}$ \\
\hline $\mathrm{CHF}(\%)$ & 13.2 & 23.3 & -10.1 & $<0.001^{1}$ \\
\hline COPD (\%) & 4.2 & 8.4 & -4.2 & $0.002^{1}$ \\
\hline \multicolumn{5}{|l|}{ Treatment related parameters } \\
\hline Vintage (years) & $3.7 \pm 4.0$ & $3.9 \pm 4.1$ & $-0.2(-0.7$ to 0.3$)$ & $0.36^{2}$ \\
\hline Pre-dialysis SBP (mmHg) & $143.9 \pm 19.8$ & $146.9 \pm 19.4$ & $-3.0(-5.1$ to -1.0$)$ & $0.004^{2}$ \\
\hline Post-dialysis SBP (mmHg) & $136.1 \pm 19.3$ & $137.2 \pm 18.2$ & $-1.1(-3.1$ to 0.8$)$ & $0.26^{2}$ \\
\hline IDWG (kg) & $2.4 \pm 1.0$ & $2.3 \pm 0.8$ & 0.1 (0.0 to 0.23$)$ & $0.01^{2}$ \\
\hline Treatment time ( $\mathrm{min})$ & $219.4 \pm 27.5$ & $215.9 \pm 25.0$ & $3.5(0.7$ to 6.3$)$ & $0.01^{2}$ \\
\hline Ultrafiltration rate $(\mathrm{ml} / \mathrm{h} / \mathrm{kg})$ & $8.3 \pm 3.1$ & $8.1 \pm 3.0$ & $0.2(-0.1$ to 0.5$)$ & $0.23^{2}$ \\
\hline Ultrafiltration volume (I) & $2.4 \pm 1.0$ & $2.3 \pm 0.8$ & 0.1 (0.0 to 0.2 ) & $0.04^{2}$ \\
\hline Equilibrated Kt/V & $1.5 \pm 0.3$ & $1.5 \pm 0.3$ & $0.0(0.0$ to 0.0$)$ & $0.65^{2}$ \\
\hline \multicolumn{5}{|l|}{ Laboratory parameters } \\
\hline Serum albumin (g/dl) & $3.9 \pm 0.4$ & $4.0 \pm 0.3$ & $-0.1(-0.2$ to -0.7$)$ & $<0.001^{2}$ \\
\hline $\mathrm{Hgb}(\mathrm{g} / \mathrm{dl})$ & $10.7 \pm 1.0$ & $10.9 \pm 0.9$ & $-0.2(-0.3$ to -0.1$)$ & $<0.001^{2}$ \\
\hline Serum bicarbonate $(\mathrm{mmol} / \mathrm{l})$ & $23.5 \pm 2.4$ & $23.2 \pm 2.0$ & $0.3(0.1$ to 0.6$)$ & $0.006^{2}$ \\
\hline WBC $(1000 / \mu \mathrm{l})$ & $6.8 \pm 2.4$ & $6.6 \pm 3.1$ & $0.2(-0.1$ to 0.5$)$ & $0.20^{2}$ \\
\hline Platelets $(1000 / \mu \mathrm{l})$ & $209.6 \pm 72.7$ & $205.0 \pm 62.9$ & $4.6(-3.4$ to 12.6$)$ & $0.26^{2}$ \\
\hline NLR & $4.2 \pm 3.1$ & $3.7 \pm 2.1$ & $0.5(0.2$ to 0.8$)$ & $0.001^{2}$ \\
\hline Ferritin (ng/ml) & $1019 \pm 586$ & $923 \pm 460$ & $96(33$ to 158$)$ & $0.003^{2}$ \\
\hline Transferrin saturation (\%) & $32.5 \pm 10.8$ & $33.7 \pm 8.7$ & $-1.3(-2.4$ to -0.2$)$ & $0.02^{2}$ \\
\hline Serum iron $(\mu \mathrm{g} / \mathrm{dl})$ & $71.1 \pm 25$ & $77.7 \pm 22.4$ & $-6.5(-9.2$ to -3.9$)$ & $<0.001^{2}$ \\
\hline \multirow[t]{2}{*}{ Medication } & Median & Median & & \\
\hline & $\left(25^{\text {th }}, 75^{\text {th }}\right.$ percentile) & $\left(25^{\text {th }}, 75^{\text {th }}\right.$ percentile) & & \\
\hline Epo Dose (Units per treatment) & $2013(835,4054)$ & $1584(610,3240)$ & 429 (164 to 698$)$ & $<0.001^{3}$ \\
\hline Iron Dose (mg per treatment) & $13.0(0,24.4)$ & $15.1(7.1,23.3)$ & $-1.2(-3.7$ to -0.2$)$ & $0.005^{3}$ \\
\hline
\end{tabular}

${ }^{1}$ Chi-square test; ${ }^{2}$ t-test; ${ }^{3}$ Wilcoxon test; CHF: congestive heart failure; COPD: chronic obstructive pulmonary disease; SBP: systolic blood pressure; IDWG: interdialytic weight gain; Hgb: Hemoglobin; WBC: white blood cells; NLR: neutrophil-tolymphocyte ratio; Epo: Erythropoetin alfa 
Table S2.3 Comparison of outcomes during the follow-up period in patients excluded from analysis and the final study cohort. Patients with $\leq 10$ treatments with $\mathrm{SaO}_{2}$ measurements during baseline and were excluded from final study cohort. Note, only patients that had 6 month of data were included in this analysis

\begin{tabular}{lcccc}
\hline Characteristics & $\begin{array}{c}\text { Excluded } \\
\text { Mean } \pm \text { SD }\end{array}$ & $\begin{array}{c}\text { Included } \\
\text { Mean } \pm \text { SD }\end{array}$ & $\begin{array}{c}\text { Difference } \\
\text { Mean (95\%Cl) }\end{array}$ & P-value \\
\hline Patients (N) & 427 & 983 & & \\
\hline Outcomes during follow-up & & & & \\
Hospitalizations per patient year & $1.56 \pm 3.20$ & $1.62 \pm 2.81$ & $-0.06(-0.44$ to 0.33) & 0.77 \\
Deaths per 100 patient years & 11.7 & 11.6 & 0.1 & 0.96 \\
\hline
\end{tabular}

Table S2.4 Comparison of the hospitalization rates of the whole analytical dataset and after exclusion of patients that have either COPD or CHF

\begin{tabular}{|c|c|c|c|c|c|}
\hline \multicolumn{2}{|l|}{ Variables } & \multicolumn{3}{|c|}{ Prolonged intradialytic hypoxemia } & \multirow[t]{2}{*}{ P-value } \\
\hline & & Present & Absent & Differenc & \\
\hline \multirow{3}{*}{$\begin{array}{l}\text { All included } \\
\text { patients }\end{array}$} & & & & & \\
\hline & Number of patients & 100 & 883 & & \\
\hline & $\begin{array}{l}\text { Crude hospitalization } \\
\text { rate }\end{array}$ & 2.21 (0 to 3.4 ) & 1.55 (0 to 2.04$)$ & 0.66 (0.07 to 1.34$)$ & 0.009 \\
\hline \multirow{2}{*}{$\begin{array}{l}\text { Only patients } \\
\text { without COPD or } \\
\mathrm{CHF}\end{array}$} & Number of patients & 56 & 650 & & \\
\hline & $\begin{array}{l}\text { Crude hospitalization } \\
\text { rate }\end{array}$ & 1.86 (1.07 to 2.65$)$ & 1.47 (1.27 to 1.68$)$ & $0.39(-0.36$ to 1.13$)$ & 0.34 \\
\hline
\end{tabular}

$\mathrm{Cl}$ : confidence interval; COPD: chronic obstructive pulmonary disease; $\mathrm{CHF}$ : congestive heart failure

Table S2.5 Adjusted hazard ratio (HR) for all-cause mortality of the whole analytical dataset and after exclusion of patients that have either COPD or CHF

\begin{tabular}{|c|c|c|c|c|c|}
\hline Population & Population size & Events & Confounders & $\begin{array}{c}\mathrm{HR} \\
(95 \% \mathrm{Cl}) \\
\end{array}$ & P-value \\
\hline $\begin{array}{l}\text { All included } \\
\text { patients }\end{array}$ & 983 & 89 & $\begin{array}{c}\text { age, gender, race, vintage, COPD, CHF, } \\
\text { diabetes, albumin, hemoglobin, Epoetin } \\
\text { alfa Dose, NLR, IDWG, post-dialysis SBP, } \\
\text { and UFR }\end{array}$ & 1.98 (1.14 to 3.43$)$ & 0.02 \\
\hline $\begin{array}{l}\text { Only patients } \\
\text { without COPD or } \\
\text { CHF }\end{array}$ & 706 & 30 & $\begin{array}{l}\text { age, gender, race, vintage, diabetes, } \\
\text { albumin, hemoglobin, Epoetin alfa Dose, } \\
\text { NLR, IDWG, postdialysis SBP, and UFR }\end{array}$ & 2.21 (1.00 to 4.90$)$ & 0.05 \\
\hline
\end{tabular}

$\mathrm{Cl}$ : confidence interval; COPD: chronic obstructive pulmonary disease; CHF: congestive heart failure; NLR: neutrophil-tolymphocyte ratio; IDWG: interdialytic weight gain; SBP: systolic blood pressure; UFR; ultrafiltration rate 


\section{Chapter}

Intradialytic hypertension is associated with low intradialytic arterial oxygen saturation 


\section{Abstract}

\section{Background}

The pathophysiology of a paradoxical systolic blood pressure (SBP) rise during hemodialysis is not yet fully understood. Recent research indicated that $10 \%$ of chronic hemodialysis patients suffer from prolonged intradialytic hypoxemia. Since hypoxemia induces a sympathetic response we entertained the hypothesis that peridialytic SBP change is associated with arterial oxygen saturation $\left(\mathrm{SaO}_{2}\right)$.

\section{Methods}

We retrospectively analyzed intradialytic $\mathrm{SaO}_{2}$ and peridialytic SBP change in chronic hemodialysis patients with arterio-venous vascular access. Patients were followed over 6 months. We defined persistent intradialytic hypertension (piHTN) as average peridialytic SBP increase $>10 \mathrm{mmHg}$ over 6 months. Linear mixed effects (LME) models were used to explore associations between peridialytic SBP change and intradialytic $\mathrm{SaO}_{2}$ in univariate and adjusted analyses.

\section{Results}

We assessed 982 patients (29,872 HD treatments, 59\% males; 53\% whites). Pre-dialysis SBP was $146.7 \pm 26.5 \mathrm{mmHg}$ and decreased on average by $10.1 \pm 24.5 \mathrm{mmHg}$. Fifty-three (5.7\%) patients had piHTN. piHTN patients had lower intradialytic $\mathrm{SaO}_{2}$, body weight and interdialytic weight gain. LME models revealed that with every percent point lower mean $\mathrm{SaO}_{2}$ the peridialytic SBP change increased by $0.46 \mathrm{mmHg}(p<0.001)$. This finding was corroborated in multivariate analyses.

\section{Conclusion}

We observed an inverse relationship between intradialytic $\mathrm{SaO}_{2}$ and the blood pressure response to hemodialysis. These findings support the notion that hypoxemia activates mechanisms that partially blunt the intradialytic blood pressure decline, possibly by sympathetic activation and endothelin-1 secretion. To further explore that hypothesis specifically designed prospective studies are required. 


\section{Introduction}

In most hemodialysis (HD) patients blood pressure at the end of hemodialysis (postHD) is below starting levels (preHD). This peridialytic blood pressure decline is attributed to fluid and salt removal ${ }^{1}$. However, in some patients, postHD blood pressure is regularly increased above preHD levels ${ }^{2,3}$. This phenomenon - termed intradialytic hypertension (iHTN) - is recurrent and persistent in a subset of maintenance HD patients. While there is currently no universally accepted definition of iHTN, most authors use a peridialytic rise of systolic blood pressure (SBP) of $\geq 10 \mathrm{mmHg}$ as a threshold ${ }^{4,5}$. Cohort studies showed an iHTN prevalence of 8 to $13 \% \%^{2,4}$. iHTN patients have an increased risk for hospitalizations and mortality compared to those whose blood pressure decreases during $\mathrm{HD}^{4,5}$. Park et al. ${ }^{6}$ reported in a large cohort study that both a $30 \mathrm{mmHg}$ peridialytic SBP decrease or any peridialytic SBP rise were associated with increased mortality rates ${ }^{6}$. This emphasizes the risks associated with iHTN and the clinical need to identify the underlying mechanisms and develop preventive interventions.

While the iHTN pathophysiology is not yet fully understood and likely multifactorial, observational studies noticed that older age, lower body weight, lower serum creatinine and albumin levels, as well as the use of more antihypertensive medication are associated with peridialytic SBP increase ${ }^{4,5}$. Additionally, an association between dialysate-to-serum sodium gradient and intradialytic change of SBP has been observed ${ }^{7}$, indicating a role of diffusive intradialytic sodium gain in the development of iHTN. Other proposed mechanisms are an activation of the sympathetic nervous system $^{8}$, stimulation of the renin-angiotensin-aldosterone system (RAAS), increased endothelin-1 secretion, dialytic removal of antihypertensive drugs, and variations in potassium or ionized calcium blood levels ${ }^{9}$. The potential pathophysiologic pathways of iHTN and treatment options have been reviewed recently ${ }^{10,11}$.

In a recent study we found that $10 \%$ of chronic HD patients had arterial oxygen saturation $\left(\mathrm{SaO}_{2}\right)<90 \%$ for more than $1 / 3$ of their treatment time, which was associated with increased hospitalization and mortality rates ${ }^{12}$. Fluid overload, impaired respiratory function and ventilation-perfusion-mismatch are potential causes of intradialytic hypoxemia ${ }^{13}$. Of note, intradialytic hypoxemia may stimulate sympathetic activation ${ }^{14,15}$. Given these strands of evidence we set out to test the hypothesis of an inverse association between peridialytic SBP change and intradialytic $\mathrm{SaO}_{2}$ in the aforementioned hemodialysis cohort where concurrent measurements of both peridialytic SBP and intradialytic $\mathrm{SaO}_{2}$ were available. 


\section{Subjects and methods}

\section{Population and study design}

We conducted this retrospective study in a recently reported cohort of chronic HD patients from 17 U.S. facilities of the Renal Research Institute (RRI) ${ }^{12}$. Records between January 2012 and September 2014 were reviewed. A 6-months observation period was defined on a patient level, which started on the date of a patient's first hemodialysis with both $\mathrm{SaO}_{2}$ and SBP measurements. Only patients with arterio-venous access and at least $10 \mathrm{HD}$ treatments with eligible $\mathrm{SaO}_{2}$ measurements were included in the analysis. Patients were treated with bicarbonate dialysate and polysulfone membranes. Patients were censored in the event of kidney transplantation, dialysis modality change, transfer to outside of RRI, or recovery of kidney function. The study was conducted in accordance with the Helsinki Declaration and was approved by the New England Institutional Review Board (\#14-446), which waived the need for informed consent.

\section{Measurement of oxygen saturation}

We measured the intradialytic $\mathrm{SaO}_{2}$ as reported recently ${ }^{12}$ using the Crit-Line Monitor (CLM) (Fresenius Medical Care North America, Waltham, MA, USA), which is approved by the U.S. Food and Drug Administration for the measurement of hematocrit and oxygen saturation in the extracorporeal circuit. The CLM reports oxygen saturation $1 \mathrm{x} /$ minute. The manufacturer reported accuracy of $\mathrm{SaO}_{2}$ measurement is $2 \%$. CLM data were automatically transferred to the RRI data warehouse and subsequently to the study database. The use of CLM is standard care in RRI clinics, albeit with some utilization variability related to the phased device roll-out 2012-2014. CLM values with the following characteristics were deemed implausible or unreliable and hence excluded: relative blood volume $>102 \%$; $\mathrm{SaO}_{2}>100 \%$; hematocrit levels $\leq 15 \%$ or $>55 \%$; and data points collected after the end of the prescribed treatment time. In the absence of acceptable data during more than $50 \%$ of the treatment time, the entire HD session was excluded. Likewise, the entire treatment was excluded if the rate of change of relative blood volume was greater than 5 percent points compared to values 10 minutes and 5 minutes earlier on $\geq 1$ occasion, if $\mathrm{SaO}_{2}$ of $50 \%$ was recorded more than 40 times, or the mean intradialytic $\mathrm{SaO}_{2}$ was $\leq 80 \%$, a level indicative of venous rather than arterial blood.

\section{Measurement of blood pressure}

Across all RRI clinics the staff pays particular attention to the methodology of blood pressure measurement and follows a standardized protocol, where blood pressure is obtained by an automated device integrated in the HD machine on the non-access arm 
with the patient seated in the dialysis chair. For this research we used SBP measurements that were taken shortly before and after HD.

\section{Clinical and laboratory data}

Laboratory measurements (Spectra Laboratories, New Jersey, NJ, USA) were downloaded to the RRI data warehouse and extracted to the study database.

\section{Comorbidities}

Congestive heart failure (CHF), diabetes, and chronic obstructive pulmonary disease (COPD) were defined using International Classification of Diseases, Ninth Revision (ICD-9) codes.

\section{Statistical analysis}

Descriptive statistics comprised mean ( \pm standard deviation; SD) for continuous variables and percentages for categorical variables. $\mathrm{SaO}_{2}$ and SBP related variables were calculated first per HD treatment, then per patient and finally per group. To avoid potential interference with priming and rinsing procedures, Start $\mathrm{SaO}_{2}$ was defined as the mean $\mathrm{SaO}_{2}$ between treatment minutes 5 and 20, and End $\mathrm{SaO}_{2}$ as the mean $\mathrm{SaO}_{2}$ between the final 20 and 5 minutes.

Peridialytic SBP change was calculated as postHD SBP - preHD SBP. In line with current literature we defined iHTN as a peridialytic SBP increase $\geq 10 \mathrm{mmHg}$ and piHTN as average peridialytic SBP increase $\geq 10 \mathrm{mmHg}$ throughout the entire 6-months observation period. Patients were stratified based on the presence or absence of piHTN. We compared characteristics of piHTN and non-piHTN patients by computing mean group differences with 95\% confidence intervals (95\% Cl).

Using linear mixed effects (LME) models we also explored on a continuous scale the association between peridialytic SBP change and mean intradialytic $\mathrm{SaO}_{2}$ or the fraction (\%) of treatment time spent with a $\mathrm{SaO}_{2} \leq 90 \%$. Here, the peridialytic SBP change was the outcome variable and $\mathrm{SaO}_{2}$ indicators the exposure. Variables were calculated per patient on a treatment level. We conducted unadjusted and adjusted analyses. Confounders were selected based on their documented or hypothesized association with exposure and outcome. In the minimally adjusted model we included age, diabetes, interdialytic weight gain (IDWG) in \% of postHD weight, ultrafiltration rate, preHD SBP and epoietin alfa dose as additional independent variables. The fully adjusted model included in addition race, gender and vintage in addition. 
Statistical analyses were performed using SAS version 9.3 (SAS Institute, Cary, NC) and R i386 3.0.2 (R Foundation for Statistical Computing, Vienna, Austria).

\section{Results}

\section{Patient characteristics}

Out of 1,532 patients with $\mathrm{SaO}_{2}$ measurements, 550 patients (36\%) were excluded because they had less than $10 \mathrm{HD}$ sessions with eligible $\mathrm{SaO}_{2}$ recordings (Supplemental Figure S3.1). The final analytical cohort comprised 982 chronic HD patients with 29,872 $\mathrm{HD}$ treatments with eligible $\mathrm{SaO}_{2}$ measurements.

Detailed patient characteristics are depicted in Table 3.1. Briefly, age was 62.1 \pm 15.2 years, $59.1 \%$ were male, and $52.6 \%$ were white. Dialysis vintage was $3.9 \pm 4.1$ years, $50.7 \%$ were diabetic, $23.3 \%$ had $\mathrm{CHF}$ and $8.4 \%$ had COPD.

Table 3.1 Characteristics of the entire study population and after stratification into groups with and without persistent intradialytic hypertension

\begin{tabular}{|c|c|c|c|c|}
\hline \multirow[t]{2}{*}{ Variables } & \multirow[t]{2}{*}{ All patients } & \multicolumn{2}{|c|}{$\begin{array}{l}\text { Persistent Intradialytic } \\
\text { Hypertension }\end{array}$} & \multirow[t]{2}{*}{$\begin{array}{c}\text { Difference between } \\
\text { Groups, Mean }(95 \% \mathrm{Cl})\end{array}$} \\
\hline & & Present & Absent & \\
\hline Patients, N (\%) & $982(100)$ & $53(5.4)$ & $929(96.4)$ & n.a. \\
\hline $\begin{array}{l}\text { Number of treatments with } \mathrm{SaO}_{2} \\
\text { measurements }\end{array}$ & 29,872 & 1,266 & 28,606 & n.a. \\
\hline \multicolumn{5}{|l|}{ Demographics } \\
\hline Men,\% & 59.1 & 45.3 & 59.9 & $-14.6(-29.3$ to 0.2$)$ \\
\hline Race, \% white & 52.6 & 52.8 & 52.6 & $0.2(-13.8$ to 14.2$)$ \\
\hline Age, years & $62.1 \pm 15.2$ & $63.9 \pm 15.4$ & $61.9 \pm 15.2$ & $1.9(-2.4$ to 6.3$)$ \\
\hline Vintage, years & $3.9 \pm 4.1$ & $3.7 \pm 3.8$ & $3.9 \pm 4.1$ & $-0.3(-1.4$ to 0.9$)$ \\
\hline $\mathrm{BMI}, \mathrm{kg} / \mathrm{m}^{2}$ & $28.7 \pm 7.7$ & $26.2 \pm 5.7$ & $28.8 \pm 7.8$ & $-2.6(-4.4$ to -0.9$)$ \\
\hline Obese, \% & $35.1 \pm 47.8$ & $19.2 \pm 39.8$ & $36.0 \pm 48.0$ & $-16.8(-29.6$ to -4.0$)$ \\
\hline Post Weight, kg & $82.1 \pm 22.7$ & $69.7 \pm 17.7$ & $82.7 \pm 22.8$ & $-13.0(-14.0$ to -12.0$)$ \\
\hline \multicolumn{5}{|l|}{ Oxygen saturation, \% } \\
\hline Mean $\mathrm{SaO}_{2}$ & $92.8 \pm 2.21$ & $92.1 \pm 2.53$ & $92.9 \pm 2.19$ & $-0.8(-0.9$ to -0.6$)$ \\
\hline$\%$ of time spent below $90 \% \mathrm{SaO}_{2}$ & $10.0 \pm 23.5$ & $17.9 \pm 30.9$ & $9.6 \pm 23.1$ & $8.3(6.6$ to 10.0$)$ \\
\hline$\%$ of time spent below $87 \% \mathrm{SaO}_{2}$ & $2.5 \pm 12.2$ & $5.5 \pm 18.2$ & $2.4 \pm 11.9$ & 3.1 (2.1 to 4.1$)$ \\
\hline Start $\mathrm{SaO}_{2}$ & $92.8 \pm 2.52$ & $92.0 \pm 2.7$ & $92.8 \pm 2.5$ & $-0.8(-1.0$ to -0.7$)$ \\
\hline End $\mathrm{SaO}_{2}$ & $93.4 \pm 2.30$ & $92.6 \pm 2.5$ & $93.4 \pm 2.3$ & $-0.8(-1.0$ to -0.7$)$ \\
\hline \multicolumn{5}{|l|}{ Comorbidities, \% } \\
\hline Diabetes & 50.7 & 60.4 & 50.2 & $10.2(-4.3$ to 24.8$)$ \\
\hline $\mathrm{CHF}$ & 23.3 & 26.4 & 23.1 & $3.3(-9.9$ to 16.4$)$ \\
\hline COPD & 8.4 & 7.5 & 8.5 & $-1.0(-9.3$ to 7.3$)$ \\
\hline
\end{tabular}


Table 3.1 (continued)

\begin{tabular}{|c|c|c|c|c|}
\hline \multirow[t]{2}{*}{ Variables } & \multirow[t]{2}{*}{ All patients } & \multicolumn{2}{|c|}{$\begin{array}{l}\text { Persistent Intradialytic } \\
\text { Hypertension }\end{array}$} & \multirow[t]{2}{*}{$\begin{array}{l}\text { Difference between } \\
\text { Groups, Mean }(95 \% \mathrm{Cl})\end{array}$} \\
\hline & & Present & Absent & \\
\hline \multicolumn{5}{|l|}{$\begin{array}{l}\text { Laboratory and treatment-related } \\
\text { parameters }\end{array}$} \\
\hline $\begin{array}{l}\% \text { of treatments with iHTN } \\
\text { per patient }\end{array}$ & $19.1 \pm 16.5$ & $61.9 \pm 12.1$ & $16.7 \pm 13.0$ & 45.2 (41.7 to 48.6$)$ \\
\hline Peridialytic SBP change ${ }^{b}, \mathrm{mmHg}$ & $-10.1 \pm 24.5$ & $16.3 \pm 22.5$ & $-11.3 \pm 23.9$ & 27.6 (26.3 to 28.9$)$ \\
\hline PreHD SBP, mmHg & $146.7 \pm 26.5$ & $139.2 \pm 24.2$ & $147.1 \pm 26.5$ & $-7.8(-9.2$ to -6.5$)$ \\
\hline PostHD SBP, mmHg & $136.6 \pm 25.0$ & $155.5 \pm 25.0$ & $135.8 \pm 24.7$ & 19.7 (18.3 to 21.2$)$ \\
\hline IDWG, kg & $2.3 \pm 1.4$ & $2.1 \pm 1.4$ & $2.3 \pm 1.4$ & $-0.2(-0.3$ to -0.1$)$ \\
\hline IDWG, \% of post-HD weight & $2.9 \pm 1.6$ & $3.2 \pm 1.8$ & $2.9 \pm 1.5$ & $0.3(0.2$ to 0.4$)$ \\
\hline Treatment time, min & $203.5 \pm 36.4$ & $198.9 \pm 38.7$ & $203.7 \pm 36.3$ & $-4.8(-7.0$ to -2.6$)$ \\
\hline Ultrafiltration rate, $\mathrm{ml} / \mathrm{h} / \mathrm{kg}$ & $8.2 \pm 4.0$ & $9.0 \pm 4.8$ & $8.1 \pm 4.0$ & 0.9 (0.6 to 1.2$)$ \\
\hline Ultrafiltration volume, I & $2.3 \pm 1.2$ & $2.1 \pm 1.2$ & $2.3 \pm 1.2$ & $-0.2(-0.3$ to -0.1$)$ \\
\hline Blood flow rate, $\mathrm{ml} / \mathrm{min}$ & $438 \pm 53$ & $431 \pm 59$ & $439 \pm 53$ & $-8(-11$ to -5$)$ \\
\hline Serum albumin, g/dl & $4.0 \pm 0.4$ & $3.9 \pm 0.4$ & $4.0 \pm 0.3$ & $-0.1(-0.2$ to -0.1$)$ \\
\hline $\mathrm{Hgb}, \mathrm{g} / \mathrm{dl}$ & $10.9 \pm 1.3$ & $10.3 \pm 1.2$ & $11.0 \pm 1.3$ & $-0.6(-0.8$ to -0.5$)$ \\
\hline WBC, $1000 / \mu \mathrm{l}$ & $6.5 \pm 3.1$ & $6.6 \pm 2.5$ & $6.5 \pm 3.2$ & $0.1(-0.4$ to 0.6$)$ \\
\hline NLR & $3.6 \pm 2.4$ & $4.6 \pm 4.3$ & $3.6 \pm 2.3$ & 1.0 (0.2 to 1.9$)$ \\
\hline $\begin{array}{l}\text { Equilibrated } \mathrm{Kt} / \mathrm{V}, \mathrm{g} / \mathrm{kg} \\
\text { body weight/day }\end{array}$ & $1.5 \pm 0.4$ & $1.6 \pm 0.4$ & $1.5 \pm 0.3$ & 0.1 (0.0 to 0.2 ) \\
\hline Creatinine & $8.9 \pm 3.0$ & $7.8 \pm 2.8$ & $9.0 \pm 3.0$ & $-1.2(-1.7$ to -0.6$)$ \\
\hline Dialysate sodium, mmol// & $137.2 \pm 0.6$ & $137.0 \pm 0.4$ & $137.2 \pm 0.6$ & $-0.1(-0.2$ to -0.1$)$ \\
\hline Serum Sodium, mmol/l & $138.9 \pm 3.2$ & $138.4 \pm 4.1$ & $139.0 \pm 3.2$ & $-0.6(-1.4$ to 0.2$)$ \\
\hline Sodium gradient ${ }^{c}$ & $-1.8 \pm 3.2$ & $-1.3 \pm 4.1$ & $-1.8 \pm 3.1$ & $0.5(-0.4$ to 1.2$)$ \\
\hline Serum potassium, $\mathrm{mmol} / \mathrm{l}$ & $4.8 \pm 0.6$ & $4.7 \pm 0.7$ & $4.8 \pm 0.6$ & $-0.1(-0.2$ to 0.1$)$ \\
\hline Serum bicarbonate, $\mathrm{mmol} / \mathrm{I}$ & $23.2 \pm 2.8$ & $23.2 \pm 2.9$ & $23.2 \pm 2.8$ & $0.0(-0.5$ to 0.6$)$ \\
\hline PTH, pg/ml & $584 \pm 561$ & $523 \pm 458$ & $588 \pm 566$ & $-65(-181$ to 51$)$ \\
\hline Ferritin, ng/ml & $938 \pm 529$ & $846 \pm 479$ & $943 \pm 530$ & $-97(-263$ to 70$)$ \\
\hline Serum iron $\mu g / d l$ & $78.5 \pm 33.3$ & $72.2 \pm 34.3$ & $78.8 \pm 33.4$ & $-6.6(-13.3$ to 0.0$)$ \\
\hline \multicolumn{5}{|l|}{ Medication } \\
\hline Epo Dose, U per treatment & $2542 \pm 4075$ & $3900 \pm 4907$ & $2482 \pm 4024$ & 1418 (1144 to 1693 ) \\
\hline Iron Dose, mg per treatment & $14.8 \pm 32.2$ & $20.7 \pm 36.7$ & $14.5 \pm 31.9$ & $6.2(4.1$ to 8.3$)$ \\
\hline
\end{tabular}

Continuous variables are reported as mean \pm standard deviation; $\mathrm{Cl}$, confidence interval; $\mathrm{BMI}$, body mass index; $\mathrm{SaO}_{2}$, arterial oxygen saturation; $\mathrm{CHF}$, congestive heart failure; $\mathrm{COPD}$, chronic obstructive pulmonary disease; SBP, systolic blood pressure; IDWG, interdialytic weight gain; Hgb, hemoglobin; WBC, white blood cells; NLR, neutrophil-to-lymphocyte ratio; Epo, epoetin alfa; iHTN, Intradialytic hypertension; n.a., not applicable. ${ }^{a}$ BMI $\geq 30 \mathrm{~kg} / \mathrm{m}^{2}$; ${ }^{b}$ postHD SBP - preHD SBP; ${ }^{c}$ dialysate sodium concentration - preHD serum sodium concentration

\section{Peridialytic SBP change and intradialytic $\mathrm{SaO}_{2}$ characteristics}

Mean preHD and postHD SBP were $146.7 \pm 26.5$ and $136.6 \pm 25.0 \mathrm{mmHg}$, respectively. On average, SBP decreased by $10.1 \pm 24.5 \mathrm{mmHg}$ from preHD to postHD. Figure 3.1 displays the frequency of iHTN. On average patients had iHTN in $19.1 \pm 16.5 \%$ of their treatments. 
Mean intradialytic $\mathrm{SaO}_{2}$ was $92.8 \pm 2.2 \%$. On average patients spent $10 \pm 23.5 \%$ of their treatment time at $\mathrm{SaO}_{2}$ levels $\leq 90 \%$.

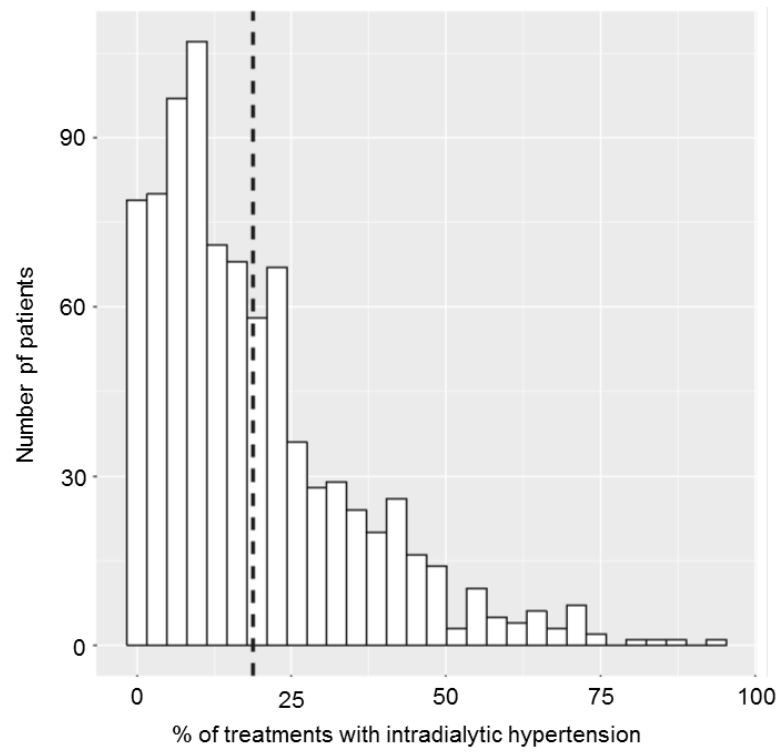

Figure 3.1 Histogram of percent of HD sessions with intradialytic hypertension. The denominator is the number of patient-level HD treatments. The dashed line indicates the population mean. Intradialytic hypertension was defined as a peridialytic SBP change $>10 \mathrm{mmHg}$.

\section{Comparison between piHTN and non-piHTN patients}

Fifty-three (5.7\%) patients had piHTN. A comparison between piHTN and non-piHTN patients is displayed in Table 3.1. In piHTN patients peridialytic SBP increased $\geq 10$ $\mathrm{mmHg}$ in $62 \%$ of treatments. On average peridialytic SBP increased by $16.3 \pm 22.5$ $\mathrm{mmHg}$, from preHD $139.2 \pm 24.2 \mathrm{mmHg}$ to postHD $155.5 \pm 25.0 \mathrm{mmHg}$. In non-piHTN patients peridialytic SBP increased $\geq 10 \mathrm{mmHg}$ in $17 \%$ of treatments, and decreased on average by $11.3 \pm 23.9 \mathrm{mmHg}$, from preHD $147.1 \pm 26.5 \mathrm{mmHg}$ to postHD $135.8 \pm 24.7$ $\mathrm{mmHg}$. piHTN patients were more likely to be female, had lower body weight and BMI, and were less likely to be obese. Mean, Start and End $\mathrm{SaO}_{2}$ were lower in piHTN patients. These patients also spent a significantly higher fraction of their treatment time with a $\mathrm{SaO}_{2}<90 \%$ and $<87 \%$, respectively. IDWG and ultrafiltration volume were lower in piHTN patients, while IDWG and ultrafiltration rate normalized to postHD body weight were higher. In piHTN patients serum albumin levels were lower and neutrophil-to-lymphocyte ratios higher. piHTN patients had lower hemoglobin levels while receiving significantly more epoietin and iron per treatment. 


\section{Correlates of peridialytic SBP change}

Results from LME models are listed in Table 3.2. In the unadjusted analysis a one percent point increase in mean $\mathrm{SaO}_{2}$ was associated with a peridialytic SBP decrease of $0.46 \mathrm{mmHg}$ SBP $(p<0.001)$. A one percent point increase of treatment time spent below $90 \% \mathrm{SaO}_{2}$ was associated with a $0.03 \mathrm{mmHg}$ peridialytic SBP increase $(p=0.004)$. These point estimates remained significant at various levels of multivariate adjustment (Table 3.2).

Table 3.2 Results of LME models relating indicators of $\mathrm{SaO}_{2}$ (independent variables) with peridialytic SBP change (dependent variable)

\begin{tabular}{lcccccc}
\hline & \multicolumn{2}{c}{ Unadjusted } & \multicolumn{2}{c}{ Minimally adjusted ${ }^{\text {a }}$} & \multicolumn{2}{c}{ Fully adjusted $^{\text {b }}$} \\
\cline { 2 - 7 } & $\begin{array}{c}\text { Coefficient } \\
(95 \% \mathrm{Cl})\end{array}$ & P-value & $\begin{array}{c}\text { Coefficient } \\
(95 \% \mathrm{Cl})\end{array}$ & P-value & $\begin{array}{c}\text { Coefficient } \\
(95 \% \mathrm{Cl})\end{array}$ & P-value \\
\hline \% of treatment time & 2.57 & 0.004 & 1.85 & 0.03 & 1.86 & 0.03 \\
spent $<90 \% \mathrm{SaO}_{2}$ & $(0.81,4.33)$ & & $(0.18,3.53)$ & & $(0.19,3.5)$ & 0.05 \\
Mean $\mathrm{SaO}_{2}[\%]$ & -0.46 & $<0.001$ & -0.20 & 0.05 & -0.20 & 0.05 \\
& $(-0.66,-0.25)$ & & $(-0.41,0.002)$ & & $(-0.41,0.003)$ & \\
\hline
\end{tabular}

a adjusted for age, diabetes, IDWG \% of postHD weight, UFR, preHD SBP and Epoetin alfa Dose; $b$ adjusted for age, diabetes, IDWG \% of postHD weight, UFR, preHD SBP, Epoetin alfa Dose, race, gender and vintage. IDWG: interdialytic weight gain; SBP: systolic blood pressure; UFR: ultrafiltration rate

\section{Discussion}

Our research in a large and diverse population of chronic HD patients shows for the first time an inverse association between intradialytic $\mathrm{SaO}_{2}$ and peridialytic blood pressure changes, iHTN, and piHTN.

While observational studies reported several associations of iHTN with clinical parameters, the exact mechanisms are still not fully understood ${ }^{3,5,10,16-21}$. Our study corroborates recently reported data of iHTN prevalence, where iHTN occurred in $90 \%$ of the patients at least once when observed over 6 months².

A retrospective analysis of the dry-weight reduction in hypertensive hemodialysis patients (DRIP) study revealed that dry weight probing modified the intradialytic blood pressure slope in addition to lowering the ambulatory blood pressure. Patients whose dry weight decreased the most during the study changed from flat intradialytic blood pressure slopes at baseline to steep declines at the end of the trial ${ }^{22}$. More recently, bioimpedance measurements have demonstrated that patients with intradialytic SBP rise were fluid overloaded and had a higher extracellular-to-total body water ratio $^{17,23,24}$. Those studies concluded that reassessment of dry weight should be the initial approach in patients with increased postHD SBP. It is important to note that fluid 
overload may reduce alveolar oxygen diffusion, resulting in reduced $\mathrm{SaO}_{2}$ and tissue hypoxia. In fact, Anand et al. ${ }^{25}$ found a positive relationship between the slope of the relative blood volume (RBV) curve, an indirect marker of volume status, and change in $\mathrm{SaO}_{2}$ indicating a contribution of volume overload to hypoxemia. In our population piHTN patients had a lower IDWG and UFV in absolute terms, but higher if normalized to body weight; this finding is explained by their lower postHD weight. Furthermore, piHTN patients had a lower BMI and a lower fraction of obese patients.

We hypothesize that the activation of at least two pathways may result in a SBP rise in the face of low $\mathrm{SaO}_{2}$. First, poor $\mathrm{SaO}_{2}$ may result in tissue hypoxia. Evidence from both humans and rodents indicates that hypoxia triggers sympathetic activation and elevation of blood pressure ${ }^{26-29}$. Peripheral chemoreflex sensitivity is particularly enhanced in patients with sleep apnea, which is highly prevalent in end stage renal disease patients and frequently associated with hypertension ${ }^{30,31}$. Additionally, sympathetic overactivity has been observed in patients with $\mathrm{iHTN}^{8}$. Further, in vitro studies have shown that hypoxemia induces endothelin-1 secretion from endothelial cells, a process promoted by reactive oxygen species (ROS) ${ }^{32-34}$. Kanagy et al. ${ }^{35}$ have shown in rats that intermittent hypoxemia triggered a significant increase of endothelin-1 plasma levels, causing increased mean arterial pressure ${ }^{35}$. Another study in mice observed that endothelin-1 is a major contributor to the vascular inflammatory remodeling induced by intermittent hypoxia ${ }^{36}$. Of note, in patients with sleepdisordered breathing hypoxemia is associated with elevated plasma levels of endothelin- $1^{37}$ and facilitates endothelial dysfunction ${ }^{38,39}$. Similarly, iHTN is associated with severe impairments of endothelial function with altered NO/ET-1 balance ${ }^{16,40,41}$. It is intriguing to speculate, that increased ROS production due to intradialytic hypoxemia and tissue hypoxia induces endothelin-1 secretion, consecutive vasoconstriction, and eventually iHTN. Testing the hypothesis of a direct link between intradialytic hypoxia and $\mathrm{BP}$ changes would require simultaneous measurements of $\mathrm{SaO}_{2}$, sympathetic activity, BP, and endothelin-1 levels during HD. To the best of our knowledge this has not been done yet.

Carvedilol is suggested as treatment for patients with iHTN. Besides to being an alphaand beta-adrenoceptor antagonist, carvedilol is also a potent antioxidant. Therefore it may act by preventing the effects caused by hypoxemia on endothelial cells. In a pilot study carvediol has been shown to reduce intradialytic blood pressure surges by targeting endothelial cell dysfunction ${ }^{42}$.

Patients with iHTN are also prone to interdialytic hypertension ${ }^{10,43}$. It has been shown that the elevated postHD blood pressure persists for many hours ${ }^{44}$. Similarly, dialysis induced hypoxemia has been observed lasting for hours beyond the end of the HD 
session ${ }^{45}$. Future studies with concurrent measurements of interdialytic SBP and $\mathrm{SaO}_{2}$ would be of great interest.

Admittedly, our study has a few limitations. First, as it is a retrospective observational study, no conclusions towards causation can be drawn. While we employed a widely used definition of iHTN based on peridialytic SBP change, a systematic prospective study of intradialytic blood pressure relative to $\mathrm{SaO}_{2}$ would be important. In addition, postHD SBP may have been modified by intradialytic interventions like change in ultrafiltration rate or fluid infusion on some occasions. Unfortunately, data regarding fluid status (e.g. by using bioimpedance), antihypertensive drugs, and residual renal function are not recorded in our database; we acknowledge that this kind of data would have greatly added to our analysis. Lastly, our study is limited to patients with arterio-venous access.

In conclusion, this is the first study to report an association between low intradialytic arterial oxygen saturation and intradialytic hypertension. We hypothesize that low $\mathrm{SaO}_{2}$ may result in sympathetic activation and increased endothelin-1 secretion, both processes that would favor a blood pressure rise. Testing this hypothesis will require specifically designed prospective clinical studies with concurrent biochemical and physiological measurements. We believe that our results will motivate and encourage adequately equipped and trained clinical researchers to embark on specialized studies to that end, since further investigations in the pathophysiological mechanisms behind intradialytic hypertension and its association with hypoxemia are clearly required. 


\section{References}

1. Dinesh K, Kunaparaju S, Cape K, et al. A model of systolic blood pressure during the course of dialysis and clinical factors associated with various blood pressure behaviors. Am J Kidney Dis. 2011;58(5): 794-803.

2. Van Buren PN, Kim C, Toto RD, et al. The prevalence of persistent intradialytic hypertension in a hemodialysis population with extended follow-up. Int J Artif Organs. 2012;35(12):1031-1038.

3. Cirit $\mathrm{M}$, Akcicek $\mathrm{F}$, Terzioglu E, et al. 'Paradoxical' rise in blood pressure during ultrafiltration in dialysis patients. Nephrol Dial Transplant. 1995;10(8):1417-1420.

4. Inrig JK, Oddone EZ, Hasselblad V, et al. Association of intradialytic blood pressure changes with hospitalization and mortality rates in prevalent ESRD patients. Kidney Int. 2007;71(5):454-461.

5. Inrig JK, Patel UD, Toto RD, et al. Association of blood pressure increases during hemodialysis with 2year mortality in incident hemodialysis patients: a secondary analysis of the Dialysis Morbidity and Mortality Wave 2 Study. Am J Kidney Dis. 2009;54(5):881-890.

6. Park J, Rhee CM, Sim JJ, et al. A comparative effectiveness research study of the change in blood pressure during hemodialysis treatment and survival. Kidney Int. 2013;84(4):795-802.

7. Movilli E, Camerini C, Gaggia P, et al. Role of dialysis sodium gradient on intradialytic hypertension: an observational study. Am J Nephrol. 2013;38(5):413-419.

8. Rubinger D, Backenroth R, Sapoznikov D. Sympathetic activation and baroreflex function during intradialytic hypertensive episodes. PLoS One. 2012;7(5):e36943.

9. Fellner SK, Lang RM, Neumann A, et al. Physiological mechanisms for calcium-induced changes in systemic arterial pressure in stable dialysis patients. Hypertension. 1989;13(3):213-218.

10. Georgianos PI, Sarafidis PA, Zoccali C. Intradialysis Hypertension in End-Stage Renal Disease Patients: Clinical Epidemiology, Pathogenesis, and Treatment. Hypertension. 2015;66(3):456-463.

11. Van Buren PN, Inrig JK. Mechanisms and Treatment of Intradialytic Hypertension. Blood Purif. 2016;41(1-3):188-193.

12. Meyring-Wosten A, Zhang H, Ye X, et al. Intradialytic Hypoxemia and Clinical Outcomes in Patients on Hemodialysis. Clin J Am Soc Nephrol. 2016;11(4):616-625.

13. Campos I, Chan L, Zhang H, et al. Intradialytic Hypoxemia in Chronic Hemodialysis Patients. Blood Purif. 2016;41(1-3):177-187.

14. Hering D, Zdrojewski Z, Krol E, et al. Tonic chemoreflex activation contributes to the elevated muscle sympathetic nerve activity in patients with chronic renal failure. J Hypertens. 2007;25(1):157-161.

15. Xie A, Skatrud JB, Puleo DS, et al. Exposure to hypoxia produces long-lasting sympathetic activation in humans. J Appl Physiol. (1985) 2001;91(4):1555-1562.

16. Chou KJ, Lee PT, Chen CL, et al. Physiological changes during hemodialysis in patients with intradialysis hypertension. Kidney Int. 2006;69(10):1833-1838.

17. Nongnuch A, Campbell N, Stern E, et al. Increased postdialysis systolic blood pressure is associated with extracellular overhydration in hemodialysis outpatients. Kidney Int. 2015;87(2):452-457.

18. Mattos MS, Lemes HP, Ferreira-Filho SR. Correlation between pre- and post-dialysis blood pressure levels in hemodialysis patients with intradialytic hypertension. Int Urol Nephrol. 2016;48(12): 2095-2099.

19. Eftimovska-Otovic N, Grozdanovski R, Taneva B, et al. Clinical Characteristics of Patients with Intradialytic Hypertension. Pril (Makedon Akad Nauk Umet Odd Med Nauki). 2015;36(2):187-193.

20. Locatelli F, Cavalli A, Tucci B. The growing problem of intradialytic hypertension. Nat Rev Nephrol. 2010;6(1):41-48.

21. Assimon MM, Flythe JE. Intradialytic Blood Pressure Abnormalities: The Highs, The Lows and All That Lies Between. Am J Nephrol. 2015;42(5):337-350.

22. Agarwal R, Light RP. Intradialytic hypertension is a marker of volume excess. Nephrol Dial Transplant. 2010;25(10):3355-3361.

23. Van Buren PN, Zhou Y, Neyra JA, et al. Extracellular Volume Overload and Increased Vasoconstriction in Patients With Recurrent Intradialytic Hypertension. Kidney Blood Press Res. 2016;41(6):802-814. 
24. Sebastian S, Filmalter C, Harvey J, et al. Intradialytic hypertension during chronic haemodialysis and subclinical fluid overload assessed by bioimpedance spectroscopy. Clin Kidney J. 2016;9(4):636-643.

25. Anand S, Sinha AD, Agarwal R. Determinants and short-term reproducibility of relative plasma volume slopes during hemodialysis. Clin J Am Soc Nephrol. 2012;7(12):1996-2001.

26. Lusina SJ, Kennedy PM, Inglis JT, et al. Long-term intermittent hypoxia increases sympathetic activity and chemosensitivity during acute hypoxia in humans. J Physiol. 2006;575(Pt 3):961-970.

27. Shell B, Faulk K, Cunningham JT. Neural Control of Blood Pressure in Chronic Intermittent Hypoxia. Curr Hypertens Rep. 2016;18(3):19.

28. Ferreira CB, Schoorlemmer GH, Rossi MV, et al. Brainstem areas activated by intermittent apnea in awake unrestrained rats. Neuroscience. 2015;297:262-271.

29. Prabhakar NR, Kumar GK. Mechanisms of sympathetic activation and blood pressure elevation by intermittent hypoxia. Respir Physiol Neurobiol. 2010;174(1-2):156-161.

30. Roumelioti ME, Brown LK, Unruh ML. The Relationship Between Volume Overload in End-Stage Renal Disease and Obstructive Sleep Apnea. Semin Dial. 2015;28(5):508-513.

31. Zoccali C, Mallamaci F, Tripepi G. Sleep apnea in renal patients. J Am Soc Nephrol. 2001;12(12): 2854-2859.

32. Faller DV. Endothelial cell responses to hypoxic stress. Clin Exp Pharmacol Physiol. 1999;26(1):74-84.

33. Kourembanas S, Marsden PA, McQuillan LP, et al. Hypoxia induces endothelin gene expression and secretion in cultured human endothelium. J Clin Invest. 1991;88(3):1054-1057.

34. Chen HC, Guh JY, Shin SJ, et al. Reactive oxygen species enhances endothelin-1 production of diabetic rat glomeruli in vitro and in vivo. J Lab Clin Med. 2000;135(4):309-315.

35. Kanagy NL, Walker BR, Nelin LD. Role of endothelin in intermittent hypoxia-induced hypertension. Hypertension. 2001;37(2 Pt 2):511-515.

36. Gras E, Belaidi E, Briancon-Marjollet $A$, et al. Endothelin-1 mediates intermittent hypoxia-induced inflammatory vascular remodeling through HIF-1 activation. J Appl Physiol. (1985) 2016;120(4): 437-443.

37. Gjorup PH, Sadauskiene L, Wessels J, et al. Abnormally increased endothelin-1 in plasma during the night in obstructive sleep apnea: relation to blood pressure and severity of disease. Am J Hypertens. 2007;20(1):44-52.

38. Hoyos CM, Melehan KL, Liu PY, et al. Does obstructive sleep apnea cause endothelial dysfunction? A critical review of the literature. Sleep Med Rev. 2015;20:15-26.

39. Sawatari H, Chishaki A, Nishizaka M, et al. Cumulative Hypoxemia During Sleep Predicts Vascular Endothelial Dysfunction in Patients With Sleep-Disordered Breathing. Am J Hypertens. 2016;29(4): 458-463.

40. Dubin R, Owens C, Gasper W, et al. Associations of endothelial dysfunction and arterial stiffness with intradialytic hypotension and hypertension. Hemodial Int. 2011;15(3):350-358.

41. Inrig JK, Van Buren P, Kim C, et al. Intradialytic hypertension and its association with endothelial cell dysfunction. Clin J Am Soc Nephrol. 2011;6(8):2016-2024.

42. Inrig JK, Van Buren P, Kim C, et al. Probing the mechanisms of intradialytic hypertension: a pilot study targeting endothelial cell dysfunction. Clin J Am Soc Nephrol. 2012;7(8):1300-1309.

43. Van Buren PN, Kim C, Toto R, et al. Intradialytic hypertension and the association with interdialytic ambulatory blood pressure. Clin J Am Soc Nephrol. 2011;6(7):1684-1691.

44. Hompesch C, Ma TW, Neyra JA, et al. Comparison of Ambulatory Blood Pressure Patterns in Patients With Intradialytic Hypertension and Hemodialysis Controls. Kidney Blood Press Res. 2016;41(3): 240-249.

45. Dhakal MP, Kallay MC, Talley TE. Hemodialysis associated hypoxia extends into the post-dialysis period Int J Artif Organs. 1997;20(4):204-207. 


\section{Supplementary material}

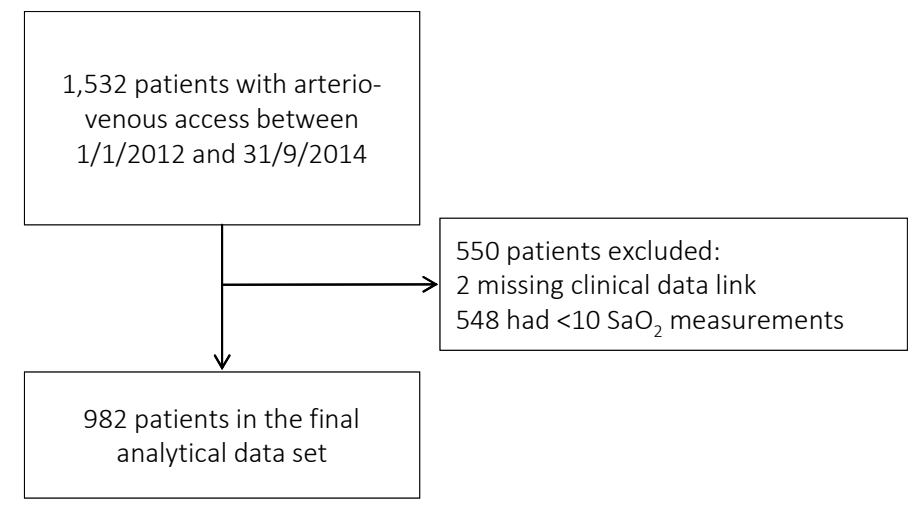

Figure S3.1 Study flow chart 


\section{Chapter 4}

Intradialytic central venous oxygen saturation is associated with clinical outcomes in hemodialysis

patients

Lili Chan, Hanjie Zhang, Anna Meyring-Wösten, Israel Campos, Doris Fuertinger, Stephan Thijssen, Peter Kotanko Sci Rep. 2017;7(1):8581 


\section{Abstract}

Central venous oxygen saturation $\left(\mathrm{ScvO}_{2}\right)$ in the superior vena cava is predominantly determined by cardiac output, arterial oxygen content, and oxygen consumption by the upper body. While abnormal $\mathrm{ScvO}_{2}$ levels are associated with morbidity and mortality in non-uremic populations, $\mathrm{ScvO}_{2}$ has received little attention in hemodialysis patients. From 1/2012 to 8/2015, 232 chronic hemodialysis patients with central venous catheters as vascular access had their $\mathrm{ScvO}_{2}$ monitored during a 6-month baseline period and followed for up to 36 months. Patients were stratified into upper and lower two tertiles by a $\mathrm{ScvO}_{2}$ of $61.1 \%$. Survival analysis employed Kaplan-Meier and adjusted Cox proportional hazards. Patients in the lower tertiles of $\mathrm{ScvO}_{2}$ were older, had longer hemodialysis vintage, lower systolic blood pressure, lower ultrafiltration rates, higher leukocyte counts and neutrophil-to-lymphocyte ratios. Kaplan-Meier analysis indicated a shorter survival time in the lower tertiles of $\mathrm{ScvO}_{2} \quad(P=0.005$, log-rank test). In adjusted Cox analysis, a 1 percent point decrease in mean $\mathrm{ScvO}_{2}$ was associated with a $4 \%$ increase in mortality ( $\mathrm{HR} 1.04$ [95\% Cl 1.01-1.08], $\mathrm{P}=0.044)$. Low $\mathrm{ScvO}_{2}$ is associated with poor outcomes. Research on the relative contributions of cardiac output and other factors is warranted to further elucidate the pathophysiology underlying this novel finding. 


\section{Introduction}

The mortality rate of hemodialysis (HD) patients is elevated compared to the normal population ${ }^{1}$. The primary cause of mortality is cardiovascular disease (CVD), and there is evidence that the mechanism for CVD in HD patients differ from the traditional CVD risk factors in the general population ${ }^{2,3}$. High ultrafiltration rates (UFR), episodes of intradialytic hypotension, presence of congestive heart failure (CHF) and left ventricular hypertrophy (LVH) are some of the factors that have been associated with increased mortality ${ }^{4,5}$. Additionally nocturnal hypoxemia in HD patients has been demonstrated to be associated with worse cardiovascular outcomes ${ }^{6,7}$.

Mixed venous oxygen saturation $\left(\mathrm{SmvO}_{2}\right)$ and central venous oxygen saturation ( $\left.\mathrm{ScvO} 2\right)$ have been used in critical care to guide fluid resuscitation ${ }^{8} . \mathrm{SmvO}_{2}$ is the oxygen saturation in the pulmonary artery, which receives blood from the superior vena cava, the inferior vena cava, and the coronary sinus, and therefore reflects - in the absence of arterial venous shunts - the aggregated effects of oxygen delivery to and utilization by the entire body. $\mathrm{ScvO}_{2}$ from upper body central venous catheters (CVC) is the oxygen saturation of blood in the superior vena cava, which reflects the aggregate of oxygen delivery to and utilization by the upper body. Although resting $\mathrm{SmvO}_{2}$ and $\mathrm{ScvO}_{2}$ differ due to the higher oxygen extraction in the upper body, the time trends of $\mathrm{SmvO}_{2}$ and $\mathrm{ScvO}_{2}$ are comparable under most circumstances ${ }^{9-11}$. While the measurement of $\mathrm{SmvO}_{2}$ requires pulmonary artery catheterization, $\mathrm{ScvO}_{2}$ can be more easily obtained from a CVC.

$\mathrm{ScvO}_{2}$ is determined by oxygen delivery to and oxygen consumption of the arms, head, and upper portion of the torso; the former depends on the arterial blood oxygen content and the cardiac output (CO). At rest with stable arterial oxygen saturation $\left(\mathrm{SaO}_{2}\right)$, hemoglobin, and tissue oxygen consumption, $\mathrm{ScvO}_{2}$ can serve as a surrogate of $\mathrm{CO}$. Poor oxygen delivery can be caused by decreased $\mathrm{CO}$, e.g. from $\mathrm{CHF}$ or reduced cardiac preload, or decreased arterial oxygen content, e.g. due to anemia or hypoxemic states. Oxygen consumption is determined by metabolic status and is altered in sepsis, fever, exercise and sedation ${ }^{12} . \mathrm{ScvO}_{2}$ in the general population is poorly defined, as obtaining this measurement requires a CVC, and patients who require CVC placement are generally significantly ill. One study in healthy subjects found a $\mathrm{ScvO}_{2}$ of $76.8 \pm 5.2 \%$ during cardiac catheterization ${ }^{13}$.

Studies in non-uremic populations, have found that abnormal $\mathrm{ScvO}_{2}$ levels are associated with worse morbidity and mortality ${ }^{8,14-18}$. $\mathrm{ScvO}_{2}$ levels in $\mathrm{HD}$ patients have not been well described. In patients who have ESRD with CVC as vascular access, $\mathrm{ScvO}_{2}$ can be easily and continuously obtained during HD treatments by using the Crit-Line monitor $^{\mathrm{TM}}$ (CLM). The CLM is used routinely Renal Research Institute HD units, which allowed us to investigate the $\mathrm{ScvO}_{2}$ in maintenance HD patients. The goals of our study 
were to evaluate the baseline characteristics of patients with different levels of intradialytic $\mathrm{ScvO}_{2}$ and to examine the associations between $\mathrm{ScvO}_{2}$ and mortality.

\section{Methods}

\section{Population and study design}

This is a retrospective multi-center study of a cohort of maintenance HD patients from 17 facilities of the Renal Research Institute (RRI) across the United States between January 2012 and August 2015. In these clinics, CLM use is part of standard care. All patients were treated with bicarbonate dialysate and polysulfone membranes. Over $80 \%$ of patients had a prescribed dialysate temperature of $37^{\circ} \mathrm{C}$. All patients who received HD via a CVC and had at least 6 months of clinical data and 10 dialysis treatments with eligible $\mathrm{ScvO}_{2}$ recordings (definition of eligibility see below) were eligible for inclusion into the study. Therefore our study included both incident and prevalent HD patients. The CLM was rolled out into dialysis units in a staggered manner, and we used the first treatment with CLM data as start date of the patients' 6 month baseline period. Since eligible patients had to contribute 6 months' worth of data, by design only those patients who survived for at least 6 months were included into the study (Figure 4.1). Patient characteristics were assessed over the baseline period, and mortality was assessed during a follow-up period for a maximum duration of three years. Figure 4.2 summarizes the study design. For group comparison patients were stratified based on the population $\mathrm{ScvO}_{2}$ that separated the top tertile from the bottom two tertiles. Descriptive statistics of the $\mathrm{ScvO}_{2}$ distribution showed a $\mathrm{ScvO}_{2}$ of $61.1 \%$ to be the cut-off between these two groups. Patients were censored in the event of kidney transplantation, transfer to a non-RRI facility, dialysis treatment modality change, recovery of kidney function, or end of follow-up.

The study was approved by the New England Institutional Review Board (14-446) and conducted in accordance with the Declaration of Helsinki. Informed consent was not obtained as this was determined not to be human subject research, and we were working with de-identified data.

This study has been registered at clinicaltrials.gov (NCT02501044). 


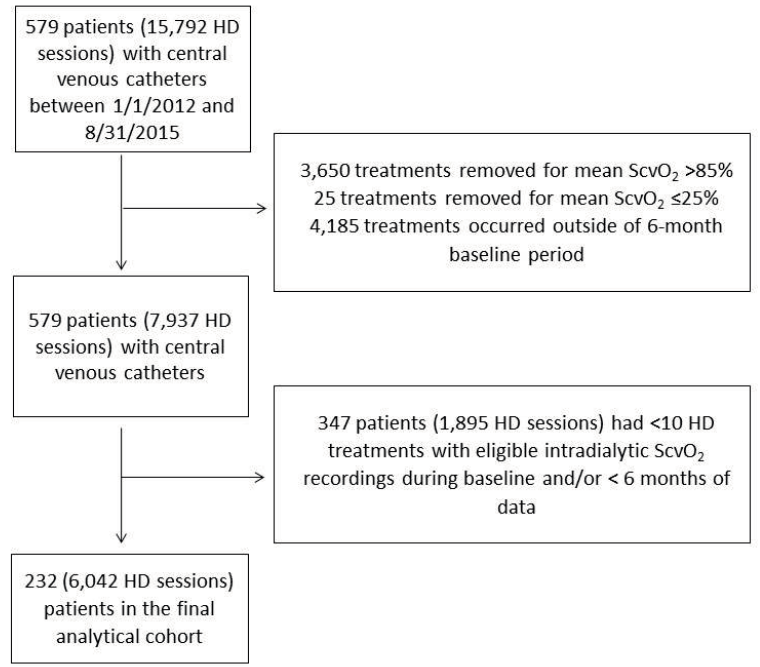

Figure 4.1 HD: hemodialysis, $\mathrm{ScvO}_{2}$ : central venous oxygen saturation

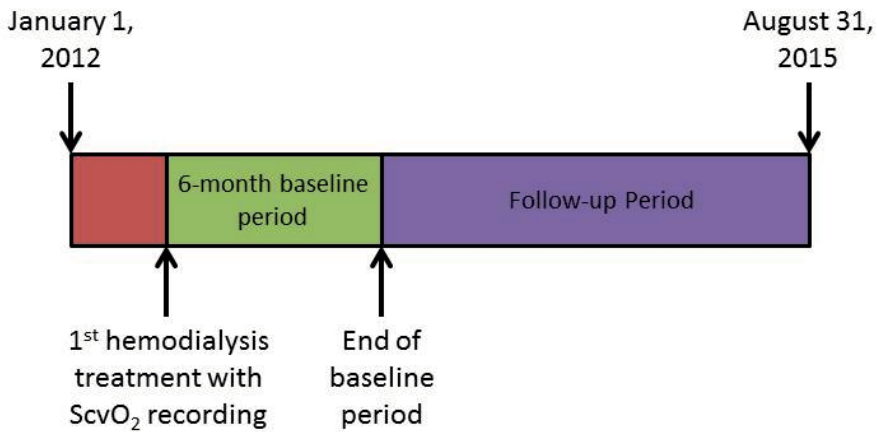

Figure 4.2 Data were reviewed starting from January 1, 2012. Due to the staggered deployment of Critline monitors to dialysis units, patients were enrolled into the study on a rolling basis. The first hemodialysis treatment with $\mathrm{ScvO}_{2}$ measurements marked the beginning the 6-month baseline period. Follow-up ended with either end of study (August 31, 2015), death, treatment modality change, recovery of renal function, or transfer to another dialysis facility. $\mathrm{ScvO}_{2}$ : central venous oxygen saturation

\section{Measurement of $\mathrm{ScvO}_{2}$}

Intradialytic $\mathrm{ScvO}_{2}$ measurements were obtained by the CLM. The CLM has been approved by the U.S. Food and Drug Administration (FDA) for the measurement of hematocrit, relative blood volume, and oxygen saturation in the extracorporeal dialysis circuit. The CLM measures oxygen saturation 9,000 times per minute and reports the 
mean of these measurements every minute. The manufacturer reported accuracy for oxygen saturation measurement is $2 \%$. Patients' mean, median, minimum, maximum, standard deviation, start- $\mathrm{HD}$, end-HD $\mathrm{ScvO}_{2}$ was calculated per treatment and then averaged across all treatments per patient and subsequently across patients. We chose to do our analysis using the mean $\mathrm{ScvO}_{2}$ as there was low variability across treatments for each patient (mean coefficient of variability of $7.5 \pm 4 \%$ ).

\section{Clinical and laboratory data}

Laboratory measurements were done at Spectra East Laboratories (Rockleigh, NJ, USA). The results were downloaded to the RRI data warehouse and extracted to the study database. Continuous variables were averaged during the baseline period. BMI was calculated using post-HD dry weight.

\section{Data eligibility}

To ensure appropriate data quality, we included only treatments where mean $\mathrm{ScvO}_{2}$ was below $85 \%$, as higher values are incompatible with central venous blood. ${ }^{13}$ Mean $\mathrm{ScvO}_{2}$ measurements less than 25\% were excluded because they are considered incompatible with life. ${ }^{19}$ Additionally, data points with relative blood volume measurements above $102 \%$ were considered very unlikely, potentially due to saline administration, and hence excluded. This constituted $3 \%$ of all data points.

\section{Comorbidities}

$\mathrm{CHF}, \mathrm{DM}$, and COPD were defined using International Classification of Diseases - 9 (ICD-9) codes.

\section{Statistical analysis}

Continuous variables are presented as mean \pm standard deviation (SD) if normally distributed and as median $\left(25^{\text {th }}, 75^{\text {th }}\right.$ percentile) otherwise. Categorical variables are presented as percentages of the respective group. Statistics of $\mathrm{ScvO}_{2}$ variables were calculated on a HD treatment level and then aggregated on a patient level.

Baseline characteristics of exposed and unexposed were compared using chi-square test for categorical variables and two-sample $t$ test for continuous variables, Wilcoxon Rank-Sum test were used for non-parametric variables. Survival characteristics were compared using Kaplan-Meier plots, log-rank test, and Cox proportional hazards models. 
Statistical analyses were performed using SAS version 9.3 (SAS Institute Inc., Cary, NC) and R 3.0.2 (libraries ggplot2, splines, survival, pspline; R Foundation for Statistical Computing, Vienna, Austria).

\section{Results}

\section{Baseline patient characteristics}

The final analytical cohort comprised of 232 patients with 6,042 HD treatments and was derived after a deliberate step-by-step data cleaning process at the treatment level. Patients were only excluded in the event that they did not contribute sufficient data during baseline, either because of end of study, death, treatment modality change, recovery of renal function, or transfer to another dialysis facility (Figure 4.1).

The initial population comprised of 579 patients with CVC as dialysis access, with a total of 15,792 $\mathrm{HD}$ treatments with $\mathrm{ScvO}_{2}$ measurements from January 1, 2012 until August 31,2015 . We excluded 3,650 treatments $(23 \%)$ as they had a mean $\mathrm{ScvO}_{2}$ of greater than $85 \%$ and 25 treatments $(0.16 \%)$ as they had a mean $\mathrm{ScvO}_{2}$ of less than or equal to $25 \%$. We also excluded 4,185 treatments (26.5\%) that occurred after the 6-month baseline period. This left us with 579 patients and 7,937 HD sessions, from which we excluded 347 patients with 1,895 HD treatments from the subsequent analysis because they had less than the required $10 \mathrm{HD}$ treatments with $\mathrm{ScvO}_{2}$ recordings and/or less than 6 months of follow up (Figure 4.1). Out of the 155 patients excluded for not having 6 months of follow up time, 79 were due to death.

In our study population, the mean age was $62.7 \pm 15.7$ years, dialysis vintage was $2.9 \pm 4.6$ years, $56 \%$ were white, $48.3 \%$ were male, $59 \%$ had diabetes mellitus (DM), $22 \%$ had CHF, and $10.3 \%$ had chronic obstructive pulmonary disease (COPD) (Table 4.1). Median follow-up time was 431 days.

During baseline, $\mathrm{ScvO}_{2}$ was recorded in $26 \pm 13.3 \mathrm{HD}$ treatments per patient. On a population level the $\mathrm{ScvO}_{2}$ was normally distributed with a mean of $58.7 \pm 7.3 \%$. Analysis of intradialytic $\mathrm{ScvO}_{2}$ dynamics across all patients indicated that on average $\mathrm{ScvO}_{2}$ slightly increased over the first 60 minutes of treatment, and then progressively declined below starting levels towards the end of HD (Figure 4.3). 
Table 4.1 Baseline characteristics of all patients, lower tertiles and upper tertile

\begin{tabular}{|c|c|c|c|c|c|}
\hline Variables & $\begin{array}{l}\text { All patients } \\
\text { Mean } \pm S D\end{array}$ & 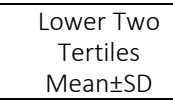 & $\begin{array}{c}\text { Upper Tertile } \\
\text { Mean } \pm S D\end{array}$ & $\begin{array}{c}\text { Group Difference } \\
\text { Mean }(95 \% \mathrm{Cl})\end{array}$ & P-value \\
\hline Patients [N] & 232 & 154 & 78 & & \\
\hline $\begin{array}{l}\text { Number of eligible HD } \\
\text { treatments during baseline } \\
\text { [per patient] }\end{array}$ & $26.1 \pm 13.3$ & $26.1 \pm 13.1$ & $26.1 \pm 13.8$ & $0.0(-3.8$ to 3.6$)$ & $0.953^{\mathrm{a}}$ \\
\hline \multicolumn{6}{|l|}{ Demographics } \\
\hline Age [years] & $62.7 \pm 15.7$ & $66.0 \pm 13.8$ & $56.2 \pm 17.3$ & 9.8 (5.3 to 14.2 ) & $0.001^{a}$ \\
\hline Race [\% white] & 56.0 & 53.9 & 60.3 & -6.4 & $0.357^{b}$ \\
\hline Gender [\% male] & 48.3 & 48.1 & 48.7 & -0.6 & $0.924^{b}$ \\
\hline Vintage [years] & $2.9 \pm 4.6$ & $3.3 \pm 5.1$ & $2.0 \pm 3.6$ & 1.3 & $0.0136^{c}$ \\
\hline $\mathrm{BMI}\left[\mathrm{kg} / \mathrm{m}^{2}\right]$ & $28.1 \pm 6.9$ & $28.6 \pm 7.0$ & $27.3 \pm 6.5$ & $1.2(-0.7$ to 3.2$)$ & $0.207^{a}$ \\
\hline \multicolumn{6}{|l|}{$\mathrm{ScvO}_{2}$ saturation [\%] } \\
\hline Mean $\mathrm{ScvO}_{2}$ & $58.7 \pm 7.3$ & $54.9 \pm 5.3$ & $66.3 \pm 4.2$ & $-11.4(-12.6$ to -10.1$)$ & n.a. \\
\hline Median $\mathrm{ScvO}_{2}$ & $59.1 \pm 7.3$ & $55.2 \pm 5.3$ & $66.6 \pm 4.2$ & $-11.4(-12.7$ to -10.1$)$ & n.a. \\
\hline Minimum $\mathrm{ScvO}_{2}$ & $48.4 \pm 9.7$ & $44.4 \pm 8.9$ & $56.3 \pm 5.7$ & $-11.9(-13.8$ to -10.0$)$ & n.a. \\
\hline Maximum $\mathrm{ScvO}_{2}$ & $65.2 \pm 6.2$ & $62.0 \pm 4.6$ & $71.5 \pm 3.6$ & $-9.5(-10.6$ to -8.4$)$ & n.a. \\
\hline $\mathrm{SD} \mathrm{ScvO} 2$ & $3.4 \pm 1.1$ & $3.6 \pm 1.1$ & $2.9 \pm 0.8$ & 0.7 (0.4 to 0.9$)$ & $<0.001^{\mathrm{a}}$ \\
\hline Start $\mathrm{ScvO}_{2}$ & $59.1 \pm 7.4$ & $55.4 \pm 5.6$ & $66.5 \pm 4.4$ & $-11.1(-12.4$ to -9.8$)$ & n.a. \\
\hline End $\mathrm{ScvO}_{2}$ & $57.3 \pm 7.8$ & $53.5 \pm 6.2$ & $64.8 \pm 4.8$ & $-11.3(-12.7$ to -9.8$)$ & n.a. \\
\hline End - Start $\mathrm{ScvO}_{2}$ & $-1.8 \pm 3.6$ & $-1.9 \pm 3.7$ & $-1.7 \pm 3.5$ & $-0.2(-1.2$ to 0.8$)$ & 0.62 \\
\hline \multicolumn{6}{|l|}{ Comorbidities [\%] } \\
\hline Diabetes & 59.0 & 60.4 & 56.4 & 4.0 & $0.560^{b}$ \\
\hline $\mathrm{CHF}$ & 22.0 & 21.4 & 23.1 & -1.7 & $0.775^{\mathrm{b}}$ \\
\hline COPD & 10.3 & 11.0 & 9.0 & 2.0 & $0.626^{b}$ \\
\hline \multicolumn{6}{|l|}{ Treatment parameters } \\
\hline Pre-dialysis SBP [mmHg] & $146.4 \pm 22.0$ & $143.7 \pm 22.9$ & $151.7 \pm 19.1$ & $-8.0(-14.0$ to -2.1$)$ & $0.009^{a}$ \\
\hline Post-dialysis SBP [mmHg] & $140.3 \pm 20.1$ & $137.8 \pm 20.5$ & $145.5 \pm 18.2$ & $-7.6(-13.0$ to -2.2$)$ & $0.006^{\mathrm{a}}$ \\
\hline $\begin{array}{l}\text { Peridialytic SBP change } \\
{[\mathrm{mmHg}]}\end{array}$ & $-6.1 \pm 11.9$ & $-6.0 \pm 11.7$ & $-6.4 \pm 12.4$ & $0.4(-2.9$ to 3.7$)$ & $0.820^{a}$ \\
\hline IDWG [kg] & $2.0 \pm 0.8$ & $1.9 \pm 0.8$ & $2.1 \pm 0.8$ & $-0.12(-0.3$ to 0.1$)$ & $0.249^{a}$ \\
\hline $\begin{array}{l}\text { IDWG relative to } \\
\text { post-dialysis weight [\%] }\end{array}$ & $2.6 \pm 0.9$ & $2.5 \pm 0.9$ & $2.8 \pm 1.0$ & $-0.3(-0.6$ to -0.1$)$ & $0.007^{\mathrm{a}}$ \\
\hline UFV [I] & $1.9 \pm 0.8$ & $1.9 \pm 0.79$ & $2.0 \pm 0.8$ & $-0.1(-0.4$ to 0.1$)$ & $0.173^{a}$ \\
\hline Normalized UFV [mL/kg] & $25.3 \pm 9.7$ & $24 \pm 8.9$ & $28 \pm 10.7$ & $-4(-6.6$ to -1.4$)$ & $0.003^{a}$ \\
\hline Post-dialysis weight [kg] & $77.4 \pm 20.4$ & $79.0 \pm 21.4$ & $74.3 \pm 18.1$ & $4.6(-0.9$ to 10.2$)$ & $0.102^{a}$ \\
\hline Treatment time [minutes] & $219.0 \pm 23$ & $217.7 \pm 23.8$ & $221.5 \pm 21.1$ & $-3.7(-10.1$ to 2.5$)$ & $0.235^{\mathrm{a}}$ \\
\hline Equilibrated Kt/V & $1.5 \pm 0.3$ & $1.5 \pm 0.3$ & $1.5 \pm 0.2$ & $0.0(-0.1$ to 0.1$)$ & $0.610^{a}$ \\
\hline \multicolumn{6}{|l|}{ Laboratory parameters } \\
\hline $\mathrm{Hgb}[\mathrm{g} / \mathrm{dl}]$ & $10.6 \pm 0.9$ & $10.6 \pm 0.9$ & $10.6 \pm 0.96$ & $0.0(-0.3$ to 0.3$)$ & $0.962^{a}$ \\
\hline Serum sodium [mmol/l] & $138.6 \pm 3.1$ & $138.6 \pm 3.2$ & $138.7 \pm 2.8$ & $-0.1(-0.9$ to 0.7$)$ & $0.782^{a}$ \\
\hline $\begin{array}{l}\text { Serum potassium } \\
{[\mathrm{mmol} / \mathrm{l}]}\end{array}$ & $4.7 \pm 0.6$ & $4.6 \pm 0.6$ & $4.7 \pm 0.4$ & $-0.1(-0.2$ to 0.1$)$ & $0.292^{\mathrm{a}}$ \\
\hline Intact PTH [pg/ml] & $518.3 \pm 481.1$ & $538.3 \pm 498.3$ & $478.6 \pm 445.4$ & $59.7(-72.9$ to 192.2$)$ & $0.376^{a}$ \\
\hline $\begin{array}{l}\text { Serum bicarbonate } \\
{[\mathrm{mmol} / \mathrm{l}]}\end{array}$ & $23.4 \pm 2.2$ & $23.3 \pm 2.3$ & $23.7 \pm 2.2$ & $-0.4(-1.0$ to 0.2$)$ & $0.165^{a}$ \\
\hline Leukocytes $[1000 / \mu l]$ & $7.0 \pm 2.0$ & $7.2 \pm 2.1$ & $6.6 \pm 1.7$ & $0.6(0.1$ to 1.1$)$ & $0.019^{a}$ \\
\hline Platelets $[1000 / \mu l]$ & $212.9 \pm 63.9$ & $216.9 \pm 65.1$ & $205.1 \pm 61.3$ & $11.8(-6.5$ to 30.1$)$ & $0.204^{\mathrm{a}}$ \\
\hline NLR & $4.4 \pm 2.6$ & $4.6 \pm 2.8$ & $3.8 \pm 2.0$ & $0.79(0.2$ to 1.4$)$ & $0.015^{a}$ \\
\hline Serum albumin [g/dl] & $3.8 \pm 0.4$ & $3.7 \pm 0.4$ & $3.8 \pm 0.4$ & $-0.1(-0.2$ to 0.04$)$ & $0.165^{\mathrm{a}}$ \\
\hline Ferritin $[\mathrm{ng} / \mathrm{ml}]$ & $780.5 \pm 510.2$ & $798.8 \pm 487.9$ & $744.7 \pm 552.9$ & $54.1(-86.8$ to 195.0$)$ & $0.45^{a}$ \\
\hline Transferrin saturation [\%] & $30.7 \pm 9.5$ & $29.8 \pm 8.9$ & $32.6 \pm 10.5$ & $-2.8(-5.4$ to -0.2$)$ & $0.036^{\mathrm{a}}$ \\
\hline
\end{tabular}

$95 \% \mathrm{Cl}, 95 \%$ confidence interval; $\mathrm{SD}$, standard deviation; $\mathrm{ScvO}_{2}$, central venous oxygen saturation; $\mathrm{BMI}$, body mass index; $\mathrm{CHF}$, congestive heart failure; COPD, chronic obstructive pulmonary disease; SBP, systolic blood pressure; UFV, ultrafiltration volume; IDWG, interdialytic weight gain; Hgb, hemoglobin; PTH, parathyroid hormone; NLR, neutrophil-to-lymphocyte ratio; n.a., not applicable. ${ }^{a} t$ test; ${ }^{b}$ Chi-square test; ${ }^{c}$ Wilcoxon test 


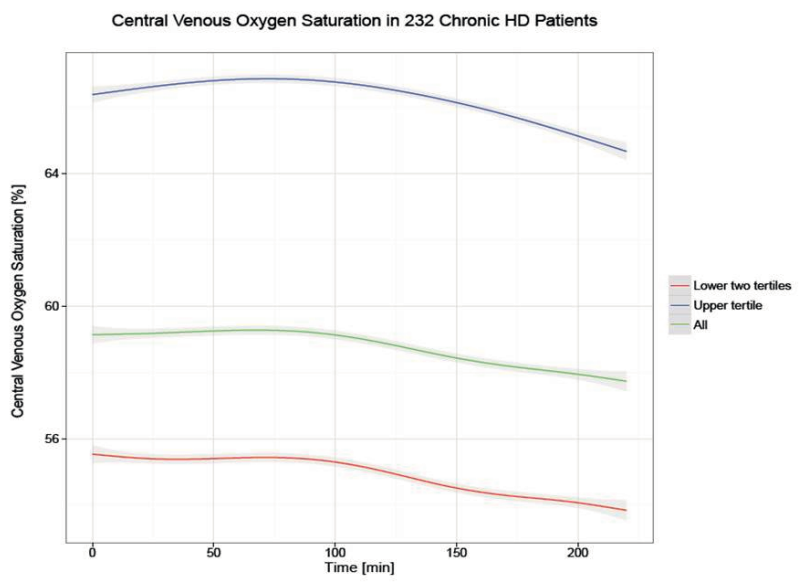

Figure 4.3 Time course of mean $\mathrm{ScvO}_{2}$ during hemodialysis in all patients (green), lower two tertiles (red) and upper tertile (blue). The respective 95\% confidence intervals are indicated in gray

\section{$\mathrm{ScvO}_{2}$ as a dichotomous outcomes}

\section{Comparison of baseline characteristics between upper and lower tertiles}

Patients were stratified into upper tertile $(\mathrm{N}=78)$ and lower two tertiles $(\mathrm{N}=154)$; a mean $\mathrm{ScvO}_{2}$ level below $61.1 \%$ during baseline period separated the two groups. A comparison of baseline characteristics between upper and lower tertiles is presented in Table 4.1. The patients in the lower tertiles were older $(66.0 \pm 13.8$ years vs. $56.2 \pm 17.3$ years, $\mathrm{P}<0.001)$, had longer dialysis vintage $(3.3 \pm 5.1$ years vs. $2.0 \pm 3.6$ years, $\mathrm{P}=0.031)$, lower pre-dialysis systolic blood pressure (SBP) $(143.7 \pm 22.9 \mathrm{mmHg}$ vs. $151.7 \pm 19$ $\mathrm{mmHg}, \mathrm{P}=0.009)$, lower post-dialysis SBP $(137.8 \pm 20.5 \mathrm{mmHg}$ vs. $145.5 \pm 18.2 \mathrm{mmHg}$, $P=0.006)$, and had lower normalized UFR $(6.8 \pm 2.4 \mathrm{ml} / \mathrm{kg} / \mathrm{hr}$ vs. $7.7 \pm 2.9 \mathrm{ml} / \mathrm{kg} / \mathrm{hr}$, $\mathrm{P}=0.015)$. Furthermore, lower tertile subjects had higher leukocyte counts $(7.2 \pm 2.1$ * $1000 / \mu \mathrm{l}$ vs. $6.6 \pm 1.7 * 1000 / \mu \mathrm{l}, \mathrm{P}=0.019)$ and higher neutrophil-to-lymphocyte ratio (NLR) (4.6 \pm 2.8 vs $3.8 \pm 2.0, P=0.015)$. There was no statistically significant difference in comorbidities of DM, CHF or COPD.

\section{Mortality between upper and lower tertiles}

During the 36-month follow-up period, there were a total of 54 deaths, 45 in the lower two tertiles and 9 in the upper tertile. Mortality rate was 24.1/100 patient years in lower two tertiles and $9.0 / 100$ patient years in upper tertile $(P=0.005)$. Univariate Kaplan-Meier analysis indicated a significantly shorter survival among lower tertile patients ( $P=0.005$, log-rank test) (Figure 4.4). 


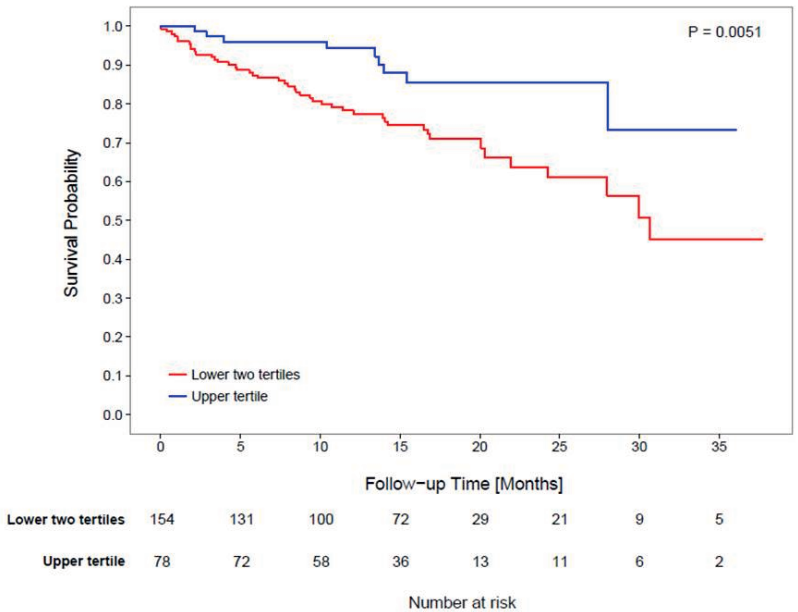

Figure 4.4 Kaplan-Meier estimates for survival probabilities in exposed (red) and unexposed (blue) cohorts, respectively. Median follow up for the lower two tertiles was 428 days while the median follow up time for the upper tertile was 432 days. The number of patients at risk is indicated in the table below the graph. The time to death differs significantly between the two groups ( $\mathrm{P}=0.0051$, log-rank test

\section{$\mathrm{ScvO}_{2}$ as a continuous variable}

In unadjusted Cox analysis, for every 1 percent point decrease in mean $\mathrm{ScvO}_{2}$ there was an associated 6\% increase in mortality (HR 1.06 (1.03-1.10)). There was no material change in the results after adjustment for age, gender, comorbidities (COPD and CHF), log vintage, inflammatory markers (albumin, NLR), hemoglobin and erythropoietin dose (HR 1.04 (1.01-1.08)) (Table 4.2).

Table 4.2 Crude and adjusted hazard ratios for all-cause mortality for a $1 \%$ decrease in central venous oxygen saturation.

\begin{tabular}{lccccccc}
\hline & & \multicolumn{2}{c}{ Crude $^{\mathrm{a}}$} & & \multicolumn{2}{c}{ Minimally Adjusted $^{\mathrm{b}}$} & \multicolumn{2}{c}{ Fully Adjusted $^{\mathrm{c}}$} \\
Outcome & Events & $\mathrm{HR}(95 \% \mathrm{Cl})$ & $\mathrm{PV}$ Value & $\mathrm{HR}(95 \% \mathrm{Cl})$ & $\mathrm{PV}$ Value & HR (95\% Cl) & P Value \\
\hline $\begin{array}{l}\text { All-cause } \\
\text { mortality }\end{array}$ & 54 & $1.06(1.03$ to 1.10) & $<0.001$ & $1.05(1.02$ to 1.09) & 0.003 & 1.04 (1.01 to 1.08) & 0.0437 \\
\hline
\end{tabular}

HR, hazard ratio. ${ }^{a}$ Unadjusted model; ${ }^{b}$ Adjusted for age, gender, chronic obstructive pulmonary disease and congestive heart failure; ${ }^{\mathrm{C} A d j u s t e d ~ f o r ~ a g e, ~ g e n d e r, ~ c h r o n i c ~ o b s t r u c t i v e ~ p u l m o n a r y ~ d i s e a s e, ~ c o n g e s t i v e ~ h e a r t ~}$ failure, albumin, hemoglobin, erythropoietin dose, neutrophil to lymphocyte ratio and log vintage

\section{Correlates of $\mathrm{ScvO}_{2}$}

Figure 4.5 depicts the relationship between $\mathrm{ScvO}_{2}$ and patient characteristics that were found to differ between the two groups. Mean $\mathrm{ScvO}_{2}$ across patients was plotted 
against age, log vintage, body mass index (BMI), interdialytic weight gain (IDWG) relative to post-HD weight, post-HD SBP, and NLR. As vintage was not normally distributed, it was log transformed. Age, BMI, log vintage and NLR were negatively associated with $\mathrm{ScvO}_{2}$, while post-HD SBP and IDWG were positively correlated with $\mathrm{ScvO}_{2}$. While all correlates were statistically significant except for $\mathrm{ScvO}_{2}$ and log vintage $(\mathrm{P}=0.9)$, correlation coefficients were relatively low.
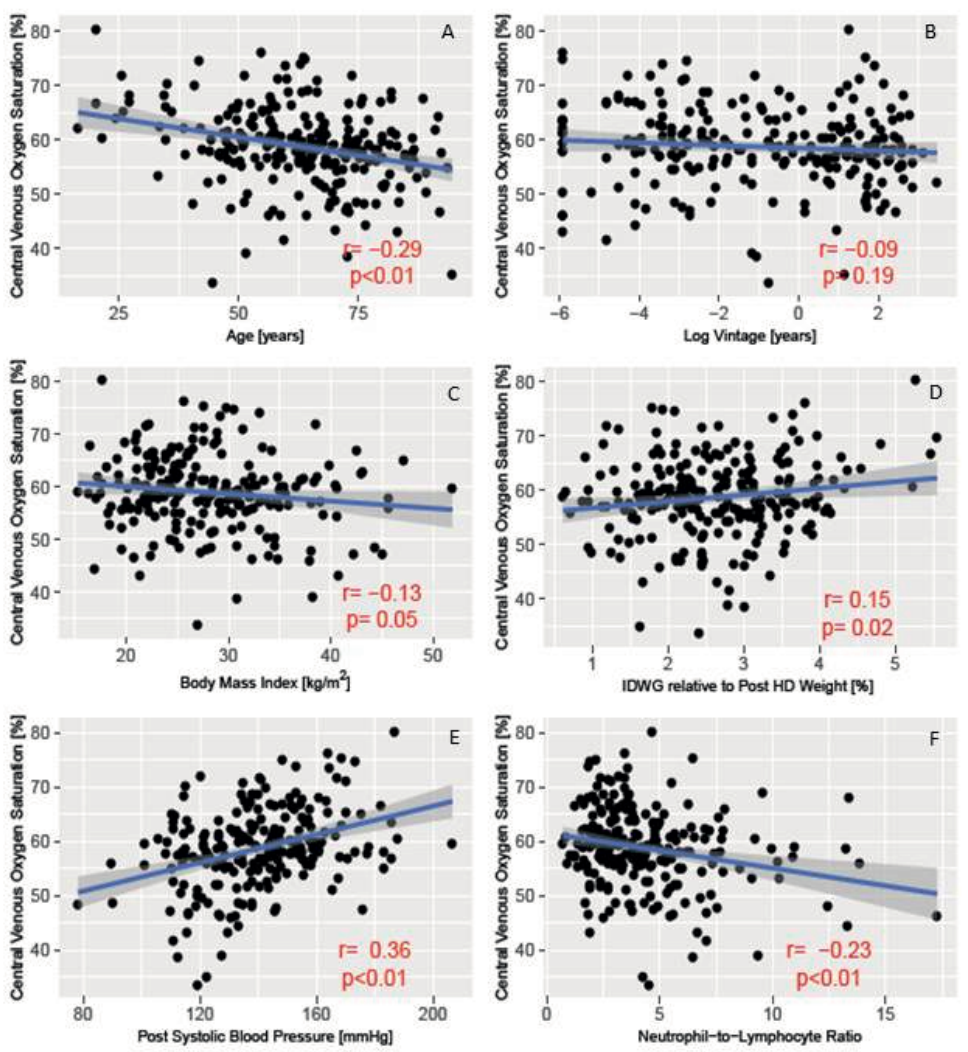

Figure 4.5 Correlates of central venous oxygen saturation with respect to patient characteristics. Each point represents one patient; the depicted data points represent the respective parameter averages during the 6-month baseline period. (A) Age; (B) Log vintage; (C) Body mass index; (D) Interdialytic weight gain relative to post-dialysis body weight; (E) Post-dialysis systolic blood pressure; (F) Neutrophil-to-lymphocyte ratio 


\section{Discussion}

Our study indicates that in chronic HD patients with CVC as vascular access, lower $\mathrm{ScvO}_{2}$ levels are associated with poorer survival.

Despite the relative ease with which $\mathrm{ScvO}_{2}$ can be obtained in HD patients with CVC as access, to date only small studies have examined this key indicator of cardiac function. Cordtz et al. $^{20}$ in 2008 evaluated 20 HD patients and classified them as either hypotension prone or hypotension resistant and measured their $\mathrm{ScvO}_{2}$ at treatment initiation and end. The authors found a significant decrease in $\mathrm{ScvO}_{2}$ in hypotension prone patients. Harrison et al..$^{21}$ investigated $18 \mathrm{HD}$ patients and found a strong inverse correlation between $\mathrm{ScvO}_{2}$ at the end of dialysis and ultrafiltration volume normalized to post-HD body weight. A recent review of intradialytic oxygen saturation did not identify any previous research examining the association between $\mathrm{ScvO}_{2}$ and patient survival. $^{22}$

In the study by Harrison et al. the mean $\mathrm{ScvO}_{2}$ was $63.5 \pm 13 \%$ pre-HD and $56.4 \pm 8 \%$ post- $-\mathrm{HD}^{21}$, whereas in the study by Cordtz et al. the initial $\mathrm{ScvO}_{2}$ was $52.2 \pm 6.7 \%$ in hypotension prone and $49.7 \pm 6.9 \%$ in hypotension resistant patients. ${ }^{20}$ While these studies focused on $\mathrm{ScvO}_{2}$ at $\mathrm{HD}$ start and end, we examined $\mathrm{ScvO}_{2}$ continuously throughout the $\mathrm{HD}$ session. The $\mathrm{ScvO}_{2}$ levels found in our study are below the levels of $70 \%$ observed in healthy subjects ${ }^{13}$, but consistent with those reported in HD patients. The exact etiology of low intradialytic $\mathrm{ScvO}_{2}$ in $\mathrm{HD}$ patients is not well established, but may be partially explained by the lower hemoglobin levels, and the higher prevalence of cardiac dysfunction and pulmonary hypertension in HD patients.

In our cohort, when $\mathrm{ScvO}_{2}$ was assessed throughout the entire HD treatment, on average $\mathrm{ScvO}_{2}$ increased slightly over the first hour and then progressively declined during the remaining treatment time. The determinants of $\mathrm{ScvO}_{2}$ can be visualized by rearrangement of the familiar form of Fick's law and replacement of $\mathrm{SmvO}_{2}$ with $\mathrm{ScvO}_{2}$, and $\mathrm{CO}$ with upper body blood flow (UBBF), which results in the following equation

$$
\mathrm{ScvO}_{2}=\mathrm{SaO}_{2}-\frac{100 * \text { Upper body oxygen consumption }}{\mathrm{K}^{*} \mathrm{Hgb}{ }^{*} \mathrm{UBBF}}
$$

with $\mathrm{ScvO}_{2}$ and $\mathrm{SaO}_{2}$ in \%, upper body oxygen consumption in $\mathrm{ml} / \mathrm{min}$, $\mathrm{Hgb}$ in $\mathrm{g} / \mathrm{l}, \mathrm{UBBF}$ in $\mathrm{I} / \mathrm{min}$, and $\mathrm{K}$ being 1.34 , the amount of oxygen (in $\mathrm{ml}$ ) bound per $\mathrm{g}$ of hemoglobin.

Therefore, there are four components which may change during HD and that will cause a decrease in $\mathrm{ScvO}_{2}$; (i) increased tissue oxygen consumption; (ii) a decrease in $\mathrm{SaO}_{2}$, (iii) a decrease in hemoglobin concentration, and (iv) a decrease in upper body blood flow. An increase in oxygen consumption can occur due to an increase in metabolic rate. A small study done in maintenance HD patients found that whole body energy expenditure, measured by indirect calorimetry, increased during $\mathrm{HD}^{23}$. However, to 
what extent the upper body energy expenditure changes during HD is currently unknown. It would be of interest to know if oxygen consumption by the brain, by far the largest consumer of oxygen in the upper body, changes during HD. Intradialytic $\mathrm{SaO}_{2}$ has been demonstrated to decrease during the first hour of HD; unfortunately we do not have $\mathrm{SaO}_{2}$ levels in these patients ${ }^{24}$. While HD patients have lower hemoglobin levels than the general population, during HD as UF occurs and the relative blood volume decreases, hemoglobin levels generally rise due to hemoconcentration ${ }^{25}$. We suspect that a reduction in $\mathrm{CO}$ and consequently a decrease in upper body blood flow is the predominant driving factor leading to a drop in $\mathrm{ScvO}_{2}$. The almost linear relation between cerebral perfusion and $\mathrm{CO}$ has been recently reviewed ${ }^{26}$. When faced with any of the other possibilities in a patient with intact cardiac function, there should be a compensatory response in $\mathrm{CO}^{27}$. There is growing literature on depressed $\mathrm{CO}$ during $\mathrm{HD}$ treatment due to poor vascular refill and regional wall motion abnormalities $(\text { RWMA })^{28,29}$. In fact, a recent study using intradialytic magnetic resonance imaging of the heart demonstrated that systolic contractile function fell during $H D$, with all 12 patients experiencing some degree of segmental left ventricular dysfunction along with evidence of decreased intravascular volume and an inadequate heart rate response ${ }^{30}$.

$\mathrm{ScvO}_{2}$ in patients with sepsis, post-surgery, and trauma has been examined, with studies finding that abnormal $\mathrm{ScvO}_{2}$ levels are associated with increased morbidity and mortality. ${ }^{15,16,18}$ However, the ESRD population is unique in many aspects, and the results of prior studies in other populations therefore may not be fully applicable.

We and others have observed a left shift of the $\mathrm{ScvO}_{2}$ distribution in $\mathrm{HD}$ patients compared to healthy subjects, possibly related to anemia and lower $\mathrm{CO}$. Therefore we refrained from defining comparison groups based on $\mathrm{ScvO}_{2}$ levels obtained in healthy subjects but rather used $\mathrm{ScvO}_{2}$ tertiles obtained from our large HD population, where a $\mathrm{ScvO}_{2}$ of $61.1 \%$ separated the top from the bottom two tertiles ${ }^{13,31}$. In a review of literature, $\mathrm{ScvO}_{2}$ levels below $64.4 \%$ were associated with morbidity post-surgery, and values below $62 \%$ were associated with mortality in patients with pulmonary hypertension ${ }^{18,32}$. In the trauma setting, $\mathrm{ScvO}_{2}<65 \%$ on initial evaluation in the emergency room predicted higher blood loss and greater severity of injuries. ${ }^{16} \mathrm{We}$ complemented this binary analysis with a continuous spline analysis of the association between $\mathrm{ScvO}_{2}$ and hazard ratio for all-cause mortality; that analysis indicated that mean $\mathrm{ScvO}_{2}$ levels below $63 \%$ were associated with increased mortality.

Our finding that patients with lower $\mathrm{ScvO}_{2}$ were older may reflect the poorer cardiac function expected in older subjects. Of note, the prevalence of $\mathrm{CHF}$ increases with age, as does $\mathrm{CHF}$ mortality ${ }^{33}$. On univariate analysis, age was an independent risk factor for mortality. However, even after adjustment for age in our analysis, $\mathrm{ScvO}_{2}$ as a continuous variable remained a significant predictor of mortality.

While the correlation coefficients were low, we identified several significant correlations between $\mathrm{ScvO}_{2}$ and patient variables such as the association between 
lower $\mathrm{ScvO}_{2}$ levels and longer dialysis vintage. We speculate that this finding may be related to recurrent hemodynamic stress and cardiac injury caused by HD. Mclntyre et al. demonstrated that HD induced RWMA in a subset of maintenance HD patients. While at baseline there was no difference in left ventricular ejection fraction (LVEF) between patients who developed RWMA and those that did not, at 1 year follow-up, the group of patients that developed RWMA during HD had significantly lower resting LVEF. $^{5}$

In our study, lower tertile patients had lower pre-HD and lower post-HD SBP, a finding possibly related to low CO. Of note, an association between low pre-HD SBP and mortality has been repeatedly shown ${ }^{34,35}$. It is interesting to note that in our study the prevalence of CHF did not differ between lower and upper tertiles. Unfortunately, no routine echocardiography assessments were available in our patients, so we cannot comment on the possibility of deficient documentation, classification or misdiagnosis of CHF. One intriguing possibility is that we may be identifying a group of patients without clinically overt signs and symptoms of $\mathrm{CHF}$ at rest, who however have reduced cardiac reserve or autonomic dysfunction and are unable to mount the necessary increase in sympathetic response and CO when faced with the hemodynamic stress of $H D^{28,36}$.

The main limitation of our study is its observational nature, which prevents any conclusions related to causality. As mentioned earlier, routine echocardiograms are unfortunately not available in our study population, making potentially very insightful correlational analyses of $\mathrm{ScvO}_{2}$ and cardiac structure and function impossible. Lastly, we appreciate that $\mathrm{ScvO}_{2}$ measurements may be altered by changes in catheter tip position due to changes in body position; however, we have no indication that this may affect one of the two groups disproportionally and created any bias.

Considering a recent review of this topic, we believe that this is the largest study to date examining the epidemiology of $\mathrm{ScVO}_{2}$ in maintenance $\mathrm{HD}$ patients ${ }^{22}$. CVC are used as vascular access in the majority of U.S. patients starting HD. ${ }^{1}$ While this situation is certainly not desirable, the presence of a CVC allows us to measure $\mathrm{ScvO}_{2}$, a vitally important physiological parameter. This additional diagnostic opportunity may be particularly important in the incident period, the time with the highest cardiovascular morality rate. ${ }^{1}$ In fact, a recent study published by Mancini et al. demonstrates that variability in $\mathrm{SaO}_{2}$ is associated with intradialytic hypotension ${ }^{37}$. This supports the potential role of oxygen saturation monitoring during dialysis.

In conclusion, our research shows that routine measurement of $\mathrm{ScvO}_{2}$ during $\mathrm{HD}$ provides a novel window into patients' biology that may help to improve our care for this vulnerable patient population. 


\section{References}

1. United States Renal Data System. 2015 USRDS annual data report: Epidemiology of kidney disease in the United States. (National Institutes of Health, National Institute of Diabetes and Digestive and Kidney Diseases, Bethesda, MD, 2015)

2. Ragosta $\mathrm{M}$, et al. Coronary flow reserve abnormalities in patients with diabetes mellitus who have endstage renal disease and normal epicardial coronary arteries. Am Heart J. 2004;147:1017-1023.

3. Schneider A, et al. Determinants of cardiovascular risk in haemodialysis patients: post hoc analyses of the AURORA study. Am J Nephrol 2013;37:144-151.

4. Stefansson BV, et al. Intradialytic hypotension and risk of cardiovascular disease. Clin J Am Soc Nephrol. 2014;9:2124-2132.

5. Burton JO, Jefferies HJ, Selby NM, Mclntyre CW. Hemodialysis-induced cardiac injury: determinants and associated outcomes. Clin J Am Soc Nephrol. 2009;4:914-920.

6. Zoccali C, Mallamaci F, Tripepi G. Nocturnal hypoxemia predicts incident cardiovascular complications in dialysis patients. J Am Soc Nephrol. 2002;13:729-733.

7. Zoccali $C$, et al. Nocturnal hypoxemia, night-day arterial pressure changes and left ventricular geometry in dialysis patients. Kidney Int. 1998;53:1078-1084.

8. Rivers E, et al. Early goal-directed therapy in the treatment of severe sepsis and septic shock. N Engl J Med. 2001;345:1368-1377.

9. Schou H, Perez de Sa V, Larsson A. Central and mixed venous blood oxygen correlate well during acute normovolemic hemodilution in anesthetized pigs. Acta Anaesthesiol Scand. 1998;42:172-177.

10. Chawla LS, et al. Lack of equivalence between central and mixed venous oxygen saturation. Chest 2004;126:1891-1896.

11. Scheinman MM, Brown MA, Rapaport E. Critical assessment of use of central venous oxygen saturation as a mirror of mixed venous oxygen in severely ill cardiac patients. Circulation 1969;40:165-172.

12. Vincent JL, ebrary Inc. Yearbook of intensive care and emergency medicine 2005. (Springer,, Berlin, 2005).

13. Barratt-Boyes BG, Wood EH. The oxygen saturation of blood in the venae cavae, right-heart chambers, and pulmonary vessels of healthy subjects. J Lab Clin Med. 1957;50:93-106.

14. Balzer $F$, et al. High central venous saturation after cardiac surgery is associated with increased organ failure and long-term mortality: an observational cross-sectional study. Crit Care. 2015;19:168.

15. Textoris J, et al. High central venous oxygen saturation in the latter stages of septic shock is associated with increased mortality. Crit Care. 2011;15:R176.

16. Scalea TM, et al. Central venous oxygen saturation: a useful clinical tool in trauma patients. J Trauma. 1990;30:1539-1543.

17. Futier $\mathrm{E}$, et al. Central venous $\mathrm{O}(2)$ saturation and venous-to-arterial $\mathrm{CO}(2)$ difference as complementary tools for goal-directed therapy during high-risk surgery. Crit Care. 2010;14:R193.

18. Pearse $\mathrm{R}$, et al. Changes in central venous saturation after major surgery, and association with outcome. Crit Care. 2005;9:R694-699.

19. Marx, G. \& Reinhart, K. Venous oximetry. Current opinion in critical care 12, 263-268 (2006).

20. Cordtz, J., Olde, B., Solem, K. \& Ladefoged, S.D. Central venous oxygen saturation and thoracic admittance during dialysis: new approaches to hemodynamic monitoring. Hemodial Int 12, 369-377 (2008).

21. Harrison, L.E., Selby, N.M. \& Mclntyre, C.W. Central venous oxygen saturation: a potential new marker for circulatory stress in haemodialysis patients? Nephron Clin Pract. 2014;128:57-60.

22. Campos I, et al. Intradialytic Hypoxemia in Chronic Hemodialysis Patients. Blood Purif. 2016;41: 177-187.

23. Ikizler TA, et al. Increased energy expenditure in hemodialysis patients. J Am Soc Nephrol. 1996;7: 2646-2653.

24. De Backer WA, et al. Hypoxemia during hemodialysis: effects of different membranes and dialysate compositions. Kidney Int. 1983;23:738-743. 
25. Wink J, Vaziri ND, Barker S, Hyatt J, Ritchie C. The effect of hemodialysis on whole blood, plasma and erythrocyte viscosity. Int J Artif Organs. 1988;11:340-342.

26. Meng L, Hou W, Chui J, Han R, Gelb AW. Cardiac Output and Cerebral Blood Flow: The Integrated Regulation of Brain Perfusion in Adult Humans. Anesthesiol. 2015;123:1198-1208.

27. Blumberg A, Keller G. Oxygen consumption during maintenance hemodialysis. Nephron. 1979;23: 276-281.

28. Daugirdas JT. Dialysis hypotension: a hemodynamic analysis. Kidney Int. 1991;39:233-246.

29. Selby NM, Lambie SH, Camici PG, Baker CS, Mclntyre CW. Occurrence of regional left ventricular dysfunction in patients undergoing standard and biofeedback dialysis. Am J Kidney Dis. 2006;47: 830-841.

30. Buchanan C, et al. Intradialytic cardiac magnetic resonance imaging to assess cardiovascular responses in a short-term trial of hemodiafiltration and hemodialysis. J Am Soc Nephrol. 2017;28:1269-1277.

31. Madsen $\mathrm{P}$, Iversen $\mathrm{H}$, Secher $\mathrm{NH}$. Central venous oxygen saturation during hypovolaemic shock in humans. Scand J Clin Lab Invest. 1993;53, 67-72.

32. Sitbon $\mathrm{O}$, et al. Long-term intravenous epoprostenol infusion in primary pulmonary hypertension: prognostic factors and survival. J Am Coll Cardiol. 2002;40:780-788.

33. Schocken DD, Arrieta MI, Leaverton PE, Ross EA. Prevalence and mortality rate of congestive heart failure in the United States. J Am Coll Cardiol. 1992;20:301-306.

34. Li Z, et al. The epidemiology of systolic blood pressure and death risk in hemodialysis patients. Am J Kidney Dis. 2006;48:606-615.

35. Port FK, et al. Predialysis blood pressure and mortality risk in a national sample of maintenance hemodialysis patients. Am J Kidney Dis. 1999;33:507-517.

36. Chesterton $L$, et al. Categorization of the hemodynamic response to hemodialysis: the importance of baroreflex sensitivity. Hemodial Int. 2010;14:18-28.

37. Mancini E, et al. Intra-dialytic blood oxygen saturation (SO2): association with dialysis hypotension (the SOGLIA Study). J Nephrol. 2017;30:811-819. 


\section{Chapter}

Association between intradialytic central venous oxygen saturation and ultrafiltration volume in chronic hemodialysis patients

Zhang H, Chan L, Meyring-Wösten A, Campos I, Preciado P, Kooman JP, van der Sande FM, Fuertinger D, Thijssen S, Kotanko $P$ Nephrol Dial Transplant. 2017 Sep 12. doi: 10.1093/ndt/gfx271 


\section{Abstract}

\section{Background}

Cardiac disease is highly prevalent in hemodialysis patients. Decreased tissue perfusion, including cardiac, due to high ultrafiltration volumes (UFV) is considered to be one driver of cardiac dysfunction. While central venous oxygen saturation $\left(\mathrm{ScvO}_{2}\right)$ is frequently used as an indicator of cardiac output in non-uremic populations, the relationship of $\mathrm{ScvO}_{2}$ and UFV in hemodialysis patients remains unclear. Our aim was to determine how intradialytic $\mathrm{ScvO}_{2}$ changes associate with UFV.

\section{Methods}

We conducted a 6-months retrospective cohort study in maintenance hemodialysis patients with central venous catheters as vascular access. Intradialytic $\mathrm{ScvO}_{2}$ was measured with the Critline monitor. We computed treatment-level slopes of intradialytic $\mathrm{ScvO}_{2}$ over time $\left(\mathrm{ScvO}_{2}\right.$ trend) and applied linear mixed effects models to assess the association between patient-level $\mathrm{ScvO}_{2}$ trends and UFV corrected for body weight (cUFV).

\section{Results}

We studied 6,042 dialysis sessions in 232 patients. In about $62.4 \%$ of treatments $\mathrm{ScvO}_{2}$ decreased. We observed in nearly $80 \%$ of patients an inverse relationship between cUFV and $\mathrm{ScVO}_{2}$ trend, indicating that higher cUFV is associated with steeper decline in $\mathrm{ScvO}_{2}$ during dialysis.

\section{Conclusions}

In most patients higher cUFV volumes are associated with steeper intradialytic $\mathrm{ScvO}_{2}$ drops. We hypothesize that in a majority of patients the intradialytic cardiac function is fluid dependent, so that in the face of high ultrafiltration rates or volume, cardiac preload and consequently cardiac output decreases. Direct measurements of cardiac hemodynamics are warranted to further test this hypothesis. 


\section{Introduction}

Cardiac disease accounts for over $40 \%$ of mortality in end stage renal dialysis (ESRD) patients. While the prevalence of cardiac disease is higher in older hemodialysis (HD) patients, the prevalence of cardiac disease in patients aged 20-44 years is greatly elevated compared to an age-matched general population ${ }^{1}$. While traditional risk factors such as hypertension, diabetes mellitus and hyperlipidemia are contributors, dialysis specific factors such as anemia, hypoalbuminemia, and chronic inflammation have also been incriminated ${ }^{2}$. Congestive heart failure (CHF) is highly prevalent among ESRD patients, and HD treatment factors such as recurrent hemodynamic stress due to high ultrafiltration rates (UFR), intradialytic cardiac stunning due to decrease myocardial perfusion, and episodes of intradialytic hypotension (IDH) may play a role in CHF pathogenesis ${ }^{3-5}$.

The concurrence of CHF and ESRD makes fluid management particularly challenging. Not only are these patients more volume sensitive and prone to volume overload, but CHF patients are particularly prone to hypotension, and fluid removal is limited by IDH episodes. A common therapeutic response to IDH is to administer saline boluses and often by the end of treatment patients are unable to attain their prescribed fluid status target. Additionally, episodes of IDH are not only uncomfortable for patients, but associated with worse outcomes ${ }^{6}$.

Central venous oxygen saturation $\left(\mathrm{ScvO}_{2}\right)$ is determined by cardiac output, hemoglobin levels, arterial oxygen saturation, and oxygen extraction by the organs that drain into the superior vena cava. Therefore, $\mathrm{ScvO}_{2}$ may serve as a proxy of cardiac output, more specifically of upper body blood flow ${ }^{7,8}$. This relationship has been recognized for decades and hence intensivists use $\mathrm{ScvO}_{2}$ for directed fluid management in sepsis, trauma, and post-surgery. In the renal field, a study in 18 maintenance HD patients revealed a significant inverse association between $\mathrm{ScvO}_{2}$ at the end of dialysis and ultrafiltration volume corrected for body weight (cUFV) $)^{9}$. However, the dynamical changes of $\mathrm{ScvO}_{2}$ relative to cUFV are currently unclear.

The goal of our study was to explore the relationship between intradialytic $\mathrm{ScvO}_{2}$ changes and CUFV in a large and diverse population of chronic HD patients, employing automated intradialytic minute-to-minute measurements of $\mathrm{ScvO}_{2}$ during multiple treatments per patient.

\section{Subjects and methods}

\section{Population and study design}

This retrospective multi-center study utilized routinely collected data from maintenance HD patients dialyzed in 17 U.S. facilities of the Renal Research Institute 
(RRI) between January 2012 and August 2015. In these clinics, the Critline monitor (CLM; Fresenius Medical Care, Waltham, MA) was used as part of standard of care. All patients were treated with bicarbonate dialysate and polysulfone membranes.

As the CLM was introduced into RRI clinics on a rolling basis, patient recruitment also occurred on a rolling basis. Patient characteristics, $\mathrm{ScvO}_{2}$ and other clinical factors were monitored for 6 months starting with the first hemodialysis treatment with eligible $\mathrm{ScvO}_{2}$ readings. Only patients with at least 10 hemodialysis treatments with eligible $\mathrm{ScvO}_{2}$ recordings were included in the final analysis.

\section{Data eligibility}

Only patients with documented CVC were included in this study. To ensure sound CLM data, we included only treatments with a mean $\mathrm{ScvO}_{2}$ below $85 \%$, as higher values are likely from patients inappropriately documented as having CVC and instead likely have fistulas/grafts and therefore are arterial. Mean $\mathrm{ScvO}_{2}$ levels below 25\% are considered incompatible with life and were thus excluded. $\mathrm{ScvO}_{2}$ measurements concurrent with a relative blood volume (RBV) above $102 \%$ may indicate CLM readings e.g. during saline administration and were thus excluded. $\mathrm{ScvO}_{2}$ measurements concurrent with a relative blood volume (RBV) above $102 \%$ may indicate CLM readings e.g. during saline administration and were thus excluded. As rapid changes in RBV may also be due to administration of saline which may impact $\mathrm{ScvO}_{2}$ measurements, we performed a sensitivity analysis excluding treatments where RBV increased by more than 5 percentage points compared to the preceding 5 minutes on one or more occasions.

\section{Measurement of $\mathrm{ScvO}_{2}$}

Intradialytic $\mathrm{ScvO}_{2}$ measurements were done by the CLM. The CLM is approved by the U.S. Food and Drug Administration (FDA) for the measurement of hematocrit and oxygen saturation in the extracorporeal dialysis circuit. The CLM automatically measures oxygen saturation 9,000 times per minute and reports an average $1 \mathrm{x} /$ minute. As per the manufacturer, the CLM accuracy for oxygen saturation measurement is within $2 \%$.

\section{Assessing the relationship between $\mathrm{ScvO}_{2}$ and cUFV}

In order to explore the association between $\mathrm{ScvO}_{2}$ and cUFV on a population level, we employed linear mixed effects models (see detailed description below) to combine multi-level data, starting from a treatment level, to a patient level, and lastly to the population level. First, we calculated on a treatment level the trend of $\mathrm{ScvO}_{2}$ over time based on $1 \mathrm{x} /$ minute $\mathrm{ScvO}_{2}$ recordings. We then assessed the patient level association between cUFV and $\mathrm{ScvO}_{2}$ trend by computing the slope of $\mathrm{ScvO}_{2}$ over cUFV across all treatments in a given patient. Lastly, this association was quantitated on a population level by combining all patient level results. 


\section{Clinical and laboratory data}

Laboratory measurements (Spectra Laboratories, NJ) were downloaded to the RRI data warehouse and extracted to the study database. Clinical data were retrieved from electronic health records. Continuous clinical variables were averaged over the 6-months observation period. Body mass index was calculated using post-HD weight.

\section{Comorbidities}

$\mathrm{CHF}$, diabetes, and chronic obstructive pulmonary disease (COPD) were defined using International Classification of Diseases - 9 codes.

\section{Statistical analysis}

Continuous variables are presented as mean \pm SD when normally distributed and as medians (interquartile range) otherwise. Categorical variables are presented as percentages of the group from which they were derived. Statistics of $\mathrm{ScvO}_{2}$ variables were calculated first per HD treatment, then per patient across all his/her treatments, and then per group.

Patients were stratified into two groups based on the direction (positive or negative slope) of the $\mathrm{ScvO}_{2} / \mathrm{CUFV}$. Point estimates and $95 \%$ confidence intervals of the group differences are reported.

Since we had repeated $\mathrm{ScvO}_{2}$ measurements from all patients available, we employed linear mixed effects models that considered both fixed and random effects to evaluate the relationship between $\mathrm{ScvO}_{2}$ and cUFV on a population level. The model takes into account that each patient has a random intercept and slope for the relationship between $\mathrm{ScVO}_{2}$ and $\mathrm{CUFV}$; the fixed effects produces estimates of population intercept and slope.

Statistical analyses were performed using SAS version 9.3 (SAS Institute Inc., Cary, NC) and R 3.0.2 (libraries ggplot2, nlme); R Foundation for Statistical Computing, Vienna, Austria. The study was approved by the New England Institutional Review Board (14-446), and conducted in accordance with the Declaration of Helsinki. This study is registered at clinicaltrials.gov (NCT02501044).

\section{Results}

\section{Baseline characteristics}

Between January $1^{\text {st }} 2012$ and August 31 $1^{\text {st }} 2015,579$ patients with central venous catheters (CVC) as vascular access received 7,937 HD treatments at the 17 U.S. RRI clinics. Of these, 232 patients with 6,042 HD sessions met our inclusion criteria of at least 10 baseline $\mathrm{HD}$ treatments with $\mathrm{ScvO}_{2}$ readings and 6 months of follow up time 
(Supplemental Figure S5.1). Patients contributed on average $25 \pm 13.3$ treatments with $\mathrm{ScvO}_{2}$ measurement. Patient age was $62.7 \pm 15.7$ years, dialysis vintage $2.9 \pm 4.6$ years, $56 \%$ were white, and $48.3 \%$ were males (Table 5.1 ).

Table 5.1

\begin{tabular}{|c|c|c|c|c|}
\hline Variable & $\begin{array}{l}\text { All patients } \\
\text { Mean } \pm S D\end{array}$ & $\begin{array}{c}\text { Negative } \mathrm{ScvO}_{2} \\
\text { trend } \\
\text { Mean } \pm \mathrm{SD}\end{array}$ & $\begin{array}{c}\text { Positive } \mathrm{ScvO}_{2} \\
\text { trend } \\
\text { Mean } \pm \mathrm{SD}\end{array}$ & $\begin{array}{c}\text { Difference between } \\
\text { groups } \\
\text { Mean }(95 \% \mathrm{Cl}) \\
\end{array}$ \\
\hline Patients, N (\%) & 232 & $181(78)$ & $51(22)$ & n.a. \\
\hline $\begin{array}{l}\mathrm{HD} \text { treatments with } \mathrm{ScvO}_{2} \\
\text { measurements }\end{array}$ & $26 \pm 13.3$ & $27.4 \pm 13.7$ & $21.1 \pm 10.3$ & 6.4 (2.9 to 9.9$)$ \\
\hline \multicolumn{5}{|l|}{ Demographics } \\
\hline Age [years] & $62.7 \pm 15.7$ & $62.5 \pm 15.2$ & $63.6 \pm 17.7$ & $-1.1(-6.0$ to 3.8$)$ \\
\hline Race [\% white] & $56 \pm 0.5$ & 56.4 & 54.9 & 1.5 (-13.6 to 17.0$)$ \\
\hline Gender [\% male] & $48.3 \pm 0.5$ & 45.9 & 56.9 & $-11.0(-26.1$ to 4.7$)$ \\
\hline Vintage [years] & $2.9 \pm 4.6$ & $2.7 \pm 3.9$ & $3.6 \pm 6.6$ & $-0.9(-2.9$ to 1.0$)$ \\
\hline BMI $\left[\mathrm{kg} / \mathrm{m}^{2}\right]$ & $28.1 \pm 6.9$ & $28.2 \pm 6.8$ & $27.6 \pm 7.3$ & $0.6(-1.6$ to 2.9$)$ \\
\hline \multicolumn{5}{|l|}{$\mathrm{ScvO}_{2}[\%]$} \\
\hline Mean $\mathrm{ScvO}_{2}$ & $58.7 \pm 7.3$ & $58.3 \pm 7.1$ & $60.3 \pm 8.1$ & $-2.0(-4.3$ to 0.3$)$ \\
\hline Median $\mathrm{ScvO}_{2}$ & $59.1 \pm 7.3$ & $58.6 \pm 7.1$ & $60.7 \pm 8.0$ & $-2.0(-4.3$ to 0.2$)$ \\
\hline Minimum $\mathrm{ScvO}_{2}$ & $48.4 \pm 9.7$ & $48.0 \pm 9.4$ & $50.0 \pm 10.6$ & $-2.0(-5.0$ to 1.0$)$ \\
\hline Maximum $\mathrm{ScvO}_{2}$ & $65.2 \pm 6.2$ & $64.9 \pm 6.0$ & $66.5 \pm 6.9$ & $-1.6(-3.5$ to 0.3$)$ \\
\hline $\mathrm{SD} \mathrm{ScvO}_{2}$ & $3.4 \pm 1.1$ & $3.4 \pm 1.0$ & $3.3 \pm 1.3$ & $0.1(-0.3$ to 0.5$)$ \\
\hline \multicolumn{5}{|l|}{ Comorbidities [\%] } \\
\hline Diabetes & 59.0 & 58.0 & 62.8 & $-4.8(-19.8$ to 10.6$)$ \\
\hline $\mathrm{CHF}$ & 22.0 & 23.2 & 17.7 & $5.5(-6.7$ to 17.3$)$ \\
\hline COPD & 10.3 & 11.6 & 5.9 & $5.7(-2.7$ to 13.0$)$ \\
\hline \multicolumn{5}{|l|}{ Treatment Parameters } \\
\hline Pre-dialysis SBP [mmHg] & $146.4 \pm 22.0$ & $146.7 \pm 20.8$ & $145.5 \pm 25.8$ & $1.2(-6.7$ to 9.0$)$ \\
\hline Post-dialysis SBP [mmHg] & $140.3 \pm 20.1$ & $140.2 \pm 19.0$ & $140.7 \pm 23.8$ & $-0.5(-7.7$ to 6.7$)$ \\
\hline IDWG [kg] & $2.0 \pm 0.8$ & $2.0 \pm 0.8$ & $1.8 \pm 1.6$ & $0.2(-0.008$ to 0.5$)$ \\
\hline IDWG [\% of post HD weight] & $2.6 \pm 0.9$ & $2.7 \pm 0.9$ & $2.4 \pm 1.0$ & $0.2(-0.06$ to 0.5$)$ \\
\hline UFR $[\mathrm{ml} / \mathrm{kg} / \mathrm{hr}]$ & $7.1 \pm 2.6$ & $7.3 \pm 2.5$ & $6.6 \pm 2.9$ & $0.6(-0.2$ to 1.4$)$ \\
\hline UFV [I] & $1.9 \pm 0.8$ & $2.0 \pm 0.8$ & $1.7 \pm 0.8$ & 0.3 (0.04 to 0.5$)$ \\
\hline Corrected UFV [mL/kg] & $25.3 \pm 9.7$ & $26.0 \pm 9.5$ & $22.9 \pm 10.2$ & $3.1(0.05$ to 6.1$)$ \\
\hline Post dialysis weight [kg] & $77.4 \pm 20.4$ & $77.9 \pm 20.8$ & $75.9 \pm 19.3$ & $2.0(-4.4$ to 8.4$)$ \\
\hline $\begin{array}{l}\text { Difference between post } \\
\text { dialysis weight and EDW (kg) }\end{array}$ & $0.2 \pm 1.3$ & $0.3 \pm 1.3$ & $-0.1 \pm 1.3$ & $0.4(-0.1$ to 0.8$)$ \\
\hline Treatment time [minutes] & $219.0 \pm 23$ & $220.4 \pm 23.1$ & $214 \pm 22.2$ & $6.4(-0.7$ to 13.6$)$ \\
\hline Equilibrated Kt/V & $1.5 \pm 0.3$ & $1.5 \pm 0.3$ & $1.4 \pm 0.2$ & $0.05(-0.03$ to 0.1$)$ \\
\hline \multicolumn{5}{|l|}{ Laboratory Parameters } \\
\hline Serum albumin [g/dl] & $3.8 \pm 0.4$ & $3.8 \pm 0.4$ & $3.7 \pm 0.5$ & $0.1(-0.02$ to 0.3$)$ \\
\hline $\mathrm{Hgb}[\mathrm{g} / \mathrm{dl}]$ & $10.6 \pm 0.9$ & $10.7 \pm 0.9$ & $10.5 \pm 0.9$ & $0.2(-0.1$ to 0.5$)$ \\
\hline Serum sodium [mmol/l] & $138.6 \pm 3.1$ & $138.7 \pm 3.0$ & $138.7 \pm 3.5$ & $-0.005(-1.0$ to 1.0$)$ \\
\hline Serum potassium [mmol/l] & $4.7 \pm 0.6$ & $4.7 \pm 0.6$ & $4.6 \pm 0.5$ & $0.04(-0.1$ to 0.2$)$ \\
\hline
\end{tabular}

95\% Cl, 95\% confidence interval; SD, standard deviation; $\mathrm{ScvO}_{2}$, central venous oxygen saturation; $\mathrm{BMI}$, body mass index; $\mathrm{CHF}$, congestive heart failure; COPD, chronic obstructive pulmonary disease; SBP, systolic blood pressure; UFV, ultrafiltration volume; EDW, estimated dry weight; IDWG, interdialytic weight gain; Hgb, hemoglobin; n.a., not applicable. 


\section{Changes in $\mathrm{ScvO}_{2}$ on a treatment level}

We observed treatments where $\mathrm{ScvO}_{2}$ decreased (negative trend) as well as treatments where $\mathrm{ScvO}_{2}$ increased (positive trend). Figures 5.1a and 5.1b show examples from two different patients. $62.4 \%$ of all treatments showed a $\mathrm{ScvO}_{2}$ decline during dialysis (Figure 5.2).

(A) Negative trend

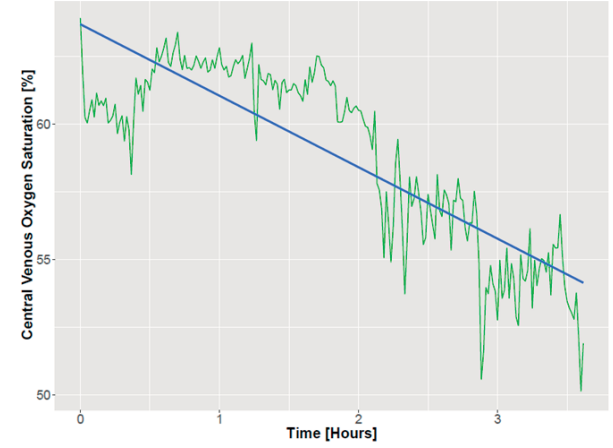

(B) Positive trend

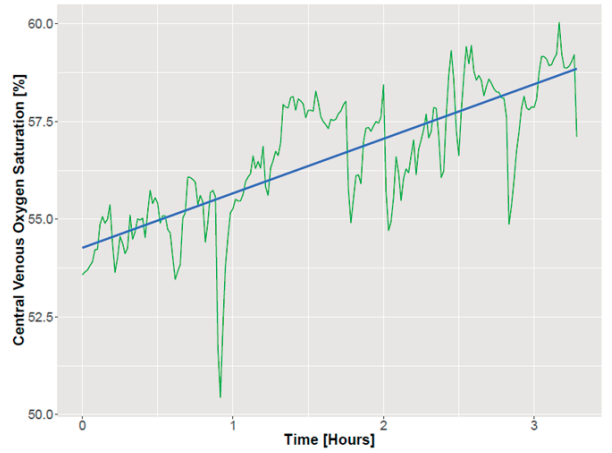

Figure 5.1 Changes in central venous oxygen saturation during a hemodialysis treatment for two different patients. (A) Negative trend (B) Positive trend. Green lines represent actual central venous oxygen saturation reading, the blue line represents the regression line fitted to the data.

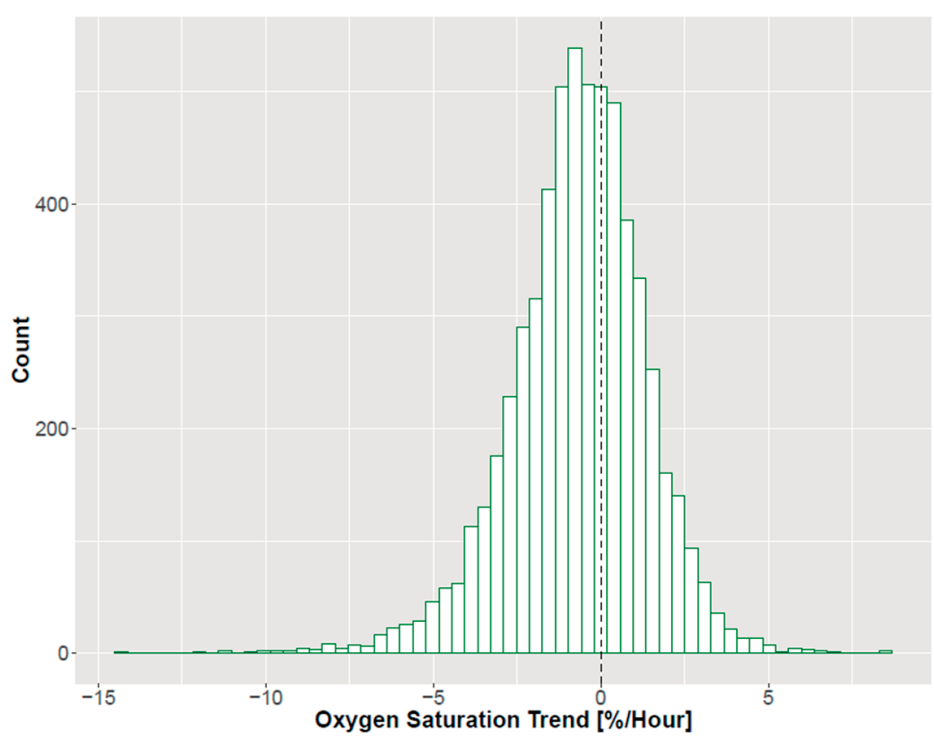

Figure 5.2 Distribution of central venous oxygen saturation trend on treatment level. Dotted line denotes a slope of zero, meaning no change in central venous oxygen saturation throughout treatment. 


\section{Patient level relationship between $\mathrm{ScvO}_{2}$ trend and cUFV}

To analyze the relationship between the $\mathrm{ScvO}_{2}$ trend and cUFV we combined all the treatment-level $\mathrm{ScvO}_{2}$ trends and cUFV data on a patient level. Examples are illustrated in Figure 5.3. Figure 5.3a shows a patient with an inverse (i.e. negative) $\mathrm{ScvO}_{2} / \mathrm{cUFV}$ relationship. In this figure each green dot represents one dialysis treatment. Of note, data points with a $\mathrm{ScvO}_{2}$ trend $>0$ indicate treatments where $\mathrm{ScvO}_{2}$ increased. In the patient depicted in Figure 5.3a a low CUFV (e.g. point 1) was associated with a positive $\mathrm{ScvO}_{2}$ trend, while a high cUFV (e.g. point 2) was associated with a negative $\mathrm{ScvO}_{2}$ trend, meaning that $\mathrm{ScvO}_{2}$ decreased during those treatments. Therefore in this patient, with increasing cUFV, the intradialytic $\mathrm{ScvO}_{2}$ trend changed from increasing, to zero, to decreasing.

In contrast, Figure 5.3b demonstrates a patient with a positive $\mathrm{ScVO}_{2} / \mathrm{cUFV}$ slope. At low levels of cUFV (e.g. point 1), the $\mathrm{ScvO}_{2}$ trend is negative (meaning that $\mathrm{ScvO}_{2}$ decreased during the treatment), while at high levels of cUFV the $\mathrm{ScvO}_{2}$ trend is positive (meaning that $\mathrm{ScvO}_{2}$ increases during the treatment).

(A) Negative relationship

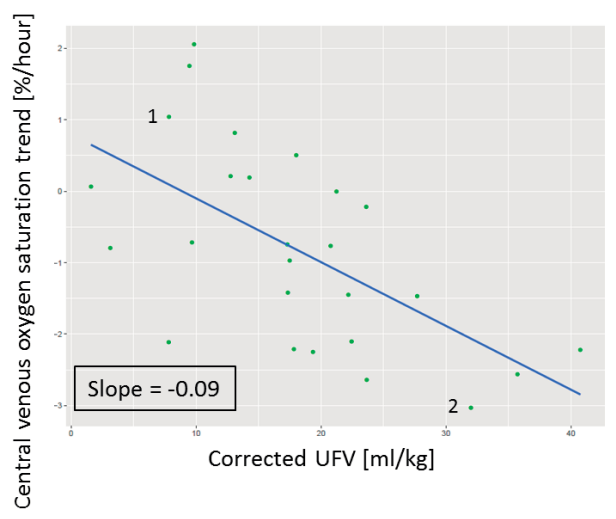

(B) Positive relationship

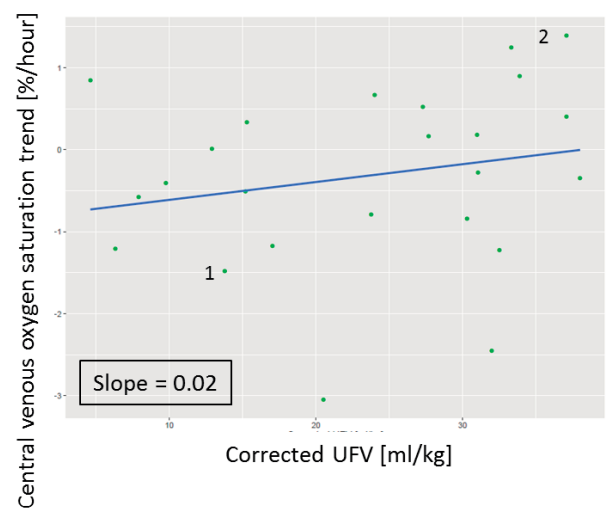

Figure 5.3 Examples showing changes in central venous oxygen saturation $\left(\mathrm{ScvO}_{2}\right)$ over corrected ultrafiltration volume (cUFV) in two patients. Each green dot represents a treatment; blue lines represent the regression line. (a) negative $\mathrm{ScvO}_{2} / \mathrm{cUFV}$ relationship where point 1 indicates a dialysis treatment with low CUFV and a positive $\mathrm{ScvO}_{2}$ trend and point 2 indicates a dialysis treatment with a high cUFV and a negative $\mathrm{ScvO}_{2}$ trend and (b) positive $\mathrm{ScvO}_{2} / \mathrm{cUFV}$ relationship where point 1 represents a low cUFV and a negative $\mathrm{ScvO}_{2}$ trend and point 2 indicates a high cUFV and a positive $\mathrm{ScvO}_{2}$ trend.

A vast majority of patients (80\%) showed an inverse $\mathrm{ScvO}_{2} / \mathrm{cUFV}$ relationship (Figure 5.4), akin to the patient example in Figure 5.3a. Figure 5.5 shows on a population level the $\mathrm{ScVO}_{2} / \mathrm{cUFV}$ relationship. Blue lines represent patients with a negative $\mathrm{ScVO}_{2} / \mathrm{cUFV}$ slope and red lines those with a positive slope. The purple line represents the 
population fixed effect slope derived from the linear mixed model, slope of - 0.03 $(P<0.001)$. After taking into account fixed and random effects, we find that on a population level, increasing cUFV is associated with lower $\mathrm{ScvO}_{2}$ trend, meaning that most patients have a decrease in $\mathrm{ScvO}_{2}$ during dialysis with higher cUFV. The sensitivity analysis excluding treatments with rapid RBV changes showed a materially identical slope of the population fixed effect. (Supplemental Figure S5.2)

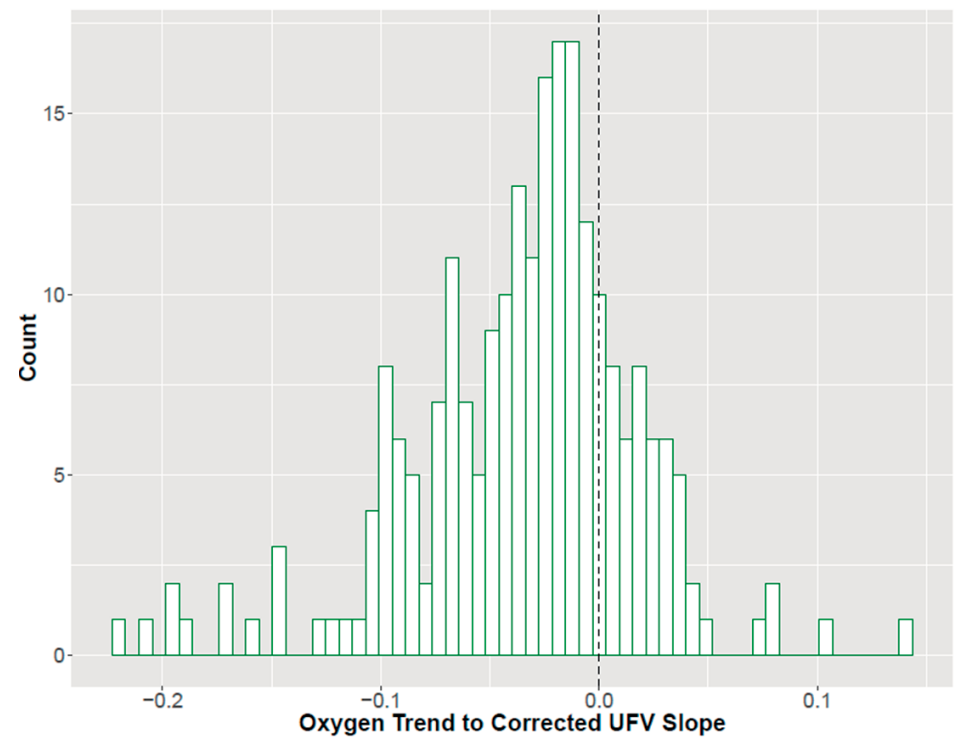

Figure 5.4 Distribution of $\mathrm{ScvO}_{2} / \mathrm{cUFV}$ slopes. The dotted line represents a flat relationship, meaning that there is no change in $\mathrm{ScVO}_{2}$ trend regardless of the cUFV.

\section{Comparison of patients stratified by ScvO2/cUFV relationship (Table 5.1)}

Patients with negative $\mathrm{ScvO}_{2} / \mathrm{CUFV}$ slopes had higher ultrafiltration volumes (UFV) (2.0 \pm 0.8 vs. $1.7 \pm 0.8 \mathrm{~L}$, difference $0.3 \mathrm{~L} ; 95 \%$ confidence interval 0.04 to 0.5 ) as compared to patients with positive $\mathrm{ScvO}_{2} / \mathrm{cUFV}$. There were no differences in the prevalence of diabetes mellitus, $\mathrm{CHF}$, and COPD or other patient and treatment parameters. 


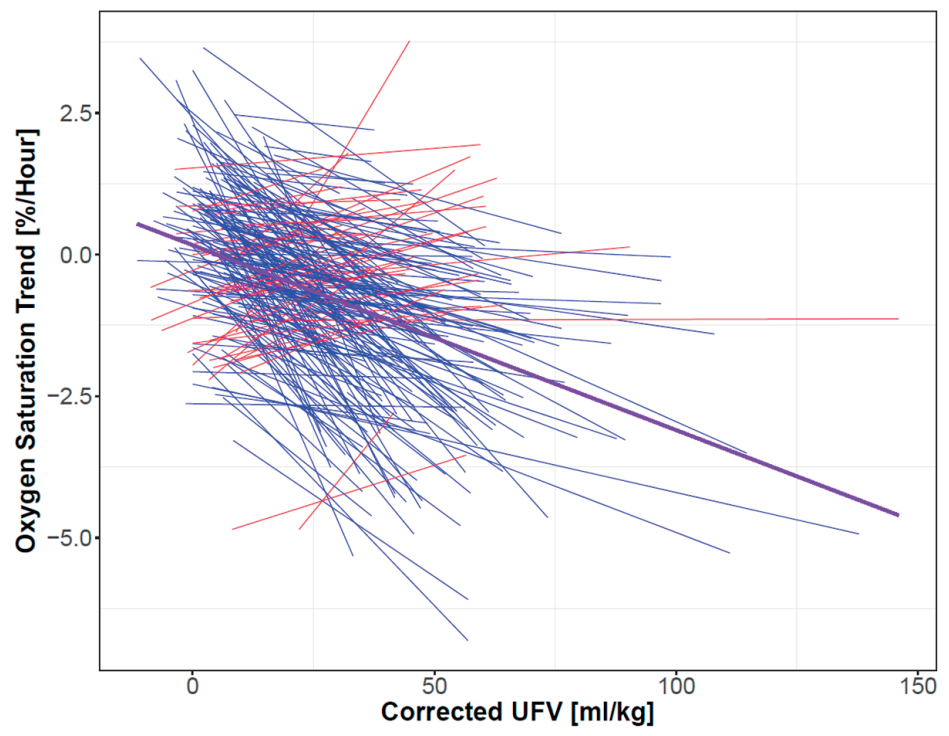

Figure 5.5 Linear Mixed Model of central venous oxygen saturation and corrected ultrafiltration. Each line represents an individual patient, blue lines indicate patients with a negative relationship, and red lines show patients with a positive relationship. The purple line is population fixed effect slope derived from the linear mixed model.

\section{Discussion}

This is the to-date largest study exploring the relationship between $\mathrm{ScvO}_{2}$ and cUFV in chronic HD patients. The main finding of this research in a diverse population of chronic hemodialysis patients is an inverse relationship between intradialytic $\mathrm{ScvO}_{2}$ change and CUFV, meaning that most patients at high cUFV experience a more pronounced intradialytic $\mathrm{ScvO}_{2}$ decline.

We hypothesize that this finding is driven by a decline in cardiac preload when UFR exceeds plasma refill rate. This preload reduction may result in a drop in stroke volume, cardiac output, and decreased tissue perfusion such as decreased cardiac microcirculation leading to an increase in stunned myocardial segments.

In the absence of measurements of cardiac output and upper body blood flow (UBBF), our hypothesis is based on the following rationale. The CVC tip typically resides at either the superior vena cava or the right atrium ${ }^{10}$. Therefore the oxygen saturation in the venous blood flowing in a CVC resembles $\mathrm{ScvO}_{2}$. The physiological determinants of $\mathrm{ScvO}_{2}$ can be appreciated by rearranging Fick's equation. While the original Fick's equation was used to calculate cardiac output based on measurements of mixed venous oxygen saturation $\left(\mathrm{SmvO}_{2}\right)$ in the pulmonary artery, the equation also holds 
true for local territories of the circulation where the oxygen saturation of the outflowing venous blood is known. Compared to the "classical" Fick's equation, in our case $\mathrm{SmvO}_{2}$ has been replaced with $\mathrm{ScvO}_{2}$, and cardiac output with UBBF.

The rearranged equation is:

$$
\mathrm{ScvO}_{2}=\mathrm{SaO}_{2}-\frac{100 * \text { Upper body oxygen consumption }}{\mathrm{K} * \mathrm{Hgb} * \mathrm{UBBF}}
$$

It becomes clear from that rearranged Fick equation that a decrease in $\mathrm{ScvO}_{2}$ can be due to (1) a decrease in arterial oxygen saturation $\left(\mathrm{SaO}_{2}\right),(2)$ an increase in upper body oxygen consumption, (3) a decrease in hemoglobin ( $\mathrm{Hgb}$ ) level, and (4) a decrease in UBBF. $\mathrm{K}$ is a constant that describes the amount of oxygen carried by $\mathrm{Hgb}$. Recent studies in $\mathrm{HD}$ patients reported a biphasic intradialytic $\mathrm{SaO}_{2}$ dynamic, where an initial $\mathrm{SaO}_{2}$ drop is followed by a rise, so that $\mathrm{SaO}_{2}$ returns to above starting levels by the end of dialysis ${ }^{11,12}$. Therefore, changes in intradialytic $\mathrm{SaO}_{2}$ are unlikely to explain the intradialytic $\mathrm{ScvO}_{2}$ decrease. At rest, the brain is by far the largest consumer of oxygen in the upper body. Brain oxygen consumption appears to be stable, except in extreme situations such as general anesthesia or stroke; therefore it is reasonable to assume that brain oxygen consumption does not change materially during $\mathrm{HD}^{13,14}$. Because of ultrafiltration $\mathrm{Hgb}$ levels generally rise during $\mathrm{HD}$, making $\mathrm{Hgb}$ an unlikely candidate to explain the $\mathrm{ScvO}_{2}$ drop observed in the majority of HD patients.

This leaves us with a decline in UBBF as the most plausible explanation for the $\mathrm{ScvO}_{2}$ drop. In situations where UFR outpaces plasma refill rate from the interstitial to intravascular space, right ventricular preload and stroke volume will drop and - if not compensated for by a sufficient increase in heart rate - a decline in cardiac output will ensue. A decline in cardiac output has recently been shown in an elaborate study utilizing cardiac magnet resonance imaging (MRI) during dialysis. ${ }^{15}$ In this study stroke volume and cardiac index declined during dialysis, and the degree of decline was inversely and significantly corrected with UFV. Importantly, in this study the number of stunned myocardial segments was positively correlated with UFV. In another study that compared cardiac parameters during conventional and extended HD found that in extended HD, UFR was lower and UFV was not significantly different, there was less pronounced decrease in cardiac output compared to conventional HD. ${ }^{16}$ Therefore, not only is the absolute change in UBBF important, but also the rate of the change likely plays a role.

As depicted in Figures 5.3 to 5.5, $\mathrm{ScVO}_{2} / \mathrm{cUFV}$ associations differ widely between individual patients. Additionally, there is large variation in cUFV across treatments per patient. This variation may be due to timing of treatment (after a short or long interdialytic interval), early termination or extra HD treatments, and changes in residual renal function during the study period. On a population level the fixed effect derived 
from the linear mixed model indicates that $\mathrm{ScVO}_{2}$ decreases once cUFV exceeds 5 $\mathrm{mL} / \mathrm{kg}$ body weight (Figure 5.5). This cUFV translates into an UFV of $400 \mathrm{~mL}$ in an $80 \mathrm{~kg}$ patient. This is in line with the aforementioned MRI study by Buchanan et al., where stroke volume and cardiac index fell at even smaller UFV.

Of note, a minority of patients showed a positive $\mathrm{ScvO}_{2}$ trend with higher cUFV. We hypothesize that those patients may actually be well above their dry weight while being prescribed a too low UFV. In the presence of excess fluid in the interstitial compartment and thus elevated interstitial hydrostatic pressures, the plasma refill rate can keep up with UFR and hence prevents a decline in cardiac preload and cardiac output. $^{17,18}$ It is important to appreciate that fluid overload and interdialytic weight gain (the main determinant of UFV) are not necessarily correlated. ${ }^{19}$ While these population-level results are important, we of course consider the inter-individual variability in the $\mathrm{ScvO}_{2}$ /cUFV relationship (Figure 5.5). To what extent a patient's $\mathrm{ScVO}_{2} / \mathrm{cUFV}$ relationship is associated with outcomes warrants further studies.

Our study expands the results of Harrison et al. ${ }^{9}$ In their study of 18 prevalent HD patients the authors measured $\mathrm{ScvO}_{2}$ at the end of $\mathrm{HD}$ and found that higher CUFV was associated with low $\mathrm{ScvO}_{2}$. However, only examining end-dialysis $\mathrm{ScvO}_{2}$ levels precludes an assessment of intradialytic $\mathrm{ScvO}_{2}$ dynamics. Therefore, we chose to expand that research and determined the association between $\mathrm{ScvO}_{2}$ trend throughout the entire dialysis and cUFV. Based on their findings, Harrison et al. hypothesized that $\mathrm{ScvO}_{2}$ may serve as a marker of circulatory stress induced by ultrafiltration. Our findings in a 12 times larger patient population with multiple treatments per patient support that notion. As a next step it will be important to directly test this hypothesis by comprehensive hemodynamic studies during dialysis.

In our study cohort only very limited data regarding blood recirculation is available. Depending on catheter type and tip location, recirculation has been estimated between $0-23 \%{ }^{20}$. The effect of blood recirculation on $\mathrm{ScvO}_{2}$ is currently unclear. However, we expect this to be limited, given the poor solubility of oxygen in plasma and the resultant minimal oxygen transfer across the dialyzer membrane ${ }^{21}$.

Our study suggests that $\mathrm{ScvO}_{2}$ could evolve into a novel marker to monitor hemodynamic response to $\mathrm{HD}$. In addition, it is conceivable that $\mathrm{ScvO}_{2}$ could serve as input into a system that controls the UFR. A recent study also supports the role of oxygen monitoring during $\mathrm{HD}$ as the researchers found that variability of $\mathrm{SaO}_{2}$ to be associated with IDH in both patients with arteriovenous fistula and $\mathrm{CVCs}^{22}$. Such a control system could prevent undue $\mathrm{ScvO}_{2}$ drops by appropriate UFR adjustments; this could benefit in particular those with frequent episodes of intradialytic hypotension and incident HD patients, who have both a high morbidity and mortality and frequently use CVC as vascular access ${ }^{1,23}$.

Admittedly, our study has a few limitations. First, as it is retrospective in nature, thus we are unable to determine causality. Additionally, no technical means (e.g. bioimpedance) to quantitate patients' fluid status are routinely available in U.S. dialysis 
facilities. Knowledge of the fluid status would have allowed us to further explore the association between the patient $\mathrm{ScvO}_{2}$ and cUFV, since this relationship may be influenced by the vascular refilling dynamics, and, consequently, by fluid status and "dry" weight. We do not have echocardiograms on these patients, so the relationship between $\mathrm{ScvO}_{2} /$ cUFV and cardiac output remains conjectural. Also we do not have the availability of arterial oxygen saturation in these patients, since pulse oximetry is not done as part of standard of care in our dialysis facilities. While intradialytic blood pressures were not routinely captured in our EHR database, we do have pre and post SBP. Our analysis shows that these SBPs were neither clinically nor statistically different between the two groups (Table 5.1). Lastly, the exact positions of the CVC tips are unknown to us, since our electronic health records do not report the related chest $X$-ray findings. Strengths are the diversity and large number of patients studied the availability of multiple HD sessions per patients, and automatic and frequent intradialytic $\mathrm{ScvO}_{2}$ measurements.

In conclusion, cUFV and intradialytic $\mathrm{ScvO}_{2}$ dynamics are inversely correlated, so that high cUFV is associated with a $\mathrm{ScvO}_{2}$ decrease in the majority of our HD patients. We hypothesize that a decline in $\mathrm{ScvO}_{2}$ reflects a reduction in cardiac output. Future studies with direct hemodynamic measurements are warranted to further elucidate the relation between $\mathrm{ScvO}_{2}$ dynamics and circulatory stress on dialysis, and their relation with outcome. 


\section{References}

1. United States Renal Data System. 2015 USRDS annual data report: Epidemiology of kidney disease in the United States. Bethesda, MD: National Institutes of Health, National Institute of Diabetes and Digestive and Kidney Diseases;2015.

2. Foley RN, Parfrey PS. Risk factors for cardiac morbidity and mortality in dialysis patients. Curr Opin Nephrol Hypertens. 1994;3(6):608-614.

3. McIntyre CW, Burton JO, Selby NM, et al. Hemodialysis-induced cardiac dysfunction is associated with an acute reduction in global and segmental myocardial blood flow. Clin J Am Soc Nephrol. 2008;3(1):19-26.

4. Burton JO, Jefferies HJ, Selby NM, Mclntyre CW. Hemodialysis-induced cardiac injury: determinants and associated outcomes. Clin J Am Soc Nephrol. 2009;4(5):914-920.

5. Assa S, Hummel YM, Voors AA, et al. Hemodialysis-induced regional left ventricular systolic dysfunction: prevalence, patient and dialysis treatment-related factors, and prognostic significance. Clin J Am Soc Nephrol. Oct 2012;7(10):1615-1623.

6. Flythe JE, Xue H, Lynch KE, Curhan GC, Brunelli SM. Association of mortality risk with various definitions of intradialytic hypotension. J Am Soc Nephrol. 2015;26(3):724-734.

7. Yazigi A, Abou-Zeid H, Madi-Jebara S, Haddad F, Hayek G, Jabbour K. Correlation between central venous oxygen saturation and oxygen delivery changes following fluid therapy. Acta Anaesthesiol Scand. 2008;52(9):1213-1217.

8. Perner A, Haase N, Wiis J, White JO, Delaney A. Central venous oxygen saturation for the diagnosis of low cardiac output in septic shock patients. Acta Anaesthesiol Scand. 2010;54(1):98-102.

9. Harrison LE, Selby NM, McIntyre CW. Central venous oxygen saturation: a potential new marker for circulatory stress in haemodialysis patients? Nephron. Clin Pract. 2014;128(1-2):57-60.

10. Work J. Chronic catheter placement. Semin Dial. 2001;14(6):436-440.

11. Meyring-Wosten A, Zhang H, Ye X, et al. Intradialytic Hypoxemia and Clinical Outcomes in Patients on Hemodialysis. Clin J Am Soc Nephrol. 2016;11(4):616-625.

12. Campos I, Chan L, Zhang H, et al. Intradialytic Hypoxemia in Chronic Hemodialysis Patients. Blood Purif. 2016;41(1-3):177-187.

13. Masamoto K, Tanishita K. Oxygen transport in brain tissue. J Biomech Eng. 2009;131(7):074002.

14. Verweij BH, Amelink GJ, Muizelaar JP. Current concepts of cerebral oxygen transport and energy metabolism after severe traumatic brain injury. Prog Brain Res. 2007;161:111-124.

15. Buchanan C, Mohammed A, Cox E, et al. Intradialytic Cardiac Magnetic Resonance Imaging to Assess Cardiovascular Responses in a Short-Term Trial of Hemodiafiltration and Hemodialysis. J Am Soc Nephrol. 2017;28(4):1269-1277.

16. Cornelis $\mathrm{T}$, van der Sande FM, Eloot $\mathrm{S}$, et al. Acute hemodynamic response and uremic toxin removal in conventional and extended hemodialysis and hemodiafiltration: a randomized crossover study. Am J Kidney Dis. 2014;64(2):247-256.

17. Ebah LM, Wiig H, Dawidowska I, et al. Subcutaneous interstitial pressure and volume characteristics in renal impairment associated with edema. Kidney Int. 2013;84(5):980-988.

18. de los Reyes VA, Fuertinger DH, Kappel F, Meyring-Wosten A, Thijssen S, Kotanko P. A physiologically based model of vascular refilling during ultrafiltration in hemodialysis. J Theor Biol. 2016;390:146-155.

19. Hecking $M$, Karaboyas $A$, Antlanger $M$, et al. Significance of interdialytic weight gain versus chronic volume overload: consensus opinion. Am J Nephrol. 2013;38(1):78-90.

20. Tal MG. Comparison of recirculation percentage of the palindrome catheter and standard hemodialysis catheters in a swine model. J Vasc Interv Radiol. 2005;16(9):1237-1240.

21. Sombolos $\mathrm{KI}$, Bamichas $\mathrm{Gl}$, Christidou FN, et al. pO2 and pCO2 increment in post-dialyzer blood: the role of dialysate. Artif Organs. 2005;29(11):892-898.

22. Mancini E, Perazzini C, Gesualdo L, et al. Intra-dialytic blood oxygen saturation (SO2): association with dialysis hypotension (the SOGLIA Study). J Nephrol. 2017;30(6):811-819 
23. Bradbury BD, Fissell RB, Albert JM, et al. Predictors of early mortality among incident US hemodialysis patients in the Dialysis Outcomes and Practice Patterns Study (DOPPS). Clin I Am Soc Nephrol. 2007;2(1):89-99. 


\section{Supplemental material}

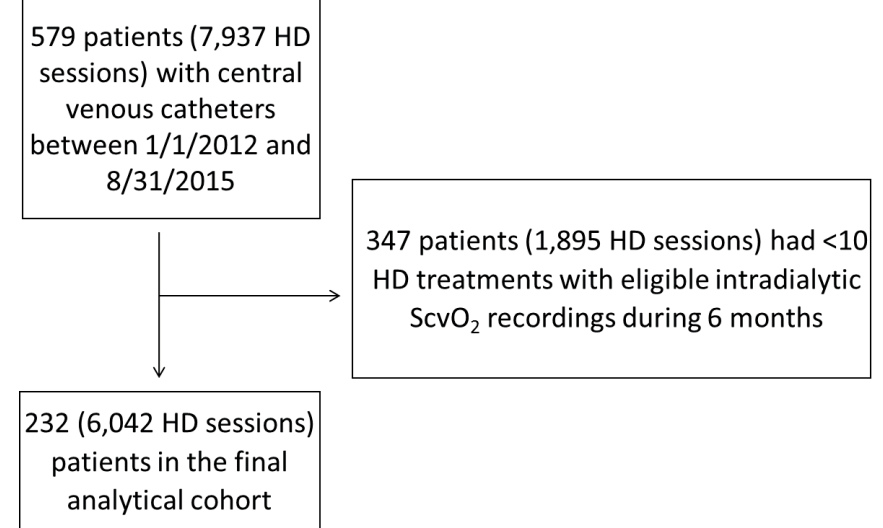

Figure S5.1 Study flow diagram.

Without sudden RBV increases

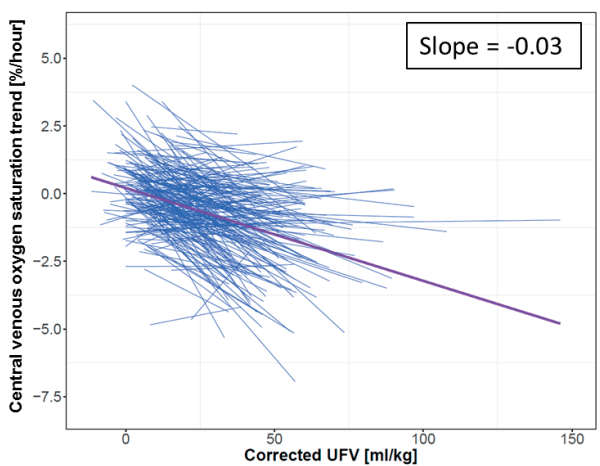

With sudden RBV increases

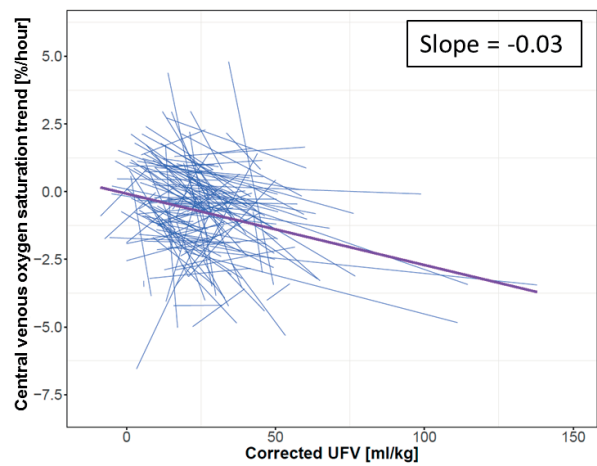

Figure S5.2 Linear Mixed Model of central venous oxygen saturation and corrected ultrafiltration A) without sudden relative blood volume increase and B) with sudden relative blood volume increase. Each blue line represents an individual patient, while the purple line is population fixed effect slope derived from the linear mixed model. 


\section{Chapter}

All-cause mortality in relation to changes in relative blood volume during hemodialysis

Preciado $\mathrm{P}^{*}$, Zhang $\mathrm{H}^{*}$, Thijssen S, Kooman JP, van der Sande FM, Kotanko P Nephrol Dial Transplant. 2018 


\section{Abstract}

\section{Background}

Relative blood volume (RBV) monitoring is widely used in hemodialysis patients, yet the association between intradialytic RBV and mortality is unknown.

\section{Methods}

Intradialytic RBV was recorded 1x/minute during a 6-month baseline period; all-cause mortality was noted during follow-up. RBV at 1, 2, and 3 hours into hemodialysis served as predictor of all-cause mortality during follow-up. We employed Kaplan-Meier analysis, univariate and adjusted Cox proportional hazards models for survival analysis.

\section{Results}

We studied 842 patients. During follow-up (median 30.8 months) 249 patients (29.6\%) died. The following hourly RBV ranges were associated with improved survival: first hour, 93-96\% (hazard ratio [HR] 0.58; 95\% confidence interval [Cl] 0.42-0.79); second hour, 89-94\% (HR 0.54; 95\% Cl 0.39-0.75); third hour, 86-92\% (HR 0.46; 95\% Cl 0.330.65). In about one third of patients the RBV was within these ranges and in two-thirds above. Subgroup analysis by median age ( $\leq />61$ years), sex, race (white/non-white), pre-dialysis systolic blood pressure (SBP; $\leq />130 \mathrm{mmHg})$, and interdialytic weight gain $(\leq />2.3 \mathrm{~kg})$ showed comparable favorable RBV ranges. Patients with a 3-hour RBV between $86-92 \%$ were younger, had higher ultrafiltration volumes and rates, similar intradialytic average and nadir SBP, and hypotension rates, lower post-dialysis SBP, and a lower prevalence of congestive heart failure when compared to patients with an RBV above 92\%. In the multivariate Cox analysis RBV ranges remained independent significant outcome predictors.

\section{Conclusion}

Specific hourly intradialytic RBV ranges are associated with lower all-cause mortality in chronic hemodialysis patients. 


\section{Introduction}

In hemodialysis patients adequate volume control is one of the major challenges. Between consecutive treatments, interdialytic weight gain (IDWG) results primarily in expansion of the extracellular volume $(E C V)^{1}$. Excessive and chronic ECV expansion is associated with cardiovascular morbidity, such as hypertension, left ventricular hypertrophy, pulmonary congestion, inflammation, and increased mortality ${ }^{2-5}$. In most hemodialysis sessions, the ultrafiltration rate (UFR) exceeds the refill rate of fluid from the interstitium into the vascular space, resulting in a decline in blood volume, potentially precipitating intradialytic hypotension (IDH) and decreased perfusion of vital organs ${ }^{6-9}$.

Intradialytic monitoring of relative blood volume (RBV) has been introduced with the expectation that it may prevent IDH by allowing the staff or the dialysis machine to maintain the RBV above a patient-specific critical level ${ }^{10-13}$. Since some of the technologies derive RBV changes from measured hematocrit changes, the term "crashcrit" has been coined. It was hoped that there would be a patient-specific critical RBV that could be identified, below which IDH would be more likely to occur. Unfortunately, no firm evidence for the existence of a reproducible patient-specific crash-crit (or, conversely, RBV threshold) has been established. Andrulli et al. ${ }^{14}$ were not able to identify critical RBV levels for the development of symptomatic hypotension, neither in hypotensive, normotensive, nor hypertensive patients, showing the variability of RBV across patients and also across treatments. The randomized controlled Crit-Line Intradialytic Monitoring Benefit (CLIMB) Study ${ }^{15}$ tested the hypothesis that the availability of hematocrit-based intradialytic RBV monitoring with the Crit-Line monitor (CLM) as a voluntary adjunct to clinical care would decrease morbidity associated with ultrafiltration in comparison with patients managed using conventional clinical care. The primary outcome was hospitalization and the study team developed an intricate monitoring and intervention protocol that called for specific steps when certain predefined clinical and RBV threshold criteria were met. The study failed to yield positive results; in fact, the use of RBV monitoring was associated with increased morbidity and mortality.

Several manufacturers offer devices that allow for a continuous measurement of RBV during hemodialysis and therefore RBV monitoring is frequently used to assist volume management during dialysis. However, there is a paucity of data that associate attained intradialytic RBV levels with outcomes, resulting in primarily empirical use of RBV monitoring. The goal of our research was to fill this knowledge gap by exploring the association between attained intradialytic RBV levels and all-cause mortality in a large and diverse hemodialysis population. 


\section{Materials and methods}

\section{Population and study design}

This multi-center observational retrospective study was conducted in maintenance hemodialysis patients from 17 facilities of the Renal Research Institute (RRI) across the United States between January 2012 and December 2016. The CLM was deployed to the RRI dialysis clinics on a rolling basis and is standard of care. A 6-month baseline period and an up to 54-month follow-up period were defined on a patient-level (Supplemental Figure S6.1). We used the first treatment with eligible CLM data as start date of the baseline period. All patients who had at least 10 eligible CLM recordings during the baseline period were included in the study. A treatment time of less than 200 minutes was the only exclusion criterion. Patient characteristics were assessed during baseline. All-cause mortality was recorded during follow-up. The New England Institutional Review Board (\#14-446) waived the need for informed consent.

\section{Relative blood volume calculation}

The RBV (expressed in \% of the blood volume at the start of dialysis) at time $t$ is calculated as follows:

RBV (\%) at time $t=100 \times \mathrm{HCT}_{0} / \mathrm{HCT}_{\mathrm{t}}$

$\mathrm{HCT}_{0}$ and $\mathrm{HCT}_{\mathrm{t}}$ are the hematocrits at the start and at a given time $t$ during hemodialysis, respectively. Hematocrit was measured quasi-continuously using the CLM (Fresenius Medical Care North America, Waltham, MA, USA). The CLM reports the RBV $1 x / m i n$. The RBV data were electronically transferred to an RRI data repository and the study database. Patients' RBVs were calculated per treatment and then averaged across all treatments per patient and subsequently across patients. We used RBV at 1 , 2 , and 3 hours into the hemodialysis session as outcome predictors. To that end we averaged the RBV data between minutes 50 and 70, 110 and 130, and 170 and 190, respectively.

\section{Blood pressure measurement}

In RRI clinics blood pressure is automatically measured every 30 minutes oscillometrically. We calculated average pre-dialysis, post-dialysis, and intradialytic systolic blood pressure (SBP) and report nadir SBP and IDH rate; IDH was defined as intradialytic SBP $<90 \mathrm{mmHg}^{16}$. Intradialytic SBP during baseline was available in 10,181 treatments in 219 patients. 


\section{Laboratory data}

Laboratory measurements (Spectra Laboratories, New Jersey, NJ, USA) were downloaded to the RRI data warehouse and extracted to the study database.

\section{Comorbidities}

Congestive heart failure (CHF), diabetes mellitus (DM), and chronic obstructive pulmonary disease (COPD) were documented using ICD-9 codes in the patients' electronic health records.

\section{Statistical analysis}

Descriptive statistics comprised means ( \pm standard deviation; SD) for continuous variables and percentages for categorical variables.

To explore the association between all-cause mortality and RBV at 1, 2, and 3 hours, we built Cox proportional hazards models with spline terms, allowing us to model nonlinear effects of RBV as a continuous variable and its relationship with all-cause mortality at these three hourly time points. This spline analysis allowed us to identify hourly RBV ranges associated with hazard ratios (HR) significantly below ("favorable") or above ("unfavorable") 1.0, respectively.

For additional analysis we stratified patients into 2 groups depending on them being within the "favorable" 3-hours RBV range or not. Survival characteristics were compared using Kaplan-Meier plots, log-rank tests, and Cox proportional hazards models. Minimally and fully adjusted Cox models complemented the crude survival analysis. The minimally adjusted model included age, sex, CHF, and COPD, respectively. In addition, the fully adjusted model included serum albumin and hemoglobin, the neutrophil-to-lymphocyte ratio (NLR; an inflammatory marker [17]), UFR, pre-dialysis SBP, diabetes, and race. Patients were censored in the event of kidney transplantation, transfer to a non-RRI facility, dialysis treatment modality change, or end of follow-up.

We report also baseline descriptive statistics, group differences and 95\% confidence intervals in patients within or outside the "favorable" 3-hours RBV range, respectively.

To further explore these findings and to account for possible bias considering only 3 hours and not the full treatment time, we examined the association between all-cause mortality and RBV by relative elapsed treatment time, with total treatment time defined as $100 \%$. We used $25 \%, 50 \%, 75 \%$ and $100 \%$ of treatment time elapsed by averaging the RBV between 21 to $30 \%, 46$ to $55 \%, 71$ to $80 \%$ and 91 to $100 \%$ of the total treatment time, respectively.

Additionally, we also examined the association between RBV slope and all-cause mortality. RBV slope was computed using simple linear regression with an intercept at 100\% RBV (per definition the initial RBV). 
We also conducted a sensitivity analysis excluding patients with RBVs below the favorable hourly RBV ranges.

Statistical analyses were performed using SAS version 9.4 (SAS Institute, Cary, NC) and R i386 3.0.2 (library: ggplot2, splines, survival) (R Foundation for Statistical Computing, Vienna, Austria).

\section{Results}

\section{Patient baseline characteristics}

We studied 842 patients with a total of 28,119 dialysis sessions with eligible RBV recordings during a 6-months baseline, resulting in $33.4 \pm 13.8$ eligible sessions per patient (Table 6.1). Age was $61.0 \pm 14.8$ years, dialysis vintage was $3.9 \pm 4.1$ years, $50.6 \%$ were white, $62 \%$ males, $55.8 \%$ had diabetes, $24 \% \mathrm{CHF}$, and $9.4 \%$ COPD. Intradialytic RBVs were $97.9 \pm 1.9 \%, 94.8 \pm 2.6 \%$ and $93.1 \pm 3.3 \%$ after 1,2 , and 3 hours, respectively.

\section{Intradialytic RBV and all-cause mortality}

During the median follow-up of 30.8 months, 249 patients (29.6\%) died. HRs for allcause mortality were significantly $<1.0$ in patients with 1-hour RBV 93-96\%, 2-hour RBV 89-94\%, and 3-hour RBV 86-92\%. Approximately 65\% of the patients attained RBVs above, 32\% within, and around $2.5 \%$ below these RBV ranges (Table 6.2). RBV ranges associated with HRs significantly $>1.0$ were $97-100 \%$ (1-hour), 95-99\% (2-hours), and 93-99\% (3-hours) (Figure 6.1; Figure 6.2). Multivariate Cox analysis corroborated the lower HRs for all-cause mortality in those patients whose RBV fell inside these RBV ranges (Table 6.3). Analysis by percent of elapsed treatment time instead of by hours showed materially identical results (Supplemental Figure S6.2). Subgroup analyses by median age ( $\leq />61$ years), race (white, non-white), sex, pre-dialytic SBP $(\leq 130 />130$ $\mathrm{mmHg})$, and IDWG $(\leq />2.3 \mathrm{~kg}$ ) showed comparable favorable RBV ranges (Table 6.4). Kaplan-Meier analysis and Cox proportional hazards models indicated a significantly better survival in patients with 3-hours RBVs inside 86-92\% compared to those patients outside (Figures 6.3 and 6.4).

Analysis on the RBV slope and all-cause mortality showed significantly increased HR with a slope between -2.47 to $-0.34 \% / \mathrm{hr}$, and significantly reduced HR with slope from -5.18 to $-3.04 \% /$ hr (Figure 6.5 ). 
Table 6.1 Baseline characteristics of all patients and after stratification into two groups based on the attained relative blood volume (RBV) 3 hours into the hemodialysis treatment.

\begin{tabular}{|c|c|c|c|c|}
\hline Variable & All patients & $\begin{array}{c}\text { RBV outside } \\
86-92 \% \text { at } 3 \\
\text { hours into } \\
\text { dialysis }\end{array}$ & $\begin{array}{l}\text { RBV inside } 86- \\
92 \% \text { at } 3 \text { hours } \\
\text { into dialysis }\end{array}$ & $\begin{array}{l}\text { Group Difference } \\
\text { Mean }(95 \% \mathrm{Cl})\end{array}$ \\
\hline Number of patients & 842 & 569 & 273 & n.a. \\
\hline $\begin{array}{l}\text { Number of eligible hemodialysis } \\
\text { treatments during baseline [per } \\
\text { patient] }\end{array}$ & $33.4 \pm 13.8$ & $33.7 \pm 13.4$ & $32.7 \pm 14.5$ & $-1.0(-3.0$ to 1.0$)$ \\
\hline Age [years] & $61.0 \pm 14.8$ & $63.6 \pm 14.1$ & $55.7 \pm 14.9$ & $-7.9(-9.9$ to -5.8$)$ \\
\hline White race [\%] & 50.6 & 51.5 & 48.7 & $-2.8(-4.5$ to 9.9$)$ \\
\hline Males [\%] & 62.1 & 63.8 & 58.6 & $-5.2(-2.0$ to 12.4$)$ \\
\hline Hemodialysis vintage [years] & $3.9 \pm 4.1$ & $3.9 \pm 4.1$ & $3.7 \pm 4.2$ & $-0.2(-0.8$ to 0.4$)$ \\
\hline $\mathrm{BMI}\left[\mathrm{kg} / \mathrm{m}^{2}\right]$ & $29.8 \pm 8.2$ & $29.8 \pm 8.6$ & $29.9 \pm 7.6$ & $0.12(-1.0$ to 1.3$)$ \\
\hline Diabetes mellitus [\%] & 55.8 & 57.1 & 53.1 & $-4.0(-3.1$ to 11.3$)$ \\
\hline $\mathrm{CHF}[\%]$ & 24.0 & 26.2 & 19.4 & $-6.8(0.7$ to 12.5$)$ \\
\hline COPD [\%] & 9.4 & 8.3 & 11.7 & $3.4(-0.07$ to 0.00$)$ \\
\hline Pre-dialysis SBP [mmHg] & $146.3 \pm 20.1$ & 146. $5 \pm 20.4$ & $145.7 \pm 19.6$ & $-0.7(-3.7$ to 2.1$)$ \\
\hline Post-dialysis SBP [mmHg] & $136.6 \pm 18.5$ & $137.8 \pm 19.1$ & $134.2 \pm 16.8$ & $-3.6(-6.1$ to -1.0$)$ \\
\hline Intradialytic SBP [mmHg] ${ }^{\mathrm{a}}$ & $134.9 \pm 19.3$ & $135.2 \pm 21.6$ & $134.4 \pm 14.6$ & $-0.8(-6.2$ to 4.6$)$ \\
\hline Nadir intradialytic SBP [mmHg] & $115.2 \pm 18.1$ & $116.1 \pm 20.2$ & $113.9 \pm 14.1$ & $-2.2(-7.3$ to 2.9$)$ \\
\hline Treatments with IDH [\%] & 13.6 & 14.7 & 12.6 & $-2.1(-8.2$ to 4.1$)$ \\
\hline IDWG [kg] & $2.4 \pm 0.8$ & $2.2 \pm 0.8$ & $2.7 \pm 0.8$ & $0.5(0.4$ to 0.6$)$ \\
\hline $\begin{array}{l}\text { IDWG relative to post-dialysis } \\
\text { weight [\%] }\end{array}$ & $2.9 \pm 1.0$ & $2.7 \pm 0.9$ & $3.3 \pm 0.9$ & 0.6 (0.5 to 0.7$)$ \\
\hline UFV [I] & $2.4 \pm 0.8$ & $2.2 \pm 0.8$ & $2.7 \pm 0.8$ & 0.5 (0.4 to 0.6$)$ \\
\hline UFR $[\mathrm{ml} / \mathrm{kg} / \mathrm{hr}]$ & $7.7 \pm 2.7$ & $7.1 \pm 2.5$ & $8.8 \pm 2.7$ & 1.7 (1.4 to 2.1$)$ \\
\hline Post-dialysis weight $[\mathrm{kg}]$ & $85.7 \pm 23.5$ & $85.7 \pm 23.7$ & $85.7 \pm 23.1$ & $0.0(-3.4$ to 3.4$)$ \\
\hline Treatment time [min] & $227.5 \pm 18.0$ & $228.6 \pm 18.1$ & $225.1 \pm 17.4$ & $-3.4(-6.0$ to -0.8$)$ \\
\hline Equilibrated Kt/Nurea & $1.5 \pm 0.2$ & $1.5 \pm 0.3$ & $1.5 \pm 0.2$ & $0.03(-0.00$ to 0.07$)$ \\
\hline $\mathrm{Hgb}[\mathrm{g} / \mathrm{dl}]$ & $10.9 \pm 0.9$ & $10.9 \pm 1.0$ & $11.0 \pm 0.9$ & 0.1 (0.00 to 0.28$)$ \\
\hline Serum albumin [g/dl] & $3.9 \pm 0.4$ & $3.9 \pm 0.4$ & $4.0 \pm 0.3$ & $0.07(0.02$ to 0.13$)$ \\
\hline Serum sodium [mmol/l] & $138.8 \pm 2.6$ & $139.0 \pm 2.5$ & $138.3 \pm 2.8$ & $-0.6(-1.0$ to -0.3$)$ \\
\hline Serum potassium [mmol/l] & $4.8 \pm 0.5$ & $4.7 \pm 0.5$ & $4.8 \pm 0.6$ & 0.09 (0.02 to 0.17$)$ \\
\hline Intact PTH [pg/ml] & $552.8 \pm 498.8$ & $546.9 \pm 516.3$ & $565.3 \pm 460.3$ & $18.4(-51.2$ to 88.0$)$ \\
\hline Serum bicarbonate $[\mathrm{mmol} / \mathrm{l}]$ & $23.2 \pm 1.9$ & $23.4 \pm 1.9$ & $22.8 \pm 1.8$ & $-0.6(-0.8$ to -0.3$)$ \\
\hline 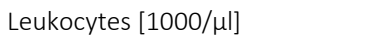 & $6.7 \pm 2.0$ & $6.6 \pm 2.0$ & $6.7 \pm 1.9$ & $0.1(-0.2$ to 0.4$)$ \\
\hline Platelets $[1000 / \mu \mathrm{l}]$ & $206.8 \pm 65.0$ & $203.4 \pm 67.7$ & $214.1 \pm 58.3$ & 10.7 (1.3 to 20.0$)$ \\
\hline NLR & $3.8 \pm 2.1$ & $4.0 \pm 2.3$ & $3.3 \pm 1.7$ & $-0.7(-0.9$ to -0.4$)$ \\
\hline Transferrin saturation [\%] & $33.0 \pm 5.1$ & $32.4 \pm 9.0$ & $34.1 \pm 8.5$ & $1.7(0.5$ to 3.0$)$ \\
\hline
\end{tabular}

Data are expressed as mean \pm SD, or percentage (\%). $95 \% \mathrm{Cl}, 95 \%$ confidence interval; SD, standard deviation; $\mathrm{BMI}$, body mass index; RBV, relative blood volume; $\mathrm{CHF}$, congestive heart failure; COPD, chronic obstructive pulmonary disease; SBP, systolic blood pressure; IDWG, interdialytic weight gain; UFV, ultrafiltration volume; UFR, ultrafiltration rate; Hgb, hemoglobin; PTH, parathyroid hormone; NLR, neutrophil-to-lymphocyte ratio; n.a., not applicable. ${ }^{a}$ Intradialytic SBP was available in 176 patients, 111 of them had RBVs outside the $86-92 \%$ range at 3 hours, and 66 patients were within. 

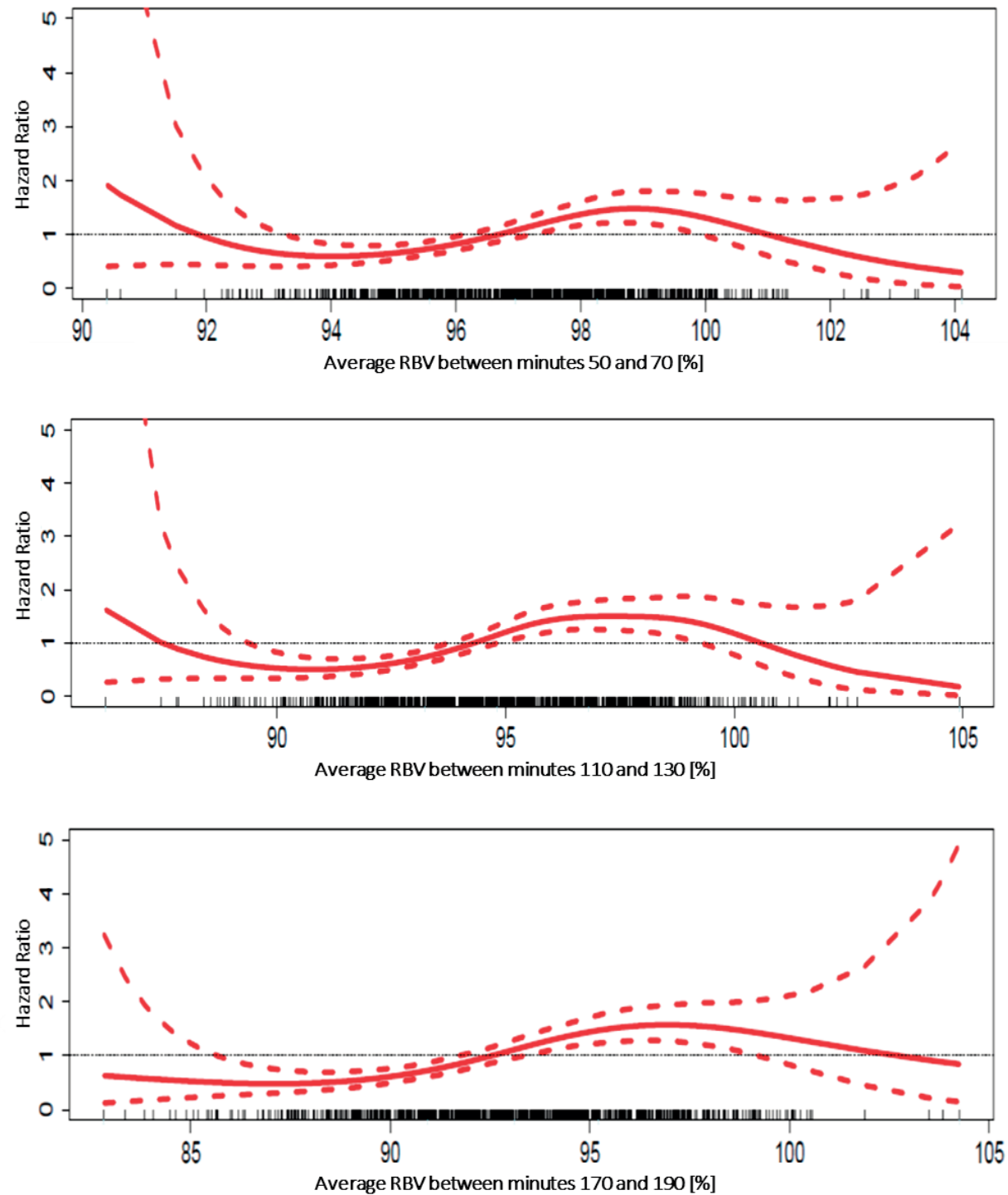

Figure 6.1 Association between intradialytic RBV and all-cause mortality. Hazard ratios and 95\% confidence limits of achieved RBV levels after 1 (top), 2 (middle), and 3 (bottom) hours, respectively. 


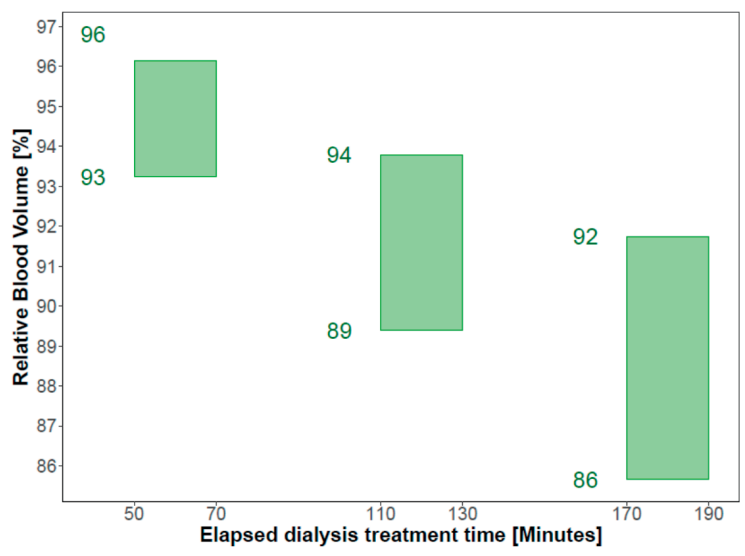

Figure 6.2 Intradialytic RBV ranges that are associated with hazard ratios significantly below 1.0 for allcause mortality.

Table 6.2 Distribution of patients relative to the RBV ranges by hours into the hemodialysis session.

\begin{tabular}{lccc}
\hline Favorable RBV range & 1 hour & 2 hours & 3 hours \\
& 93 to $96 \%$ & 89 to $94 \%$ & 86 to $92 \%$ \\
\hline & & Number (\%) of patients & $554(65.8)$ \\
Above & $550(65.3)$ & $551(65.4)$ & $273(32.5)$ \\
Within & $270(32.1)$ & $273(32.5)$ & $15(1.8)$ \\
Below & $22(2.6)$ & $18(2.1)$ & \\
\hline
\end{tabular}

RBV, relative blood volume

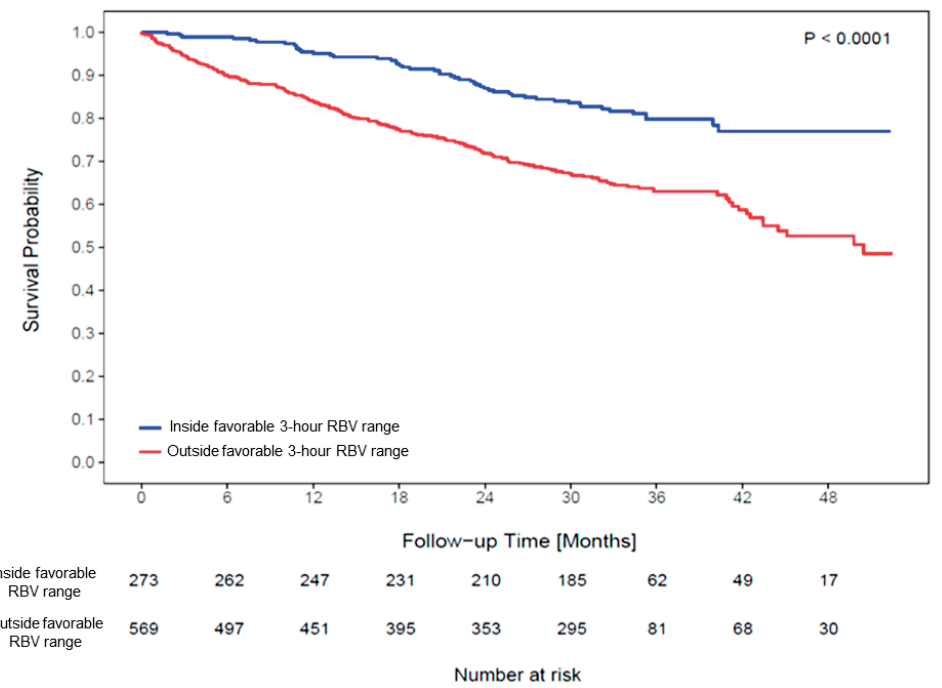

Figure 6.3 Kaplan-Meier analysis for survival probabilities for RBV achieved after 3 hours (86-92\%). 
Table 6.3 Crude and adjusted hazard ratios (HR) for all-cause mortality associated with attainment of favorable RBV ranges after 1, 2, and 3 hours, respectively.

\begin{tabular}{lcccccc}
\hline Time (Favorable & \multicolumn{2}{c}{ Crude model $^{\text {a }}$} & \multicolumn{2}{c}{ Minimally adjusted model $^{\mathrm{b}}$} & \multicolumn{2}{c}{ Fully adjusted model $^{c}$} \\
RBV Range) & HR $(95 \% \mathrm{Cl})$ & P-value & HR $(95 \% \mathrm{Cl})$ & P-value & HR $(95 \% \mathrm{Cl})$ & P-value \\
\hline First hour & 0.57 & 0.0002 & 0.64 & 0.003 & 0.58 & 0.0005 \\
$(93-96 \%)$ & $(0.43$ to 0.77$)$ & & $(0.48$ to 0.87$)$ & & $(0.42$ to 0.79$)$ & \\
Second hour & 0.52 & $<0.001$ & 0.63 & 0.002 & 0.54 & $<0.001$ \\
$(89-94 \%)$ & $(0.38$ to 0.69$)$ & & $(0.46$ to 0.85$)$ & & $(0.39$ to 0.75$)$ & \\
Third hour & 0.43 & $<0.001$ & 0.57 & 0.0006 & 0.46 & $<0.001$ \\
$(86-92 \%)$ & $(0.31$ to 0.58$)$ & & $(0.42$ to 0.79$)$ & & $(0.33$ to 0.65$)$ & \\
\hline
\end{tabular}

a Unadjusted model, ${ }^{b}$ Adjusted for age, sex, COPD, and $\mathrm{CHF},{ }^{c}$ Adjusted for age sex, race, COPD, CHF, diabetes, albumin, hemoglobin, NLR, pre-dialysis SBP, and UFR. Cl, confidence interval; COPD, chronic obstructive pulmonary disease; CHF, congestive heart failure; NLR, neutrophil-to-lymphocyte ratio; RBV, relative blood volume; SBP, systolic blood pressure; UFR, ultrafiltration rate

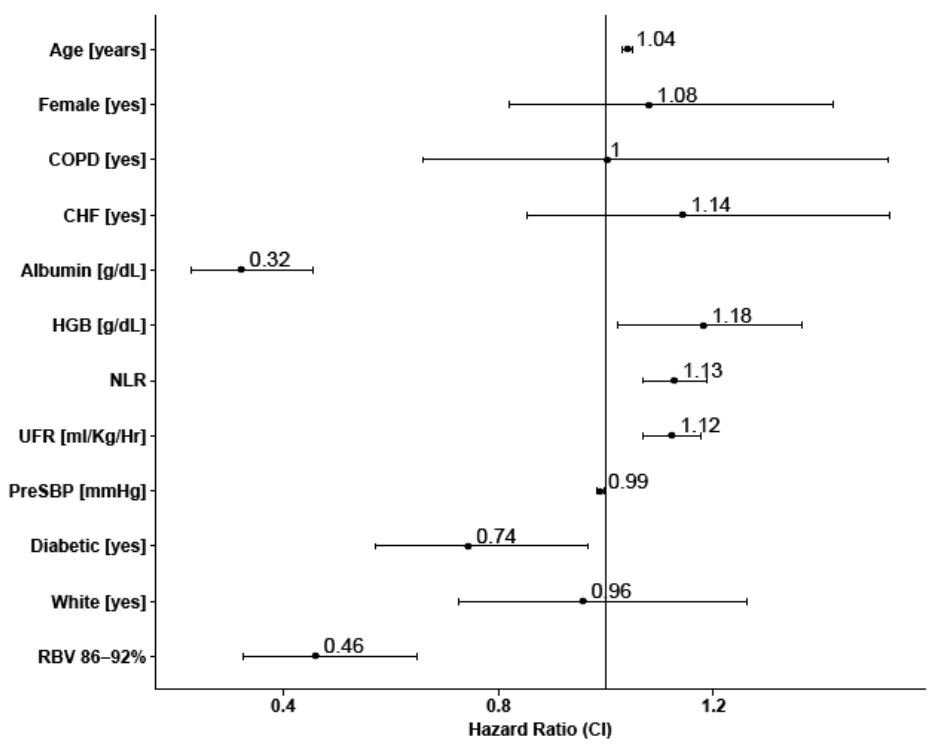

Figure 6.4 Forest Plots showing hazard ratios of baseline clinical characteristics and attainment of favorable RBV ranges after 3 hours. Cl: confidence interval; COPD: chronic obstructive pulmonary disease; CHF: congestive heart failure; NLR: neutrophil-to-lymphocyte ratio; RBV, relative blood volume; SBP: systolic blood pressure; UFR; ultrafiltration rate. 


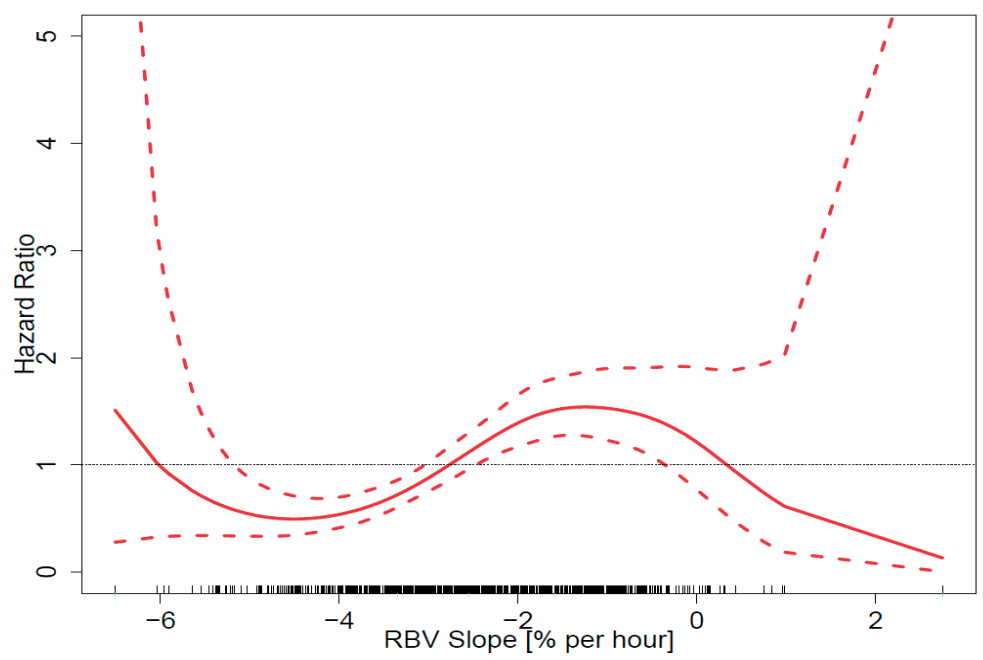

Figure 6.5 Association between intradialytic RBV slope and hazard ratios for all-cause mortality. The RBV slope is expressed in \% RBV per hour. Hazard ratios (solid line) and 95\% confidence limits (dashed lines) are shown. The tick marks at the $\mathrm{x}$-axis represent individual patients.

\section{Patient characteristics relative to RBV level 3 hours into the treatment}

We compared clinical, laboratory, and treatment variables between patients who did and did not attain the 3-hours RBV of $86-92 \%$ (Table 6.1). RBVs of 273 patients (32.5\%) were within this 3-hours RBV range, while 554 patients (65.8\%) had RBVs above $92 \%$ and 15 patients (1.8\%) below 86\%. Patients outside the 86-92\% 3-hour RBV range were older (64.0 \pm 13.9 vs. $55.7 \pm 14.9$ years, $P<0.001)$, had more frequently CHF ( $26 \%$ vs. $19 \%$, $P=0.03)$, lower IDWG ( $2.2 \pm 0.8$ vs. $2.8 \pm 0.8 \mathrm{~kg}, \mathrm{P}<0.001)$, normalized UFR $(7.0 \pm 2.4$ vs. $9.0 \pm 2.8 \mathrm{~mL} / \mathrm{kg} /$ hour, $\mathrm{P}<0.001$ ), equilibrated normalized protein catabolic rate (enPCR; $0.9 \pm 0.2$ vs. $1.0 \pm 0.2 \mathrm{~g} /$ day $/ \mathrm{kg}, P<0.001)$, albumin levels $(3.9 \pm 0.4$ vs.4.0 $\pm 0.3 \mathrm{~g} / \mathrm{dL}$; $\mathrm{P}=0.003)$, transferrin saturation $(32.4 \pm 9.0$ vs. $34.1 \pm 8.5 \% ; \mathrm{P}=0.007)$, and higher NLR (4.1 \pm 2.3 vs. $3.3 \pm 1.7, P<0.001)$.

\section{Association between RBV, SBP, and intradialytic hypotension}

Mean pre-dialysis SBP, post-dialysis, intradialytic, and nadir SBP were $146.3 \pm 20.1$, $136.6 \pm 18.5,135.3 \pm 19.0$ and $116.2 \pm 19.0 \mathrm{mmHg}$, respectively. Neither pre-dialysis nor SBP during dialysis differed between patients who did or did not attain a 3-hours RBV of 86 -92\%. Post-dialysis SBP was significantly higher in patients with RBV outside that range (Table 6.1, Figure 6.6).

To explore if peridialytic SBP behavior was associated with specific RBV levels, we stratified patients based on their peridialytic SBP change (post-HD SBP minus pre-HD 
SBP). We found that hourly RBV levels were comparable across all groups of peridialytic SBP change (Supplemental Table S6.1).

Table 6.4 RBV ranges are associated with HRs significantly below 1.0 for all-cause mortality in clinical subgroups.

\begin{tabular}{lccc}
\hline Subgroup & RBV [\%] & RBV [\%] & RBV [\%] \\
(N) & 1 hour & 2 hours & 3 hours \\
\hline All patients (842) & $93-96$ & $89-94$ & $86-92$ \\
Age [years] & & & \\
$\quad \leq 61(421)$ & $95-96$ & $90-93$ & $86-90$ \\
$\quad>61(421)$ & $93-96$ & $90-94$ & $88-92$ \\
Race & & & $81-92$ \\
$\quad$ White (426) & $94-96$ & $91-94$ & $86-91$ \\
$\quad$ Non-white (416) & $94-96$ & $90-93$ & $87-92$ \\
Sex & & & $86-91$ \\
$\quad$ Male (523) & $94-96$ & $90-94$ & $87-92$ \\
$\quad$ Female (319) & $93-96$ & $90-93$ & $86-91$ \\
Pre-dialysis systolic blood pressure [mmHg] & & & \\
$\quad \leq 130(180)$ & $96-96$ & $90-94$ & $90-92$ \\
$>130(662)$ & $94-96$ & $90-93$ & $85-91$ \\
Interdialytic weight gain [kg] & & & n.s \\
$\quad \leq 2.3(421)$ & n.s & $89-93$ & \\
$\quad>2.3(421)$ & $93-96$ & & \\
\hline
\end{tabular}

RBV, relative blood volume. n.s., not significant

To explore the association between RBV and intradialytic SBP patterns we analyzed those 219 patients with available intradialytic RBV and SPB data. Seventy-six patients (34.7\%) were inside the favorable 3-hours RBV range and 143 (65.3\%) outside. Neither intradialytic average SBP nor nadir SBP and IDH rate differed between these 2 groups (Supplemental Tables S6.2 and S6.3). Treatment-level hourly RBVs were comparable between sessions with and without IDH, respectively (Supplemental Table S6.4).

\section{Intradialytic fluid administration}

Acknowledging the possible influence of fluid administration on RBV, we examined hourly RBV levels in treatments with documented fluid administration; hourly RBV levels were materially identical (Supplemental Table S6.5). Furthermore, neither fluid administration rate nor fluid administration rate in the presence of IDH differed between patients inside or outside the 86-92\% 3-hour RBV range, respectively (Supplemental Table S6.3). 


\section{Inside favorable range —outside favorable range}

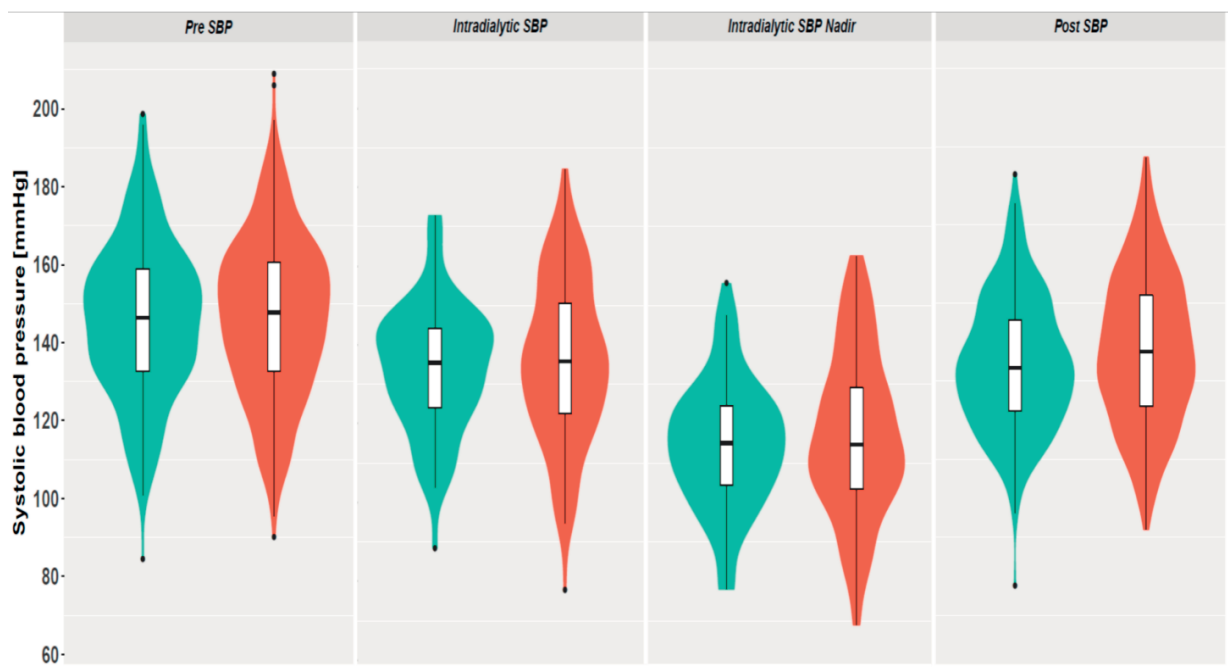

Figure 6.6 Violin plots and box-whisker plots showing the distribution and comparison of SBP during baseline between patients who attained RBVs within the favorable 3-hour RBV range (86-92\%) and those who did not. The widths of the violin plot represent frequency of measurements.

\section{Sensitivity analysis}

To explore the influence of RBVs levels below the favorable RBV ranges on outcomes, we computed HRs for all-cause mortality after excluding patients with RBVs below the lower limits of the hourly favorable RBV ranges. This sensitivity analysis showed materially identical results (Supplemental Table S6.6, Supplemental Figure S6.3).

To further explore the effect of intradialytic fluid administration on the association between RBV and all-cause mortality, we performed a sensitivity analyses in patients with available intradialytic data. Cox proportional hazards models (crude, minimally, and fully adjusted models) excluding treatments with fluid administration showed essentially identical results (data not shown).

\section{Discussion}

In this study we explored the association between hourly intradialytic RBV levels and all-cause mortality in a large and diverse cohort of chronic hemodialysis patients. The main finding is that specific intradialytic RBV ranges are associated with significantly lower all-cause mortality. 
Since the inception of dialysis, fluid management has been of central concern. Fluid overload as well as fluid depletion have been related to cardiovascular events and increased mortality ${ }^{3-5,8,18,19}$. Fluid management in standard in-center hemodialysis has been likened to sailing between Scylla and Charybdis: on one hand, in patients without residual kidney function ultrafiltration is the only means to remove fluid accumulated between hemodialysis treatments and to avoid fluid overload; on the other hand, excessive fluid removal may impact intradialytic hemodynamic stability. Indeed, ultrafiltration-induced blood volume reduction is considered a causal factor of intradialytic cardiovascular instability, depending on the rates of ultrafiltration and vascular refilling ${ }^{6,20}$. Given these competing factors, it is conceivable that on a population level certain RBV ranges are associated with lower (or higher) mortality. While the genesis of the RBV curve is easy to understand qualitatively as the relative difference between UFR and vascular refilling rate, attempts to quantitatively model and predict RBV dynamics are notoriously complicated and currently not applicable to routine care ${ }^{21,22}$. The matter is further complicated by the absence of randomized controlled trials (RCTs) looking at the relationship between RBV and patient outcomes. In this situation, clinical practitioners who use RBV monitoring resort to an empirical assessment of RBV curves, where flat curves are considered to indicate fluid overload and steep curves intravascular volume depletion that may precipitate IDH ${ }^{23,24}$.

This study is the first one to investigate the association between RBV levels attained in routine care and patient survival. We are cognizant of the fact that causality cannot be derived from observational studies, and that this study cannot provide a recommendation for certain RBV ranges. Only one RCT explored the clinical use of RBV monitoring. In the CLIMB Study ${ }^{15} 443$ participants were randomized to either using RBV monitoring as a voluntary adjunct to clinical care, or conventional care. Patients assigned to the intervention arm may have had their ultrafiltration rates adjusted at the discretion of the staff using a suggested ultrafiltration algorithm, when a predefined RBV target was reached. While RBV monitoring did not result in a marked change in UFR, increased hospitalization and mortality rates were noted in the intervention arm, calling into question the utility of blood volume monitoring. Of note, the RBV targets used in CLIMB were - to the best of our knowledge - not based on prior published evidence ${ }^{25}$.

In an observational study of 308 patients Agarwal ${ }^{26}$ used relative plasma volume (RPV) recordings from a single HD treatment to calculate RPV slopes. The author found that flatter RPV slopes ( $<1.39 \%$ / hour) were associated with higher mortality (HR 1.72). After adjustment for several covariates, including interdialytic blood pressure, flat RPV slopes remained a significant predictor (HR 2.46). While it is difficult to compare these RPV and our RBV results, their directional agreement is notable. In another observational study, Ficociello et al. reported 64.5\% lower all-cause hospitalization rate in patients with an end-dialytic RBV <85\% compared to patients with flat RBV [abstract, National Kidney Foundation meeting, 2015]. 
RBV monitoring was introduced with the hope of preventing IDH ${ }^{13,14,27,28}$. However, several studies failed to demonstrate any relationship between changes in RBV and intradialytic blood pressure ${ }^{14,29,30}$. Most studies intended to find patient-specific RBVs associated with IDH, yet no critical RBV levels have been identified ${ }^{11,29}$. These findings were corroborated in our study, where in patients who attained the favorable 3-hours RBV range IDH rates were not increased, despite higher UFR.

In our study, about two-thirds of patients attained RBVs above the favorable ranges and less than $3 \%$ of patients were below. These results support reports where a substantial fraction of patients had minor or no change in RBV during dialysis ${ }^{23,31}$. Lopot et al. ${ }^{23}$ reported that in 30\% of their patients RBV did not decline, and Steuer et al. ${ }^{31}$ reported in $18 \%$ of their patients a RBV reduction by less than 5 -percentage points.

In our study, patients with 3-hours RBV above the upper limits of the favorable range had clinical signs of fluid overload, such as higher post-dialysis SBP and a higher prevalence of CHF (Table 6.1). While plausible, this observation needs corroboration using objective measurements of fluid status, such as bioimpedance (currently not available in the U.S. for use in patients). Noteworthy, Agarwal also concluded that flatter RBV slopes were a sign of fluid overload, consistent with our hypothesis ${ }^{26}$.

Patients outside the favorable RBV range were older, had higher prevalence of CHF, lower enPCR, and had lower UFRs compared with those patients within the favorable range. These findings are consistent with studies showing lower ultrafiltration volumes and rates in elderly patients ${ }^{32}$, possibly because this group is particularly vulnerable to intradialytic morbid events ${ }^{14}$. Higher age predisposes to comorbidities, including diabetes and $\mathrm{CHF}$, which may prompt a more cautious approach to fluid removal. Therefore, it cannot be excluded that higher RBVs indicate intolerance to fluid removal, which may in part explain the observed association with poor outcomes, despite extensive adjustment for confounders.

Our study has several strengths, firstly its large and diverse dialysis population, the substantial number of dialysis treatments, standardized care protocols, automated RBV and blood pressure recordings, and the long follow-up period. While observational studies are ill-suited to guide general protocols for clinical practice, our results are valuable for the planning of future trials designed to attain (or avoid) specific RBV levels, e.g., by using automatic UFR feedback control.

Study limitations are mainly due to its observational nature. Objective indicators of fluid status (e.g. bioimpedance) are missing; these would allow a more extensive probing into the relationship between RBV and fluid status. Second, data were incomplete for intradialytic blood pressure and for fluid administration, and the dialysis staff was not blinded to RBV data. Despite statistical adjustments for baseline characteristics, residual confounding cannot be ruled out. Lastly, we acknowledge the lack of quantitative data on residual kidney function (RKF), that could have an impact on RBV behavior. However, the long HD vintage of our population makes substantial RKF unlikely ${ }^{33,34}$. Also, substantial RKF would result in less IDWG, lower UFR and 
consequently flatter RBV curves. Since RKF is associated with better survival, the presence of RKF would have increased the odds for better outcomes with flatter RBV, contrary to what we have observed.

In conclusion, our study indicates that specific intradialytic RBV ranges are associated with all-cause mortality in hemodialysis patients. These findings may serve as a valuable basis for future clinical trials into the relationship between RBV profiles, fluid status as determined by objective methods, and patient outcomes. 


\section{References}

1. Dou Y, Zhu F, Kotanko P. Assessment of extracellular fluid volume and fluid status in hemodialysis patients: current status and technical advances. Semin Dial. 2012;25(4):377-387.

2. Kalantar-Zadeh K, Regidor DL, Kovesdy CP, et al. Fluid retention is associated with cardiovascular mortality in patients undergoing long-term hemodialysis. Circulation. 2009;119(5):671-679.

3. Wizemann V, Wabel P, Chamney P, et al. The mortality risk of overhydration in haemodialysis patients. Nephrology, dialysis, transplantation : official publication of the European Dialysis and Transplant Association - European Renal Association. 2009;24(5):1574-1579.

4. Xu Y, Chen Y, Li D, et al. Hypertension, fluid overload and micro inflammation are associated with left ventricular hypertrophy in maintenance hemodialysis patients. Ren Fail. 2013;35(9):1204-1209.

5. Dekker MJ, Marcelli D, Canaud BJ, et al. Impact of fluid status and inflammation and their interaction on survival: a study in an international hemodialysis patient cohort. Kidney Int. 2017;91(5):1214-1223.

6. Daugirdas JT. Dialysis hypotension: A hemodynamic analysis. Kidney International. 1991;39(2):233-246.

7. van der Sande F, Kooman JP, Leunissen KM. Intradialytic hypotension-new concepts on an old problem. Nephrology, dialysis, transplantation : official publication of the European Dialysis and Transplant Association - European Renal Association. 2000.

8. Mclntyre CW, Burton JO, Selby NM, et al. Hemodialysis-induced cardiac dysfunction is associated with an acute reduction in global and segmental myocardial blood flow. Clin J Am Soc Nephrol. 2008;3(1):19-26.

9. Buchanan C, Mohammed A, Cox E, et al. Intradialytic Cardiac Magnetic Resonance Imaging to Assess Cardiovascular Responses in a Short-Term Trial of Hemodiafiltration and Hemodialysis. J Am Soc Nephrol. 2017;28(4):1269-1277.

10. Barth C, Boer W, Garzoni D, et al. Characteristics of hypotension-prone haemodialysis patients: is there a critical relative blood volume? Nephrology Dialysis Transplantation. 2003;18(7):1353-1360.

11. Steuer RR, Leypoldt JK, Cheung AK, et al. Hematocrit as an indicator of blood volume and predictor of intradialytic morbid events. ASAIO J. 1994;40(3):M691-M696.

12. Steuer RR, Leypoldt JK, Cheung AK, et al. Reducing symptoms during hemodialysis by continuously monitoring the hematocrit. Am J Kidney Dis. 1996;27(4):525-532.

13. Santoro A, Mancini E, Basile C, et al. Blood volume controlled hemodialysis in hypotension-prone patients: a randomized, multicenter controlled trial. Kidney Int. 2002;62(3):1034-1045.

14. Andrulli S, Colzani S, Mascia F, et al. The role of blood volume reduction in the genesis of intradialytic hypotension. Am J Kidney Dis. 2002;40(6):1244-1254.

15. Reddan DN, Szczech LA, Hasselblad V, et al. Intradialytic blood volume monitoring in ambulatory hemodialysis patients: a randomized trial. J Am Soc Nephrol. 2005;16(7):2162-2169.

16. Flythe JE, Xue H, Lynch KE, et al. Association of mortality risk with various definitions of intradialytic hypotension. J Am Soc Nephrol. 2015;26(3):724-734.

17. Malhotra R, Marcelli D, von Gersdorff G, et al. Relationship of Neutrophil-to-Lymphocyte Ratio and Serum Albumin Levels with C-Reactive Protein in Hemodialysis Patients: Results from 2 International Cohort Studies. Nephron. 2015;130(4):263-270.

18. Flythe JE, Kshirsagar AV, Falk RJ, et al. Associations of Posthemodialysis Weights above and below Target Weight with All-Cause and Cardiovascular Mortality. Clin J Am Soc Nephrol. 2015;10(5):808-816.

19. Chazot C, Wabel P, Chamney $P$, et al. Importance of normohydration for the long-term survival of haemodialysis patients. Nephrology, dialysis, transplantation : official publication of the European Dialysis and Transplant Association - European Renal Association. 2012;27(6):2404-2410.

20. Daugirdas JT. Pathophysiology of dialysis hypotension: an update. Am J Kidney Dis. 2001;38(4 Suppl 4):S11-S17.

21. de los Reyes VA, Fuertinger DH, Kappel F, et al. A physiologically based model of vascular refilling during ultrafiltration in hemodialysis. J Theor Biol. 2016;390:146-155.

22. Paguio VME, Kappel F, Kotanko P. A model of vascular refilling with inflammation. Math Biosci, 2018.

23. Lopot $F$, Kotyk P, Blaha J, et al. Use of continuous blood volume monitoring to detect inadequately high dry weight. Int J Artif Organs. 1996;19(7):411-414. 
24. Beige J, Sone J, Sharma AM, et al. Computational analysis of blood volume curves and risk of intradialytic morbid events in hemodialysis. Kidney Int. 2000;58(4):1805-1809.

25. Howard AD, Palmer B, Howard RS, et al. Assessing the value of blood volume monitoring to improve outcomes. A comparative observational study. Nephrol News Issues. 1998;12(5 Suppl):24-26.

26. Agarwal R. Hypervolemia is associated with increased mortality among hemodialysis patients. Hypertension. 2010;56(3):512-517.

27. Agarwal R, Kelley K, Light RP. Diagnostic utility of blood volume monitoring in hemodialysis patients. Am J Kidney Dis. 2008;51(2):242-254.

28. Santoro A, Mancini E, Paolini F, et al. Blood Volume Regulation During Hemodialysis. American Journal of Kidney Diseases. 1998;32(5):739-748.

29. Krepel HP, Nette RW, Akcahuseyin E, et al. Variability of relative blood volume during haemodialysis. Nephrology, dialysis, transplantation : official publication of the European Dialysis and Transplant Association - European Renal Association. 2000;15(5):673-679.

30. Booth J, Pinney J, Davenport A. Do changes in relative blood volume monitoring correlate to hemodialysis-associated hypotension? Nephron Clin Pract. 2011;117(3):c179-c183.

31. Steuer RR, Germain MJ, Leypoldt JK, et al. Enhanced fluid removal guided by blood volume monitoring during chronic hemodialysis. Artif Organs. 1998;22(8):627-632.

32. Canaud B, Tong L, Tentori F, et al. Clinical practices and outcomes in elderly hemodialysis patients: results from the Dialysis Outcomes and Practice Patterns Study (DOPPS). Clin J Am Soc Nephrol. 2011;6(7):1651-1662.

33. Rottembourg J, et al. Evolution of residual renal function in patients undergoing maintenance haemodialysis or continuous ambulatory peritoneal dialysis. Proc Eur Dial Transplant Assoc. 1983;19: 397-403.

34. Misra M, et al. Effect of cause and time of dropout on the residual GFR: a comparative analysis of the decline of GFR on dialysis. Kidney Int. 2001;59(2):754-763. 


\section{Supplemental material}

Table S6.1 Mean hourly RBV levels in relation to peridialytic SBP changes. The peridialytic SBP change was calculated as post-HD SBP minus pre-HD SBP.

\begin{tabular}{lcccc}
\hline Peridialytic SBP change [mmHg] & Number of patients & $\begin{array}{c}\text { RBV } \\
\text { First hour [\%] }\end{array}$ & $\begin{array}{c}\text { RBV } \\
\text { Second hour [\%] }\end{array}$ & $\begin{array}{c}\text { RBV } \\
\text { Third hour [\%] }\end{array}$ \\
\hline Decreased between 0-30 & 592 & 96.9 & 94.9 & 93.0 \\
Decreased $>$ 30 & 58 & 96.0 & 93.8 & 91.8 \\
Increased & 192 & 97.3 & 95.5 & 93.7 \\
\hline
\end{tabular}

$\mathrm{RBV}$, relative blood volume; SBP, systolic blood pressure.

Table S6.2 Intradialytic SBP levels based on the attained RBV 3 hours into the hemodialysis treatment. SBP data are expressed as average \pm SD

\begin{tabular}{lcc}
\hline Group (number of patients) & Intradialytic SBP $(\mathrm{mmHg})$ & Intradialytic nadir SBP $(\mathrm{mmHg})$ \\
\hline RBV inside $86-92 \%$ & $134.2 \pm 16.2$ & $114.5 \pm 16.1$ \\
3 hours into dialysis $(\mathrm{N}=76)$ & & \\
RBV outside $86-92 \%$ & $135.9 \pm 20.4$ & $117.1 \pm 20.3$ \\
3 hours into dialysis $(\mathrm{N}=143)$ & $-1.7(-6.7$ to +3.3$)$ & $-2.5(-7.5$ to +2.4$)$ \\
Difference $(95 \% \mathrm{Cl})$ & 0.5 & 0.3 \\
P-value &
\end{tabular}

$\mathrm{Cl}$, confidence interval; RBV, relative blood volume; SBP, systolic blood pressure.

Table S6.3 Rates of IDH and fluid administration in patients inside and outside the favorable 3-hour RBV range, respectively. The rates are presented in $\%$ of HD sessions.

\begin{tabular}{lccc}
\hline Group (number of patients) & IDH & $\begin{array}{c}\text { Fluid } \\
\text { administration }\end{array}$ & $\begin{array}{c}\text { IDH and fluid } \\
\text { administration }\end{array}$ \\
\hline RBV inside 86-92\% at 3 hours into dialysis ( $\mathrm{N}=76)$ & 13.1 & 16.9 & 4.0 \\
RBV outside 86-92\% at 3 hours into dialysis ( $\mathrm{N}=143)$ & 13.0 & 21.1 & 4.3 \\
P-value & 0.97 & 0.12 & 0.74 \\
\hline
\end{tabular}

$\mathrm{IDH}$, intradialytic hypotension; RBV, relative blood volume.

Table S6.4 Hourly RBV levels in session with and without IDH episodes, respectively. Data are presented as median and $25^{\text {th }}$ and $75^{\text {th }}$ percentile, respectively.

\begin{tabular}{lccc}
\hline HD sessions (number of sessions) & RBV First hour & RBV Second hour & RBV Third hour \\
\hline With IDH (N=418) & $96.4(94.5 ; 98.2)$ & $94.3(91.8 ; 96.8)$ & $93.2(90.0 ; 95.9)$ \\
Without IDH ( $=2406)$ & $96.6(94.6 ; 98.5)$ & $94.4(91.8 ; 97.0)$ & $92.5(89.2 ; 95.5)$ \\
\hline
\end{tabular}

$\mathrm{IDH}$, intradialytic hypotension; RBV, relative blood volume.

Table S6.5 Hourly RBV levels in session with and without fluid administration, respectively. Data are presented as median and $25^{\text {th }}$ and $75^{\text {th }}$ percentile, respectively.

\begin{tabular}{llll}
\hline HD session (number of sessions) & RBV First hour & RBV Second hour & RBV Third hour \\
\hline With fluid administration $(\mathrm{N}=576)$ & $96.3(94.2 ; 98.4)$ & $94.2(91.7 ; 97.3)$ & $93.3(90.1 ; 96.2)$ \\
Without fluid administration $(\mathrm{N}=2248)$ & $96.6(94.7 ; 98.5)$ & $94.4(91.8 ; 96.9)$ & $92.4(89.2 ; 95.3)$ \\
\hline
\end{tabular}

RBV, relative blood volume. 
Table S6.6 Adjusted hazard ratio (HR) for all-cause mortality of the whole analytical dataset and after exclusion of patients with RBVs levels below the favorable RBV ranges at first, second, and third hour, respectively.

\begin{tabular}{lccccc}
\hline & \multicolumn{2}{c}{$\begin{array}{c}\text { All patients } \\
\mathrm{N}=842\end{array}$} & & \multicolumn{2}{c}{$\begin{array}{c}\text { Population after exclusion of patients with RBVs } \\
\text { levels below the favorable ranges }\end{array}$} \\
\cline { 2 - 6 } Time & $\mathrm{HR}(95 \% \mathrm{Cl})$ & P-value & $\mathrm{N}$ & $\mathrm{HR}(95 \% \mathrm{Cl})$ & P-value \\
\hline First hour & $0.58(0.42$ to 0.79$)$ & $<0.001$ & 820 & $0.56(0.41$ to 0.77$)$ & $<0.001$ \\
Second hour & $0.54(0.39$ to 0.75$)$ & $<0.001$ & 824 & $0.53(0.38$ to 0.73$)$ & $<0.001$ \\
Third hour & $0.46(0.33$ to 0.65$)$ & $<0.001$ & 827 & $0.46(0.32$ to 0.65$)$ & $<0.001$ \\
\hline
\end{tabular}

Adjusted for age, sex, race, COPD, CHF, diabetes, albumin, hemoglobin, NLR, pre-dialysis SBP, and UFR.

$\mathrm{Cl}$, confidence interval; $\mathrm{COPD}$, chronic obstructive pulmonary disease; $\mathrm{CHF}$, congestive heart failure; NLR, neutrophil-to-lymphocyte ratio; SBP, systolic blood pressure; UFR, ultrafiltration rate.
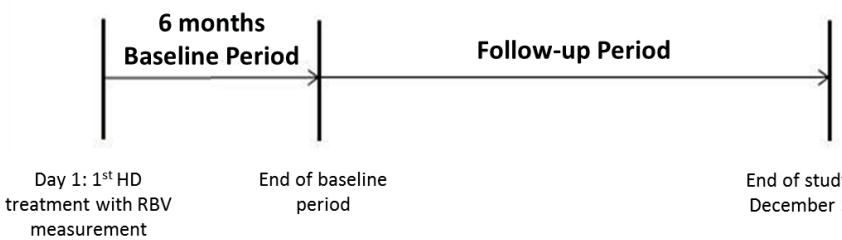
End of baseline
period

End of study period:

December 31,2016

Figure S6.1 Study design.

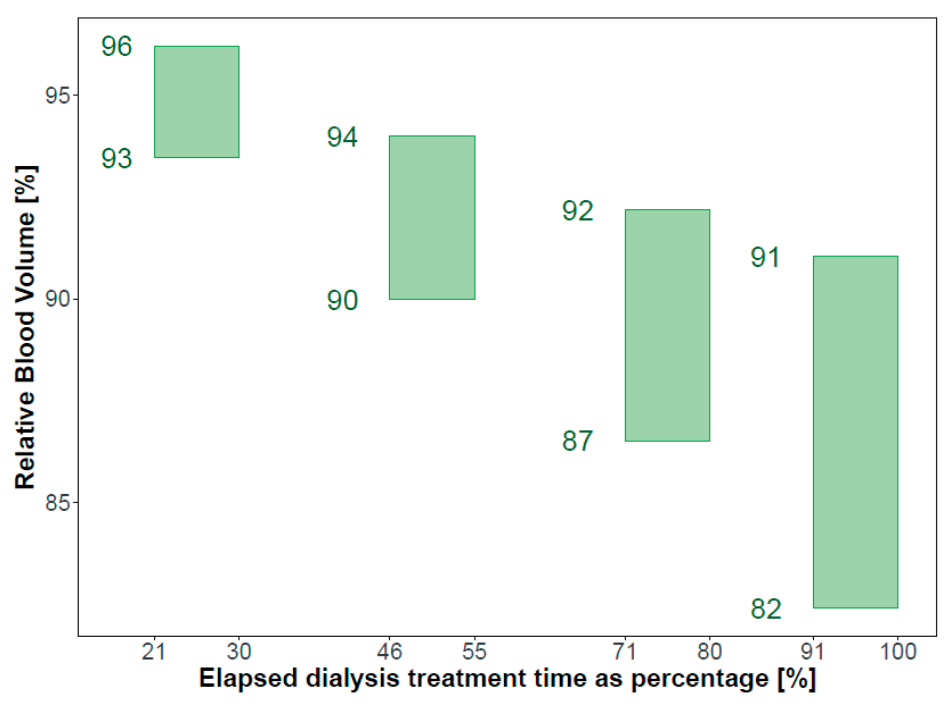

Figure S6.2 Intradialytic RBV ranges that are associated with hazard ratios significantly below 1.0 for allcause mortality after $25 \%, 50 \%, 75 \%$ and $100 \%$ of the elapsed dialysis treatment time. 

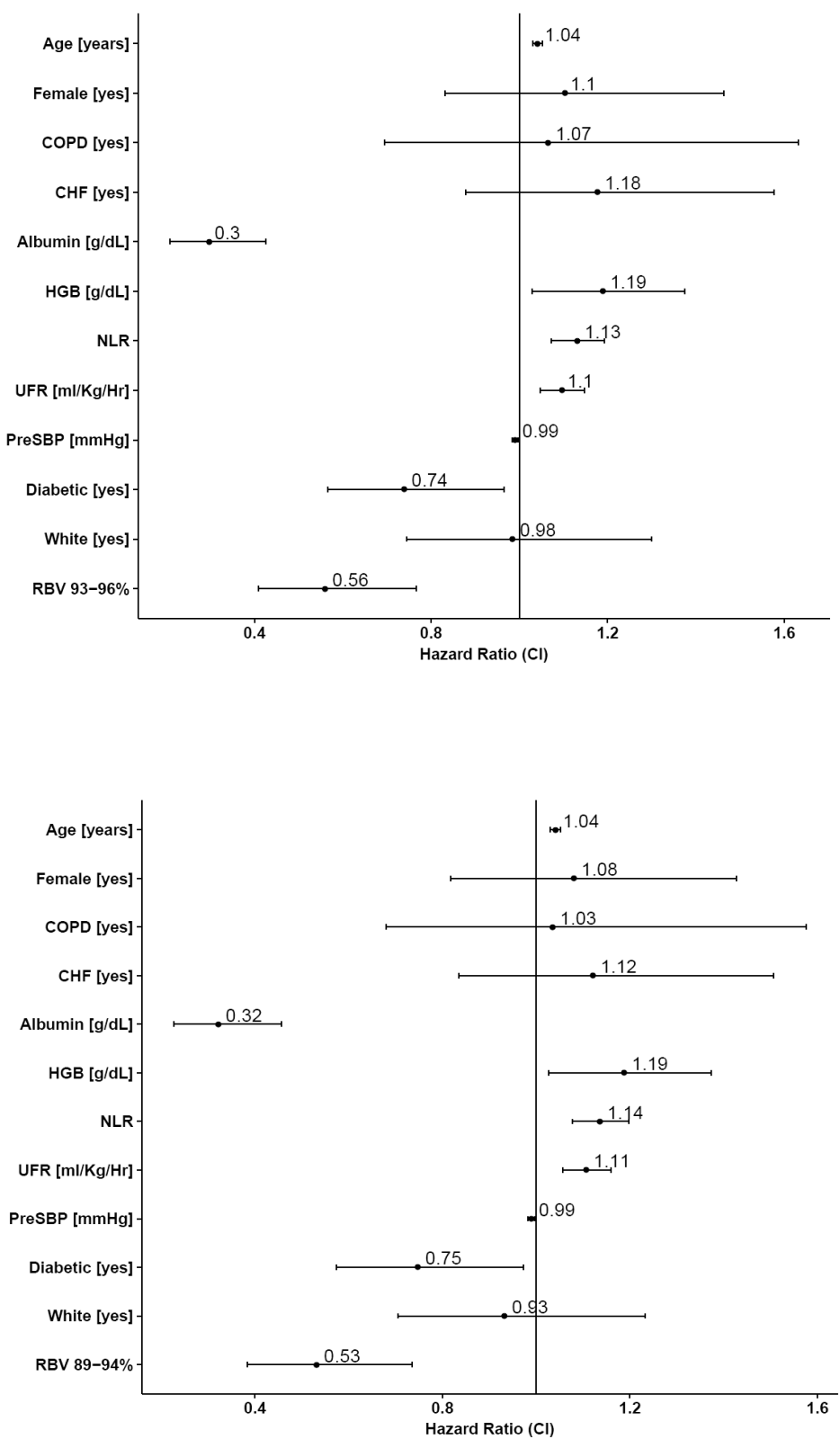


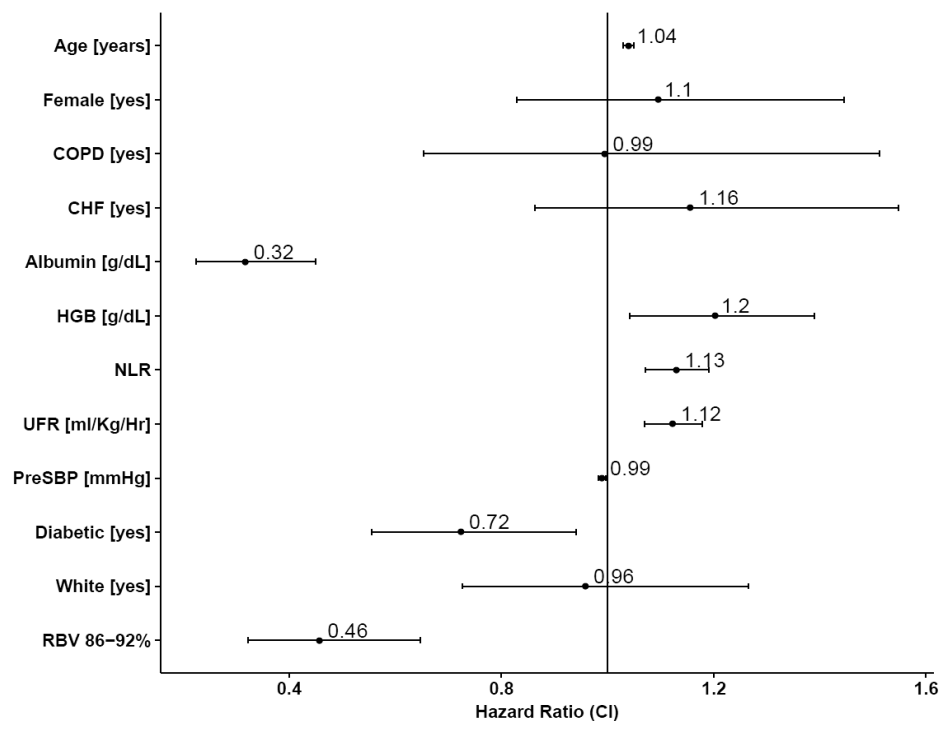

Figure S6.3 Results of the sensitivity analysis after exclusion of patients with RBVs below the favorable hourly RBV ranges. The forest plots show hazard ratios of baseline clinical characteristics and attainment of favorable RBV ranges after 1 (top), 2 (middle), and 3 (bottom) hours, respectively. 


\section{Chapter 7}

Association of peridialytic systolic blood pressure
change and pre-dialysis systolic blood pressures on
mortality among hemodialysis patients

Zhang H, Preciado P, Wang Y, Meyring Wosten A, Topping A, Raimann JG, Kooman JP, van der Sande FM, Usvyat LA, Maddux D, Maddux FW, Kotanko P 


\section{Abstract}

\section{Background and objectives}

Pre-dialysis systolic blood pressure (pre-SBP) and peridialytic SBP change have been associated with morbidity and mortality among hemodialysis patients in previous studies, but the nature of this interaction is not well understood.

\section{Material \& methods}

We analyzed pre-SBP and peridialytic SBP change (post-SBP minus pre-SBP) between $1 / 2001$ and 12/2012 in hemodialysis patients treated in U.S. Fresenius Medical Care facilities. The baseline period was defined as months 4-6 after hemodialysis initiation, all-cause mortality was noted during follow-up. Only patients who survived the baseline and had no missing covariates were included. Censoring events were renal transplantation, modality change, or study end. We fitted Cox proportional hazard model with a bivariate spline functions for the primary predictors, pre-SBP and peridialytic SBP change, with adjustment for age, gender, race, diabetes, access-type, relative interdialytic weight gain, body mass index, albumin, equilibrated normalized protein catabolic rate, and ultrafiltration rate ( $\geq 13$ or $<13 \mathrm{~mL} / \mathrm{kg}$ body weight/hour).

\section{Results}

A total of 172,199 patients were included. We found that a peridialytic SBP rise combined with high pre-SBP was associated with higher mortality. In contrast, when concurrent with low pre-SBP, a peridialytic SBP rise was associated with better survival.

\section{Conclusion}

The association of pre-SBP and peridialytic SBP change with mortality is complex. Our findings call for a joint interpretation of pre-HD SBP and peridialytic SBP change. 


\section{Introduction}

Cardiovascular (CV) mortality remains the most common cause of death among hemodialysis (HD) patients ${ }^{1,2}$. In the general population, high blood pressure (BP) is associated with higher $\mathrm{CV}$ risk ${ }^{3,4}$. Hypertension is common among HD patients with a prevalence varying between $60-90 \%{ }^{5}$, and has been associated with increased CV morbidity and mortality ${ }^{6}$. Yet, the association between BP and outcomes in the dialysis population is somewhat controversial ${ }^{1,7-9}$. Foley et al. ${ }^{10}$ reported that both high and low pre and post-HD BP were associated with increased mortality among patients with end stage kidney disease (ESKD) undergoing dialysis.

Absence of an accepted, "normal" BP range for dialysis patients is a major barrier for developing definitions for BP-related clinical phenomena. A major concern is the timing of clinically actionable BP. While some authors advocate for interdialytic BP measurements (home BP; ambulatory BP monitoring), others favor in-center BP measurements (pre-HD; post-HD; peridialytic BP change) for clinical decision making. The problem is further compounded by the lack of definitive evidence which one of these BP is more strongly associated with outcomes ${ }^{1,8}$. To date, pre- and post-HD BP levels form the basis of the National Kidney Foundation's Kidney Outcomes Quality Initiative (KDOQI) guidelines ${ }^{11}$. Nonetheless, conflicting data exists; although consistently more studies based on large cohorts of patients showing elevated mortality in patients with low rather than high pre-HD BP, particularly low systolic BP $(\mathrm{SBP})^{12-15}$. To further complicate matters, some large epidemiologic studies using peridialytic SBP change (defined as post-HD minus pre-HD SBP) have shown a U-shaped association with adverse outcomes ${ }^{13,16-18}$.

Although during $\mathrm{HD}$ a decline in BP is seen in the majority of cases, a peridialytic SBP increase can occur in up to $15 \%$ prevalent HD patients and has been associated with adverse outcomes ${ }^{18-20}$. Park et al. ${ }^{16}$ reported that both large peridialytic SBP falls and rises were associated with higher mortality.

The pathophysiology of both increases and decreases of BP, as well as intradialytic BP variability, is not fully understood and is mostly multifactorial. Factors associated with the development of intradialytic hypotension include, next to fluid removal during dialysis, an impaired vasoreactivity, a reduced sympathetic response, older age, atherosclerosis, and poor cardiac reserve ${ }^{21,22}$, while intradialytic hypertension has been associated with chronic fluid overload, increased peripheral vascular resistance, and intradialytic hypoxemia ${ }^{23}$, among others ${ }^{24,25}$.

Despite the notable literature regarding pre-HD SBP and peridialytic SBP changes, the nature of interaction between pre-HD SBP and peridialytic SBP changes with outcomes has not yet been investigated. The goal of our research was to explore the combined 
association between pre-HD SBP and peridialytic SBP changes as recorded in the same HD session and all-cause mortality in a large and diverse United States HD population.

\section{Materials and methods}

\section{Population and study design}

This multi-center observational retrospective study was conducted in a cohort of HD patients from Fresenius Medical Care North America clinics across the United States between January 2001 and December 2012. Baseline was defined as the months 4-6 following HD initiation. Patient characteristics were assessed during baseline, and allcause mortality recorded during follow-up. Censoring events were change in treatment modality, renal transplantation, loss to follow-up, and end of study period. Only patients who survived baseline and had no missing covariates were included. The New England Institutional Review Board (\#14-446) waived the need for informed consent.

\section{Blood pressure measurements}

Patients visited dialysis facilities on average 3 times per week, and had their BP measured before each treatment in a sitting position per a standard protocol using an automated device, either in the doctor's office or integrated in the HD machine with an appropriately sized pressure cuff around the non-access upper arm positioned at heart level. After HD, BP was taken in a sitting position following the same protocol. We calculated peridialytic SBP changes as post-HD SBP minus pre-HD SBP.

\section{Clinical and laboratory data}

Laboratory measurements (Spectra Laboratories, New Jersey, NJ, USA) were downloaded to the RRI data warehouse and extracted to the study database.

\section{Comorbidities}

Diabetes mellitus (DM) and congestive heart failure (CHF) were defined using ICD-9 codes documented in the patients' electronic health records.

\section{Statistical analysis}

Descriptive statistics comprised mean ( \pm standard deviation; SD) for continuous variables and percentages for categorical variables. The primary outcome was all-case mortality. We fitted several Cox proportional hazard models: (a) two models with univariate spline terms for pre-SBP and peridialytic SBP, respectively and (b) one model 
with bivariate spline terms for pre-HD SBP and peridialytic SBP. All Cox models were adjusted for age, gender, race, DM, type of vascular access, interdialytic weight gain normalized to post-HD body weight (IDWG), body mass index (BMI), albumin, equilibrated normalized protein catabolic rate (enPCR), and ultrafiltration rate categories ( $\geq 13$ or $<13 \mathrm{~mL} / \mathrm{kg}$ body weight/hour).

We conducted two sensitivity analyses, one without CHF patients, and one in CHF patients only.

\section{Results}

\section{Patient baseline characteristics}

Our study population included 172,199 patients (Table 7.1). Mean age was 62.1 years, $61.6 \%$ were white, $55 \%$ were male, $64.2 \%$ had diabetes mellitus, $31.9 \%$ had $\mathrm{CHF}$, and 29.9.\% were using central venous catheter as vascular access.

Table 7.1 Baseline characteristics of all patients.

\begin{tabular}{lc}
\hline Variable & All patients \\
\hline Number of patients & 191,446 \\
Age [years] & $62.8 \pm 14.9$ \\
Gender [\% Male] & 54.9 \\
Race [\% White] & 60.5 \\
Diabetic [\%] & 61.1 \\
Catheter [\%] & 10.9 \\
Pre SBP [mmHg] & $149.4 \pm 19.5$ \\
Post SBP [mmHg] & $139.5 \pm 17.2$ \\
Post SBP - Pre SBP [mmHg] & $-9.9 \pm 13.9$ \\
UFR [ml/kg/hr] & $9.3 \pm 3.5$ \\
BMI [kg/m 2$]$ & $28.1 \pm 7.5$ \\
Serum albumin [g/dl] & $3.7 \pm 0.4$ \\
enPCR [g/kg/day] & $0.9 \pm 0.2$ \\
\hline
\end{tabular}

Data are expressed as mean \pm SD, or percentage (\%). SD, standard deviation; BMI, body mass index; SBP, systolic blood pressure; UFR, ultrafiltration rate; enPCR, equilibrated normalized protein catabolic rate, CVC, central venous catheter.

\section{Blood pressure caractheristics}

Pre-HD and post-HD SBP were 149.6 $\pm 19.3 \mathrm{mmHg}$ and $139.6 \pm 17.2 \mathrm{mmHg}$, respectively. Peridialytic SBP change was $-10.0 \pm 13.3 \mathrm{mmHg}$. 


\section{Association between pre-dialysis SBP and peridialytic SBP change with all cause mortality}

The median follow-up was 25.0 months. During follow-up, 73,529 patients $(42.7 \%)$ died. In Cox models with univariate spline terms a pre-HD SBP $\leq 138 \mathrm{mmHg}$ (Figure 7.1) and a peridialytic SBP change $>-6.9 \mathrm{mmHg}$ (Figure 7.2) were associated with increased all-cause mortality.

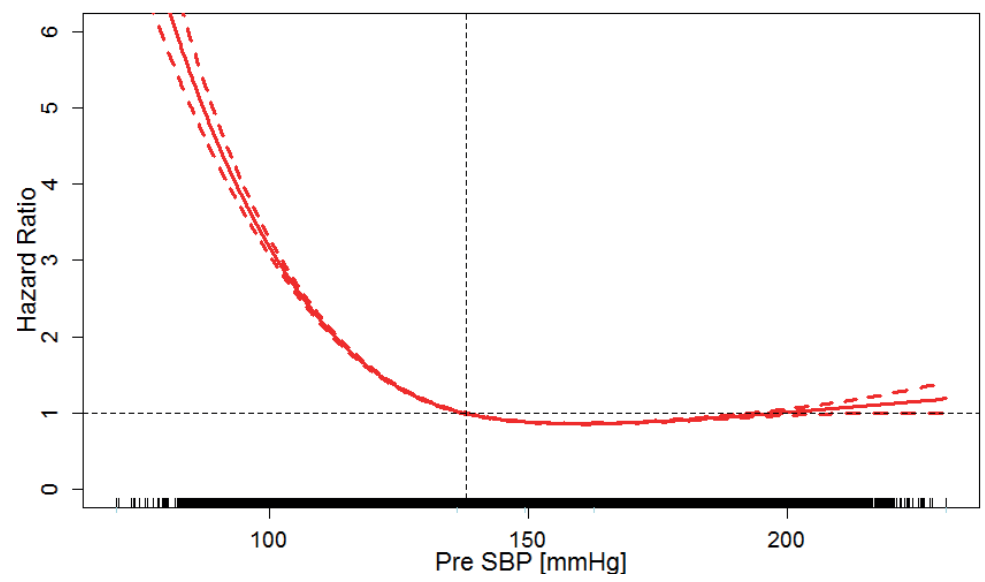

Figure 7.1 Association between pre-HD SBP and all-cause mortality. Mean hazard ratios (HR, solid line) and $95 \%$ confidence interval (dotted lines). Pre-HD SBP $<138 \mathrm{mmHg}$ (vertical line) is associated with an $H R>1.0$ for all-cause mortality. The ticks on the $x$-axis represent individual patients.

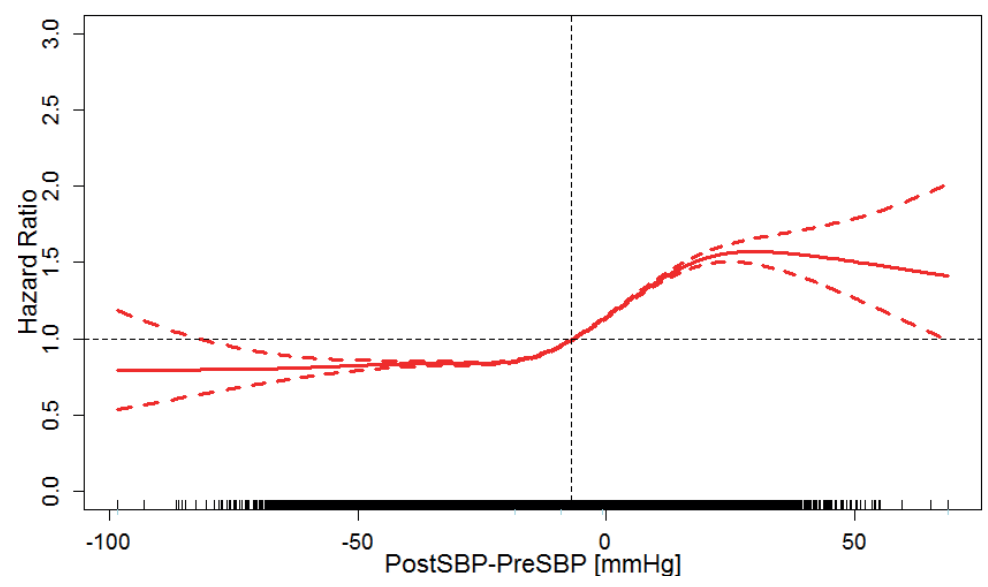

Figure 7.2 Association between peridialytic SBP change and all-cause mortality. Mean hazard ratios (HR, solid line) and 95\% confidence interval (dotted lines). A peridialytic SBP change $<-6.9 \mathrm{mmHg}$ (vertical line) is associated with an $\mathrm{HR}>1.0$ for all-cause mortality. The ticks on the $\mathrm{x}$-axis represent individual patients. 
The joint association of pre-HD SBP and peridialytic SBP change with all-cause mortality was more complex (Figure 7.3). We identified a general trend, namely an increased mortality in patients with either high pre-HD SBP and concurrent peridialytic SBP increase or low pre-HD SBP and concurrent peridialytic SBP decline.

To translate the non-linear association depicted in Figure 7.3 into clinically more applicable discrete thresholds, we analyzed different pre-HD SBP levels, from a lower level $(110 \mathrm{mmHg})$ to a higher level $(180 \mathrm{mmHg})$. In the presence of a "normal" pre-HD SBP $(130 \mathrm{mmHg})$ a peridialytic SBP increase was associated with increased mortality, whereas a peridialytic SBP decreased was associated with better survival. In patients with low pre-HD SBP any degree of peridialytic SBP increase was associated with better survival, while a peridialytic SBP decrease was associated with increased mortality (Figure 7.4). In contrast, for higher pre-HD SBP a peridialytic SBP increase was associated with increased mortality, whereas a peridialytic SBP decrease was associated with better survival (Figure 7.4).

In the multivariate Cox analysis, after adjusting for several cofounders, these results were corroborated.

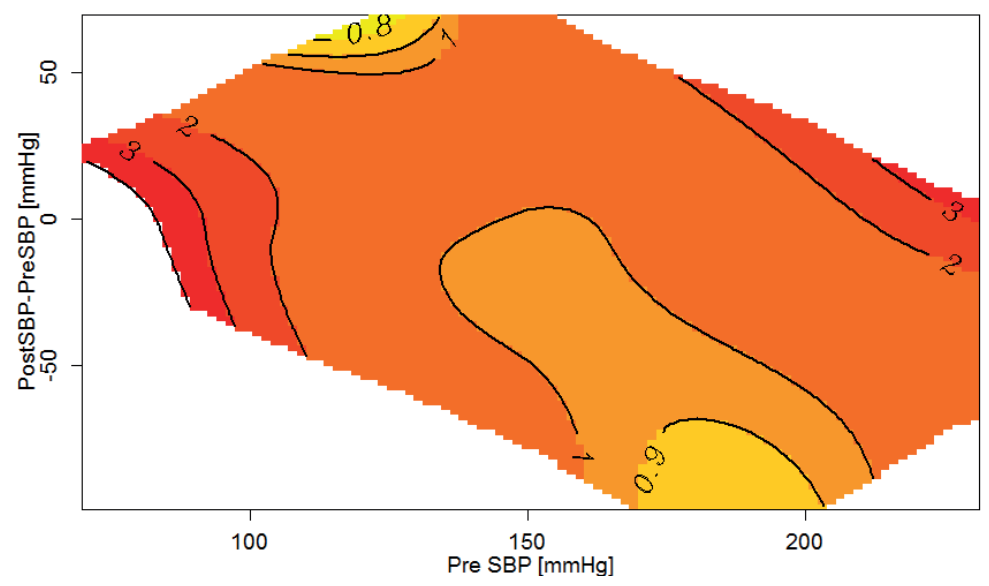

Figure 7.3 Contour plot showing the bivariate joint association between pre-HD SBP and peridialytic SBP change, and all-cause mortality. The contour plot can be read like a topographic map, with lines and colors indicating discrete hazard ratios for all-cause mortality.

\section{Sensitivity analyses}

This sensitivity analysis showed directionally equivalent results (Supplemental Figure S7.1 and Supplemental Figure S7.2). 

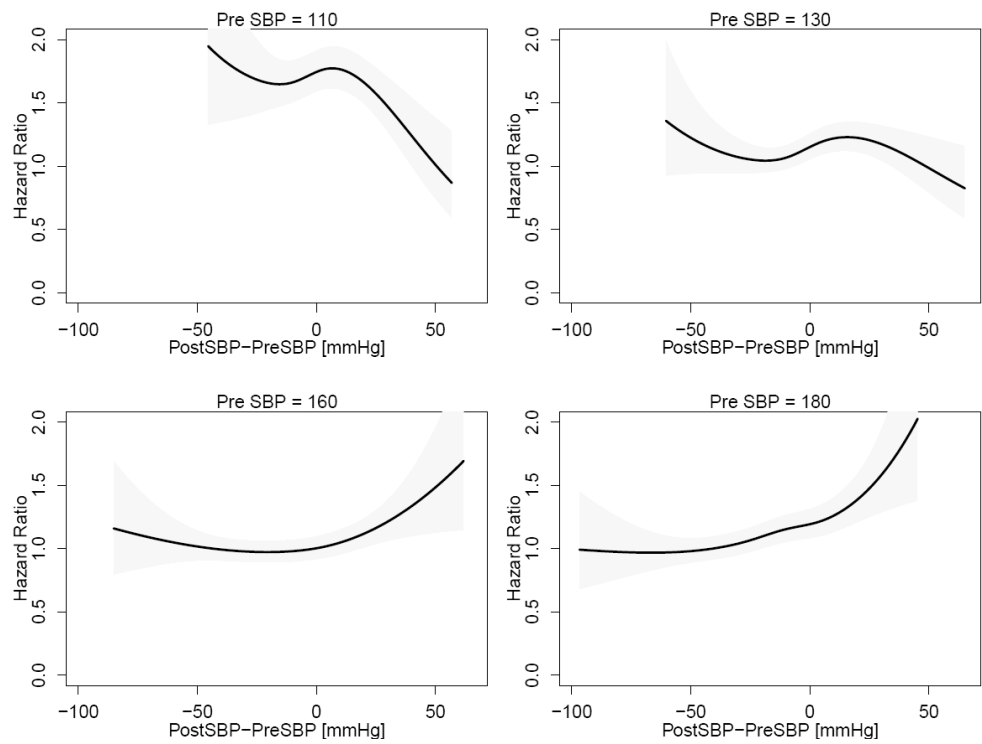

Figure 7.4 Hazard ratios as a function of peridialytic SBP at four levels of pre-HD SBP. The black lines indicate the average HRs, the grey areas the $95 \%$ confidence intervals.

\section{Discussion}

Our study explored the joint association of pre-HD SBP and peridialytic SBP changes with all-cause mortality in over 170,000 U.S. HD patients. The results clearly indicate that neither pre-HD nor peridialytic SBP change should be interpreted in isolation but jointly instead, because the same pre-HD SBP can be associated with either increased or decreased mortality, depending on the direction and degree of peridialytic SBP change. We showed that in the presence of lower pre-HD SBP a peridialytic SBP rise is beneficial, while a further peridialytic SBP decline is unfavorable.

Despite decades of research into the association between BP and outcomes in chronic hemodialysis many basic questions have not been resolved. Unlike the clear association with high BP and cardiovascular outcomes in the general population, studies done in dialysis patients showed an inverse relationship of BP recorded before or after dialysis $^{26-29}$. BP recordings obtained before or after HD sessions show high variability ${ }^{30}$, poor reproducibility and provide inaccurate estimates of the interdialytic burden. Outof-dialysis-unit blood pressure measurements provided superior prognostic information compared to in-center blood pressure ${ }^{31}$. Clinical studies indicate that ambulatory blood pressure monitoring (ABPM) is predictive of left ventricular hypertrophy (LVH) and hard patient outcomes ${ }^{32}$. However, ABPM has not been utilized 
on a large scale in HD patients, primarily because of logistic and financial constraints. Home BP measurements provide a valuable alternative ${ }^{33-35}$, but has gained only limited traction. A single-center cross-sectional study showed that home BP was better than pre-HD BP in predicting $\mathrm{LVH}^{35}$. Although the clear advantage of both ABPM and home $\mathrm{BP}$, these may not be feasible to use for most dialysis patients.

In contrast, in-center BP measurement is part of regular care and pre- and post-HD BP measurements are recommended by KDOQI guidelines ${ }^{11}$. However, conflicting results regarding their association with mortality have been reported. Port et al. ${ }^{14}$ analyzed 4,839 prevalent HD patients in the Unites Stated Renal Data System (USRDS) case mix adequacy study and found that both pre- and post-HD SBP below 120 to $149 \mathrm{mmHg}$ were associated with increased mortality, whereas only post-dialysis SBP hypertension (>180 $\mathrm{mmHg}$ ) was associated with increased mortality. Other observational studies have confirmed the "U-shaped" or "reverse J-shaped" relationship between BP and mortality, with the highest risk of death at lower pre- and post-dialysis SBP (generally $<130 \mathrm{mmHg}$ ) and only a slight increase, if any, at higher SBP ranges (>180 $\mathrm{mmHg})^{8,13,14,17}$. These differences in outcomes with pre and post SBP levels may be due to the different mechanisms influencing these BP changes during hemodialysis. BP dynamics in HD patients is complex, affected by time on dialysis, comorbidities, baseline cardiac function, fluid volume, medication, sodium load and other factors that interplay with one another ${ }^{36}$.

Peridialytic SBP increase, also called "intradialytic hypertension" in the event of a peridialytic SBP increase $>10 \mathrm{mmHg}$, has been recognized as a predictor of outcomes ${ }^{37}$. Park et al. ${ }^{16}$ studied 113,255 U.S. hemodialysis patients from 2001 to 2006 and found a U-shaped relationship between peridialytic SBP changes and all-cause and cardiovascular mortality. The best survival was seen with moderate declines in SBP (-30 to $0 \mathrm{mmHg}$ ), whereas SBP declines by more than $30 \mathrm{mmHg}$ and any peridialytic SBP increase were associated with higher mortality. Of note, in a subgroup analysis with stratification by pre-HD SBP $(<120,120-140,140-160,>160 \mathrm{mmHg})$ the authors found that the aforementioned U-shaped relationship between peridialytic SBP change and mortality was not seen in patients with pre-HD SBP $<120 \mathrm{mmHg}$. In these patients a peridialytic SBP rise was not associated with better or worse survival. However, the authors identified an increased mortality in those patients in the event of a peridialytic SBP decline.

In a post hoc analysis of 443 patients from the Crit-Line Intradialytic Monitoring Benefit (CLIMB) Study, Inrig et al. ${ }^{18}$ found that in patients whose SBP rose or failed to be reduced with $\mathrm{HD}$ had a two-fold increase in non-access related hospitalization and death at 6 months compared to patients with a peridialytic SBP fall. These results were validated in a sensitivity analysis where the authors excluded patients with a pre-HD SBP $<140 \mathrm{mmHg}$. Our results essentially corroborate these findings in patients with a high pre-HD SBP. However, because of the 388-times larger population in our study, we 
were able to further extend the analysis to patients with pre-HD SBP of $130 \mathrm{mmHg}$ and below, who clearly showed poor outcomes with peridialytic SBP decline.

In our study, when examining the results in patients with or without documented CHF, we observed directionally equivalent results compared to the entire population.

Blood pressure behavior is influenced by a variety of patient related factors, such as comorbidities burden and risk factors as autonomic dysfunction, stiff vasculature, impaired vasoreactivity, antihypertensive medications; and procedural factors including ultrafiltration rate, dialysate concentration of sodium and calcium concentrations [36]. The reaction of the resistance and capacitance of vessels during a decline in blood volume may be impaired during hemodialysis ${ }^{28,36,38}$. BP changes also occur because of a decline in preload, impaired cardiac response and reduced constriction of resistance and capacitance vessels. Depending on patient- and treatment-related factors, the relative importance of these factors may vary and are difficult to discern for a given patient without detailed physiological studies.

Our study helps to better understand the effect of BP behavior during HD, as we identified a subset of patients that could in fact benefit from SBP increases during HD, those with a low pre-HD SBP. In these patients a pre-existing low pre-HD SBP may reflect a worse cardiovascular condition with autonomic dysfunction and more comorbidities or with a too low target weight. Patients low pre-HD SBP who can increase their SBP during hemodialysis likely represent a phenotype that is able to mount a sufficient hemodynamic response in the face of ultrafiltration. This hemodynamic response may identify patients with a better overall cardiovascular state that eventually translates into better survival.

On the other end of the spectrum, patients with a high pre-dialysis SBP may suffer from chronic fluid overload and vascular stiffness ${ }^{25,39,40}$. In these patients a further peridialytic SBP increase could reflect poor fluid removal. Recent studies using bioimpedance measurements have demonstrated that patients with intradialytic SBP rise were fluid overloaded and had a higher extracellular-to-total body water ratio ${ }^{24,25,41}$. These patients would benefit from a more intensive ultrafiltration. Agarwal et al. $^{42}$ showed in the DRIP study that dry weight probing with more intensive ultrafiltration lowered both dialysis BP and ambulatory BP within 4 weeks. Patients whose dry weight decreased the most during the study changed from flat intradialytic BP slopes at baseline to steep declines at the end of the trial. Another possibility is that a rise in SBP during HD could be reflection of increased vascular resistance. Chou et al. $^{43}$ demonstrated an increased vascular resistance associated with intradialytic hypertension. Some studies have implicated an imbalance of vasoconstrictors and vasodilators to explain this increase in vascular resistance $37,44,45$.

Our study has several strengths, first and foremost its large and diverse HD population, the substantial number of baseline HD treatments per patient, standardized care protocols, automated BP recordings, and the long follow-up period. 
Some limitations should be addressed. First, its observational nature prevents causal conclusions. Second, we lack detailed records of intradialytic interventions that may have impacted post-HD SBP, such as change in ultrafiltration rate or fluid infusion. Third, objective indicators of fluid status (e.g. bioimpedance) are missing; these would allow a more extensive probing into the relationship between peridialytic SBP changes and fluid status. Fourth, use and timing of antihypertensive drugs are not documented in our data base; the same is true for residual renal function.

In conclusion, this study reports the joint association between pre-HD SBP levels and peridialytic SBP changes with all-cause mortality. It shows for the first time that increases in SBP during HD could in fact be beneficial for patients with low pre-HD SBP. These findings could aid the identification of different patient phenotypes and lead to a more patient-specific treatment. To further our understanding of the underlying pathophysiology requires specifically designed prospective studies with concurrent biochemical and physiological measurements. 


\section{References}

1. Charra B, et al. Survival as an index of adequacy of dialysis. Kidney Int. 1992;41(5):1286-1291.

2. Foley RN, Parfrey PS, Sarnak MJ. Clinical epidemiology of cardiovascular disease in chronic renal disease. Am J Kidney Dis. 1998;32(5 Suppl 3):S112-119.

3. Sytkowski PA, et al. Secular trends in long-term sustained hypertension, long-term treatment, and cardiovascular mortality. The Framingham Heart Study 1950 to 1990. Circulation. 1996;93(4):697-703.

4. Page MR. The JNC 8 hypertension guidelines: an in-depth guide. Am J Manag Care. 2014;20(1 Spec No.):E8.

5. Agarwal R, et al. Prevalence, treatment, and control of hypertension in chronic hemodialysis patients in the United States. Am J Med. 2003;115(4):291-297.

6. Foley RN, et al. Impact of hypertension on cardiomyopathy, morbidity and mortality in end-stage renal disease. Kidney Int. 1996;49(5):1379-1385.

7. Salem MM, Bower J. Hypertension in the hemodialysis population: any relation to one-year survival? Am J Kidney Dis. 1996;28(5):737-740.

8. Mazzuchi N, Carbonell E, Fernandez-Cean J. Importance of blood pressure control in hemodialysis patient survival. Kidney Int. 2000;58(5):2147-2154.

9. Duranti E, Imperiali P, Sasdelli M. Is hypertension a mortality risk factor in dialysis? Kidney Int Suppl. 1996;55:S173-174.

10. Foley RN, Herzog CA, Collins AJ. Blood pressure and long-term mortality in United States hemodialysis patients: USRDS Waves 3 and 4 Study. Kidney Int. 2002;62(5):1784-1790.

11. K/DOQI clinical practice guidelines for cardiovascular disease in dialysis patients. Am J Kidney Dis. 2005; 45(4 Suppl 3):S1-153.

12. Salem MM. Hypertension in the haemodialysis population: any relationship to 2-years survival? Nephrol Dial Transplant. 1999;14(1):125-128

13. Kalantar-Zadeh $\mathrm{K}$, et al. Reverse epidemiology of hypertension and cardiovascular death in the hemodialysis population: the 58th annual fall conference and scientific sessions. Hypertension. 2005; 45(4):811-817.

14. Port FK, et al. Predialysis blood pressure on survival in hemodialysis patients. Kidney Int. 2017;91(3): 755-756.

15. Robinson BM, et al. Blood pressure levels and mortality risk among hemodialysis patients in the Dialysis Outcomes and Practice Patterns Study. Kidney Int. 2012;82(5):570-580.

16. Park J, et al. A comparative effectiveness research study of the change in blood pressure during hemodialysis treatment and survival. Kidney Int. 2013;84(4):795-802.

17. Zager PG, et al. "U" curve association of blood pressure and mortality in hemodialysis patients. Medical Directors of Dialysis Clinic, Inc. Kidney Int. 1998;54(2):561-569.

18. Inrig JK, et al. Association of intradialytic blood pressure changes with hospitalization and mortality rates in prevalent ESRD patients. Kidney Int. 2007;71(5):454-461.

19. Inrig JK, et al. Association of blood pressure increases during hemodialysis with 2-year mortality in incident hemodialysis patients: a secondary analysis of the Dialysis Morbidity and Mortality Wave 2 Study. Am J Kidney Dis. 2009;54(5):881-890.

20. Chen J, Gul A, Sarnak MJ. Management of intradialytic hypertension: the ongoing challenge. Semin Dial. 2006;19(2):141-145.

21. Daugirdas JT. Pathophysiology of dialysis hypotension: an update. Am J Kidney Dis. 2001;38(4 Suppl 4): S11-17.

22. van der Sande FM, et al. Novel insights into the pathogenesis and prevention of intradialytic Hypotension. Blood Purif. 2018;45(1-3):230-235.

23. Meyring-Wosten, A., et al., Intradialytic hypertension is associated with low intradialytic arterial oxygen saturation. Nephrol Dial Transplant, 2018. 33(6): p. 1040-1045.

24. van Buren PN, et al. Extracellular volume overload and increased vasoconstriction in patients with recurrent intradialytic hypertension. Kidney Blood Press Res. 2016;41(6):802-814. 
25. Agarwal R, Light RP. Intradialytic hypertension is a marker of volume excess. Nephrol Dial Transplant. 2010;25(10):3355-3361.

26. Agarwal R. Exploring the paradoxical relationship of hypertension with mortality in chronic hemodialysis. Hemodial Int. 2004;8(3):207-213.

27. Agarwal R. Hypertension and survival in chronic hemodialysis patients--past lessons and future opportunities. Kidney Int. 2005;67(1):1-13.

28. Georgianos PI, Agarwal R. Epidemiology, diagnosis and management of hypertension among patients on chronic dialysis. Nat Rev Nephrol. 2016;12(10):636-647.

29. Georgianos PI, Agarwal R. Blood Pressure and Mortality in Long-Term Hemodialysis-Time to Move Forward. Am J Hypertens. 2017;30(3):211-222.

30. Rohrscheib MR, et al. Age-related blood pressure patterns and blood pressure variability among hemodialysis patients. Clin J Am Soc Nephrol. 2008;3(5):1407-1414.

31. Agarwal R. Blood pressure and mortality among hemodialysis patients. Hypertension. 2010;55(3): 762-768.

32. Agarwal R. Epidemiology of interdialytic ambulatory hypertension and the role of volume excess. Am J Nephrol. 2011;34(4):381-390.

33. Agarwal R, et al. Home blood pressure monitoring improves the diagnosis of hypertension in hemodialysis patients. Kidney Int. 2006;69(5):900-906.

34. Agarwal R, et al. Out-of-hemodialysis-unit blood pressure is a superior determinant of left ventricular hypertrophy. Hypertension. 2006;47(1):62-68.

35. Agarwal R, et al. Out-of-office blood pressure monitoring in chronic kidney disease. Blood Press Monit. 2009;14(1):2-11.

36. Levin NW, et al. Blood pressure in chronic kidney disease stage 5D-report from a Kidney Disease: Improving Global Outcomes controversies conference. Kidney Int. 2010;77(4):273-284.

37. Inrig JK. Intradialytic hypertension: a less-recognized cardiovascular complication of hemodialysis. Am J Kidney Dis. 2010;55(3):580-589.

38. Kooman J, et al. EBPG guideline on haemodynamic instability. Nephrol Dial Transplant. 2007;22 Suppl 2:ii22-44.

39. Dekker $\mathrm{M}$, et al. Pre-dialysis fluid status, pre-dialysis systolic blood pressure and outcome in prevalent haemodialysis patients: results of an international cohort study on behalf of the MONDO initiative. Nephrol Dial Transplant. 2018;33(11):2027-2034.

40. Zoccali C, et al. Chronic Fluid Overload and Mortality in ESRD. J Am Soc Nephrol. 2017;28(8): 2491-2497.

41. Chou JA, et al. Intradialytic hypotension, blood pressure changes and mortality risk in incident hemodialysis patients. Nephrol Dial Transplant. 2018;33(1):149-159.

42. Agarwal R, et al. Dry-weight reduction in hypertensive hemodialysis patients (DRIP): a randomized, controlled trial. Hypertension. 2009;53(3):500-507.

43. Chou KJ, et al. Physiological changes during hemodialysis in patients with intradialysis hypertension. Kidney Int. 2006;69(10):1833-1838.

44. Raj DS, et al. Hemodynamic changes during hemodialysis: role of nitric oxide and endothelin. Kidney Int. 2002;61(2):697-704.

45. Georgianos PI, Sarafidis PA, Zoccali. Intradialysis hypertension in end-stage renal disease patients: Clinical epidemiology, pathogenesis, and treatment. Hypertension. 2015;66(3):456-463. 


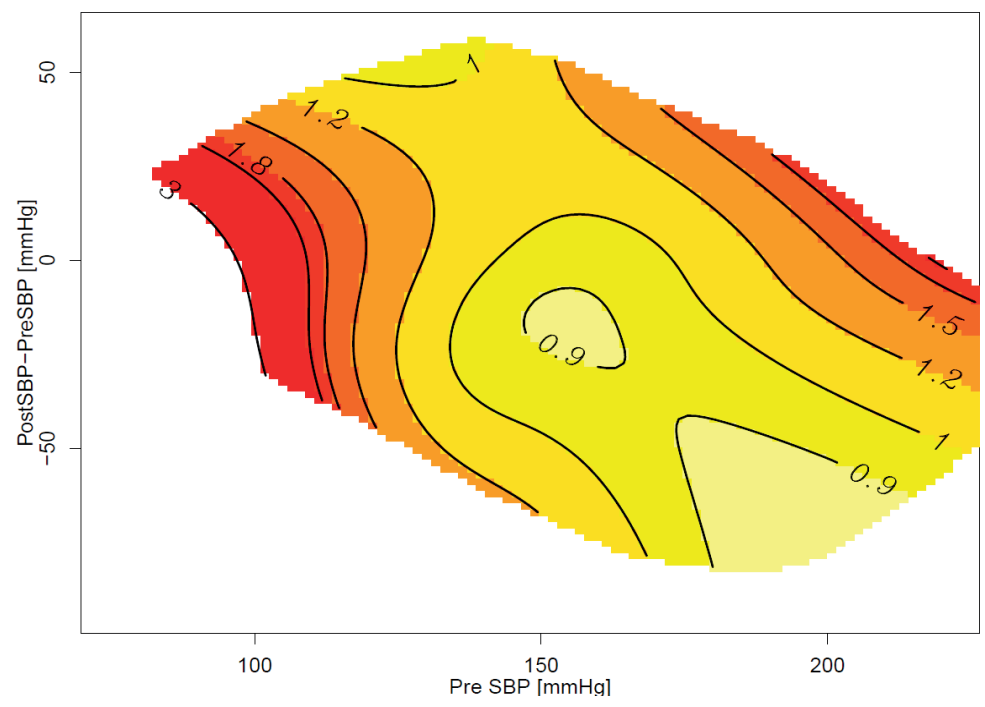

Figure S7.1 Contour plot showing the bivariate joint association between pre-HD SBP and peridialytic SBP change, and all-cause mortality in patients with CHF as a documented comorbidity. The lines and colors indicated discrete hazard ratios for all-cause mortality.

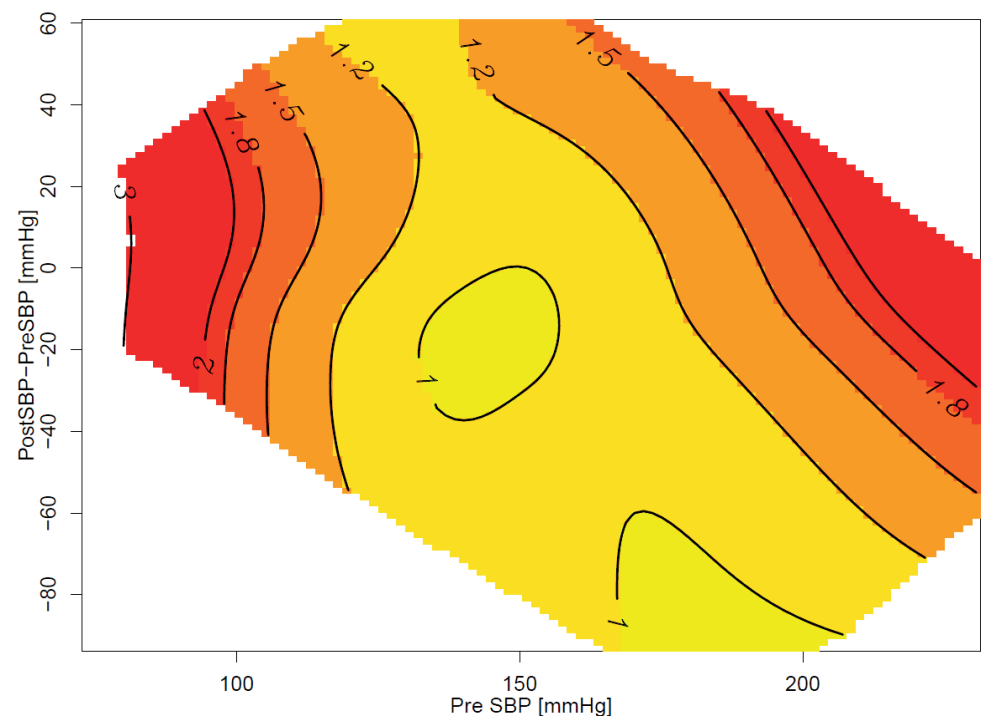

Figure S7.2 Contour plot showing the bivariate joint association between pre-HD SBP and peridialytic SBP change, and all-cause mortality after exclusion of patients with documented CHF. The lines and colors indicated discrete hazard ratios for all-cause mortality. 


\section{Chapter 8}

General discussion 



\section{General discussion}

The mortality rates of hemodialysis (HD) patients are substantially higher compared to those in the general population ${ }^{1}$. While traditional risk factors operative in the general population such as hypertension, diabetes mellitus and hyperlipidemia are reported as contributors to the high cardiovascular mortality, factors commonly found in this population such as anemia, hypoalbuminemia, and chronic inflammation, and dialysisspecific factors such as chronic fluid overload, uremia and those associated with the treatment per se, are putting dialysis patients at a substantially higher risk ${ }^{2}$.

With the investigations presented in this thesis we aimed to provide a deeper insight into the pathophysiological effects of the HD treatment, for which we had novel information measured by the Crit-Line monitor ${ }^{\mathrm{TM}}$ (CLM). These information included continuous measurements of blood oxygen saturation and relative blood volume (RBV) at very high frequency during $\mathrm{HD}^{3}$. In the context of the measurements of blood oxygen saturation it is of note that depending on the type of vascular access, the CLM can determine central-venous or arterial oxygen saturation. Deployment of the CLM in a large population of U.S. HD patients allowed for conduction of research into the potential clinical relevance of intradialytic blood oxygen saturation and RBV. The studies presented in this thesis focused on the associations between intradialytic measurements reflecting arterial and venous oxygen saturation, systolic blood pressure (SBP), and RBV with clinical outcomes. In Chapter 2 and Chapter 3, the associations of intradialytic arterial oxygen saturation with clinical outcomes such as intradialytic hypertension, hospitalization and mortality were studied. The relationship between central venous oxygen saturation and mortality and ultrafiltration volume corrected for body weight are discussed in Chapter 4 and Chapter 5. Intradialytic RBV was also associated with patient survival, which was studied in Chapter 6. Lastly, the relation between peri-dialytic SBP and outcome was investigated in Chapter 7.

Chapter 2 and Chapter 3 dealt with arterial oxygen saturation during HD. In Chapter 2, our research in a large cohort of chronic HD patients indicates a high rate of intradialytic hypoxemia, with $10 \%$ of studied patients experiencing prolonged intradialytic hypoxemia, a condition characterized by hypoxemia, defined by an arterial oxygen saturation below $90 \%$ lasting for more than $1 / 3$ of the dialysis treatment time. For these patients we report a significant association between prolonged intradialytic hypoxemia and the clinical outcomes all-cause hospitalization and mortality. Moreover, patients suffering from prolonged intradialytic hypoxemia showed a laboratory profile compatible with an inflammatory phenotype, and significantly higher epoetin alfa use. Notably, also congestive heart failure (CHF) and chronic obstructive pulmonary disease were more prevalent in patients presenting with prolonged intradialytic hypoxemia. Hypoxemia during HD has been recognized as a problem in the treatment since the early days of dialysis ${ }^{4-10}$. Over the years several mechanistic explanations have been put forward: One suggestion was leukocyte trapping with bioincompatible membranes 
amongst patients receiving standard acetate HD. Another was independent of the membrane and suggested that the metabolic effects of acetate could at least partially be responsible for the observed hypoxemia ${ }^{11}$. Another reason may also be sleep apnea, both central and obstructive, a condition highly prevalent in dialysis patients, which has been observed in patients while sleeping on dialysis ${ }^{12,13}$. Another plausible theory focuses on intradialytic $\mathrm{CO}_{2}$ loss which results from diffusion from the blood into the dialysate, with a subsequent decreased partial pressure of $\mathrm{CO}_{2}$ and a resulting respiratory drive. As breathing is tightly controlled by chemoreceptors which respond to the partial pressure of $\mathrm{CO}_{2}$ as well as $\mathrm{pH}$ in blood and cerebrospinal fluid, such a reduction in $\mathrm{CO}_{2}$ tension may result in hypoventilation and hypoxemia ${ }^{14}$.

An additional explanation for the occurrence of hypoxemia can be found in fluid overload causing pulmonary congestion which may affect oxygen diffusion, resulting in reduced blood oxygenation. Consequently, approaching the post-dialysis target weight during dialysis should improve arterial oxygen saturation. In our study, arterial oxygen saturation at the end of dialysis was generally above starting levels, and patients suffering from prolonged intradialytic hypoxemia had a slightly higher interdialytic weight gain, pointing towards fluid status as a determinant of arterial oxygen saturation. Also age-related changes of the respiratory system, such as a reduced neuro-mechanical link between chemosensors, brain stem and respiratory muscles, may impact ventilatory drive ${ }^{15}$. In that context it is noteworthy that patients with prolonged intradialytic hypoxemia were older, had a longer HD vintage, and a higher arterial oxygen saturation variability, possibly reflecting an instability of respiratory control. Previous studies related a high variability and decrease of arterial oxygen saturation during dialysis to intradialytic hypotension ${ }^{16,17}$. In the study reported in Chapter 2, hypotensive episodes were not sufficiently documented. However, we did not observe a difference in pre- and post-SBP and the changes during HD between the two groups.

Although a relationship between intradialytic hypoxemia and the morbidity and mortality of HD patients has been hypothesized ${ }^{4,18,19}$, the results of the study presented in Chapter 2 are to the best of our knowledge the first to show an association between adverse clinical outcomes and intradialytic hypoxemia. Notably these findings were consistent with reports from patients with CHF and sleep apnea, where it was observed that not only the frequency, but also the time spent with arterial oxygen saturation below 90\%, the hypoxic "burden", is a predictor for hemodynamic stress ${ }^{20}$. The decision in Chapter 2 to perform a dichotomous analysis and consider one third of the treatment time below $90 \%$ as the predefined diagnostic threshold was based on the "hypoxic burden" concept described in these patients with CHF. The notion of "prolonged intradialytic hypoxemia" was developed in appreciation of this concept ${ }^{20}$.

In Chapter 3, our research in a large and diverse population of chronic HD patients also showed for the first time a lower risk with higher intradialytic arterial oxygen saturation and intradialytic hypertension (defined as a peridialytic SBP increase $\geq 10 \mathrm{mmHg}$ ), and 
persistent intradialytic hypertension (defined as average peridialytic SBP increase $\geq 10 \mathrm{mmHg}$ throughout the entire 6-months observation period). Of note, our data are consistent with a report of intradialytic hypertension occurring at least once over an observation period of 6 months in $90 \%$ of patients ${ }^{21}$. While it was hypothesized that a rise in SBP is caused by fluid overload more detailed investigations are currently underway ${ }^{22-24}$.

Fluid overload may reduce alveolar oxygen diffusion, resulting in reduced arterial oxygen saturation which partly explains the association between arterial oxygen saturation and intradialytic SBP rise. Anand et al. found a positive relationship between the slope of the RBV curve, an indirect marker of volume status, and change in arterial oxygen saturation indicating a contribution of volume overload to hypoxemia ${ }^{25}$. Consistently, in our population those with persistent intradialytic hypertension patients had interdialytic weight gains indicating higher fluid overload after the interdialytic period. However, also reciprocal mechanisms may explain the relation between intradialytic SBP rise and arterial oxygen saturation. First, poor arterial oxygen saturation may result in tissue hypoxia. Evidence from both humans and rodents indicates that hypoxia triggers sympathetic activation and elevation of blood pressure $^{26-29}$. As a prime example in the published literature an increased peripheral chemoreflex sensitivity has been reported in patients with sleep apnea, which is also highly prevalent in end stage renal disease patients and frequently associated with hypertension ${ }^{30,31}$ whereas also sympathetic overactivity has been observed in patients with intradialytic hypertension ${ }^{32}$. Secondly, in vitro studies have shown that hypoxia induces endothelin-1 secretion from endothelial cells, a process promoted by reactive oxygen species ${ }^{33-35}$. Kanagy et al. have shown in rats that intermittent hypoxia triggered a significant increase of endothelin-1 plasma levels, causing increased mean arterial pressure ${ }^{36}$. Another study in mice observed that endothelin-1 is a major contributor to the vascular inflammatory remodelling induced by intermittent hypoxia $^{37}$. Of note, in patients with sleep-disordered breathing hypoxemia is associated with elevated plasma levels of endothelin- $1^{38}$ and facilitates endothelial dysfunction ${ }^{39,40}$. It is intriguing to speculate, that increased reactive oxygen species production due to intradialytic hypoxemia and tissue hypoxia induces endothelin-1 secretion, consecutive vasoconstriction, and eventually intradialytic hypertension. Testing these hypotheses to explain the link between intradialytic hypoxemia and blood pressure changes would require simultaneous measurements of arterial oxygen saturation, sympathetic activity, blood pressure, and endothelin-1 levels during HD, which should be addressed in future studies and remains speculative in the light of our studies.

Chapter 4 focused on the relation between changes in central venous oxygen saturation and survival in HD patients and found that that in chronic HD patients lower central venous oxygen saturation levels are associated with poorer survival. Central venous oxygen saturation is easily obtained in $\mathrm{HD}$ patients with central venous 
catheters, as the catheter tip is usually located at the cavoatrial junction. Central venous oxygen saturation is clinically valuable as it is a surrogate of pulmonary artery mixed venous oxygen saturation, which reflects cardiac output, tissue oxygen delivery, and tissue oxygen extraction ${ }^{41}$.

The central venous oxygen saturation levels found in our study was normally distributed with a mean of $58.7 \pm 7.3 \%$, which is substantially lower as compared to the levels of around $70 \%$ of that observed in healthy subjects ${ }^{42}$, but consistent with those reported in $\mathrm{HD}$ patients ${ }^{43}$. The exact etiology of low intradialytic central venous oxygen saturation in HD patients is not well established but may be partially explained by the lower hemoglobin levels, and the higher prevalence of cardiac dysfunction and pulmonary hypertension in HD patients.

The determinants of central venous oxygen saturation can be visualized by rearrangement of the familiar form of Fick's law ${ }^{44}$ and replacement of mixed venous oxygen saturation with central venous oxygen saturation, and cardiac output with upper body blood flow, which results in the following equation with central venous oxygen saturation ( $\mathrm{ScvO2}$ ) and arterial oxygen saturation ( $\mathrm{SaO} 2)$ in \%, upper body oxygen consumption in $\mathrm{ml} / \mathrm{min}$, hemoglobin (Hgb) in $\mathrm{g} / \mathrm{l}$, upper body blood flow (UBBF) in $\mathrm{l} / \mathrm{min}$, and $\mathrm{K}$ being 1.34 , the amount of oxygen (in $\mathrm{ml}$ ) bound per $\mathrm{g}$ of $\mathrm{Hgb}$.

$$
\mathrm{ScvO}_{2}=\mathrm{SaO}_{2^{-}} \frac{100 * \text { Upper body oxygen consumption }}{\mathrm{K}^{*} \mathrm{Hgb}{ }^{*} \mathrm{UBBF}}
$$

As outlined in Chapter 4 there are four components which may change during HD and cause a decrease in central venous oxygen saturation; (i) increased tissue oxygen consumption; (ii) a decrease in arterial oxygen saturation, (iii) a decrease in hemoglobin concentration, and (iv) a decrease in upper body blood flow. We suspect that a reduction in cardiac output and consequently a decrease in upper body blood flow is the predominant driving factor leading to a drop in central venous oxygen saturation. The almost linear relation between cerebral perfusion and cardiac output has been recently reviewed ${ }^{45}$. When faced with any of the other possibilities in a patient with intact cardiac function, there should be a compensatory response in cardiac output ${ }^{46}$. Cardiac output may decline during HD treatment due to poor vascular refill, which in combination with reduced venoconstriction may result in a reduction in venous return to the heart ${ }^{47,48}$ as well as by the effect of regional wall motion abnormalities ${ }^{49,50}$.

Our finding that patients with lower central venous oxygen saturation were older may reflect the poorer cardiac function expected in older subjects. The prevalence of CHF increases with age, as does CHF mortality ${ }^{51}$. On univariate analysis, age was an independent risk factor for mortality. However, even after adjustment for age in our analysis, central venous oxygen saturation as a continuous variable remained a significant predictor of mortality.

In our study, patients in the lower tertile of central venous oxygen saturation had lower pre-HD and lower post-HD SBP, a finding possibly related to low cardiac output. An 
association between low pre-HD SBP and mortality has been repeatedly shown ${ }^{52,53}$. It is interesting that in our study the prevalence of CHF did not differ between lower and upper tertiles of central venous oxygen saturation. No routine echocardiography assessments were available in our patients, so we cannot comment on the possibility of classification or misdiagnosis of CHF. One intriguing possibility is that we may be identifying a group of patients without clinically overt signs and symptoms of CHF at rest, who however have reduced cardiac reserve or autonomic dysfunction and are unable to mount the necessary increase in sympathetic response and cardiac output when faced with the hemodynamic stress of $\mathrm{HD}^{49,54}$.

In Chapter 5, we report an inverse relationship between intradialytic central venous oxygen saturation change and ultrafiltration volume corrected for body weight, meaning that most patients at high ultrafiltration volume corrected for body weight experienced a more pronounced intradialytic central venous oxygen saturation decline. This finding is likely driven by a decline in cardiac preload when ultrafiltration rate exceeds plasma refill rate. The acute reduction of the preload results in drop in stroke volume, cardiac output, and decreased tissue perfusion such as decreased cardiac microcirculation leading to an increase in stunned myocardial segments.

In situations where ultrafiltration rate exceeds plasma refill rate from the interstitial to intravascular space, right ventricular preload and stroke volume will drop and - if not compensated for by a sufficient increase in heart rate - a decline in cardiac output will ensue. A decline in cardiac output has recently been shown in an elaborate study utilizing cardiac magnet resonance imaging during dialysis ${ }^{55}$. In this study stroke volume and cardiac index declined during dialysis, and the degree of decline was inversely and significantly corrected with ultrafiltration volume. Importantly, in this study the number of stunned myocardial segments was positively correlated with ultrafiltration volume.

A minority of patients showed a positive central venous oxygen saturation trend with higher ultrafiltration volume corrected for body weight. We hypothesize that those patients may actually be well above their dry weight while being prescribed a too low ultrafiltration volume. RBV monitoring have been used for detecting hypervolemia. The association between RBV slopes and mortality have been found to be independent of ultrafiltration volume or ultrafiltration rate ${ }^{56}$. In the presence of excess fluid in the interstitial compartment and thus elevated interstitial hydrostatic pressures, the plasma refill rate can compensate (and even exceed) the fluid volume removal by ultrafiltration and hence prevent a decline in cardiac preload and cardiac output ${ }^{57,58}$. It is important to appreciate that fluid overload and interdialytic weight gain (the main determinant of ultrafiltration volume) are not necessarily correlated ${ }^{59}$

Based on our findings central venous oxygen saturation might evolve into a novel marker to monitor hemodynamic response to HD. In addition, it is conceivable that central venous oxygen saturation and the instantaneous estimation of cardiac output could serve as input into a system that controls the ultrafiltration rate. Such a control 
system could prevent undue central venous oxygen saturation drops by appropriate ultrafiltration rate adjustments; this could benefit in particular those with frequent episodes of intradialytic hypotension and incident HD patients, who have both a high morbidity and mortality and use central venous catheters as vascular access ${ }^{1,60}$.

In Chapter 6, our study aimed to explore the association between hourly intra-dialytic RBV levels and all-cause mortality in a large and diverse cohort of chronic HD patients with a sufficiently long follow-up. Our study found that HRs for all-cause mortality were significantly below 1 in patients whose RBV levels were $93-96 \%$ at the first hour, 89$94 \%$ at the second hour, and $86-92 \%$ at the third hour, respectively, indicate a significantly better survival in patients with RBVs within these favorable ranges compared to those with RBVs outside. While observational, our results add to the existing body of literature by suggesting that specific intradialytic RBV levels are associated with significantly lower all-cause mortality.

Fluid management in standard in-center HD need to be balanced: on one hand, ultrafiltration is the only means to remove fluid accumulated between HD treatments and to avoid acute and chronic fluid overload; on the other hand, excessive fluid removal may impact intradialytic hemodynamic stability. Indeed, HD-induced blood volume reduction is considered an important causal factor of intradialytic cardiovascular instability and depends on rates of ultrafiltration and vascular refilling ${ }^{49,61}$. Given these competing factors, it is conceivable that on a population level and over the course of an HD session certain RBV ranges are associated with lower (or higher) mortality. While the genesis of the RBV curve is easy to understand qualitatively as the relative difference between ultrafiltration rate and vascular refilling rate, attempts to quantitatively model and predict RBV dynamics are notoriously complicated and currently not applicable to routine care ${ }^{58}$. The matter is further complicated by the absence of randomized controlled trials looking at the relationship between the attainment of RBV targets and patient outcomes.

A randomized controlled trial, the CLM Intradialytic Monitoring Benefit (CLIMB) Study, tested the hypothesis that the availability of hematocrit-based intradialytic RBV monitoring with CLM as a voluntary adjunct to clinical care would decrease morbidity associated with ultrafiltration in comparison with patient management using conventional clinical criteria such as symptoms, blood pressure, weight, and physical examination $^{62}$. The primary outcome for power calculations was hospitalization, based on the assumption that inadequate or overly aggressive fluid removal may independently result in increased morbidity. The study team developed a sophisticated monitoring and intervention protocol that called for specific steps in case certain predefined clinical and RBV threshold criteria were met. The study failed to yield positive results; in fact, the use of RBV monitoring was associated with increased morbidity and mortality in the CLIMB Study, calling into question the concept of RBV monitoring.

In this situation, clinical practitioners who use RBV monitoring resort to a qualitative and empirical assessment of RBV curves, where flat curves are considered to indicate 
fluid overload and steep curves intravascular volume depletion that may precipitate intradialytic hypotension ${ }^{63,64}$. This study is the first one to relate RBV on a population level to survival.

In our study, about two-thirds of our patients had RBVs above the favorable ranges. These results resemble other studies that showed that a substantial fraction of patients had minor or no change in RBV during $\mathrm{HD}^{63,65}$. Lopot et al. reported that $30 \%$ of their patients showed no intradialytic RBV decline ${ }^{63}$, and Steuer et al. reported that $18 \%$ of their patients had less than a 5-percentage point RBV reduction during $\mathrm{HD}^{65}$. In their study, Steuer et al. safely increased fluid removal guided by intradialytic RBV monitoring in $80 \%$ of these patients, showing that a large fraction of HD patients could tolerate additional fluid removal.

In our study, almost all patients with RBVs outside the favorable ranges actually had RBVs above the upper limits of these ranges. It is important to note that these patients had some clinical indicators of fluid overload, such as higher post-HD SBP. While plausible, this observation needs corroboration using measurements of fluid status, such as bioimpedance, which is currently not available in the U.S. for routine care. If fluid overload is indeed confirmed, the relatively low ultrafiltration rate of around 7 $\mathrm{mL} /$ hour/kg body weight indicates that there may exist opportunities to remove excess fluid without increasing the risk of intradialytic morbidity, although this may also be dependent upon the cardiovascular status of the patient. Indeed, it is also interesting to note that patients with RBVs outside the favorable range were older, had higher prevalence of $\mathrm{CHF}$, and had lower ultrafiltration rates compared with those patients who attained RBVs within the favorable range. These findings are consistent with epidemiological studies showing lower ultralfiltration volumes and rates in elderly patients $^{66}$, possibly because the elderly population per se is considered particularily vulnerable to intradialytic morbid events ${ }^{67}$ and tolerate lower ultrafiltration volumes. Higher age predisposes to comorbidities, including diabetes mellitus and CHF, which may prompt a more cautious approach to intradialytic fluid removal. Ficociello et al. reported $64.5 \%$ lower all-cause hospitalization rate in patients with an end-dialytic RBV below $85 \%$ compared to patients with unchanged RBV, lending further plausibility to our results ${ }^{68}$. We are cognizant of the fact that causality cannot be derived from this observational study, and that this study must not be interpreted as a recommendation for certain RBV ranges. However, our results may serve in the planning of a sufficiently powered randomized controlled trials or quality improvement project.

In Chapter 7, our study explored the association between peridialytic SBP changes in conjunction with pre-dialysis SBP levels and all-cause mortality in a large and diverse cohort of HD patients. The main finding of our study is the interaction of peridialytic SBP changes in relation to pre-dialysis SBP level with mortality, depicting baseline clinical differences among patients. In patients whose pre-dialysis SBP is low an increase in SBP during HD is associated with improved outcomes as compared to patients experiencing a further decline; whereas, contrastingly, a further increase of 
SBP in patients who already begin HD with a high SBP level is associated with adverse outcomes.

In this cohort of 191446 HD patients, we confirmed that hemodynamic responses during HD are associated with outcomes, but most importantly we demonstrated that these responses have a different relation to outcome depending on the pre-dialysis blood pressure of the patients. These results provide an opportunity to better understand the hemodynamic responses during HD and to characterize different blood pressure -patterns and different targets among HD patients.

Pre-dialysis and post-dialysis blood pressure levels are presently the recommended measurements to use by the KDOQI guidelines ${ }^{69}$, with a vast literature on pre- and post-dialysis blood pressure patterns and its association with outcomes; albeit, conflicting evidence is out there. Port et al $^{70}$ analysed data from 4839 prevalent HD patients in the Unites Stated Renal Data System (USRDS) case mix adequacy study and found that both pre- and post-dialysis SBP below 120 to $149 \mathrm{mmHg}$ were associated with increased mortality, whereas, high SBP $(>180 \mathrm{mmHg})$, only post-dialysis SBP was associated with increased mortality. Other observational studies have confirmed the "U-shaped" or "reverse J-shaped" relationship between blood pressure and mortality, with the highest risk of death at lower pre- and post-dialysis SBP (generally $<130$ $\mathrm{mmHg}$ ) and only a slight increase, if any, at higher SBP ranges $(>180 \mathrm{mmHg})^{70-73}$.

Recently an increased interest has emerged regarding the prognostic effect of peridialytic blood pressure changes during HD, with interest if these changes may reflect the physiologic or pathophysiologic hemodynamic response to the HD treatment. Some of the results in our study are in line with other studies that described that both increases and decreases in SBP as a response to HD are associated with poor outcomes. Park et al $^{74}$ included a total of 113255 US HD patients from 2001 to 2006. They found a U-shaped relationship between pre- to post-dialysis blood pressure changes and all-cause and cardiovascular mortality. The best survival was seen with moderate declines in SBP ( -30 to $0 \mathrm{mmHg}$ ), whereas greater declines $(-30 \mathrm{mmHg}$ ) and any increases in SBP (>0 mmHg) were associated with higher mortality. Interestingly and contrary with the result in our study, there were no difference in outcomes when they compared it across different strata of pre-dialysis SBP.

On the other hand, Inrig et $\mathrm{al}^{75}$ in a post hoc analysis of the Crit-Line Intradialytic Monitoring Benefit (CLIMB) Study, found that patients whose blood pressure rose or failed to lower with HD had a two-fold increase in non- access related hospitalization and death at 6 months compared to patients with pre- to post- HD blood pressure fall. This risk associated with a blood pressure increase during HD was in fact magnified in patients with low pre-HD SBP.

Blood pressure behaviour is influenced by a variety of patient related factors, such as comorbidities, antihypertensive medications and procedural factors including ultrafiltration rates and shifts during HD, neurohormonal axis, inflammatory pathways activation. 
In conclusion, blood pressure changes could occur as a result of a decline in blood volume, impaired cardiac response and impaired constriction of resistance and capacitance vessels. Depending on patient- and treatment-related factors, the relative importance of these factors may vary. Our study helps to better understand the effect of blood pressure behaviour during HD, as we identified a subset of patients that could in fact benefit from SBP increases during HD, those with a low pre-dialysis SBP. In these patients a pre-existing low pre-dialysis SBP may reflect an impaired cardiovascular response with autonomic dysfunction, more comorbidities or target weights below they real dry weights. Patients with the ability to rise SBP during HD could represent those patients with better cardiovascular and sympathetic response, supporting that the rise in SBP is in fact the reflection of a better overall cardiovascular state that translates into better survival.

On the other end, higher pre-dialysis SBP may reflect chronic fluid overload ${ }^{75,76}$, stiff vasculature, more comorbidities. In these patients a further increase in SBP during HD could reflect poor fluid removal. Recent studies using bioimpedance measurements have demonstrated that patients with intradialytic SBP rise were fluid overloaded and had a higher extracellular-to-total body water ratio $22,23,76,77$. In this scenario, patients would benefit with a more intensive ultrafiltration leading to a lower SBP. Agarwal et $\mathrm{al}^{78}$ revealed that dry weight probing with more intensive ultrafiltration lowered both dialysis blood pressure as well as ambulatory blood pressure in as little as 4 weeks. Patients whose dry weight decreased the most during the study changed from flat intradialytic blood pressure slopes at baseline to steep declines at the end of the trial.

Another possibility is that a rise in SBP during HD could be reflection of increased vascular resistance. Chou et al $^{79}$ demonstrated using echocardiograms an increased vascular resistance associated with intradialytic hypertension. Some studies have implicated an imbalance of vasoconstrictor or vasodilators to explain this increase in vascular resistance ${ }^{80-82}$. Additionally, sympathetic overactivity has been observed in patients with increases in $\mathrm{SBP}^{83-85}$.

In conclusion, we report the association between pre-dialysis SBP levels and peridialytic SBP changes combine with all-cause mortality, showing for the first time that in some cases increases in SBP during treatment could in fact be beneficial for some patients. These could potentially lead to identified different phenotypes of patients and to a more patient-specific HD treatment. Testing this hypothesis requires specifically designed prospective studies with concurrent biochemical and physiological measurements. 


\section{Strength and limitations}

\section{Strengths}

Our studies have several strengths, such as the large and diverse HD population, large number of baseline HD treatments, standardized care protocols, granular data including intradialytic measurements from CLM, automated oxygen saturation and RBV data recording, and long follow-up periods. Given the uniqueness of data, we conducted thorough analyses using various analytic strategies including sensitivity and subset analyses. Our study population have large geographic variability which supports the generalizability of our findings. Also, some of the analyses related to oxygen saturation and RBV are novel findings as there are no previous studies in such detailed fashion.

\section{Limitations}

Admittedly, our studies had several limitations, first and foremost its observational nature, which prevents conclusions concerning causality. Second, there are some information we don't have, such as data regarding fluid status (e.g. by using bio impedance), antihypertensive drugs, and residual renal function are not recorded in our database, we acknowledge that this kind of data would have greatly added to our analysis. And routine echocardiograms are unfortunately not available in our study population, making potentially very insightful correlational analyses of central venous oxygen saturation and cardiac structure and function impossible. Also, the exact positions of the central venous catheters tips are unknown to us, since our electronic health records do not report the related chest X-ray findings. Lastly, we have no information on the intradialytic hypotension episodes interventions during dialysis (e.g. fluid administration), all of which cearly affect RBV.

\section{Conclusion}

Since the commencement of usage of CLM in clinics of the Renal Research Institute, New York, US, oxygen saturation, and RBV can be easily and continuously obtained during HD treatments in patients. Peri-dialytic SBP was routinely collected. Incorporating all these intradialytic measurements into clinical practice, our research had suggested that oxygen saturation, SBP, RBV, are associated with clinical outcomes such as hospitalization and mortality. A better understanding of the pathophysiology, clinical consequences and medical management requires future carefully designed in vitro and clinical studies. Our results may serve as an evidence-based guide for the development of prospective clinical studies. We believe that our results will motivate and encourage adequately equipped and trained clinical researchers to embark on specialized studies to that end. 
Currently, along with the rollout of CLM in Fresenius Medical Care North America, we believe what we have learned in the thesis will help us in the following_potential clinical implications and will be subjects of exciting future research:

- Identify prolonged intradialytic hypoxemia utilizing arterial oxygen saturation in arterio-venous fistula / graph patients

- Arterial oxygen saturation can be used for real time detection/alert of sleep apnea syndrome

- $\quad$ RBV and oxygen saturation can be utilized for real time ultrafiltration rate feedback control

- Upper body blood flow is a surrogate for cardiac output and can be used for hemodynamic monitoring during HD

- Oxygen Saturation and RBV combined with other information stored in the knowledge center can be utilized to develop machine learning algorithm(s) to predict morbidity and mortality 


\section{References}

1. United States Renal Data System. 2015 USRDS annual data report: Epidemiology of kidney disease in the United States. (National Institutes of Health, National Institute of Diabetes and Digestive and Kidney Diseases, 2015).

2. Foley RN, Parfrey PS. Risk factors for cardiac morbidity and mortality in dialysis patients. Curr Opin Nephrol Hypertens. 1994;3:608-614.

3. Balter $P$, Artemyev M, Zabetakis $P$. Methods and challenges for the practical application of crit-line monitor utilization in patients on hemodialysis. Blood Purif. 2015;39:21-24.

4. Jones JG, Bembridge JL, Sapsford DJ, Turney JH. Continuous measurements of oxygen saturation during haemodialysis. Nephrol Dial Transpl. 1992;7:110-116.

5. Fawcett S, et al. Haemodialysis-induced respiratory changes. Nephrol Dial Transpl. 1987;2:161-168.

6. Cardoso $\mathrm{M}$, et al. Hypoxemia during hemodialysis: a critical review of the facts. Am J Kidney Dis. 1988;11:281-297.

7. De Broe ME, De Backer WA. Pathophysiology of hemodialysis-associated hypoxemia. Adv Nephrol Necker Hosp. 1989;18:297-315.

8. Igarashi H, Kioi S, Gejyo F, Arakawa M. Physiologic approach to dialysis-induced hypoxemia. Effects of dialyzer material and dialysate composition. Nephron. 1985;41:62-69.

9. De Backer WA, et al. Hypoxemia during hemodialysis: effects of different membranes and dialysate compositions. Kidney Int. 1983;23:738-743.

10. Jacob Al, Gavellas G, Zarco R, Perez G, Bourgoignie JJ. Leukopenia, hypoxia, and complement function with different hemodialysis membranes. Kidney Int. 1980;18:505-509.

11. Francos GC, Besarab A, Burke JF Jr, et al. Dialysis-induced hypoxemia: membrane dependent and membrane independent causes. Am J Kidney Dis. 1985;5(3):191-198.

12. Nicholl DD, et al. Clinical presentation of obstructive sleep apnea in patients with chronic kidney disease. J Clin Sleep Med 2012;8:381-387.

13. Chan $\mathrm{CT}$, et al. Impact of nocturnal hemodialysis on the variability of heart rate and duration of hypoxemia during sleep. Kidney Int. 2004;65:661-665.

14. Pierson DJ. Respiratory considerations in the patient with renal failure. Respir Care. 2006;51:413-422.

15. Janssens JP, Pache JC, Nicod LP. Physiological changes in respiratory function associated with ageing. Eur Respir J. 1999;13:197-205.

16. Diroll D. Oxygen as an adjunct to treat intradialytic hypotension during hemodialysis. Nephrol Nurs J. 2014;41:420-423.

17. Mancini $E$, et al. Short term variability of oxygen saturation during hemodialysis is a warning parameter for hypotension appearance. Computers in Cardiology. 2008;881-884 (IEEE, 2008).

18. Alfakir $\mathrm{M}$, et al. Pulmonary gas exchange during hemodialysis: a comparison of subjects with and without COPD on bicarbonate hemodialysis. Ann Clin Lab Sci. 2011;41:315-320.

19. Nielsen AL, Jensen HAE. Oxygen status: a standard evaluation in uremic patients? Dial Transplant. 1994;23:288.

20. Gottlieb JD, et al. Hypoxia, not the frequency of sleep apnea, induces acute hemodynamic stress in patients with chronic heart failure. J Am Coll Cardiol. 2009;54:1706-1712.

21. Van Buren PN, Kim C, Toto RD, Inrig JK. The prevalence of persistent intradialytic hypertension in a hemodialysis population with extended follow-up. Int J Artif Organs. 2012;35:1031-1038.

22. Nongnuch A, et al. Increased postdialysis systolic blood pressure is associated with extracellular overhydration in hemodialysis outpatients. Kidney Int. 2015;87:452-457.

23. Van Buren PN, et al. Extracellular Volume Overload and Increased Vasoconstriction in Patients With Recurrent Intradialytic Hypertension. Kidney Blood Press Res. 2016;41:802-814.

24. Sebastian S, Filmalter C, Harvey J, Chothia MY. Intradialytic hypertension during chronic haemodialysis and subclinical fluid overload assessed by bioimpedance spectroscopy. Clin Kidney J. 2016;9:636-643.

25. Anand S, Sinha AD, Agarwal R. Determinants and short-term reproducibility of relative plasma volume slopes during hemodialysis. Clin J Am Soc Nephrol. 2012;7:1996-2001. 
26. Lusina SJ, et al. Long-term intermittent hypoxia increases sympathetic activity and chemosensitivity during acute hypoxia in humans. J Physiol. 2006;575:961-970.

27. Shell B, Faulk K, Cunningham JT. Neural Control of Blood Pressure in Chronic Intermittent Hypoxia. Curr Hypertens Rep. 2016;18:19.

28. Ferreira CB, et al. Brainstem areas activated by intermittent apnea in awake unrestrained rats. Neuroscience. 2015;297:262-271.

29. Prabhakar NR, Kumar GK. Mechanisms of sympathetic activation and blood pressure elevation by intermittent hypoxia. Respir Physiol Neurobiol. 2010;174:156-161.

30. Roumelioti ME, Brown LK, Unruh ML. The relationship between volume overload in end-stage renal disease and obstructive sleep apnea. Semin Dial. 2015;28(5):508-513.

31. Zoccali C, Mallamaci F, Tripepi G. Sleep apnea in renal patients. J Am Soc Nephrol. 2001;12:2854-2859.

32. Rubinger D, Backenroth R, Sapoznikov D. Sympathetic activation and baroreflex function during intradialytic hypertensive episodes. PLoS One. 2012;7:e36943.

33. Faller DV. Endothelial cell responses to hypoxic stress. Clin Exp Pharmacol Physiol. 1999;26:74-84.

34. Kourembanas S, Marsden PA, McQuillan LP, Faller DV. Hypoxia induces endothelin gene expression and secretion in cultured human endothelium. J Clin Invest. 1991;88:1054-1057.

35. Chen HC, Guh JY, Shin SJ, Tsai JH, Lai Y. H. Reactive oxygen species enhances endothelin-1 production of diabetic rat glomeruli in vitro and in vivo. J Lab Clin Med. 2000;135:309-315.

36. Kanagy NL, Walker BR, Nelin LD. Role of endothelin in intermittent hypoxia-induced hypertension. Hypertension. 2001;37:511-515.

37. Gras E, et al. Endothelin-1 mediates intermittent hypoxia-induced inflammatory vascular remodeling through HIF-1 activation. J Appl Physiol. 2016;120:437-443.

38. Gjorup PH, et al. Abnormally increased endothelin-1 in plasma during the night in obstructive sleep apnea: relation to blood pressure and severity of disease. Am J Hypertens. 2007;20:44-52.

39. Hoyos CM, Melehan KL, Liu PY, Grunstein RR, Phillips CL. Does obstructive sleep apnea cause endothelial dysfunction? A critical review of the literature. Sleep Med Rev. 2015;20:15-26.

40. Sawatari $\mathrm{H}$, et al. Cumulative Hypoxemia During Sleep Predicts Vascular Endothelial Dysfunction in Patients With Sleep-Disordered Breathing. Am J Hypertens. 2016;29:458-463.

41. Walley KR. Use of central venous oxygen saturation to guide therapy. Am J Respir Crit Care Med. 2011; 184:514-520.

42. Barratt-Boyes BG, Wood EH. The oxygen saturation of blood in the venae cavae, right-heart chambers, and pulmonary vessels of healthy subjects. J Lab Clin Med. 1957;50:93-106.

43. Harrison LE, Selby NM, Mclntyre CW. Central venous oxygen saturation: a potential new marker for circulatory stress in haemodialysis patients? Nephron Clin Pr. 2014;128:57-60.

44. Mathews L, Singh RKK. Cardiac output monitoring. Ann Card Anaesth. 2008;11:56-68

45. Meng L, Hou W, Chui J, Han R, Gelb AW. Cardiac Output and Cerebral Blood Flow: The Integrated Regulation of Brain Perfusion in Adult Humans. Anesthesiology. 2015;123:1198-1208.

46. Blumberg A, Keller G. Oxygen consumption during maintenance hemodialysis. Nephron. 1979;23: 276-281.

47. Kooman JP, et al. Role of the venous system in hemodynamics during ultrafiltration and bicarbonate dialysis. Kidney Int. 1992;42:718-726.

48. Cornelis $\mathrm{T}$, et al. Acute hemodynamic response and uremic toxin removal in conventional and extended hemodialysis and hemodiafiltration: a randomized crossover study. Am J Kidney Dis 2014;64:247-256.

49. Daugirdas JT. Dialysis hypotension: a hemodynamic analysis. Kidney Int. 1991;39:233-246.

50. Selby NM, Lambie SH, Camici PG, Baker CS, Mclntyre CW. Occurrence of regional left ventricular dysfunction in patients undergoing standard and biofeedback dialysis. Am J Kidney Dis. 2006;47: 830-841.

51. Schocken DD, Arrieta MI, Leaverton PE, Ross EA. Prevalence and mortality rate of congestive heart failure in the United States. J Am Coll Cardiol 1992;20:301-306.

52. Li Z, et al. The epidemiology of systolic blood pressure and death risk in hemodialysis patients. Am J Kidney Dis. 2006;48:606-615.

53. Port FK, et al. Predialysis blood pressure and mortality risk in a national sample of maintenance hemodialysis patients. Am J Kidney Dis. 1999;33:507-517. 
54. Chesterton LJ, et al. Categorization of the hemodynamic response to hemodialysis: the importance of baroreflex sensitivity. Hemodial Int. 2010;14:18-28.

55. Buchanan $\mathrm{C}$, et al. Intradialytic cardiac magnetic resonance imaging to assess cardiovascular responses in a short-term trial of hemodiafiltration and hemodialysis. J. Am. Soc. Nephrol. 2017;28(4):1269-1277.

56. Agarwal R. Hypervolemia is associated with increased mortality among hemodialysis patients. Hypertension. 2010;56:512-517.

57. Ebah LM, et al. Subcutaneous interstitial pressure and volume characteristics in renal impairment associated with edema. Kidney Int. 2013;84:980-988.

58. de los Reyes VA, et al. A physiologically based model of vascular refilling during ultrafiltration in hemodialysis. J Theor Biol. 2016;390:146-155.

59. Hecking $M$, et al. Significance of interdialytic weight gain versus chronic volume overload: consensus opinion. Am J Nephrol. 2013;38:78-90.

60. Bradbury BD, et al. Predictors of early mortality among incident US hemodialysis patients in the Dialysis Outcomes and Practice Patterns Study (DOPPS). Clin J Am Soc Nephrol. 2007;2:89-99.

61. Daugirdas JT. Pathophysiology of dialysis hypotension: An update. Am. J. Kidney Dis. 2001;38:S11-S17.

62. Reddan DN. Intradialytic Blood Volume Monitoring in Ambulatory Hemodialysis Patients: A Randomized Trial. J. Am. Soc. Nephrol. 2005;16:2162-2169.

63. Lopot F, Kotyk P, Bláha J, Forejt J. Use of continuous blood volume monitoring to detect inadequately high dry weight. Int. J. Artif. Organs 1996;19:411-414.

64. Beige J, et al. Computational analysis of blood volume curves and risk of intradialytic morbid events in hemodialysis. Kidney Int. 2000;58:1805-1809.

65. Steuer RR, Germain MJ, Leypoldt JK, Cheung AK. Enhanced fluid removal guided by blood volume monitoring during chronic hemodialysis. Artif. Organs. 1998;22:627-632.

66. Canaud B, et al. Clinical practices and outcomes in elderly hemodialysis patients: results from the Dialysis Outcomes and Practice Patterns Study (DOPPS). Clin J Am Soc Nephrol. 2011;6:1651-1662.

67. Andrulli $S$, et al. The role of blood volume reduction in the genesis of intradialytic hypotension. Am. J. Kidney Dis. 2002; 40:1244-1254.

68. Ficociello LBP, Taylor P, Mullon C, Zabetakis PKR. Lower hospital admission rate was associated with greater reduction in relative blood volume In hemodialysis patients. NKF Spring Clin. Meet. Abstr. (2015).

69. K/DOQI clinical practice guidelines for cardiovascular disease in dialysis patients. Am J Kidney Dis. 2005;45:S1-153.

70. Port FK, et al. Predialysis blood pressure on survival in hemodialysis patients. Kidney Int. 2017;91: 755-756.

71. Mazzuchi N, Carbonell E, Fernandez-Cean J. Importance of blood pressure control in hemodialysis patient survival. Kidney Int. 2000;58(5):2147-2154.

72. Kalantar-Zadeh K, Kilpatrick RD, McAllister CJ, Greenland S, Kopple JD. Reverse epidemiology of hypertension and cardiovascular death in the hemodialysis population: The 58th annual fall conference and scientific sessions. Hypertension. 2005;45(4):811-817.

73. Zager PG, et al. ' $U$ ' curve association of blood pressure and mortality in hemodialysis patients. Medical Directors of Dialysis Clinic, Inc. Kidney Int. (1998). doi:10.1046/j.1523-1755.1998.00005.x

74. Park J, et al. A comparative effectiveness research study of the change in blood pressure during hemodialysis treatment and survival. Kidney Int. 1998;54(2):561-569.

75. Inrig JK, et al. Association of intradialytic blood pressure changes with hospitalization and mortality rates in prevalent ESRD patients. Kidney Int. 2007;71(5):454-461.

76. Agarwal R, Light RP. Intradialytic hypertension is a marker of volume excess. Nephrol Dial Transpl. 2010;25:3355-3361.

77. Chou JA, et al. Intradialytic hypotension, blood pressure changes and mortality risk in incident hemodialysis patients. Nephrol Dial Transpl. 2018;33:149-159.

78. Agarwal R, Alborzi P, Satyan S, Light RP. Dry-weight reduction in hypertensive hemodialysis patients (DRIP): A randomized, controlled trial. Hypertension. 2009;53(3):500-507.

79. Chou KJ, et al. Physiological changes during hemodialysis in patients with intradialysis hypertension. Kidney Int. 2006;69:1833-1838. 
80. Raj DSC, et al. Hemodynamic changes during hemodialysis: Role of nitric oxide and endothelin. Kidney Int. 2002;61(2):697-704.

81. Inrig JK. Intradialytic Hypertension: a less-recognized cardiovascular complication of hemodialysis. Am J Kidney Dis. 2010;55(3):580-589.

82. Georgianos PI, Sarafidis PA, Zoccali C. Intradialysis hypertension in end-stage renal disease patients: Clinical epidemiology, pathogenesis, and treatment. Hypertension. 2015;66:456-463.

83. Converse RL, et al. Sympathetic overactivity in patients with chronic renal failure. N. Engl. J. Med. 1992;327(27):1912-1918

84. Augustyniak RA, Tuncel M, Zhang W, Toto RD, Victor RG. Sympathetic overactivity as a cause of hypertension in chronic renal failure. J Hypertens. 2002;20(1):3-9.

85. Grassi G, Seravalle G, Quarti-Trevano F. The 'neuroadrenergic hypothesis' in hypertension: Current evidence. Exp Physiol. 2010;95(5):581-586. 

Summary 



\section{Summary}

The investigations presented in this thesis aim to provide deeper insights into the pathophysiological effects of the hemodialysis (HD) treatment, using novel information measured by the Crit-Line monitor ${ }^{\mathrm{TM}}$ (CLM). These data include continuous measurements of blood oxygen saturation and relative blood volume (RBV) at very high frequency during HD. Regarding measurements of blood oxygen saturation it is of note that - depending on the type of vascular access - the CLM can determine either centralvenous or arterial oxygen saturation. Deployment of the CLM in a large population of U.S. HD patients allowed for conduction of research into the potential clinical relevance of intradialytic blood oxygen saturation and RBV. The studies presented in this thesis focused on the associations between intradialytic measurements reflecting arterial and venous oxygen saturation, systolic blood pressure (SBP), and RBV with clinical outcomes.

In Chapter 2 and Chapter 3, the associations of intradialytic arterial oxygen saturation with clinical outcomes such as intradialytic hypertension, hospitalization and mortality were studied. We found that in a large cohort of chronic HD $10 \%$ of the studied patients experience prolonged intradialytic hypoxemia, a condition defined by an arterial oxygen saturation below $90 \%$ lasting for more than $1 / 3$ of the dialysis treatment. A significant association between prolonged intradialytic hypoxemia and the clinical outcomes all-cause hospitalization and mortality was observed. We also showed for the first time a lower risk with higher intradialytic arterial oxygen saturation and intradialytic hypertension (defined as a peri-dialytic SBP increase $\geq 10 \mathrm{mmHg}$ ), and persistent intradialytic hypertension (defined as average peri-dialytic SBP increase $\geq 10 \mathrm{mmHg}$ throughout the entire 6-months observation period).

The relationship between central venous oxygen saturation and mortality and ultrafiltration volume are discussed in Chapter 4 and Chapter 5. We found that in chronic HD patients lower central venous oxygen saturation levels are associated with poorer survival. Also inverse relationship between intradialytic central venous oxygen saturation change and ultrafiltration volume corrected for body weight, meaning that most patients at high ultrafiltration volume weight experienced a more pronounced intradialytic central venous oxygen saturation decline.

Intradialytic RBV was also associated with patient survival, which was studied in Chapter 6. Our study found that hazard ratios for all-cause mortality were significantly below 1 in patients whose RBV levels were 93-96\% at the first hour, 89-94\% at the second hour, and $86-92 \%$ at the third hour, respectively, indicate a significantly better survival in patients with RBVs within these favourable ranges compared to those with RBVs outside.

Lastly, the relation between peri-dialytic SBP and outcome was investigated in Chapter 7. The main finding of this study is the interaction of peridialytic SBP changes in relation to pre-dialysis SBP level with mortality, depicting baseline clinical differences 
among patients. In patients whose pre-dialysis SBP is low an increase in SBP during HD is associated with improved outcomes as compared to patients experiencing a further decline; whereas, contrastingly, a further increase of SBP in patients who already begin HD with a high SBP level is associated with adverse outcomes. 
Valorization 



\section{Valorization}

Since the introduction of the Crit-Line monitor ${ }^{\mathrm{TM}}$ (CLM) in U.S. clinics of the Renal Research Institute, oxygen saturation and relative blood volume (RBV) can be easily and continuously obtained during hemodialysis (HD). Pre-HD, post-HD and peri-dialytic systolic blood pressure (SBP) are routinely collected by the dialysis staff. Incorporating all these measurements into clinical practice, our research shows that arterial and venous oxygen saturation, RBV, and peri-dialytic SBP changes are associated with hospitalization and mortality.

In this thesis, we researched a large cohort of chronic HD patients and found a high rate of intradialytic hypoxemic episodes and that $10 \%$ of the patients experienced a prolonged intradialytic hypoxemia $(\mathrm{PIH}$, defined as hypoxemia $>1 / 3$ of HD treatment time). PIH was significantly associated with higher all-cause hospitalization and mortality rates. We believe that what we have learned in this thesis will help us to identify PIH in patients with arterio-venous fistula or graft as vascular access. Building on that information, the nephrologist could then identify potential PIH causes that are amendable by adjusting the HD prescription (e.g. in cases of fluid overload), or that may require pulmonology consultation (e.g., in cases of sleep apnea). Sleep apnea is highly prevalent yet grossly underdiagnosed in HD patients. We see opportunities to develop machine learning algorithms to identify patterns in arterial oxygen saturation signals associated with sleep apnea syndrome.

We found that in chronic HD patients a low central venous oxygen saturation is associated with poor survival. In addition, we reported that patients with high ultrafiltration volume experienced a more pronounced decline of central venous oxygen saturation during HD. We hypothesize that ultrafiltration results in a reduced cardiac pre-load and cardiac output. A cardiac output reduction will result in a lower upper body blood flow and - under conditions of stable upper body oxygen consumption - a drop in central venous oxygen saturation. We propose that the central venous oxygen saturation is a surrogate marker of upper body blood flow and cardiac output. This insight allows us to utilize central venous oxygen saturation for hemodynamic monitoring during HD in patients with central venous catheter as vascular access. The real time monitoring of central venous oxygen saturation and calculation of estimated upper body blood flow could serve as an indicator of patient's hemodynamic. Coupled with alerts or e.g. ultrafiltration feedback control, these biosignals can assist in preventing intradialytic complications such as intra-dialytic hypotension.

Another valuable clinical application of central venous oxygen saturation and the derived estimated upper body blood flow is the tracking of the hemodynamic response to the creation of an arterio-venous fistula (AVF). The trajectories of central venous 
oxygen saturation and estimated upper body blood flow before and after AVF creation provide insights into the AVF maturation process and the associated hemodynamic response. These results help us to better understand if a patient has the ability to mount an appropriate increase in cardiac output in response to AVF creation and follow the AVF maturation process. This information has the potential to translate into a shorter time between AVF creation and successful cannulation and thus shorten the catheter residence time.

Intradialytic hypotension is frequently associated with a drop in blood volume due to ultrafiltration. Technologies have been developed to mitigate these effects by an automated ultrafiltration feedback control. Current technologies lack pre-defined targets that are associated with better outcomes, since there are limited researches into the relationship between attained RBV ranges during dialysis and patient outcomes. In our research we identified hourly intra-dialytic RBV ranges that are associated with significantly better patient survival. These RBV levels are 93-96\% at the first hour, $89-94 \%$ at the second hour, and $86-92 \%$ at the third hour. Based on that research we have started with the development of an RBV-guided ultrafiltration feedback control system that aims to attain these "favourable" RBV ranges. The goal of such a control system is to eventually reduce morbidity and mortality.

In HD patients oxygen supply to tissues and organs is impaired due to multiple pathological alterations; the heart, gut, and brain are particularly susceptible organs. Fluid management and means to increase intradialytic hemodynamic stability (e.g. cool dialysate; feedback ultrafiltration control) are key to improve oxygen supply to tissues and organs. One potential intervention could be the administration of oxygen during dialysis. The real time monitoring of arterial or central venous oxygen saturation could provide us with data to trigger the administration of oxygen during dialysis.

Also, knowledge of real time oxygen saturation and RBV combined with patient demographic information and treatment data can be utilized to develop machine learning algorithm(s) to predict intradialytic complications such as intra-dialytic hypotension.

Lastly, several different approaches can be used for deriving "quasi pre-HD" hemoglobin levels from CLM data. These hemoglobin estimates could replace repeated blood draws and their associated blood loss, and logistic and staff costs.

A better understanding of the pathophysiology, clinical consequences and medical management requires future carefully designed clinical studies. Our results may serve as a guide for the development of prospective clinical studies. We believe that our results will motivate and encourage adequately equipped and trained clinical researchers to embark on future specialized studies. 
Acknowledgement 



\section{Acknowledgement}

The results of this thesis would not be possible without the contributions of many including my advisors from the University of Maastricht, The Netherlands, colleagues from Renal Research Institute (RRI) in New York, colleagues from Fresenius Medical Care North America and Fresenius Medical Care in other countries, various collaborators from the US and internationally, and my family and friends. Without their guidance and help throughout all these years, I couldn't have accomplished this work.

Dr. Jeroen P Kooman and Dr. Frank M van der Sande, my advisors from University of Maastricht, guided me through the entire thesis process - from helping me with the application at the very beginning, tackling the peer review process, contributing to the writing of the introduction and discussion chapters of this thesis, and introducing me to the Dutch traditions in PhD thesis defense. Both have travelled many times thousands of miles across the Atlantic from Maastricht to New York, spending time away from their families and patients in their effort to support my PhD related research. I have learned so much from their immense knowledge, professional and personal experience, and the willingness to help their students. I express my sincere gratitude to them.

To Dr. Peter Kotanko, I would like to give my deepest and most sincere thanks. He has been a tremendous mentor since my very first day at the Renal Research Institute 4 years ago. I still remember that he was the person who opened the door to the RRI when I arrived for my job interview. He did not only open the door to the RRI, but also the door to the entire dialysis research field. He is a wonderful person who enlightens me in regard to medicine and research, and who also taught me to widen my knowledge to various perspectives. Over these years of working together, I grew from a statistician who mostly worked with numbers and models to a research scientist who can independently generate hypotheses and address scientific questions. My evolution and grow are all thanks to Dr. Kotanko's patience, motivation, enthusiasm, and plethora of knowledge. I am proud to call him a mentor and a friend.

I am also thankful to Dr. Jochen G. Raimann, who spent quite lot of time teaching me the basics of physiology and dialysis. He encouraged me to further my knowledge in medicine, statistics, and machine learning. He was also instrumental in improving my scientific writing, and presentation skills. I am immensely grateful to him for all the help and support he has provided.

I would also like to acknowledge my review committee members, Prof. dr. M. E. A. Spaanderman, Prof. dr. B. Meijers, Prof. dr. F. W. Prinzen, Dr. L. J. Schouten, Dr. C. F. M. Franssen. I am very thankful for their efforts in reviewing and approving my thesis. 
I would like to also thank Tiny Wouters from University of Maastricht, for her help in the layout and compilation of the chapters for this thesis.

I would like to express my appreciation to Dr. Stephan Thijssen, who is an excellent physician with a profound understanding of all the Critline-related research. He tirelessly taught me the rationale behind the concepts in this thesis.

I am also thankful to our nephology and research fellows at the RRI, Dr. Anna MeyringWösten, Dr. Lili Chan, Dr. Israel Campos, Dr. Priscila Preciado, Dr. Lemuel Rivera Fuentes, and Dr. Leticia M Tapia Silva. They are my co-authors and have contributed a lot to the publications in this thesis.

I also would like to express my appreciation to Dr. Yuedong Wang, Prof. of biostatistics at the University of California Santa Barbara. Over many years of working together, I have learned from him many statistical methodologies. I also would like to extend my thanks to the analytical colleagues, Alice Topping, Xiaoling Ye, Shimul M Sheth, and Mikhail Artemyev: they have been invaluable and supportive colleagues over the years. My expression of gratitude also goes to my mathematics colleagues, Prof. Franz Kappel, Dr. Doris H. Fuertinger, Dr. Stefan Fuertinger, Dr. Alhaji Cherif, Dr. Vaibhav Maheshwari, and Sabrina Rogg. Mathematics and statistics are always a family as we have a lot in common.

I also had the great opportunity to work with our laboratory and clinical colleagues, Dr. Fansan Zhu, Dr. Xia Tao, Dr. Nadja Grobe, Dr. Ohnmar Thwin, Linchun Wang, and Joy Mesio, as well as other staff from the RRI, Dr. Laura Rosales, Crystal Johnson, Sherline Pereira, Hannah Putnam, Maggie Han, Dewangi A Kothari, and Stephanie Aracena. It always been a pleasure to work together with them.

My thanks also belong to RRI Operations colleagues, Terry Sullivan, Dr. Paul Balter, Nancy Ginsberg, Brenda Chan, Marilou Mateo, Robert Levin, Seth Johnson, and Ena Applewhite; they helped me to better understand the operational aspects of dialysis clinics.

It is of great importance to thank Mike Black, to whom Critline is a labor of love. He is a leading expert in the technology, and his support and input in the Critline-related research has been invaluable.

I also would like to express my deep gratitude to my Fresenius Medical Care North America colleagues, Dr. Franklin W. Maddux, Dr. Jeffrey Hymes, Dr. Robert Kossmann, Dr. Terry Ketchersid, Dr. Dugan Maddux, and Dr. Norma Ofsthun, for their tremendous input into several large cluster randomized innovation rollouts, and also for supporting 
my utilization of data from the FMNCA clinical data warehouse. I am grateful have worked together with Dr. Len A. Usvyat, and his team members, John Larkin, Sheetal Chaudhuri, Dr. Yue Jiao, Hao Han, Dr. Thomas C Blanchard, and Dr. Andrew Long. The predictive analytics team has taught me how analytics could improve patient care.

I would like to thank Dr. Ulrike ("Ulli”) Kotanko and Dr. Len A. Usvyat for being my paranifms during the thesis defense. I am forever appreciative for their time and continued support.

Very importantly, I must thank my brother Dr. Endong Zhang, my sister-in-law Huilei Xie, and my baby niece Muyao Zhang. Also, I must thank all my extended family members and all my friends for being there whenever needed. They have been an excellent support system.

This thesis could not have been accomplished without my family's support, especially that of my husband Dongxiang Yan. Thanks to his support all these years, I could believe in myself and pursue my dreams. When I was traveling and working late nights, he took care of our twin daughters and I cannot thank him enough for his sacrifice. I am so lucky to have my twin daughters Katherine Yan and Angelina Yan, as they are such lovely and sweet girls. They have made me stronger and more fulfilled every single day. Certainly, I must thank my parents, Dr. Chaoling Zhang and Minzhang Sun. My father was a physician, and although he could not see this accomplishment, he will always be my hero and inspiration. My mother provided for me all the encouragement and help that I needed, and I am forever indebted to her.

At the end, I have to acknowledge our patients as the main motivation for my work. End stage kidney disease is one of the most complicated illnesses, a disease akin to malignancies, and our patients are suffering from a host of comorbidities, hospitalizations, and high risks of mortality. I hope the research in this thesis will expand our knowledge of the nature of uremia and will help to improve our patients' quality of life and outcomes. 

Curriculum Vitae 



\section{Curriculum Vitae}

Hanjie Zhang was born June 2, 1981 in Fuyang, Anhui province, China. In 2003 she received her Bachelor's Degree in Traditional Chinese Medicine from China Pharmaceutical University in Nanjing, Jiangsu province, China. She further received in 2006 a Master's Degree in Pharmaceutics from Shanghai Jiao Tong University in Shanghai, China. In 2007 she moved to the USA and accomplished her Master's Degree from Louisiana State University in Human Nutrition and Food in 2009. She worked as Research Associate at the Louisiana State University for 9 months before she moved to New York City in 2010. From 2010 to 2014 she worked as a Senior Research Associate at the Columbia University Medical Center. In 2013 she completed her Master's Degree in statistics at Columbia University, New York City. In 2014 she joined the Renal Research Institute, New York, as a Biostatistician, where she currently works as a Principal Biostatistician. 


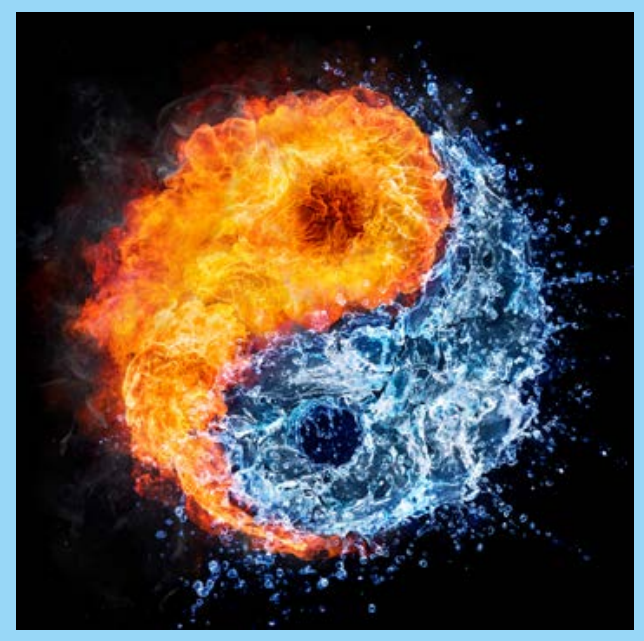

